\title{
Fracture liaison service
}

Citation for published version (APA):

Van den Berg, P. (2020). Fracture liaison service: optimizing care from a nurse practitioner's perspective.

[Doctoral Thesis, Maastricht University]. Ridderprint. https://doi.org/10.26481/dis.20201218pb

Document status and date:

Published: 01/01/2020

DOI:

10.26481/dis.20201218pb

Document Version:

Publisher's PDF, also known as Version of record

\section{Please check the document version of this publication:}

- A submitted manuscript is the version of the article upon submission and before peer-review. There can be important differences between the submitted version and the official published version of record.

People interested in the research are advised to contact the author for the final version of the publication, or visit the DOI to the publisher's website.

- The final author version and the galley proof are versions of the publication after peer review.

- The final published version features the final layout of the paper including the volume, issue and page numbers.

Link to publication

\footnotetext{
General rights rights.

- You may freely distribute the URL identifying the publication in the public portal. please follow below link for the End User Agreement:

www.umlib.nl/taverne-license

Take down policy

If you believe that this document breaches copyright please contact us at:

repository@maastrichtuniversity.nl

providing details and we will investigate your claim.
}

Copyright and moral rights for the publications made accessible in the public portal are retained by the authors and/or other copyright owners and it is a condition of accessing publications that users recognise and abide by the legal requirements associated with these

- Users may download and print one copy of any publication from the public portal for the purpose of private study or research.

- You may not further distribute the material or use it for any profit-making activity or commercial gain

If the publication is distributed under the terms of Article $25 \mathrm{fa}$ of the Dutch Copyright Act, indicated by the "Taverne" license above, 


\section{FRACTURE LIAISON SERVICE: Optimizing care from a nurse practitioner's perspective}


(c) copyright Peter van den Berg, Delft 2020

Printing: Ridderprint

Vormgeving: Publiss

ISBN: 978-94-6416-249-3

All rights reserved. No part of this publication may be reproduced, stored in a retrieval system or transmitted in any form or by any means, electronic, mechanical, photocopying, recording or otherwise, without prior permission of the author or the copyright-owning journals for previous published chapters. 


\title{
FRACTURE LIAISON SERVICE: \\ Optimizing care from a nurse practitioner's perspective
}

\author{
PROEFSCHRIFT
}

ter verkrijging van de graad van doctor aan de Universiteit Maastricht, op gezag van de Rector Magnificus, Prof. dr. Rianne M. Letschert volgens het besluit van het College van Decanen, in het openbaar te verdedigen op vrijdag 18 december 2020 om 10 uur

door

Peter van den Berg 


\section{Promotoren}

Prof. Dr. J.P.W. van den Bergh

Prof. Dr. P.P.M.M. Geusens

\section{Copromotor}

Dr. D.H. Schweitzer (Reinier de Graaf Gasthuis Delft)

\section{Beoordelingscommissie}

Prof. dr. L.W. van Rhijn (voorzitter)

Prof. dr. L.P.S. Stassen

Prof. dr. M.C. Zillikens (Erasmus Medical Center Rotterdam)

Prof. dr. M.H. Emmelot (University Medical Center Utrecht)

Dr. S.P.G. Bours 


\section{Contents}

List of abbreviations

Chapter 1 General Introduction 11

Chapter 2 Meeting international standards of secondary fracture 25 prevention: a survey on Fracture Liaison services in the Netherlands. Osteoporos Int. 2015 Sep;26(9):2257-63. doi: 10.1007/s00198-015-3117-y.

Chapter 3 Challenges and Opportunities to Improve Fracture Liaison Service 43 Attendance: Fracture Registration and Patient Characteristics and Motivations. Osteoporos Int. 2019 Aug;30(8):1597-1606. doi: 10.1007/s00198-019-05016-4.

Chapter 4 Characterization of Fracture Liaison Service Non-Responders 75 After Invitation by Home Visits and Questionnaires.

Osteoporos Int. 2020 May 13. doi:10.1007/s00198-020-05442-9.

Online ahead of print.

Chapter 5 Quantification of Calcium intake from Calcium-Dense Dairy 95 Products in a Dutch Fracture Cohort.

Nutrients. 2014 Jun 23;6(6):2404-18. doi:10.3390/nu6062404.

Chapter 6 The Use of Pulse-Echo Ultrasound in Women With a Recent NonVertebral Fracture to Identify Those Without Osteoporosis and/ or a Subclinical Vertebral Fracture: A Pilot Study. Arch Osteoporos. 2020 Apr 14;15(1):56. doi:10.1007/s11657-020-00730-7.

Chapter 7 A dedicated Fracture Liaison Service telephone program and use of bone turnover markers for evaluating 1-year persistence with oral bisphosphonates. Osteoporos Int. 2018 Apr;29(4):813-824. doi:10.1007/s00198-017-4340-5.

Chapter 8 Summary and conclusions

Chapter 9 General discussion and future perspectives 


\section{List of abbreviations}

\begin{tabular}{|c|c|}
\hline AIRE & Appraisal of Indicators, Research and Evaluation tool \\
\hline ASBMR & American Society of Bone and Mineral Research ASBMR) \\
\hline AUROC & Area under the ROC curve \\
\hline BBS & Berg Balance Scale \\
\hline BMD & Bone Mineral Density \\
\hline $\mathrm{BMI}$ & Body Mass Index \\
\hline BTM & Bone Turnover Marker \\
\hline CBS & Centraal Bureau voor de Statistiek \\
\hline CFNCS & Dutch National Food Consumption Survey \\
\hline $\mathrm{Cl}$ & Confidence Interval \\
\hline CSFII & Continuing Survey of Food Intake by Individuals (USA) \\
\hline $\mathrm{CtF} ß \mathrm{BPF}$ & Capture the Fracture ${ }^{\circledR}$ Best Practice Framework \\
\hline CTh & Cortical Thickness \\
\hline DI & Density Index \\
\hline DXA & Dual Energy X-ray Absorptiometry \\
\hline ECTS & European Calcified Tissue Society \\
\hline EUGMS & European Union Geriatric Medicine Society \\
\hline EULAR & European League against Rheumatism \\
\hline FDA & Food and Drug Administration (USA) \\
\hline FFN & Fragility Fracture Network \\
\hline FLS & Fracture Liaison Service \\
\hline FRAX & Fracture Risk Assessment Tool \\
\hline GCP & Good Clinical Practice \\
\hline Gl & Gastro Intestinal \\
\hline GP & General Practitioner \\
\hline $\mathrm{HV}$ & Home Visit \\
\hline IOF & International Osteoporosis Foundation \\
\hline IRR & Inter Rater Reliability \\
\hline IU & International Unit \\
\hline IV & Intravenous \\
\hline KP & Key Performance Indicator \\
\hline 150 & Least Significant Change \\
\hline
\end{tabular}




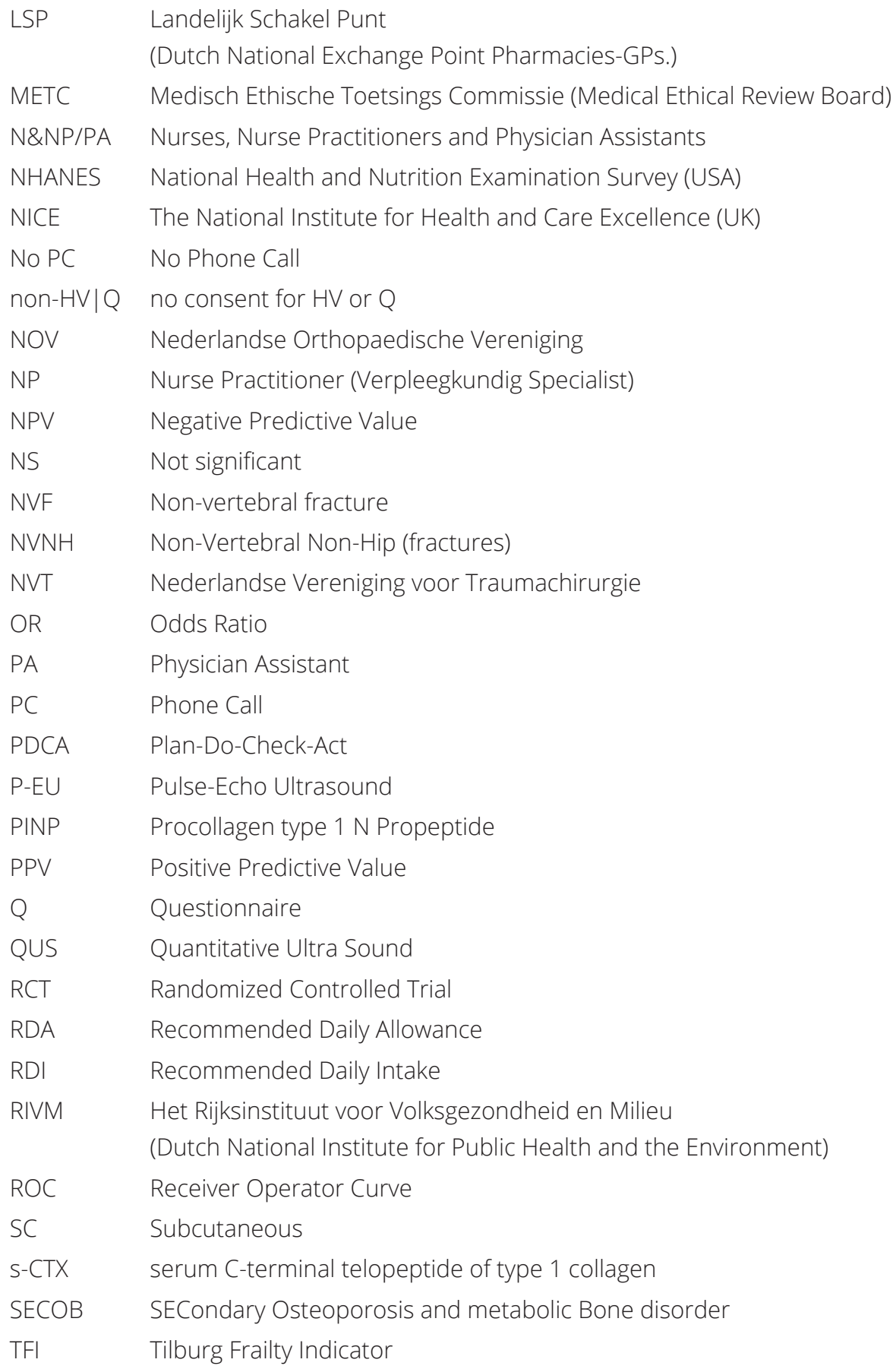


List of abbreviations

TUG Timed Up and Go Test

UMCG University Medical Centre Groningen

V\&VN Dutch National Council of Nurses

(Verpleegkundigen \& Verzorgenden in Nederland)

VF Vertebral Fracture

VF\&O Vallen, Fracturen \& Osteoporose

(Dutch FLS Nurses and Nurse Practitioners Association)

VFA Vertebral Fracture Assessment

VMS Veiligheid Management Systeem (Safety Management System)

WHO World Health Organization 


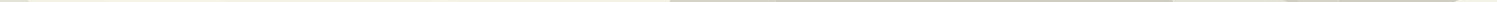




\section{CHAPTER 1}

General Introduction 


\section{Epidemiology of fractures}

Bones have evolved throughout millions of years of evolution and perform several tasks. Bones provide a framework for attachment of muscles to enable movements, they protect soft tissues against external trauma, they serve as a reservoir for calcium homeostasis, host blood cells for hematopoiesis, and immune cells and store energy, such as fat in the bone marrow. Strong bones can resist load, such as running, jumping and falls. Fractures occur when the load exceeds bone strength [1,2]. Thus, fractures are the result of weakened bones, severe or repeated trauma's or a combination of both. In 50+ subjects the most frequent trigger for fractures is a fall or an accident, in combination with postmenopausal and age-related bone loss. In adults, fracture risk increases with age and remaining lifetime fracture risk in Caucasian men and women of 50 years is $>20 \%$ and $>50 \%$ respectively [3]. With the aging of the population worldwide more fractures are expected [4]. The number of all fractures per year among the Dutch population older than 50 years is 120,000 according to data from health insurance companies [5]. This burden comes with approximately $€ 600$ million expenses per year and will even rise with $50 \%$ by $2030[6,7]$. For the Netherlands it seems that the burden in costs holds trend with that of other European countries. However, due to Dutch demographics it seems that the expected increase in health care budgets for fractures is not the highest in Europe [4]. Other European countries like Austria, the Scandinavian countries and Belgium are already facing even higher future costs and, as a consequence it will have negative effects on national health care budgets [4]. Based on extensive prospective population and cohort studies, it has become clear that the risk of subsequent fractures is particularly high within the first years after a fracture in patients older than 50 years [8-13]. This high and immediate risk of having subsequent fractures is referred to as 'imminent fracture risk' $[14,15]$. Osteoporosis has been reported in about a third of fracture patients who are older than 50 years and accounts as one of the risk factors for subsequent fractures [5]. However, there is still a huge knowledge gap regarding this imminent subsequent fracture risk in daily practice among both patients and health care professionals [16-19]. Fragility fractures are also associated with a short- and long-term excess mortality $[20,21]$. In Dutch patients older than 50 years with a non-vertebral fracture (NVF), the absolute mortality was 32\% of which nearly a third (17\%) occurred one-year post fracture [22]. An increased risk for subsequent fractures and excess mortality after initial fractures was shown in several studies [8,11,20-22]. These findings support the effort to develop fracture prevention strategies soon after first fracture. Currently, the 
fracture liaison service (FLS) is considered the most effective organizational structure for secondary fracture prevention [23-29].

\section{Fracture Liaison Service (FLS) from an historical perspective}

McLellan et al. introduced in 2003 a novel out-patient program for the evaluation and management of patients with osteoporotic fracture called the Fracture Liaison Service (FLS) [30]. In the Netherlands the first FLS related initiatives and outcomes were reported from Groningen in 2004 and from Maastricht in 2007 [31,32]. The Delft FLS was founded in 2007 after in-depth discussions with local GPS and nowadays this FLS is highly esteemed by patients, hospital specialists and general practitioners. In the Dutch guideline on osteoporosis and fracture prevention (2011) [33] it was recommended to evaluate all fracture patients of 50 years or older in preferentially a nurse-led structured program and in 2012 a set of quality indicators was developed for the evaluation of post-fracture care in Dutch Hospitals [34]. Internationally, the International Osteoporosis Foundation (IOF) started a global initiative called "Capture the Fracture ${ }^{\circledR \prime}$ [35]. Capture the Fracture ${ }^{\circledR}$ used the FLS concept as the fundament to prevent re-fractures propagating their so-called nursecoordinated multidisciplinary approach. These so-called coordinators' or 'local champions' approach consisted of a framework of 13 best practices necessary for a structured combat against secondary fractures [36]. Today, the FLS initiative is internationally endorsed by the International Osteoporosis Foundation IOF [25], the American Society of Bone and Mineral Research ASBMR) [26], the European League against Rheumatism (EULAR) [27] and the multidisciplinary Fragility Fracture Network (FFN) [28]. Formal position statements by these international scientific societies encouraged even more FLS initiatives abroad as well as in the Netherlands [37]. 
Fig 1. FLS-care: nationwide Quality Assessment and the FLS five-step approach

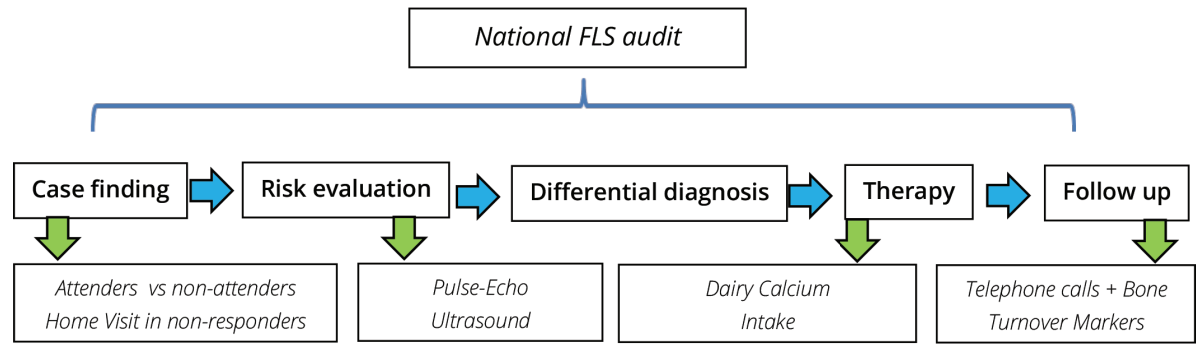

\section{FLS-care: a five-step approach}

In order to strive for standardized and optimal FLS-care, a five-step approach has been proposed by van den Bergh et al. [23]. This approach was based on the concept of a systematic, preferably coordinator-based, approach for identification, enrollment, evaluation, treatment and monitoring of patients with a fracture after the age of 50 years. After identification of patients, a detailed evaluation of medical history, medication use, clinical risk factors, vitamin D status, dietary calcium intake, known contributors to secondary osteoporosis and fall risk should then be performed, together with assessment of BMD and VFA. Next, patients need to be further evaluated for undiagnosed contributors to secondary osteoporosis and metabolic bone disorders. Then a multifactorial intervention should follow, including lifestyle management recommendations, calcium and/or vitamin D supplementation if required, and treatment of underlying disorders. Specific anti-osteoporotic treatment should be considered in line with national guidelines with organized follow-up of patients after 3 months and annually, thereafter [33].

\section{Gaps in secondary fracture prevention care}

The recognition of the FLS as a well-defined structured outpatient clinic was a fact, but gaps in knowledge of both patients and doctors have not yet been resolved. Dutch healthcare is well organized and basic medical costs are covered by all Dutch health care insurance companies. Hospitals are equipped to highest standards and care processes and logistics are demanded by Dutch law. This unique situation provides the opportunity to comply with national guidelines on osteoporosis, fracture prevention 
and falls endorsing to put maximum effort on secondary fracture prevention $[33,34]$. Unfortunately, there are still gaps in secondary fracture prevention care.

\section{Attendance gap}

In 2013, the International Osteoporosis Foundation (IOF) had recognized 'FLS attendance' as an important marker of local FLS quality (www.capturethefracture.org). FLS attendance was expected to be some $50 \%$ or even lower but exact data were not available. In many countries, FLS initiatives were initiated, but attendance was reported to be generally low and varying between 20-89\% [37]. Patient identification and selection differed markedly among FLSs, in terms of proportions of inpatients and outpatients, age, inclusion of women and/or men and fracture selection (any fracture or only patients with an NVF) [37]. The reasons for these low attendance rates are unclear, but patient views and opinions about osteoporosis and the consequent underestimation of subsequent fracture risk might be of strong influence [16-19]. In addition, besides person-related considerations, patients may be unintentionally uninvited because of administrative issues [38].

\section{Fracture risk evaluation gap}

Fracture risk evaluation includes the evaluation of the presence of clinical risk factors based on medical history and clinical evaluation (age, sex, body weight, personal and family fracture history, diseases and medication use that increase fracture and fall risk), DXA including VFA and laboratory tests to exclude underlying illness. The Dutch guideline of 2011 recommend DXA to identify osteoporosis as well as VFA to identify subclinical VFs and fall risk assessment [33]. Given the national guideline on osteoporosis and fracture prevention in the Netherlands (2011) and the excellent access to health services and the high hospital density throughout the country, the Osteoporosis Quality Indicator was introduced to monitor in all Dutch hospitals. This Quality Indicator, based on a so called Appraisal of Indicators, Research and Evaluation (AIRE) tool $[39,40]$, meaning a hospital-self-report on the proportion of patients of 50 years and older with a recent fracture that received a DXA within 6 months post fracture. Over the last years, DXA was reported to be performed in 33\% of patients on average, with a wide range (5-100\%) [34,41]. In addition, the CBS data collected in 2016 showed that DXA (with and without VFA) was performed in only $26 \%$ of 120,000 
people older than 50 years with a fracture $[7,41]$. This low proportion in spite of clear recommendations according to national guidelines (2011) [33] underpins the notion of a huge gap in our national fracture risk evaluation initiative. In addition, these indicators do not provide in depth information on the quality of post-fracture care beyond DXA measurements as described in the IOF standards and according to the five-step approach of FLS care.

\section{Treatment gap}

Treatment gap is defined as the proportion of truly osteoporosis prescriptions divided by the total number of osteoporotic fractures plus the degree of adherence to medication. Both aspects need to be addressed by the FLS in line with Capture the Fracture ${ }^{\circledR}$ Best Practice Framework and international consensus [36,26-29]. Not starting anti-resorptive treatment was mainly related to insufficient medical advice, attitudes towards medication use including concerns about side effects, and disease awareness [16,42-45]. In patients that started treatment, the one-year adherence to oral bisphosphonates in the general Dutch population was reported to be $43 \%$ [46]. The persistence in using anti-osteoporosis drugs in patients with a fracture was 75\% after 1 year and 45\% after 5 years [47], which is better than in the general Dutch population but still points at low long term persistence percentages in these high risk patients. Recently, it was suggested that individualized solutions, based on collaboration between patient and healthcare provider are needed to improve adherence and persistence in osteoporosis medication [48].

\section{Nurse Initiatives regarding Fractures, Falls and Osteoporosis}

At the time of the first introduction of FLS care in the Netherlands, there was no network for health care professionals and, therefore an informal network was launched by a small group of nurses with interest in osteoporosis and fractures. The recognition of the complexity of secondary fracture prevention care and the identification of several knowledge gaps led to a nationwide Dutch nursing initiative by the formal founding of the national board of FLS specialized osteoporosis and fracture prevention nurses (Dutch Osteoporosis Nurses Association VF\&O) in 2008 [49]. The VF\&O steering board started to initiate organized education and training on-the-job programs to improve the skills for FLS care, and national meetings twice a year. The vision of VF\&O 
is to become "best on the job" through liaising protocol-based decision making, stateof-the-art-expertise and multidisciplinary patient care. Apart from these activities, there is a growing number of nurse practitioners who are traditionally registered in the Dutch National Council of Nurses (V\&VN) [50,51]. Part of this highly trained group has the capability and skills to work in secondary fracture prevention care. In contrast to nurses, nurse practitioners and physician assistants are legally authorized to order diagnostic tests and to initiate medical treatments [52-54]. In parallel with the upcoming organization of nurses in boards and national councils there an urgent need was felt to establish an international vision on the daily role of nurses, nurse practitioners and physician assistants in the field of secondary fracture prevention [55-57]. Endorsed by the IOF in the Capture the Fracture ${ }^{\circledR}$ campaign "make the first

(fracture) the last" nurses should become entitled to become 'local champions' i.e. key players in daily secondary fracture prevention practice [35,36]. Nurses who are welltrained and capable to connect all input from disciplines (in and outside the hospital) in favor of individual fracture patient care [58-59] and who take the lead to ensure the highest FLS attendance as possible [60]. Protocols are mandatory and medical consultation must be well organized. Indeed, best practice today means 50\% FLS attendance, despite the efforts and care of expert nurse and nurse practitioners in many FLS facilities. Therefore, firm steps and original viewpoints are necessary to further optimize secondary fracture prevention and it is a challenge for nurses, nurse practitioners and physician assistants to show leadership in the organization of FLS care. These ambitions form the basis of this dissertation on FLS care from a nurse practitioner`s perspective. 


\section{Aims and outline of this dissertation.}

This dissertation has multiple aims regarding the five-step approach of FLS care.

1. To gather information on the quality of FLS care in the Netherlands, beyond the standard Dutch DXA-based quality registrations.

2. To get a better understanding of patient characteristics and motivations related to FLS attendance and non-attendance.

3. To study the performance of an ultrasound prescreening tool to exclude FLS patients without osteoporosis or subclinical vertebral fractures for DXA measurement and VFA.

4. To investigate whether FLS patients complied with recommendations for daily calcium intake.

5. To introduce a dedicated telephone program and the use of bone turnover markers for the evaluation of one-year persistence in using oral bisphosphonates.

\section{Outline}

After the introduction in Chapter 1, we studied the Dutch FLS performance in Chapter 2 by developing a nationwide audit to assess the implementation of FLS quality standards as formulated by the International Osteoporosis Foundation (IOF; CtF ${ }^{\circledR}$ Best Practice Framework (BPF)) in Dutch hospitals.

In Chapter 3 we studied hospital registration and patient-related factors that were associated with attendance and non-attendance in patients that were invited at the FLS.

In Chapter 4 we studied the reasons for non-attendance in identified FLS eligible patients by a questionnaire and by home visits.

In Chapter 5 we studied whether the application of a non-ionizing peripheral Pulse Echo Ultrasound device enables identification of women with recent non-vertebral fractures at the FLS who would not need a DXANFA.

In Chapter 6 we studied traditional dairy intake in a FLS cohort aiming to analyze the recommended daily calcium allowance (RDA).

In Chapter 7 we studied the impact of telephone calls at one-year of osteoporosis medication and the adherence to medication was objectified by means of bone markers and pharmacy delivery data. 
Chapter 8 summarizes the results of this dissertation.

Chapter 9 includes a general discussion based on findings in this dissertation and provides future perspectives for clinical practice and research. 


\section{References}

1. Charnley J. The closed treatment of common fractures. https://www.cambridge.org/core/books/ closed-treatment-of-common-fractures/9FBF0A141FD5A341743609B9CE9CA6CD.

2. Tornetta P, Ricci W, Court-Brown C, McQueen M, McKee M. Rockwood and Green's Fractures in Adults (9 $9^{\text {th }}$ Edition). ISBN/ISSN 9781496386519 Publication Date March 27, 2019Sambrook P, Cooper C. Osteoporosis. Lancet. 2006 Jun 17;367(9527):2010-8.

3. Nguyen ND, Ahlborg HG, Center JR, Eisman JA, Nguyen TV. Residual lifetime risk of fractures in women and men. J Bone Miner Res. 2007 Jun;22(6):781-8.

4. Kanis JA, Borgström F, Compston J, Dreinhöfer K, Nolte E, Jonsson L, Lems WF, McCloskey EV, Rizzoli R, Stenmark J. SCOPE: a scorecard for osteoporosis in Europe. Arch Osteoporos. 2013;8:144. doi: 10.1007/s11657-013-0144-1.

5. Lötters FJ, van den Bergh JP, de Vries F, Rutten-van Mölken MP. Current and Future Incidence and Costs of Osteoporosis-Related Fractures in The Netherlands: Combining Claims Data with BMD Measurements. Calcif Tissue Int. 2016 Mar;98(3):235-43. doi: 10.1007/s00223-015-0089-z.

6. https://www.rivm.nl/publicaties/vergrijzing-en-toekomstige-ziektelast-prognose-chronischeziektenprevalentie-2005-2025. Assessed 23-2-2020.

7. https://opendata.cbs.nl/statline/\#/CBS/nl/navigatieScherm/zoeken?searchKeywords =osteoporose. Assessed 25-3-2020.

8. Bliuc D, Nguyen ND, Nguyen TV, Eisman JA, Center JR. Compound risk of high mortality following osteoporotic fracture and refracture in elderly women and men. J Bone Miner Res. 2013 Nov;28(11):2317-24. doi: 10.1002/jbmr.1968.

9. Balasubramanian A, Zhang J, Chen L, Wenkert D, Daigle SG, Grauer A, Curtis JR. Risk of subsequent fracture after prior fracture among older women. Osteoporos Int. 2019 Jan;30(1):79-92. doi: 10.1007/s00198-018-4732-1.

10. van Geel TA, van Helden S, Geusens PP, Winkens B, Dinant GJ. Clinical subsequent fractures cluster in time after first fractures. Ann Rheum Dis. 2009 Jan;68(1):99-102. doi: 10.1136/ard.2008.092775.

11. Huntjens KM, van Geel TA, van den Bergh JP, van Helden S, Willems P, Winkens B, Eisman JA, Geusens PP, Brink PR. Fracture liaison service: impact on subsequent non-vertebral fracture incidence and mortality. J Bone Joint Surg Am. 2014 Feb 19;96(4):e29. doi: 10.2106/JBJS.L.00223.

12. Gehlbach S, Saag KG, Adachi JD, Hooven FH, Flahive J, Boonen S, Chapurlat RD, Compston JE, Cooper C, Díez-Perez A, Greenspan SL, LaCroix AZ, Netelenbos JC, Pfeilschifter J, Rossini M, Roux C, Sambrook PN, Silverman S, Siris ES, Watts NB, Lindsay R. Previous fractures at multiple sites increase the risk for subsequent fractures: the Global Longitudinal Study of Osteoporosis in Women. J Bone Miner Res. 2012 Mar;27(3):645-53. doi: 10.1002/jbmr.1476.

13. Klotzbuecher CM, Ross PD, Landsman PB, Abbott TA 3rd, Berger M. Patients with prior fractures have an increased risk of future fractures: a summary of the literature and statistical syndissertation. J Bone Miner Res. 2000 Apr;15(4):721-39.

14. van Geel TA, Huntjens KM, van den Bergh JP, Dinant GJ, Geusens PP. Timing of subsequent fractures after an initial fracture. Curr Osteoporos Rep. 2010 Sep;8(3):118-22. doi: 10.1007/ s11914-010-0023-2.

15. van Helden S, Cals J, Kessels F, Brink P, Dinant GJ, Geusens P. Risk of new clinical fractures within 2 years following a fracture. Osteoporos Int. 2006;17(3):348-54.

16. Alami S, Hervouet L, Poiraudeau S, Briot K, Roux C. Barriers to Effective Postmenopausal Osteoporosis Treatment: A Qualitative Study of Patients' and Practitioners' Views. PLoS One. 2016 Jun 29;11(6):e0158365. doi: 10.1371/journal.pone.0158365. 
17. Salminen H, Piispanen $P$, Toth-Pal E. Primary care physicians' views on osteoporosis management: a qualitative study. Arch Osteoporos. 2019 Apr 26;14(1):48. doi: 10.1007/s11657-019-0599-9.

18. Neuner JM, Schapira MM. The importance of physicians' risk perception in osteoporosis treatment decision making. J Clin Densitom. 2012 Jan-Mar;15(1):49-54. doi: 10.1016/j.jocd.2011.07.008.

19. Swart KMA, van Vilsteren M, van Hout W, Draak E, van der Zwaard BC, van der Horst HE, Hugtenburg JG, Elders PJM. Factors related to intentional non-initiation of bisphosphonate treatment in patients with a high fracture risk in primary care: a qualitative study. BMC Fam Pract. 2018 Aug 23;19(1):141. doi: 10.1186/s12875-018-0828-0.

20. Tran T, Bliuc D, van Geel T, Adachi JD, Berger C, van den Bergh J, Eisman JA, Geusens P, Goltzman D, Hanley DA, Josse RG, Kaiser SM, Kovacs CS, Langsetmo L, Prior JC, Nguyen TV, Center JR. Population-Wide Impact of Non-Hip Non-Vertebral Fractures on Mortality. J Bone Miner Res. 2017 Sep;32(9):1802-1810. doi: 10.1002/jbmr.3118.

21. Tran T, Bliuc D, Hansen L, Abrahamsen B, van den Bergh J, Eisman JA, van Geel T, Geusens P, Vestergaard P, Nguyen TV, Center JR. Persistence of Excess Mortality Following Individual Nonhip Fractures: A Relative Survival Analysis. J Clin Endocrinol Metab. 2018 Sep 1;103(9):3205-3214. doi: 10.1210/jc.2017-02656.

22. Huntjens KM, Kosar S, van Geel TA, Geusens PP, Willems P, Kessels A, Winkens B, Brink P, van Helden S. Risk of subsequent fracture and mortality within 5 years after a non-vertebral fracture. Osteoporos Int. 2010 Dec;21(12):2075-82. doi: 10.1007/s00198-010-1178-5.

23. van den Bergh JP, van Geel TA, Geusens PP. Osteoporosis, frailty and fracture: implications for case finding and therapy. Nat Rev Rheumatol. 2012 Jan 17;8(3):163-72. doi: 10.1038/ nrrheum.2011.217.

24. Kanis JA, Johansson H, Odén A, Harvey NC, Gudnason V, Sanders KM, Sigurdsson G, Siggeirsdottir K, Fitzpatrick LA, Borgström F, McCloskey EV. Characteristics of recurrent fractures. Osteoporos Int. 2018 Aug;29(8):1747-1757. doi: 10.1007/s00198-018-4502-0.

25. https://www.iofbonehealth.org/ Assessed 25-3-2020.

26. Eisman JA, Bogoch ER, Dell R, Harrington JT, McKinney RE Jr, McLellan A, Mitchell PJ, Silverman $S$, Singleton R, Siris E. Making the first fracture the last fracture: ASBMR task force report on secondary fracture prevention. J Bone Miner Res. 2012 Oct;27(10):2039-46. doi: 10.1002/ jbmr.1698.

27. Lems WF, Dreinhöfer KE, Bischoff-Ferrari H, Blauth M, Czerwinski E, da Silva J, Herrera A, Hoffmeyer P, Kvien T, Maalouf G, Marsh D, Puget J, Puhl W, Poor G, Rasch L, Roux C, Schüler S, Seriolo B, Tarantino U, van Geel T, Woolf A, Wyers C, Geusens P. EULAR/EFORT recommendations for management of patients older than 50 years with a fragility fracture and prevention of subsequent fractures. Ann Rheum Dis. 2017 May;76(5):802-810. doi: 10.1136/annrheumdis-2016-210289.

28. Dreinhöfer KE, Mitchell PJ, Bégué T, Cooper C, Costa ML, Falaschi P, Hertz K, Marsh D, Maggi S, Nana A, Palm H, Speerin R, Magaziner J; on behalf of: the Fragility Fracture Network (FFN); European Geriatric Medicine Society (EuGMS); European Federation of National Associations of Orthopaedics and Traumatology (EFORT); International Collaboration of Orthopaedic Nursing (ICON); International Geriatric Fracture Society (IGFS); International Osteoporosis Foundation (IOF). A global call to action to improve the care of people with fragility fractures. Injury. 2018 Aug;49(8):1393-1397. doi: 10.1016/j.injury.2018.06.032.

29. Conley RB, Adib G, Adler RA, Åkesson KE, Alexander IM, Amenta KC, Blank RD, Brox WT, Carmody EE, Chapman-Novakofski K, Clarke BL, Cody KM, Cooper C, Crandall CJ, Dirschl DR, Eagen TJ, Elderkin AL, Fujita M, Greenspan SL, Halbout P, Hochberg MC, Javaid M, Jeray KJ, Kearns AE, King T, Koinis TF, Koontz JS, Kužma M, Lindsey C, Lorentzon M, Lyritis GP, Michaud LB, Miciano A, Morin SN, Mujahid N, Napoli N, Olenginski TP, Puzas JE, Rizou S, Rosen CJ, Saag K, Thompson 
E, Tosi LL, Tracer H, Khosla S, Kiel DP. Secondary Fracture Prevention: Consensus Clinical Recommendations from a Multistakeholder Coalition. J Bone Miner Res. 2020 Jan;35(1):36-52. doi: 10.1002/jbmr.3877.

30. McLellan AR, Gallacher SJ, Fraser M, McQuillian C (2003). The fracture liaison service: success of program for the evaluation and management of patients with osteoporotic fracture. Osteoporos Int 14:1028-1034.

31. Hegeman JH, Oskam J, van der Palen J, Ten Duis HJ, Vierhout PA. The distal radial fracture in elderly women and the bone mineral density of the lumbar spine and hip. J Hand Surg Br. 2004 Oct;29(5):473-6.

32. van Helden S, Cauberg E, Geusens P, Winkes B, van der Weijden T, Brink P. The fracture and osteoporosis outpatient clinic: an effective strategy for improving implementation of an osteoporosis guideline. J Eval Clin Pract. 2007 Oct;13(5):801-5.

33. Dutch Institute for Healthcare Improvement CBO (2011) Richtlijn Osteoporose en Fractuurpreventie. www.diliguide.nl/document/1015/file/pdf/. (Dutch) Assessed 14-02-2019.

34. https://www.zorginzicht.nl/kwaliteitsinstrumenten/osteoporose-indicatoren assessed 9-4-2020

35. Akesson K, Marsh D, Mitchell PJ, McLellan AR, Stenmark J, Pierroz DD, Kyer C, Cooper C (IOF Fracture Working Group) (2013). Capture the Fracture ${ }^{\circledR}$ : a Best Practice Framework and global campaign to break the fragility fracture cycle. Osteoporos Int. 24(8):2135-52. doi: 10.1007/s00198-013-2348-z.

36. https://www.capturethefracture.org/ assessed 25-3-2020.

37. Vranken L, Wyers CE, van den Bergh JPW, Geusens PPMM. The Phenotype of Patients with a Recent Fracture: A Literature Survey of the Fracture Liaison Service. Calcif Tissue Int. 2017 Sep;101(3):248-258. doi: 10.1007/s00223-017-0284-1.

38. van den Berg P, van Haard PMM, Geusens PP, van den Bergh JP, Schweitzer DH. Challenges and opportunities to improve fracture liaison service attendance: fracture registration and patient characteristics and motivations. Osteoporos Int. 2019 Aug;30(8):1597-1606. doi: 10.1007/ s00198-019-05016-4. Epub 2019 May 25.

39. Berg M, Meijerink Y, Gras M, Goossensen A, Schellekens W, Haeck J, Kallewaard M, Kingma $H$. Feasibility first: developing public performance indicators on patient safety and clinical effectiveness for Dutch hospitals. Health Policy. 2005 Dec;75(1):59-73.

40. de Koning, J.S., Kallewaard, M. \& Klazinga, N.S. Prestatie-indicatoren langs de meetlat - het AIRE instrument. TVGW 85, 261-264 (2007). https://doi.org/10.1007/BF03078683

41. https://www.zorginstituutnederland.nl/ assessed 25-3-2020.

42. Grover ML, Edwards FD, Chang YH, Cook CB, Behrens MC, Dueck AC. Fracture risk perception study: patient self-perceptions of bone health often disagree with calculated fracture risk. Womens Health Issues. 2014 Jan-Feb;24(1):e69-75. doi: 10.1016/j.whi.2013.11.007.

43. Hiligsmann M, Cornelissen D, Vrijens B, Abrahamsen B, Al-Daghri N, Biver E, Brandi ML, Bruyère O, Burlet N, Cooper C, Cortet B, Dennison E, Diez-Perez A, Gasparik A, Grosso A, Hadji P, Halbout P, Kanis JA, Kaufman JM, Laslop A, Maggi S, Rizzoli R, Thomas T, Tuzun S, Vlaskovska M, Reginster JY. Determinants, consequences and potential solutions to poor adherence to anti-osteoporosis treatment: results of an expert group meeting organized by the European Society for Clinical and Economic Aspects of Osteoporosis, Osteoarthritis and Musculoskeletal Diseases (ESCEO) and the International Osteoporosis Foundation (IOF). Osteoporos Int. 2019 Nov;30(11):2155-2165. doi: 10.1007/s00198-019-05104-5. Epub 2019 Aug 7.

44. Wozniak LA, Johnson JA, McAlister FA, Beaupre LA, Bellerose D, Rowe BH, Majumdar SR. Understanding fragility fracture patients' decision-making process regarding bisphosphonate treatment. Osteoporos Int. 2017 Jan;28(1):219-229. doi: 10.1007/s00198-016-3693-5. 
45. Gleeson T, Iversen MD, Avorn J, et al. Interventions to improve adherence and persistence with osteoporosis medications: a systematic literature review. Osteoporos Int. 2009; 20(12):2127-2134.

46. Netelenbos JC, Geusens PP, Ypma G, Buijs SJ. Adherence and profile of non-persistence in patients treated for osteoporosis--a large-scale, long-term retrospective study in The Netherlands. Osteoporos Int. 2011 May;22(5):1537-46. doi: 10.1007/s00198-010-1372-5.

47. Klop C, Welsing PM, Elders PJ, Overbeek JA, Souverein PC, Burden AM, van Onzenoort HA, Leufkens HG, Bijlsma JW, de Vries F. Long-term persistence with anti-osteoporosis drugs after fracture. Osteoporos Int. 2015 Jun;26(6):1831-40. doi: 10.1007/s00198-015-3084-3.

48. Cornelissen D, de Kunder S, Si L, Reginster JY, Evers S, Boonen A, Hiligsmann M; European Society for Clinical and Economic Aspect of Osteoporosis, Osteoarthritis and Musculoskeletal Diseases (ESCEO). Interventions to improve adherence to anti-osteoporosis medications: an updated systematic review. Osteoporos Int. 2020 May 1. doi: 10.1007/s00198-020-05378-0. [Epub ahead of print].

49. https://osteoporoseverpleegkundige.nl/ (Dutch) assessed 26-3-2020.

50. https://venvnvs.nI/venvnvs/ (Dutch) assessed 26-3-2020.

51. https://venvnvs.nl/venvnvs/information-in-english/ assessed 26-3-2020.

52. Boeijen ERK, Peters JWB, van Vught AJAH. Nurse practitioners leading the way: An exploratory qualitative study on the added value of nurse practitioners in outpatient care in the Netherlands. J Am Assoc Nurse Pract. 2019 Oct 3. doi: 10.1097/JXX.0000000000000307.

53. Chow S. Nurse Practitioner Fracture Liaison Role: A Concept Analysis. Orthop Nurs. 2017 Nov/ Dec;36(6):385-391. doi: 10.1097/NOR.0000000000000399.

54. Rice P, Mehan U, Hamilton C, Kim S. Screening, assessment, and treatment of osteoporosis for the nurse practitioner: key questions and answers for clinical practice--a Canadian perspective. J Am Assoc Nurse Pract. 2014 Jul;26(7):378-85. doi: 10.1002/2327-6924.12134.

55. Fragility Fracture Nursing: Holistic Care and Management of the Orthogeriatric Patient [Internet]. Cham (CH): Springer; 2018. Chapter 1. Osteoporosis and the Nature of Fragility Fracture: An Overview. Van Oostwaard M. Editors Hertz K1, Santy-Tomlinson J2, editors. 2018 Jun 16.

56. Seuffert P, Sagebien CA, McDonnell M, O'Hara DA. Evaluation of osteoporosis risk and initiation of a nurse practitioner intervention program in an orthopedic practice. Arch Osteoporos. 2016;11:10. doi: 10.1007/s11657-016-0262-7.

57. Roh YH, Koh YD, Noh JH, Gong HS, Baek GH. Effect of health literacy on adherence to osteoporosis treatment among patients with distal radius fracture. Arch Osteoporos. 2017 Dec;12(1):42. doi: 10.1007/s11657-017-0337-0.

58. Raybould G, Babatunde O, Evans AL, Jordan JL, Paskins Z. Expressed information needs of patients with osteoporosis and/or fragility fractures: a systematic review. Arch Osteoporos. 2018 May 8;13(1):55. doi: 10.1007/s11657-018-0470-4.

59. Besser SJ, Anderson JE, Weinman J. How do osteoporosis patients perceive their illness and treatment? Implications for clinical practice. Arch Osteoporos. 2012;7:115-24. doi: 10.1007/ s11657-012-0089-9.

60. Huntjens KM, van Geel TC, Geusens PP, Winkens B, Willems P, van den Bergh J, Brink PR, van Helden S. Impact of guideline implementation by a fracture nurse on subsequent fractures and mortality in patients presenting with non-vertebral fractures. Injury. 2011 Sep;42 Suppl 4:S39-43. doi: 10.1016/S0020-1383(11)70011-0. 


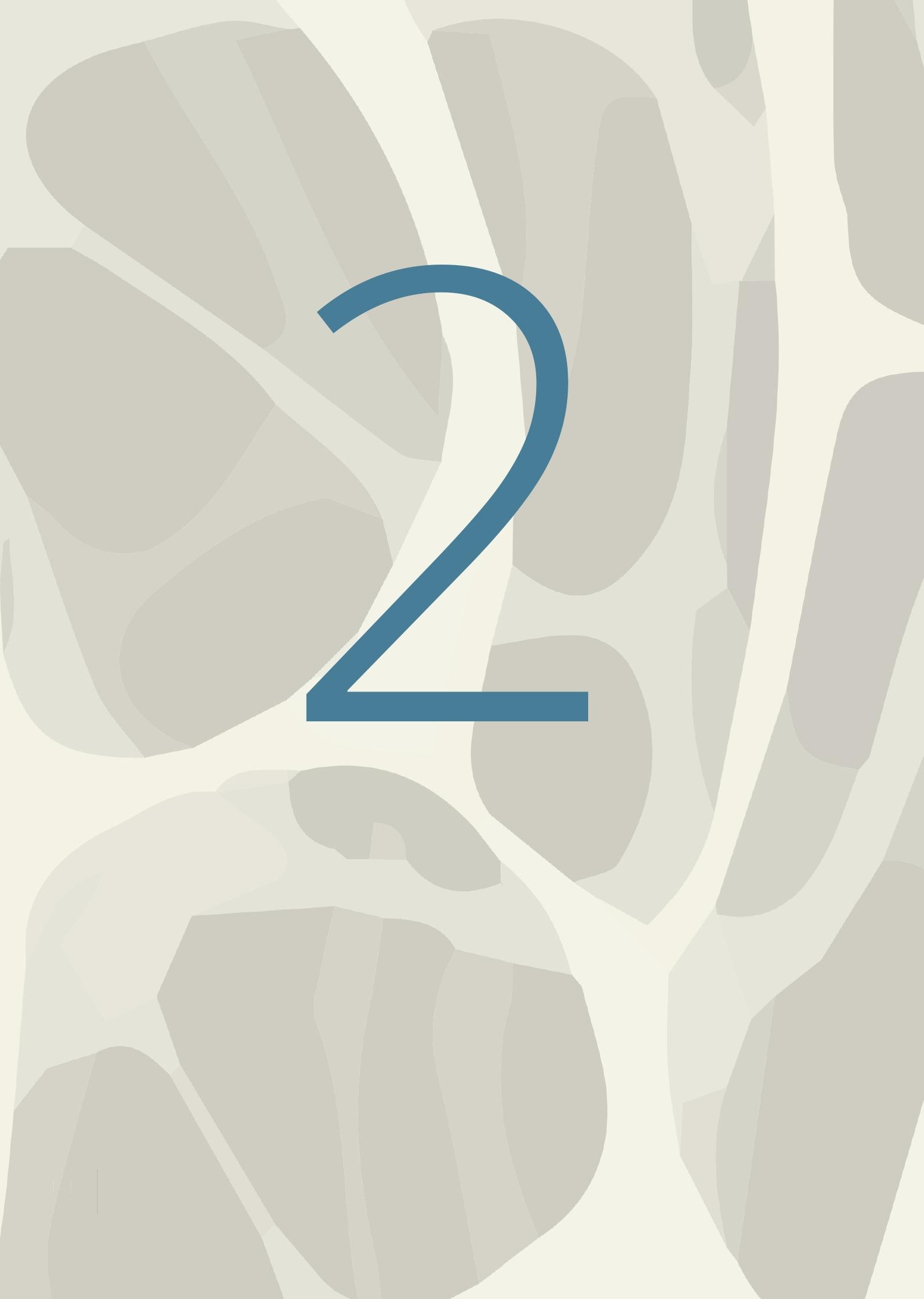




\section{CHAPTER 2}

\section{Meeting international standards of secondary fracture prevention: A Survey on Fracture Liaison Services in the Netherlands}

Peter van den Berg (1)*, Dave H. Schweitzer (2), Paul M.M. van Haard (3), Joop P. van den Bergh (4) and Piet P. Geusens (5).

1. Dept. of Orthopaedics and Surgery, Reinier de Graaf Hospital, Delft, The Netherlands.

2. Dept. of Internal Medicine, Reinier de Graaf Hospital, Delft, The Netherlands.

3. Dept. Medical Laboratories, Reinier de Graaf Hospital, Association of Clinical Chemistry, Delft, The Netherlands.

4. Dept. of Internal Medicine, VieCuri Medical Centre Noord-Limburg and Dept. of Internal Medicine, Subdivision Rheumatology, Maastricht University Medical Center, Maastricht, The Netherlands.

5. Dept. of Internal Medicine, Subdivision Rheumatology, Maastricht University Medical Center and Hasselt University, Belgium.

Corresponding author E-Mail: Pberg@rdgg.nl

Tel.: +31-15-260-4926; Fax: +31-70-260-3828.

Keywords: IOF BPF Standards; FLS ; The Netherlands. 


\title{
Mini-abstract
}

The fracture liaison service (FLS) is advocated to be effective for the prevention of secondary fractures, but implementation is variable. A questionnaire based on the IOF Capture the Fracture ${ }^{\circledR}$ FLS standards was used in the current study. The results showed high compliancy with IOF standards in the Dutch responding hospitals.

\begin{abstract}
Introduction

The fracture liaison service (FLS) is advocated for the prevention of secondary fractures, but its implementation varies between hospitals and countries. The present survey applied the standards proposed by the International Osteoporosis Foundation (IOF) to evaluate the implementation of FLSs in non-university hospitals in the Netherlands.
\end{abstract}

\section{Methods}

A questionnaire based on the IOF FLS standards was used in this study, requesting the selection, evaluation and treatment data of patients older than 50 years with a recent fracture.

\section{Results}

Of 90 invited hospitals, 24 (27\%) fully responded, providing data of 24,468 consecutive patients, corresponding with 25\% of fracture patients in the Netherlands in the year 2012. After excluding skull and toe fractures and patients exceeding the upper age limits applied by individual hospitals, 11,983 patient data were available for analysis. The data showed high compliance ( $>90 \%$ ) for fracture patient identification, invitation for FLS, timing of assessment, identification of vertebral fractures, application of national guidelines, evaluation of secondary osteoporosis, drug initiation when indicated, communication with the general practitioner, application of follow-up strategy, and $70 \%$ for fall prevention. The response rate was on average $49 \%$. 


\section{Conclusions}

The available data also showed that patients attending the FLS were evaluated, treated and followed in high compliancy with IOF standards. Some standards are open to different interpretations and may need further specification. The major shortcoming in FLS practice was that patients invited to attend the FLS showed a low response rate. None of the hospitals achieved the IOF standard patient response rate of over $90 \%$.

\section{Introduction}

The fracture liaison service (FLS) is advocated as the most appropriate approach for secondary fracture prevention $[1,2,3]$. This approach is managed by a central coordinator, mostly a qualified osteoporosis nurse [4,5]. However, the implementation of FLSs varies between hospitals [6] and countries $[7,8]$. The International Osteoporosis Foundation (IOF) has proposed standards to evaluate the implementation and the quality and performance of the FLS [9].

After a fracture, the risk of a subsequent fracture steeply increases $[10,11]$. Of all low trauma fractures in patients over 50 years of age, subsequent fractures accounted for $40 \%$ of fractures in women and $24 \%$ in men [12]. After any osteoporotic fracture in patients over 60 years of age, $24 \%$ of women (31\% of survivors) and $20 \%$ of men (32\% of survivors) had a subsequent fracture within 5 years [13]. Using composite risk analysis that takes into account subsequent fracture risk and mortality, the risk of subsequent fractures reached $40 \%$ in survivors of hip fracture during 5 year followup [14], 80\% of survivors of a hip fracture during 20 years follow-up [15], and 20\% of survivors of a hand or foot fracture during 5 year follow-up [16]. In addition, the risk of mortality is increased after a first and subsequent osteoporotic fracture [17].

The aim of the FLS is to reduce the risk of subsequent fractures in high risk patients. The first FLS was reported in Glasgow in 2003 [18]. It involved systematic identification of all fracture patients, adequate evaluation of their fracture risk, diagnostic evaluation with DXA and VFA and analysis for secondary osteoporosis or metabolic bone disorders, followed by prescription of calcium and vitamin D and specific anti-osteoporosis medication, if needed, as well as follow-up according to a 5-step approach [19]. In the Netherlands, several nationwide scientific committees have addressed the importance of initiating a FLS in hospitals in order to achieve adequate secondary fracture prevention. National guidelines on osteoporosis and fracture prevention 
strongly advocate the identification and examination of patients with a recent fracture, including risk evaluation and differential diagnosis [20,21]. These initiatives have contributed to the development of a FLS in most Dutch hospitals. At present 85 specialised FLS nurses are working in 68 non-university hospitals.

In 2012 the International Osteoporosis Foundation (IOF) launched the "Capture The Fracture ${ }^{\circledR}$ " campaign for secondary fracture prevention [3]. In this campaign, the IOF presented a Best Practice Framework (BPF) with 13 standards for evaluating the performance of FLSs. In this study, we applied these 13 standards to evaluate the implementation of FLS in non-university Dutch hospitals. As far as we know, no similar study has been performed before.

\section{Methods}

In the Netherlands, there are 90 FLSs in non-university teaching and non-teaching hospitals, and 95 osteoporosis nurses are registered in the database of VF\&O (the Dutch association for nurses on Falls, Fractures and Osteoporosis); 85 of them are working in 68 of the non-university hospitals, while the remaining 10 are working in university hospitals or in other professional settings.

For evaluation of the FLSs, the authors of this survey designed a digital questionnaire consisting of demographic questions and specific questions about the FLS organisation and the 13 BPF standards[3], which were translated from the original English text into Dutch. Next, all 90 non-university hospitals in the Netherlands were invited by mail to participate in this survey, providing a web link that gave access to the questionnaire. The questionnaire was sent to the 85 VF\&O affiliated FLS coordinators working in 68 of the non-university hospitals, and to the physicians involved in osteoporosis care in the remaining 22 non-university hospitals (Figure 1).

To ensure the anonymity of participating hospitals, the questionnaire was distributed by DeVosJansen Research Association (DVJ), a professional, independent and unrelated organisation. The results of the questionnaires were sent to DVJ using internet-based Kinesis Survey software, and DVJ delivered the results anonymously to the Research group for analysis. Only descriptive statistical analyses were performed. 
Fig 1. Flowchart on inclusion of analysed FLSS

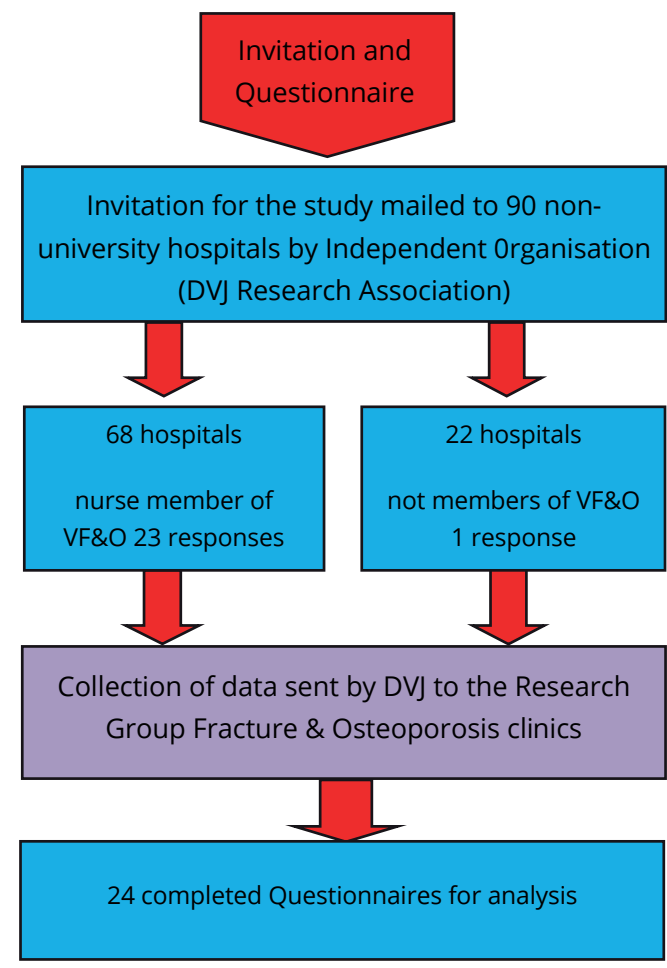

\section{Results}

From 90 hospitals, 24 FLSs (27\%) returned completed questionnaires (Figure 1). Another 6 questionnaires were incomplete and not suitable for analysis. Three hospitals reported not to be able to extract sufficient data from their database, and 57 did not respond.

\section{Demographics}

Of the included hospitals, 16 (67\%) were teaching hospitals and 8 were non-teaching hospitals. The FLS organizing departments were the Trauma and Orthopaedic Surgery in 12 hospitals (50\%) and Internal Medicine, Geriatrics and Rheumatology in another 12 hospitals (50\%). The lead clinician was either the Trauma and/or Orthopaedic Surgeon in 9 hospitals (38\%), 2 of which shared leadership with internal medicine, or a 
specialist in Internal Medicine in 15 hospitals (62\%) (8 Endocrinologists, 1 Geriatrician and 4 Rheumatologists and 2 physicians sharing leadership with surgeons).Of the 24 participating hospitals, 22 (92\%) had a coordinating nurse. For this coordinator at the FLS, they reported a median of 12 working hours/week (range 4-36 hours), with additional secretarial help in 17 hospitals (71\%) with a median of 9 working hours /week (range 4-20 hours). The supportive presence of a physiotherapist was reported in 7 hospitals. The FLS had been initiated between 2004-2006 in 6 hospitals (25\%), between 2007-2009 in 12 (50\%), and between 2010-2012 in 6 (25\%). DXA was available in 23 hospitals (96\%), and VFA in 16 hospitals (67\%). (Table 1)

Table 1. Characteristics of the FLSs (following Demographics)

\begin{tabular}{lll}
\hline & Yes & No \\
\hline Presence of a coordinating nurse & $22(92 \%)$ & $2(8 \%)$ \\
Teaching hospital & $16(67 \%)$ & $8(33 \%)$ \\
DXA scan available & $23(96 \%)$ & $1(4 \%)$ \\
VFA available & $16(67 \%)$ & $8(33 \%)$ \\
Secretarial services available & $17(71 \%)$ & $7(29 \%)$ \\
\hline
\end{tabular}

\section{BPF Standard 1. Patient identification}

All respondents had a system for tracking every patient who presented at their hospital with a fracture; 9 used hospital administration records, and 17 used emergency department records, with an overlap of 2 hospitals that reported the use of both these facilities. A total of 24,468 patients with any recent fracture were identified in year 2012, 18,001 between the age of 50 and 80 years, and 6,467 in patients older than 80 years. This represented around 25\% of all fracture patients older than 50 years in the Netherlands in that year. A median of 1,020 fracture patients were seen per participating hospital (range 217-3,377).

\section{BPF Standard 2. Patient evaluation}

This standard focuses on the response rate, which depends on selection criteria and invitation strategy. Therefore we asked for these factors, revealing that institutions varied in the use of selection criteria, invitation strategy and response rate, but all FLSs evaluated each and every responder. Of all the patients with recent fractures, the following categories were excluded for invitation: skull fractures in all FLSs, toe fractures 
in $3 \mathrm{FLS}$, patients $>90$ yrs in $9 \mathrm{FLSS},>85$ years in $4 \mathrm{FLSS}$ and $>80$ years in $1 \mathrm{FLS}$.

The process of invitation was coordinated by the osteoporosis nurse in 14 FLSs, (58\%), by the nurse practitioner/physician assistant in 3 hospitals (13\%), by the physician in 3 hospitals (13\%) and by the secretarial assistant in 6 FLSS (25\%).

Six FLSs invited patients personally, during treatment in the plaster room or during the orthopaedic outpatient clinic visit (25\%). A combination of personal and subsequently written invitation was reported in 5 FLSs (21\%). Ten FLSs used written invitations first (42\%), 5 of these (21\%) invited patients additionally by phone. Three FLSS (13\%) invited patients only by phone. In 6 FLSs, patients were invited within 1 month after fracture, in 15 between 1 and 2 months and in 3 between 2 and 3 months.

Of the 24,468 fracture patients identified by the participating hospitals in year 2012, 11,983 attended the FLS (49\%), with a median of 499 patients per FLS (range 112$1,050)$. The response rate depended on age (54\% in 50-80 yrs old, $34 \%$ in $80+)$ and timing of invitation (47\% after 1 month, 58\% after $1-3$ months). All responding patients were subsequently assessed for future fracture risk at the respective FLSs.

\section{BPF Standard 3. Post fracture assessment timing}

In 11 FLSS (46\%) patients actually visited the FLS for assessment within 8 weeks after the fracture, in 11 FLSs (46\%) they visited between 9 and 12 weeks after the fracture and in 2 (8\%) more than 13 weeks after the fracture.

\section{BPF Standard 4. Vertebral Fracture}

In all participating hospitals, all patients with clinical vertebral fractures, who attended the FLS were assessed. Ten FLSs (42\%) also reported a strategy to invite patients with non-clinical vertebral fractures as reported by the radiologist. In 15 hospitals, the FLSs reported the structural application of VFA at any BMD level in patients with a non-vertebral fracture. Seven FLSs reported VFA assessment only in patients with osteoporosis, and 6 reported VFA assessment in case of osteopenia and osteoporosis. One FLS reported the structural application of X-ray of the vertebral column instead of VFA. In 11,983 patients, 9,690 DXA scans (81\%) were performed, and 7,045 of these (73\%) included VFA. Ten FLS (42\%) reported also a strategy to invite patients with nonclinical vertebral fractures as reported by the radiologist. 


\section{BPF Standard 5. Assessment Guidelines}

A total of 22 FLSS (92\%) reported implementation of national guidelines concerning osteoporosis and fracture prevention. Two FLSs did not specify which guidelines were used.

\section{BPF Standard 6. Secondary Causes of Osteoporosis}

All FLSs assessed causes of known SECondary Osteoporosis and metabolic Bone disorders (SECOB) through medical history. Ten FLSs performed laboratory tests on all patients as standard procedure. In $22 \mathrm{FLSs}$, all the patients who required treatment additionally underwent investigation for SECOB, while 2 FLSS reported performing laboratory analyses only when secondary osteoporosis was clinically suspected.

\section{BPF Standard 7. Fall Prevention Services}

In 17 FLSs (71\%), patients were evaluated for the presence of fall risk. Implementation of national guidelines on fall prevention was reported by 14 FLSs (58\%). The content of fall risk evaluation was heterogeneous. The following evaluations were reported: attention for mobility in general, including the use of alcohol, attention for visual impairments and the use of crutches (38\%) and evaluation of orthostatic hypotension (8\%). Three FLSs (13\%) reported function and muscle tests, including the Timed Up and Go test (TUG), the Berg Balance Scale (BBS) and a Hand Grip Strength test. Three FLSs reported systematic referral to a falls prevention clinic (13\%).

\section{BPF Standard 8. Multifaceted health and lifestyle risk factor assessment}

Multifaceted health and lifestyle risk factor assessment was performed in 22 FLSs, of which 20 FLSs reported the health and lifestyle risk factors to the GP who was responsible for subsequent referral to the appropriate practitioner for further evaluation and treatment.

\section{BPF Standard 9. Medication Initiation Standard}

In all patients not on treatment at the time of fracture presentation, medication was initiated at the FLS in 19 hospitals (79\%) and initiated by the GP in 5 hospitals 
(21\%). For further follow-up prescription, all patients were referred to their GP. The analysis of this standard did not include the prescription of calcium and vitamin D supplements.

\section{BPF Standard 10. Medication Review}

A total of 22 FLSs reported to be following the national guidelines for patients already in receipt of osteoporosis medication when they presented with a fracture. This included review of medication compliance, considerations of alternative osteoporosis medication and optimization of non-pharmacological interventions.

\section{BPF Standard 11. Communication Strategy}

A total of 22 FLSs communicated the results of all patients to the GPS, and 1 FLS did so in $90 \%$ of the patients (1 FLS unknown). Of the 24 FLSs, 22 reported prescription of osteoporosis medication, 21 reported BMD results, need for adequate calcium and vitamin D intake and laboratory results, 20 reported primary osteoporosis risk factors and lifestyle health risk factor assessment, 19 reported screening on secondary osteoporosis, results of X-rays of the spine and the proposed follow-up strategy. Seventeen reported on the duration of therapy, 15 FLSs reported fracture risks and 13 reported VFA results, current drug treatment and fall risk factors. Previous fractures/time since last fracture were reported by 11 FLSs and medication compliance review was reported by 12 FLSs. The FRAX score was reported by 1 FLS as standard procedure. (Table 2)

\section{BPF Standard 12. Long-term Management}

Eight FLSs reported a follow-up protocol in the FLS after 3 months, 7 a telephone call (after 1-12 months) and 15 reported that further follow-up was delegated to the patient's GP.

\section{BPF Standard 13. Database}

All FLSs used local databases for inviting fracture patients, and 12 (50\%) had a local database on the results of examinations at the FLS. A national registry on fractures 
is available in the Netherlands and open to the public. All hospital-reported fractures have specific codes which correspond with the insured coverage [22]. However, no nationwide hospital data is available on patients evaluated in an FLS. This survey was based on individual FLS databases that included around 25\% of all fractures in the Netherlands in year 2012.

Table 2. Various aspects communicated by the FLSs to GP (following IOF CtF®BPF standard 11)

\begin{tabular}{llll}
\hline & Aspects & Yes & No \\
\hline 1 & Fracture risk score (FRAX) & $1(4 \%)$ & $23(96 \%)$ \\
2 & DXA/ BMD & $21(88 \%)$ & $3(12 \%)$ \\
3 & Vertebral column X-ray & $19(80 \%)$ & $5(20 \%)$ \\
4 & Primary Osteoporosis risk factors & $20(84 \%)$ & $4(16 \%)$ \\
5 & Screening on secondary Osteoporosis & $19(80 \%)$ & $5(20 \%)$ \\
6 & Laboratory tests & $21(88 \%)$ & $3(12 \%)$ \\
7 & Fall risk factors & $13(54 \%)$ & $11(46 \%)$ \\
8 & Current drug treatment & $13(54 \%)$ & $11(46 \%)$ \\
9 & Medication compliance review & $12(50 \%$ & $12(50 \%)$ \\
10 & Follow-up Plan & $19(80 \%)$ & $5(20 \%)$ \\
11 & Follow up Plan: Duration of therapy & $17(70 \%)$ & $7(30 \%)$ \\
12 & Lifestyle health risk-factor assessment & $20(84 \%)$ & $4(16 \%)$ \\
13 & Former fractures/ Time since last fracture & $11(46 \%)$ & $13(54 \%)$ \\
14 & Calcium intake or supplement & $21(88 \%)$ & $3(12 \%)$ \\
15 & Vitamin D intake or supplement & $21(88 \%)$ & $3(12 \%)$ \\
16 & VFA & $13(54 \%)$ & $11(46 \%)$ \\
17 & Prescription osteoporosis medication & $22(92 \%)$ & $2(8 \%)$ \\
18 & Fracture risks & $15(62 \%)$ & $9(38 \%)$ \\
\hline
\end{tabular}

\section{Discussion}

This large survey, which included one quarter of all Dutch fracture patients over 50 years of age in the year 2012, aimed at evaluating the implementation of FLS according to the proposed international BPF standards in non-university hospitals in the Netherlands. The survey reflects the huge clinical effort in each of the 24 participating hospitals, showing a median of 1,020 fracture patients per hospital, and assessing a mean of 499 fracture patients per FLS.

All the evaluated FLSs scored above 90\% for the following BPF standards: identification of patients with a recent fracture in the hospitals, invitation for FLS, timing of assessment, identification of vertebral fractures, application of national guidelines, evaluation of secondary osteoporosis, drug initiation when indicated, communication with the general practitioner, and application of follow-up strategy. Our data suggest 
that the majority of Dutch FLSs are organized in line with the best model according to Ganda Type A $[2,7,8]$, including an osteoporosis nurse, all-encompassing service and initiation of osteoporosis medication. These findings contrast with a previous survey in the Netherlands, which evaluated a smaller cohort of FLSs/hospitals before the year 2010 and found that patients were referred to the GP for treatment decisions (Ganda Type B) [2,6].

One explanation for the observed high level of FLS care is that most of the issues in the IOF standards were already included in national guidelines on osteoporosis and fracture prevention in the Netherlands $[20,21]$. These guidelines strongly advocate $1 /$ to identify patients with a recent fracture, 2 / to evaluate their fracture risk using DXA, VFA and clinical risk factors, 3/ to perform differential diagnosis, 4/ to decide about secondary fracture prevention and 5/ to follow up treatment. Another explanation is the longstanding experience of several Dutch hospitals with FLS, since 18 of the 24 participating hospitals had already started an FLS before the Dutch guidelines were revised in 2011.

Some standards were applied with high variability in implementation. While some FLSs performed evaluation of secondary osteoporosis in all patients, other FLSs only did so in patients who required treatment or if secondary osteoporosis was clinically suspected. Fall risk evaluation consisted of questionnaires alone in 12 FLSs (50\%), or in combination with evaluation of orthostatic hypotension (in 8\%), and only 3 FLSs (13\%) reported function and muscle tests. Also, FLSs differed in performing either vertebral fracture evaluation in all patients or only in patients with osteopenia or osteoporosis.

The major shortcoming in practices of the FLSs was the low response rate of patients who were invited to visit the FLS. A patient response rate of over 90\%, which is suggested as the highest BPF standard, was nowhere achieved by any FLS in the current survey. With the exception of surveys in the UK, where response rates of 75 to $85 \%$ have been reported [23-26], response rates are usually lower (between 28 and 61\%) in other countries and continents [27-32]. Further research is required to understand the causes of these lower response rates and to identify ways to increase them. Earlier studies have shown that systematic screening is more effective than referral, that personal communication is more effective than written information for patients, and that the FLS may be more effective than electronic messaging and communication with GPS [33].

An important limitation of this survey is that the response was relatively low, with 
33 out of 90 hospitals responding (37\%). Moreover, six of these hospitals delivered incomplete data and 3 indicated not to be able to generate any data. As a consequence, the analysis was based on 24 out of the 90 invited hospitals (27\%). This could implicate that well performing FLSs are overrepresented. Unfortunately, any information about responding and non-responding FLS's is lacking since anonymity was assured in this survey. The self-reporting of participants about their own hospital may be a potential bias although the majority of data were extracted from FLS derived databases.

This is the first attempt of a nationwide audit of standards of care delivered by the FLS. However, our response rate emphasizes that FLSs have to be encouraged to participate in these kind of surveys in order to improve our understanding how to optimize secondary fracture prevention per country. It is also needed to analyze and compare FLS implementation in other countries and among countries. Moreover, country-specific Quality/Clinical Standards for FLS have been published in Canada (adherent with the IOF BPF's and the osteoporosis Canada Clinical Guidelines)[34] and the UK were the 5IQ approach is advocated to quality improvement [35]. Each initiative, albeit different from the IOF Capture the Fracture ${ }^{\circledR}$ will provide useful information about the quality of FLS care on a global scale.

Of 68 FLSs run by osteoporosis nurses, 23 were analyzed (34\%). In addition, of 22 services run by physicians, 1 participated in the analysis (5\%). Therefore, the results may be not representative for the FLS care throughout the Netherlands, even though they are based on one quarter of all fractures in Dutch patients over 50 years of age.

\section{Conclusion}

In 24 of the 90 non-university hospitals in the Netherlands, we showed that patients attending the FLS were evaluated, treated and followed in high compliance with IOF standards. Some standards are open to different interpretations and will need further specification. The major shortcoming in FLS practice in this survey was that patients invited to attend the FLS showed a low response rate. Further research should identify the causes of this low response rate and ways to increase it.

\section{Responsibility}

PVDB, DHS, JPVDB and PPG designed the study, analyzed and interpreted the data, and wrote and drafted the manuscript. PVH prepared the data for statistical analysis 
and supported the statistical interpretation of data and writing of the manuscript. All authors had full access to all data including the numerical reports and tables in the study, and all take responsibility for the integrity of the data and the accuracy of the data analyses. PVDB and PPG are the guarantors.

\section{Acknowledgments}

The authors are grateful to Lisette van Hulst for her critical linguistic advice and to Agnes Offenberg, president of the board of the Dutch Osteoporosis Nurses Society VF\&O, and Harry van den Broek, president of the board of the Dutch Osteoporosis Patient Association for their enthusiastic support.

\section{Conflicts of Interest}

Peter van den Berg, Dave Schweitzer, Paul van Haard, Joop van den Bergh and Piet Geusens declare that they have no conflict of interest. 


\section{References}

1. Eisman JA, Bogoch ER, Dell R, Harrington JT, McKinney RE Jr, McLellan A, Mitchell PJ, Silverman S, Singleton R, Siris E; ASBMR Task Force on Secondary Fracture Prevention (2012) Making the first fracture the last fracture: ASBMR task force report on secondary fracture prevention. J Bone Miner Res. 27(10):2039-46. doi: 10.1002/jbmr.1698. .

2. Ganda K, Puech M, Chen JS, Speerin R, Bleasel J, Center JR, Eisman JA, March L, Seibel MJ (2013) Models of care for the secondary prevention of osteoporotic fractures: a systematic review and meta-analysis. Osteoporos Int. 24(2):393-406. doi: 10.1007/s00198-012-2090-y.

3. http://share.iofbonehealth.org/WOD/2012/report/WOD12-Report.pdf (Accessed 12 December 2012)

4. Marsh D, Akesson K, Beaton DE, Bogoch ER, Boonen S, Brandi ML, McLellan AR, Mitchell PJ, Sale JE, Wahl DA; IOF CSA Fracture Working Group.(2011) Osteoporos Int. 22(7):2051-65. doi: 10.1007/ s00198-011-1642-X.

5. Sander B, Elliot-Gibson V, Beaton DE, Bogoch ER, Maetzel A (2008) A coordinator program in postfracture osteoporosis management improves outcomes and saves costs. J Bone Joint Surg Am. 90(6):1197-205. doi: 10.2106/JBJS.G.00980.

6. Huntjens KM, van Geel TA, Blonk MC, Hegeman J.H, van der Elst M, Willems P, Geusens PP, Winkens B, Brink P, van Helden SH (2011) Implementation of osteoporosis guidelines: a survey of five large fracture liaison services in the Netherlands. Osteoporos Int. 22(7):2129-35. doi: 10.1007/s00198-010-1442-8.

7. Kanis JA, Borgström F, Compston J, Dreinhöfer K, Nolte E, Jonsson L, Lems WF, McCloskey EV, Rizzoli R, Stenmark J (2013) SCOPE: a scorecard for osteoporosis in Europe. Arch Osteoporos. 8(1-2):144. doi: 10.1007/s11657-013-0144-1.

8. Svedbom A, Hernlund E, Ivergård, M Compston J, Cooper C, Stenmark J, McCloskey EV, Jönsson B, Kanis JA \& the EU review panel of the IOF (2013) Osteoporosis in the European Union: a compendium of country-specific reports. Arch Osteoporos. 8:137 doi 10.1007/s11657-013-0137-0

9. Akesson K, Marsh D, Mitchell PJ, McLellan AR, Stenmark J, Pierroz DD, Kyer C, Cooper C (IOF Fracture Working Group) (2013). Capture the Fracture ${ }^{\circledR}$ : a Best Practice Framework and global campaign to break the fragility fracture cycle. Osteoporos Int. 24(8):2135-52. doi: 10.1007/ s00198-013-2348-z.

10. van Geel TA, Nguyen ND, Geusens PP, Center JR, Nguyen TV, Dinant GJ, Eisman JA (2010) Development of a simple prognostic nomogram for individualising 5-year and 10-year absolute risks of fracture: a population-based prospective study among postmenopausal women. Ann Rheum Dis. 70(1):92-7. doi: 10.1136/ard.2010.131813.

11. Langsetmo L, Goltzman D, Kovacs CS, Adachi JD, Hanley DA, Kreiger N, Josse R, Papaioannou A, Olszynski WP, Jamal SA; CaMos Research Group (2009) Repeat low-trauma fractures occur frequently among men and women who have osteopenic BMD. J Bone Miner Res. 24(9):1515-22. doi: 10.1359/jbmr.090319.

12. Center JR, Bliuc D, Nguyen TV, Eisman JA (2007) Risk of subsequent fracture after low-trauma fracture in men and women. JAMA. 24;297(4):387-94.

13. Bliuc D, Nguyen ND, Nguyen TV, Eisman JA, Center JR. (2013) Compound risk of high mortality following osteoporotic fracture and refracture in elderly women and men. J Bone Miner Res. 28(11):2317-24. doi: 10.1002/jbmr.1968.

14. Huntjens KM, van Geel TA, van den Bergh JP, van Helden S, Willems P, Winkens B, Eisman JA, Geusens PP, Brink PR (2014) Fracture liaison service: impact on subsequent nonvertebral fracture incidence and mortality. J Bone Joint Surg Am. 19:96(4):e29. doi: 10.2106/JBJS.L.00223. 
15. von Friesendorff M, Besjakov J, Akesson K (2008) Long-term survival and fracture risk after hip fracture: a 22-year follow-up in women. J Bone Miner Res. 23(11):1832-41. doi: 10.1359/ jbmr.080606.

16. Huntjens KM, Kosar S, van Geel TA, Geusens PP, Willems P, Kessels A, Winkens B, Brink P, van Helden S (2010) Risk of subsequent fracture and mortality within 5 years after a non-vertebral fracture. Osteoporos Int. 21(12):2075-82. doi: 10.1007/s00198-010-1178-5.

17. Bliuc D, Alarkawi D, Nguyen TV, Eisman JA, Center JR (2014) Risk of Subsequent Fractures and Mortality in Elderly Women and Men With Fragility Fractures With and Without Osteoporotic Bone Density: The Dubbo Osteoporosis Epidemiology Study. J Bone Miner Res. 31. doi: 10.1002/ jbmr.2393.

18. McLellan AR, Gallacher SJ, Fraser M, McQuillian C (2003) The fracture liaison service: Success of program for the evaluation and management of patients with osteoporotic fracture. Osteoporos Int. 14:1028-34

19. van den Bergh JP, van Geel TA, Geusens PP (2012) Osteoporosis, frailty and fracture: implications for case finding and therapy. Nat Rev Rheumatol. 8(3):163-72. doi: 10.1038/nrrheum.2011.217.

20. Dutch Institute for Healthcare Improvement CBO (2011) Richtlijn Osteoporose en Fractuurpreventie. www.diliguide.nl/document/1015/file/pdf/. (Dutch) Accessed 19 December 2011

21. https://www.nhg.org/standaarden/volledig/nhg-standaard-fractuurpreventie (Dutch) Accessed 25 December 2014

22. http://www.dutchhospitaldata.nl/Paginas/default.aspx (Dutch) Accessed 25 December 2014

23. McLellan AR, Wolowacz SE, Zimovetz EA, Beard SM, Lock S, McCrink L, Adekunle F, Roberts D (2011) Fracture liaison services for the evaluation and management of patients with osteoporotic fracture: a cost-effectiveness evaluation based on data collected over 8 years of service provision. Osteoporos Int. 22(7):2083-98. doi: 10.1007/s00198-011-1534-0.

24. Mitchell PJ (2013) Best practices in secondary fracture prevention: fracture liaison services. Curr Osteoporos Rep. 11(1):52-60. doi: 10.1007/s11914-012-0130-3

25. Gallacher SJ (2005) Setting up an osteoporosis fracture liaison service: background and potential outcomes. Best Pract Res Clin Rheumatol. 19(6):1081-94.

26. Vaile JH, Sullivan L, Connor D, Bleasel JF. (2013) A Year of Fractures: a snapshot analysis of the logistics, problems and outcomes of a hospital-based fracture liaison service. Osteoporos Int. 24(10):2619-25. doi: 10.1007/s00198-013-2357-y.

27. Dehamchia-Rehailia N, Ursu D, Henry-Desailly I, Fardellone P, Paccou J. (2014) Secondary prevention of osteoporotic fractures: evaluation of the Amiens University Hospital's fracture liaison service between January 2010 and December 2011. Osteoporos Int. 25(10):2409-16. doi: 10.1007/s00198-014-2774-6.

28. Giles M, Van Der Kallen J, Parker V, Cooper K, Gill K, Ross L, McNeill S. (2011) A team approach: implementing a model of care for preventing osteoporosis related fractures. Osteoporos Int. 22(8):2321-8. doi: 10.1007/s00198-010-1466-0.

29. Eekman DA, van Helden SH, Huisman AM, Verhaar HJ, Bultink IE, Geusens PP, Lips P, Lems WF (2014) Optimizing fracture prevention: the fracture liaison service, an observational study. Osteoporos Int. 25(2):701-9. doi: 10.1007/s00198-013-2481-8.

30. Naranjo A, Ojeda-Bruno S, Bilbao Cantarero A, Quevedo Abeledo JC, Henríquez-Hernández LA, Rodríguez-Lozano C (2013) Results of a model of secondary prevention for osteoporotic fracture coordinated by rheumatology and focused on the nurse and primary care physicians. Reumatol Clin. 10(5):299-303. doi: 10.1016/j.reuma.2013.12.007. 
Chapter 2

31. Premaor M01, Pilbrow L, Tonkin C, Adams M, Parker RA, Compston J (2010) Low rates of treatment in postmenopausal women with a history of low trauma fractures: results of audit in a Fracture Liaison Service. QJM. 103(1):33-40. doi: 10.1093/qjmed/hcp154.

32. Majumdar SR, Lier DA, Leslie WD. (2013) Cost-effectiveness of two inexpensive postfracture osteoporosis interventions: results of a randomized trial. J Clin Endocrinol Metab. 98(5):19912000. doi: 10.1210/jc.2013-1034

33. Aizer J, Bolster MB. (2014) Fracture liaison services: promoting enhanced bone health care. Curr Rheumatol Rep. 16(11):455. doi: 10.1007/s11926-014-0455-2.

34. http://www.osteoporosis.ca/wp-content/uploads/OC-Quality-Standards-ENG-Nov-2014.pdf (Accessed 13 March 2015)

35. http://training.nos.org.uk/login/index.php (Accessed 13 March 2015) 
Meeting international standards of secondary fracture prevention 2 


$$
3
$$




\section{CHAPTER 3}

\section{Challenges and opportunities to improve fracture liaison service attendance: fracture registration and patient characteristics and motivations}

Peter van den Berg (1)*, Paul M.M. van Haard (2), Piet P. Geusens (3), Joop P. van den Bergh (4), Dave H. Schweitzer (5).

1. Dept. of Orthopedics and Traumasurgery, Fracture Liaison Service, Reinier de Graaf Hospital, Delft, the Netherlands

2. Dept. of Medical Laboratories, Association of Clinical Chemistry, Reinier the Graaf Hospital, Delft, the Netherlands

3. Dept. of Internal Medicine, Subdivision Rheumatology, Maastricht University Medical Center, Maastricht, the Netherlands and Hasselt University, Hasselt, Belgium

4. Dept. of Internal Medicine, VieCuri Medical Centre Noord-Limburg and Dept. of Internal Medicine, Subdivision Rheumatology, Maastricht University Medical Center, Maastricht, the Netherlands

5. Dept. of Internal Medicine and Endocrinology, Reinier the Graaf Hospital, Delft, the Netherlands

* Corresponding author E-Mail: pberg@rdgg.nl

Tel.: +31 152604926; Fax: +31 152605982 


\section{Disclosures}

Peter van den Berg: $\quad$ no disclosures

Paul M.M. van Haard: $\quad$ no disclosures

Piet P. Geusens: no disclosures

Joop P. van den Bergh: $\quad$ no disclosures

Dave H. Schweitzer: no disclosures

\section{Conflicts of Interest}

Peter van den Berg, Paul van Haard, Piet Geusens, Joop van den Bergh and Dave Schweitzer declare that they have no conflict of interest.

\section{Acknowledgments}

We are grateful to Mrs. Wil Aarssen and Mrs. Maria van Woerden for their excellent secretarial services and to Mrs. Lisette van Hulst for her linguistic advice.

\section{Contributions.}

PVDB, DHS and PVH are responsible for the study design. PVDB and DHS were the authors, supported by PVH, who also performed all statistical analyses. PG and JVDB supported the process with important scientific contributions.

\section{Mini-abstract:}

This questionnaire-based study evaluated the reasons for attendance or nonattendance at the fracture liaison service in patients with a recent fracture. Frailty, male sex, living alone and low education were associated with non-attendance, and the information perceived by the patient was associated with attendance. Keywords: Non-attendance; FLS; Attendance. 


\begin{abstract}
Introduction

The purpose of this study was to evaluate hospital registration- and patient-related factors associated with attendance or non-attendance to the Fracture Liaison Service (FLS).
\end{abstract}

\title{
Patients and Methods
}

Out of 1728 consecutive patients registered with a recent fracture at hospital entry, and after exclusion of 440 patients because of death, residence in a nursing home, already on osteoporosis treatment or recent DXA, 1288 received an FLS invitation. We evaluated the hospital registration of fractures at entry and exit of the hospital. A questionnaire was sent to all invited patients to evaluate factors related to nonattendance (including age, gender, frailty, living alone, income, education, extrinsic motivations (impact of perceived information) and intrinsic motivations (patient's own perceived views and opinions) and to attendance (personal impact of clinical professionals`advice).

\section{Results}

There were 278 more hospital exit codes than entry codes. Of the 1288 invited patients 745 returned analyzable questionnaires (537 attenders and 208 non-attenders). Non-attendance was associated with male gender (OR:2.08, 95\% Cl:1.35;3.21), frailty (OR:1.62, Cl:1.08;2.45), living alone (OR:2.05, Cl:1.48;2.85), low education (OR:1.82,Cl:1.27;2.63), not interested in bone strength (OR:1.85 Cl:1.33;2.63) and being unaware of increased subsequent fracture risk (OR:1.75, Cl:1.08;2.86). Information perceived by the patient was significantly associated with attendance (OR: 3.32, Cl;1.75; 6.27).

\section{Conclusion}

Fracture entry registration inaccuracies, male gender, frailty, living alone, having low general education or low interest in bone health and subsequent fracture risk were independently associated with FLS non-attendance. Adequately perceived advice (to have a bone densitometry and attend the FLS) was strongly associated with FLS attendance. 


\section{Introduction}

The Fracture Liaison Service (FLS) is widely considered the most effective model of care for the prevention of subsequent fractures [1-4], and fully coordinated, intensive strategies are the most effective approach to secondary fracture prevention [5] and treatment adherence [6-7].

However, there is still a large evaluation and treatment gap in secondary fracture prevention [1-3, 8, 9], in spite of available treatments to prevent subsequent fractures [10].

The reasons for this low attendance are unclear, but patients 'views and opinions about osteoporosis and the consequent underestimation of subsequent fracture risk might be of strong influence [11-14]. Besides person-related considerations there may be administrative pitfalls to be evaluated.

Patient information is a key component of effective self-management [11], but it was not always clear whether the studies involved primary or secondary fracture prevention.

Also, patient characteristics can be involved in FLS attendance. Between FLSs, there is a high variability of selected patients according to age or sex [12]. In a study in the UK, socio-economic factors did not play a role in FLS participation [13]. Patient characteristics that could play a role in not attending the FLS include illness perception, frailty, living alone and low education [14-17]. We therefore evaluated the association of administrative fracture registration, patient characteristics and patient information with FLS non-attendance and attendance.

The first objective was to study the accuracy of the administrative fracture registration process on the proportion of patients that was or was not invited to the FLS. The second objective was to study the impact of demographic aspects, patients `views and motivations on attending.

\section{Patients and Methods}

\section{Patients}

This study was performed in patients older than 50 year who presented because of a clinical fracture between January $1^{\text {st }}$ and December $31^{\text {th }}$ in the year 2016 at the Reinier de Graaf Hospital, Delft, the Netherlands.

Identification of patients with a recent fracture was based on the administrative 
fracture registration that was registered by the clinical professional at the time of hospital entrance. Registrations were monthly reconciled by one of the FLS officers. After exclusion of patients who had deceased, following patients were also not invited according to the local FLS protocol: permanent residents in a nursing home and patients with medical conditions in need of anti-osteoporotic treatments (not including calcium or vitamin D) or who had a DXA within two years before fracture. All remaining patients were subsequently invited to attend the FLS.

We used two strategies to identify these patients to invite them for a FLS visit, in line with the Dutch Guideline on Osteoporosis and Fracture prevention as implemented in our hospital protocol [18]. Strategy 1 was to invite personally as many patients as possible by the clinical professional at the plaster department. Strategy 2 was to send an invitation letter to all patients who were not personally contacted by the clinical professional at the plaster department or who, in spite of this, had not made an FLS appointment. To accomplish strategy 2, we screened all entry fracture code registrations from the database of the Emergency Department once every month.

\section{Questionnaire}

In June 2017, all these patients, whether or not they had accepted the invitation to attend the FLS, were send a questionnaire by post mail. The content of this questionnaire is available in the Appendix.

The questionnaire consisted of 1/ Patient characteristics included age, sex, marital status, education, country of birth, income and fracture location; 2/ Therapy: use of calcium and vitamin D supplements and having osteoporosis treatment; 3/ Patient views and opinions: Intrinsic motivations (5 questions): about fracture and bone, general health and questions about patients 'views on bone quality and extrinsic motivations (11 questions): perceived advice to attend the FLS and have a DXA scan and motivations why they had decided to attend or not to attend the DXA and FLS and 4/ various aspects of frailty were evaluated, using the validated Tilburg Frailty Indicator (TFI) questionnaire [19]. The TFI has a scoring range between 1 and 15, frailty is defined by a score $\geq 5$ but $<10$ and being very frail by a score $\geq 10$ with the highest limit of 15 points.

Motivations for attending the FLS were evaluated for extrinsic and intrinsic factors. Extrinsic motivations were considered to arise from information by clinical professionals, for example the inclination to follow instructions by the health 
professional to attend the FLS. Intrinsic motivations origin from self-reflection, such as personal judgment to strive for a better bone health.

\section{Administrative registration of patients with a recent fracture}

Reimbursement of treatments in Dutch hospitals is based on administrative fracture registration by the clinical professional. This is firstly done at the time of hospital admission because of a fracture ("entry registration") [20-22], using the hospital electronic patient management system ChipSoft HiX 6.1[23]. In this study the FLS invitation process was based on entry registrations from the Emergency Departments database, which is common practice among many Dutch FLSs $[8,9]$. During the process of fracture care, this entry registration is reconciled by the Hospital Financial Dept., based on the automated collection of fracture registrations from all medical departments. In case of incomplete entry registration the Hospital Financial Dept. was entitled to make adjustments before the final registration was sent to the health insurance company for reimbursement ("exit registration"). The fracture registration accuracy was evaluated by comparing all entry fracture registration codes with all exit fracture registration codes.

Fracture types (according to exit registrations) were subdivided into Non-Vertebral Non-Hip (NVNH) minor fractures ( $n=855,43 \%)$, NVNH major fractures ( $n=740,37 \%)$, hip fractures ( $n=312,15 \%)$ or clinical vertebral fractures $(n=99,5 \%)$, based on the level of subsequent fracture risk as previously reported [24].

\section{Statistical Analysis}

Data were analyzed using Statgraphics Centurion XVII software (Version 17.2.05 for MS-Windows; Statpoint, Inc., Warrenton, VA, USA).

Analyses were performed on two age strata ( $<70$ and $>=70 \mathrm{yr}$.) in line with the Dutch VMS [25], gender, and on dichotomized variables of the 745 questionnaires. Medians of age (yr.) with respect to gender were compared with the Wilcoxon rank-sum test and the Micceri Normality test. Associations were assessed via crosstabulation, using two column-dependent variables Attending (Yes/No), and Frailty (Yes/No) using TFI. After bivariate crosstabulation, a multivariate logistic regression model was fitted to identify any possible association between the binary outcome variable attending (Yes/ No) and independent predictive variables i.e. demographics as age and gender and 
extrinsic or intrinsic motivations. We tried to decipher model enhancing and significant interactions applying R TREE package. The association was assessed by direction and absolute value of adjusted residuals. Evidence of any association in the population from which the sample was drawn was assessed with unconditional, uncorrected Pearson's Chi-Squared test; if significant, the association was measured using Odds Ratios and 95\% Confidence Intervals. Multivariate Odds Ratios were estimated with logistic regression, with non-attendance as dependent outcome and demographics, frailty, and motivations as independent outcome variables after exclusion of those independent variables that were not significant in the univariate analysis and after testing for interaction between variables. Where applicable, 95\% Confidence Intervals and correlation coefficients were used. A p-value < .05 was considered statistically significant.

\section{Ethics}

The study was carried out in accordance with the declaration of Helsinki and the guidelines of the International Conference on Harmonization Good Clinical Practice (GCP) after a certificate of no objection approved by the regional Medical Ethical Review Board (METC Zuidwest Holland) no. NL 17.109.

\section{Results}

A total of 2,006 patients of 50 years or older had a validated exit fracture code registration. As patients were only invited to attend the FLS based on entry fracture code registrations, we calculated that 278 (14\%) were missed and therefore had not received the FLS invitation by post mail. Of the remaining 1728 patients, 440 patients were excluded from invitation because they had died or were excluded based on our local FLS protocol. (Fig.1). Therefore, only 1,288 patients were invited. This resulted in 841 attenders and 447 not attenders meaning 65\% of all invited patients (Fig. 1). From these 1,288 patients we received 772 questionnaires (27 not analyzable). The remaining 745 evaluable questionnaires came from 537 attenders (72\%) and from 208 non-attenders (28\%). 
Fig 1. Flowchart of FLS patients in 2016 based on entry and exit fracture code registration and response to questionnaires

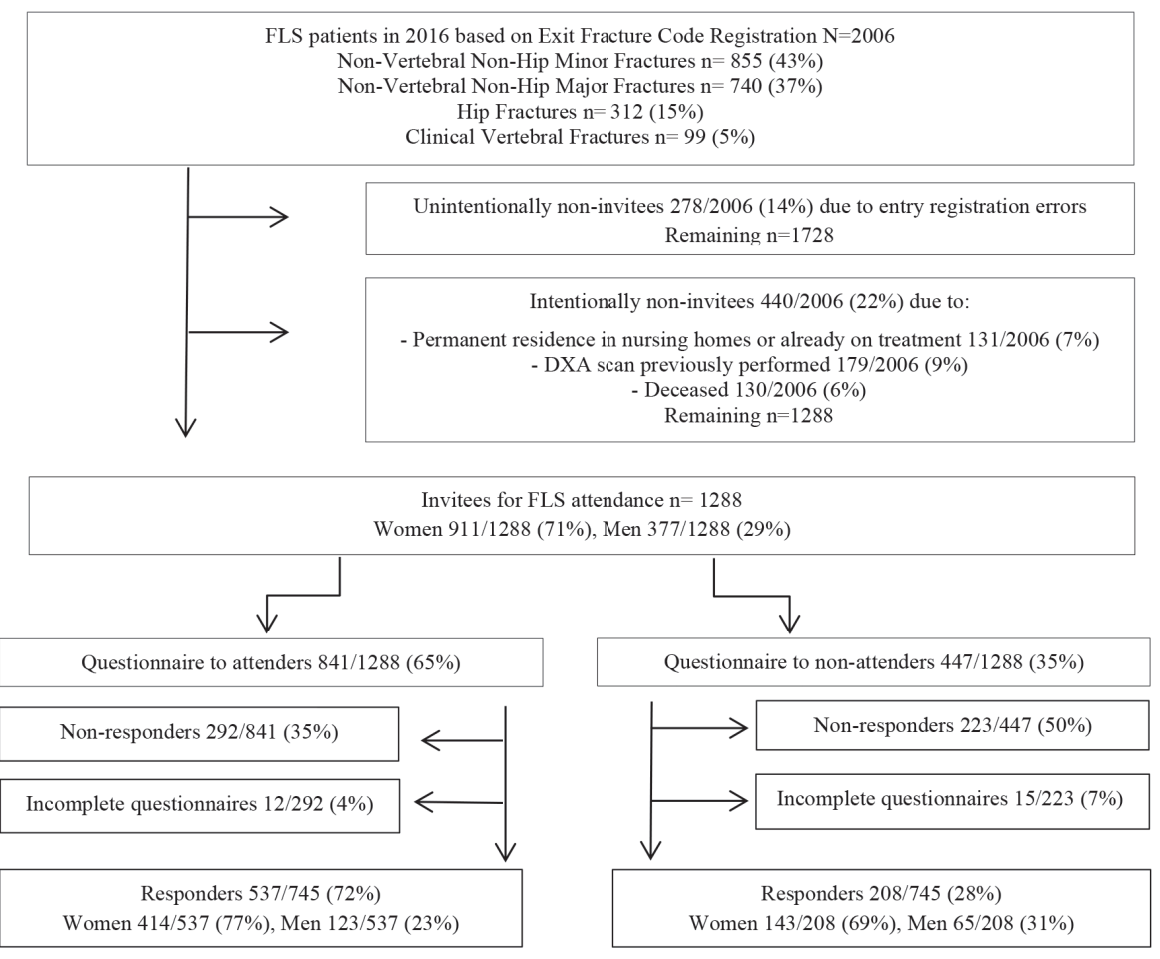

Legends: DXA: Dual Energy X-ray Absorptiometry; FLS: Fracture Liaison Service. 
Table 1. Characteristics of $745 \mathrm{FLS}$ patients that responded to the Questionnaire.

\begin{tabular}{lll}
\hline Pooled data for men and women & $\begin{array}{l}\text { ATTENDING } \\
\mathrm{n}=537(72 \%)\end{array}$ & $\begin{array}{l}\text { NOT-ATTENDING } \\
\mathrm{n}=208(28 \%)\end{array}$ \\
\hline
\end{tabular}

\section{Demographics}

\begin{tabular}{|c|c|c|}
\hline Age at Fracture & $69(50-96)$ & $75(50-95)$ \\
\hline Women & $414(77 \%)$ & $143(69 \%)$ \\
\hline Men & $123(23 \%)$ & $65(31 \%)$ \\
\hline \multicolumn{3}{|l|}{ Fracture type: } \\
\hline Minor fracture & 207 (39\%) & $68(32 \%)$ \\
\hline Major Fracture & $250(46 \%)$ & $99(48 \%)$ \\
\hline Hip Fracture & $54(10 \%)$ & $25(12 \%)$ \\
\hline Vertebral Fracture & $26(5 \%)$ & $16(8 \%)$ \\
\hline \multicolumn{3}{|l|}{ Marital status: } \\
\hline Living together (married/shared living) & $343(64 \%)$ & $98(47 \%)$ \\
\hline Not married & $47(9 \%)$ & $18(9 \%)$ \\
\hline Divorced & $43(8 \%)$ & $17(8 \%$ \\
\hline Widow/Widower & $104(19 \%)$ & $75(36 \%)$ \\
\hline \multicolumn{3}{|l|}{ Education: } \\
\hline No response & $5(1 \%)$ & $4(2 \%)$ \\
\hline Primary/secondary school vs. & $342(64 \%)$ & $154(74 \%)$ \\
\hline High school/university & $190(35 \%)$ & $50(24 \%)$ \\
\hline \multicolumn{3}{|l|}{ Country of birth: } \\
\hline The Netherlands & 507 (94\%) & $194(93 \%)$ \\
\hline Indonesia & $6(1 \%)$ & $2(1 \%)$ \\
\hline Surinam and Antilles & $5(1 \%)$ & 0 \\
\hline Turkey and Morocco & $19(4 \%)$ & $6(6 \%)$ \\
\hline \multicolumn{3}{|l|}{ Income (in € per month): } \\
\hline Low (€ $601-€ 1200)$ & $67(12 \%)$ & $34(16 \%)$ \\
\hline Normal (€ $1200-€ 1800)$ & $96(18 \%)$ & $49(24 \%)$ \\
\hline High $(\geq € 2100)$ & $275(51 \%)$ & $70(33 \%)$ \\
\hline No response & $99(19 \%)$ & $55(27 \%)$ \\
\hline \multicolumn{3}{|c|}{ Are you satisfied with your living/housing environment? } \\
\hline Yes & $519(97 \%)$ & $200(96 \%)$ \\
\hline No & $12(2 \%)$ & $6(3 \%)$ \\
\hline No response & $6(1 \%)$ & $2(1 \%)$ \\
\hline
\end{tabular}

Use of calcium and vitamin D supplementation and use of osteoporosis medication

Use of calcium tablets?

$\begin{array}{lll}\text { Yes } & 113(21 \%) & 62(30 \%) \\ \text { No } & 396(74 \%) & 137(66 \%) \\ \text { No response } & 28(5 \%) & 14(4 \%)\end{array}$




\begin{tabular}{lll}
\hline Pooled data for men and women & $\begin{array}{l}\text { ATTENDING } \\
\mathbf{n}=537(\mathbf{7 2} \%)\end{array}$ & $\begin{array}{l}\text { NOT-ATTENDING } \\
\mathbf{n}=\mathbf{2 0 8}(\mathbf{2 8 \%})\end{array}$ \\
\hline Use of Vitamin D? & & \\
Yes & $299(56 \%)$ & $74(36 \%)$ \\
No & $217(40 \%)$ & $116(56 \%)$ \\
Do not know & $10(2 \%)$ & $8(4 \%)$ \\
No response & $11(2 \%)$ & $10(4 \%)$ \\
Do you take oral bisphosphonates? & & \\
Yes & $106(20 \%)$ & $38(18 \%)$
\end{tabular}

Patients views and opinions

What caused your fracture

$\begin{array}{lll}\text { Osteoporosis } & 65(12 \%) & 23(11 \%) \\ \text { The fall } & 240(45 \%) & 79(38 \%) \\ \text { The accident } & 85(16 \%) & 36(17 \%) \\ \text { Bad physical condition } & 9(2 \%) & 3(1 \%) \\ \text { Imbalance / dizziness } & 30(6 \%) & 23(11 \%) \\ \text { No response } & 108(19 \%) & 82(39 \%) \\ \text { I think that my fracture risk is not increased although I had a fracture. } & \\ \text { Yes } & 99(18 \%) & 24(12 \%) \\ \text { No/do not know } & 432(82) & 181(88 \%) \\ \text { Perceived advice to attend the FLS } & & \\ \text { Perceived advice to attend=Yes } & 428(80 \%) & 61(29 \%) \\ \text { Perceived advice to attend= No } & 109(20 \%) & 147(71 \%) \\ \text { Taking interest in Bone Quality } & & \\ \text { Yes } & 63(12 \%) & 15(7 \%) \\ \text { No } & 236(44 \%) & 118(57 \%) \\ \text { Somewhat } & 229(43 \%) & 64(31 \%) \\ \text { No response } & 9(1 \%) & 11(5 \%)\end{array}$

\section{Various aspects of health and frailty}

How healthy is your lifestyle?

Healthy

Not healthy, not unhealthy

Unhealthy

$400(74 \%) \quad 138(66 \%)$

$134(25 \%) \quad 65(31 \%)$

Self-reported Level of Health:

$5(3 \%)$

Good

$3(1 \%)$

Poor

$\begin{array}{ll}408(76 \%) & 145(70 \%) \\ 101(19 \%) & 44(21 \%) \\ 28(5 \%) & 19(9 \%) \\ & \\ 173(32 \%) & 72(35 \%) \\ 352(66 \%) & 13163 \%) \\ 12(2 \%) & 8(2 \%)\end{array}$

No response

Do you suffer from 2 or more chronic diseases?

Yes

$352(66 \%)$

$8(2 \%)$ 


\begin{tabular}{lll}
\hline Pooled data for men and women & $\begin{array}{l}\text { ATTENDING } \\
\mathbf{n}=537(\mathbf{7 2} \%)\end{array}$ & $\begin{array}{l}\text { NOT-ATTENDING } \\
\mathbf{n}=\mathbf{2 0 8}(\mathbf{2 8 \%})\end{array}$ \\
\hline $\begin{array}{l}\text { Do you take } 4 \text { or more tablets every day? } \\
\text { Yes }\end{array}$ & $179(33 \%)$ & $84(40 \%)$ \\
No & $336(63 \%)$ & $112(54 \%)$ \\
No response & $22(4 \%)$ & $12(6 \%)$ \\
Frailty (Tilburg Frailty Indicator scores) & & \\
Women & $\underline{414(77 \%)}$ & $\underline{143(69 \%)}$ \\
\hline TFI score $\geq 5$ (frail) & $167(40 \%)$ & $60(42 \%)$ \\
TFI score $<5$ (not frail) & $247(60 \%)$ & $83(58 \%)$ \\
Men: & $\underline{123(23 \%)}$ & $\frac{65(31 \%)}{24(37 \%)}$ \\
TFI score $\geq 5$ (frail) & $16(13 \%)$ & $41(63 \%)$ \\
TFI score $<5$ (not frail) & $107(87 \%)$ & 4 \\
\hline
\end{tabular}

Legends:

Results are presented as median (range) or numbers (percentage). A Tilburg Frailty Indicator score $\geq 5$ represents frailty.

The characteristics of attenders and non-attenders are presented in table 1. Using univariate analysis (Table 2), non-attendance was significantly associated with age > 70 years, being male, living alone, having low income or low education and being frail. Out of the five questions concerning extrinsic and eleven questions concerning intrinsic motivations one extrinsic motivation and two intrinsic motivations showed significant associations. The extrinsic motivation "the clinical professional did not advise me to go for DXA" was significantly associated with non-attendance as well as the following two intrinsic motivations 1. "I am not interested in my bone strength" 2. "I do not think that my fracture risk is increased after sustaining this fracture". On the other hand, patients ' perceived advice by the clinical professional to go through DXA and visit the FLS was significantly associated with attendance (Table 2 and 3).

In multivariate analysis, all factors that were significant in univariate analysis remained significant, except age and low income (table 3). Non-attendance was independently associated with being male, living alone, low education, frailty (OR: 1.62, Cl: 1.08; 2.45), no perceived advice to go through DXA and visit the FLS as well as "I am not interested in my bone strength" and "I do not think that my fracture risk is increased after sustaining this fracture" with non-attendance but not with age, neither as bivariate $\leq 70$ $>70$ years groups, nor per decade, or categorized for highest versus lowest quartiles or per age category in standard deviation subgroups (table 3). Perceived advice to go through DXA and to visit the FLS was positively and significantly associated with 
attendance, with an OR of 3.32 (Cl: $1.75 ; 6.27)$.

Table 2. Univariate Associations of Demographics, Extrinsic and Intrinsic Motivations and Frailty with FLS non-attendance and attendance.

\begin{tabular}{|c|c|c|}
\hline & $\begin{array}{l}\text { Measure of } \\
\text { Association: } \\
\text { OR }(95 \% \mathrm{Cl})\end{array}$ & $\begin{array}{l}\text { Test of } \\
\text { Association: } \\
\text { Pearson's } \\
\text { Chi-square } \\
p \text {-value }\end{array}$ \\
\hline \multicolumn{3}{|l|}{ FLS NON-ATTENDANCE } \\
\hline \multicolumn{3}{|l|}{ Demographic factors contributing to be a non-attender } \\
\hline Male & $1.67(1.17 ; 2.42)$ & .002 \\
\hline Living alone & $1.98(1.43 ; 2.74)$ & $<.001$ \\
\hline Age $>70 \mathrm{yr}$. & $1.87(1.35 ; 2.60)$ & $<.001$ \\
\hline Low income & $3.03(2.00 ; 4.55)$ & $<.001$ \\
\hline Low education & $3.03(2.00 ; 4.55)$ & $<.001$ \\
\hline \multicolumn{3}{|l|}{ Extrinsic Motivations contributing to be a non-attender } \\
\hline $\begin{array}{l}\text { No advice was perceived to have a DXA and to visit the } \\
\text { FLS }\end{array}$ & $9.1(6.7 ; 12.5)$ & $<.001$ \\
\hline \multicolumn{3}{|l|}{ Intrinsic Motivations contributing to be a non-attender } \\
\hline I am not interested in my bone strength* & $2.08(1.50 ; 2.94)$ & $<.001$ \\
\hline $\begin{array}{l}\text { I do not think that my fracture risk is increased after } \\
\text { sustaining this fracture** }\end{array}$ & $1.72(1.08 ; 2.86)$ & .024 \\
\hline \multicolumn{3}{|l|}{ Frailty: Tilburg Frailty Indicator (TFI) } \\
\hline Frailty & $2.12(1.51 ; 2.98)$ & .002 \\
\hline \multicolumn{3}{|l|}{ FLS ATTENDANCE } \\
\hline \multicolumn{3}{|l|}{ Extrinsic Motivation contributing to be an attender } \\
\hline Advice was perceived to have a DXA and to visit the FLS & $5.9(3.7 ; 9.1)$ & $<.001$ \\
\hline
\end{tabular}

Legends:

OR: Odds Ratio; 95\%Cl: 95\% Confidence Interval, $p$-value <.05 is considered significant. Frailty: Tilburg Frailty Indicator (TFI) dichotomized: $<5$ = not frail vs. $\geq 5$ = frail, Living alone: dichotomized Yes/No meaning living with other individual(s) vs. living alone; Age: dichotomized $\leq 70 \mathrm{yr}$. or $>70 \mathrm{yr}$.; Income: dichotomized highest monthly income $\geq € 2100$ vs. $<€ 2100$; Education: dichotomized high school or university grouped vs. other levels of education. Statistical analysis (applying R package: tree) revealed no interaction between variables.

* I am not interested in my bone strength; grouped data: I am not interested in my bone strength vs. somewhat interested and interested in my bone strength.

** I do not think that my fracture risk is increased after sustaining this fracture; grouped data Yes vs. No and I do not know. 
Table 3. Multivariate logistic regression of Demographics, Extrinsic and Intrinsic motivations and Frailty with FLS non-attendance or attendance.

\begin{tabular}{|c|c|c|}
\hline & $\begin{array}{l}\text { Measure of } \\
\text { Association: } \\
\text { OR }(95 \% \mathrm{Cl})\end{array}$ & $\begin{array}{l}\text { Test of } \\
\text { Association: } \\
\text { Pearson's Chi- } \\
\text { square } \\
p \text {-value }\end{array}$ \\
\hline \multicolumn{3}{|l|}{ FLS NON-ATTENDANCE } \\
\hline \multicolumn{3}{|l|}{ Demographics contributing to be a non-attender } \\
\hline Male & $2.08(1.35 ; 3.21)$ & .002 \\
\hline Living alone & $2.05(1.48 ; 2.85)$ & $<.001$ \\
\hline Low education & $1.82(1.27 ; 2.63)$ & .0014 \\
\hline \multicolumn{3}{|c|}{ Extrinsic Motivations contributing to be a non-attender } \\
\hline $\begin{array}{l}\text { No advice was perceived to have a DXA and to } \\
\text { visit the FLS }\end{array}$ & $3.23(1.96 ; 5.56)$ & $<.001$ \\
\hline \multicolumn{3}{|c|}{ Intrinsic Motivations contributing to be a non-attender } \\
\hline I am not interested in my bone strength. & $1.85(1.33 ; 2.63)$ & $<.001$ \\
\hline $\begin{array}{l}\text { I think that my fracture risk is not increased } \\
\text { although I had a fracture }\end{array}$ & $1.75(1.08 ; 2.86)$ & .002 \\
\hline \multicolumn{3}{|l|}{ Frailty: Tilburg Frailty Indicator (TFI) } \\
\hline Frailty & $1.62(1.08 ; 2.45)$ & .002 \\
\hline \multicolumn{3}{|l|}{ FLS ATTENDANCE } \\
\hline \multicolumn{3}{|l|}{ Extrinsic Motivation contributing to be an attender } \\
\hline $\begin{array}{l}\text { Advice was perceived to have a DXA and to visit } \\
\text { the FLS }\end{array}$ & $3.32(1.75 ; 6.27)$ & $<.001$ \\
\hline
\end{tabular}

Legends:

OR: Odds Ratio; 95\%Cl: 95\% Confidence Interval, $p$-value <.05 is considered significant. 


\section{Discussion}

The aim of our study was to gain more insight into reasons of FLS non-attending or attending. We identified failures in administrative fracture entry registration as well as being male, frail, having low general education, living alone and lack of extrinsic and intrinsic motivations as independent risks for FLS non-attending. Extrinsic motivation was an independent FLS attending factor.

There was an invitation gap of $14 \%$ in our hospital due to administrative errors. This finding may provide opportunities to improve this as yet unidentified factor for nonattending the FLS. According to a previously reported study this improvement may have nationwide implications for FLS attendance and consequences for fracture reduction and cost savings $[6,26]$.

The Fracture Liaison Service (FLS) is considered the most effective approach for secondary fracture prevention, but attendance is heterogeneous $[1,8,9]$. Therefore, we evaluated the invitation process, including registration and patients' personal views. It is of note that there is no reported systemic audit on FLS registration. However, there is literature on patients 'views and considerations after fracture, highlighting the importance of the lack of information and low awareness to be at high risk for subsequent fracture. $[11,27]$. Since there are different degrees in FLS structures and populations, studies have been conducted to look for common phenotypes and socio-economic factors in order to better predict FLS non-attendance $[5,16,17]$. In addition to these factors we found being male, frail, living alone and being lower educated independently and significantly contributed to non-attendance.

Being male revealed a significant factor for non-attending. This finding has been previously published in another FLS study [28]. In a recent review on osteoporosis in men it was found that after low trauma men are less likely to be screened due to mans' reluctance to be screened, although their lifetime risk of osteoporotic fractures is between 13 and 25\% after the age of 50 [29]. Although women have a higher risk for a first fracture than men, the relative risk of a subsequent fracture is higher in men, so that the absolute subsequent fracture risk is similar between men and women [30]. Frailty leads to a negative spiral with an increase in fall risk, hospital admissions and death [31-33] and was a significant determinant of non-attendance in this study. Frailty is operationalized into phenotypes via psychometric clinical descriptions [34-36] or via a scoring system according to validated indicators [37]. In this study the Tilburg Frailty Indicator (TFI) was used because the TFI is also designed to point insight into demographic variables. TFI has been propagated previously for its robust 
validation properties, showing favorable outcomes for the relationship between phenotypical and psychometric properties [37]. In an intentionally similar survey on the use of osteoporosis medication after fracture and women's motivation, it was found that frailty was 44\% according to the TFI [27]. Moreover, 25-50\% of people older than 85 years comply with the accepted definition of frailty $[31,36,37]$. In the current study, frailty was found in $40 \%$ of non-attenders (42\% women and $37 \%$ men) who were younger (median 70 years). This underlines the importance of frailty including its associated functional restrictions in the prediction of fracture risk. [3839]. Importantly, frailty and functional restrictions are not only associated with nonattendance but also with high imminent fracture risk [38,39].

In this FLS study we found a univariate association between age (> 70 years) and nonattendance but the association was not significant in the multivariate model, indicating that other risk factors were dominant over age. This finding, although intuitively perceived to be associated, is not new in the field of osteoporosis. For example, in the Study of Osteoporotic Fractures among women of 65 years and older, age predicted one-year subsequent risk of hip and non-vertebral fractures, however, this predictive factor diminished after adjusting for functional and cognitive restrictions [39].

Low education was accounted as an independent associated factor of non-attendance in support with two previous studies from Canada and the UK. These studies point to the important role of someone's capability for self-reflection, health literacy and self-management $[11,16]$.

Living alone was also found to be a significant determinant for non-attending. In Western European countries e.g. The Netherlands, the number of adult people living alone is gradually increasing. Recent Dutch data show $43 \%$ of the elderly adult population to live alone (21\% after divorce and 22\% after death of a loved one [40]. Living alone should not be interpreted synonymous with loneliness but stands for increasing odds of losing social contacts and also the reluctance to ask support in general and for medical care [41].

Adequate motivation or the lack of it was a strong determinant associated with FLS attendance or non-attendance. Moreover, motivating patients for FLS attendance by health care professionals should take place shortly after sustenance of fracture $[1,9]$. Therefore, successful patient - health care professional interaction may well resolve part of the widely observed treatment gap. In this perspective, interfering factors like health professionals' self-assurance and the need in general for up-to-date training and uniformity in the field of fracture prevention remain essential [7]. The beneficial 
effect of face to face FLS promotion immediately post fracture has been shown effective in the current and in a previous study [8]. More than a third of all fracture registrations is attributable to osteoporosis [26]. Such a high proportion prompted to the conviction that all available instruments should be deployed to prevent new fractures as we have the insight, methods and medications $[10,27]$. Physicians, cast technicians and FLS nurses / nurse practitioners are encouraged to embrace this part of treatment to put effort in gaining patients' attention to accept treatment to prevent subsequent fractures.

The relatively high response rate of $60 \%$ to this questionnaire study is remarkable. Usually lower response rates of pencil and paper studies and of anonymous internet surveys have been reported [42].

This study has limitations. In this retrospective study, information regarding fracture treatment, either conservatively or surgery, exact time between fracture and questionnaire and duration of in- and outpatient treatment, was not available.

In addition we were not able to correlate treatment modalities and complications and time of rehabilitation to attendance. 3. To ensure statistical power demographics were analyzed as groups i.e. Living alone, Income and Level of education. These latter factors are probably different per country, region or neighborhood.

In conclusion, failures in administrative fracture entry registration as well as frailty, male gender, having low general education, living alone and low interest in bone health and subsequent fracture risk were independent determinants for FLS nonattendance. Adequate motivation of patients by the healthcare professional shortly after the fracture, or the lack of, was the strongest determinant associated with both FLS attendance and non-attendance, respectively. We advocate to increase attention on the fracture registration process and to put effort on a personal tailored approach to help patients to make an informed decision. Apart from these aspects, alternative strategies may be needed for those individuals who are frail, are living alone and have low education in order prevent subsequent fractures. 


\section{Appendix - Questionnaire}

In 2016 you were treated in the Reinier de Graaf Hospital for a broken bone. In order to get the best possible picture of your health and the health of your bones in particular, we would like you to fill in this questionnaire. In addition we find it important in order to continue to improve our services. If you are unable to give an answer to a question, you may skip it. Please make one choice per question unless indicated otherwise.

1) When you think about your bones, how much are healthy bones and breaking bones on your mind?

\begin{tabular}{|l|l|}
\hline They're on my mind a lot. & \\
\hline They' re somewhat on my mind & \\
\hline They' re not on my mind at all. & \\
\hline
\end{tabular}

2) Has your mother and/or your father ever broken a hip?

\begin{tabular}{|l|l|}
\hline Yes & \\
\hline No & \\
\hline I don't know & \\
\hline
\end{tabular}

3) In 2016 you experienced a bone fracture, please tick the bone you broke:

\begin{tabular}{|l|l|}
\hline Collarbone & \\
\hline Lower arm / wrist & \\
\hline Middle of hand / finger & \\
\hline Upper arm / shoulder & \\
\hline Elbow & \\
\hline Vertebra & \\
\hline Rib & \\
\hline Pelvis & \\
\hline Hip / Upper leg & \\
\hline Lower leg / knee & \\
\hline Ankle & \\
\hline Middle of foot / toe & \\
\hline
\end{tabular}


4) Since you were 50, have you previously broken another bone? (not counting the fracture in 2016)

Please indicate which bone that was. If you had not previously broken anything, please go on to question 6.

\begin{tabular}{|l|l|}
\hline Collarbone & \\
\hline Lower arm / wrist & \\
\hline Middle of hand / finger & \\
\hline Upper arm / shoulder & \\
\hline Elbow & \\
\hline Vertebra & \\
\hline Rib & \\
\hline Pelvis & \\
\hline Hip / Upper leg & \\
\hline Lower leg / knee & \\
\hline Ankle & \\
\hline Middle of foot / toe & \\
\hline
\end{tabular}

5) What do you think was the cause of your bone fracture in 2016 ? Please make a choice for each possibility.

\begin{tabular}{|l|l|l|l|}
\hline & Yes & No & I don't know \\
\hline Osteoporosis / Breakable bones & & & \\
\hline A fall & & & \\
\hline An accident (e.g. on the bike or in the car) & & & \\
\hline Physical weakness & & & \\
\hline Poor balance or dizziness & & & \\
\hline
\end{tabular}

6) Since your bone fracture in 2016, has a doctor suggested possible treatment options aimed at osteoporosis in order to prevent new fractures and the possibility of a DEXA scan (bone density test)?

\begin{tabular}{|l|l|}
\hline Yes & \\
\hline No & \\
\hline I don't know & \\
\hline
\end{tabular}


7) Since your bone fracture in 2016, has a cast technician /nurse suggested possible treatment options aimed at osteoporosis in order to prevent new fractures and the possibility of a DEXA scan (bone density test)?

\begin{tabular}{|l|l|}
\hline Yes & \\
\hline No & \\
\hline I don't know & \\
\hline
\end{tabular}

8) Has your GP spoken to you about `osteoporosis` (bone density loss)?

\begin{tabular}{|l|l|}
\hline Yes & \\
\hline No & \\
\hline I don't know & \\
\hline
\end{tabular}

9) After your bone fracture were you invited to go to the Fracture and Osteoporosis Out Patients' Clinic at the Reinier de Graaf Hospital?

\begin{tabular}{|l|l|}
\hline Yes & \\
\hline No & \\
\hline I don't know & \\
\hline
\end{tabular}

10) Have you had a DEXA scan (bone density test) done?

\begin{tabular}{|l|l|}
\hline Yes & \\
\hline No & \\
\hline I don't know & \\
\hline
\end{tabular}

11) Have you been to the Fracture and Osteoporosis Out Patients' Clinic ?

\begin{tabular}{|l|l|}
\hline Yes & \\
\hline No & \\
\hline I don't know & \\
\hline
\end{tabular}


12) Please will you indicate what made you decide to have a DEXA scan (bone density test) done. (If you decided not to have a DEXA scan done, please go on to question 19)

\begin{tabular}{|l|l|}
\hline $\begin{array}{l}\text { The doctor or cast technician / nurse or other healthcare specialist advised } \\
\text { me to have it done }\end{array}$ & \\
\hline $\begin{array}{l}\text { I wanted to know how healthy my bones were but it doesn't occur in my } \\
\text { family }\end{array}$ & \\
\hline There is a history of osteoporosis in my family and I was concerned & \\
\hline I had had more breaks and now I wanted to have it checked & \\
\hline I take prednisolone / medicine which can cause osteoporosis & \\
\hline I had an early menopause & \\
\hline I fall now and then because of epilepsy & \\
\hline I fall now and then because of dizziness or muscle weakness & \\
\hline I sometimes fall because of Multiple Sclerosis or Parkinson's disease & \\
\hline
\end{tabular}

13) Please indicate what made you decide not to go to the DEXA scan (bone density test) ?

\begin{tabular}{|l|l|}
\hline $\begin{array}{l}\text { The doctor or cast technician / nurse or other healthcare specialist didn't } \\
\text { advise me to do that }\end{array}$ & \\
\hline $\begin{array}{l}\text { The doctor or cast technician / nurse or other healthcare specialist advised } \\
\text { that indeed, but I haven't have it done yet }\end{array}$ & \\
\hline I don't believe that a DEXA scan will produce any useful information & \\
\hline I am of the opinion that I don't have osteoporosis: my bones are normal & \\
\hline I don't need a DEXA scan, there is no osteoporosis: it was a heavy fall & \\
\hline $\begin{array}{l}\text { I don't want to be made anxious: I don't want to know the results of the } \\
\text { DEXA scan }\end{array}$ & \\
\hline I have already had that test before & \\
\hline I am already prescribed osteoporosis medication & \\
\hline I am already prescribed calcium tablets & \\
\hline I am already prescribed vitamin D & \\
\hline I am not physically able to go to the hospital on my own for this & \\
\hline I don't want to bother my children/ carers to take me to hospital for this & \\
\hline I don't want it to make my health costs to increase & \\
\hline Other: &
\end{tabular}


14) Which source of information is the most important, in order, for finding out about the risk of breaking bones and osteoporosis (bone density loss)? (1=most important $7=$ least important)

\begin{tabular}{|l|l|}
\hline Medical specialist & \\
\hline GP & \\
\hline Nurse / Plaster-cast specialist & \\
\hline Physiotherapist & \\
\hline Other healthcare specialists (pharmacist / chemist) & \\
\hline Family and friends & \\
\hline Media (TV. radio, internet, magazines) & \\
\hline
\end{tabular}

15) Are you of the opinion that once someone has broken a bone there is a higher risk to then break something else?

\begin{tabular}{|l|l|}
\hline Yes & \\
\hline No & \\
\hline I don't know & \\
\hline
\end{tabular}

16) Are you of the opinion that treatment with medicine is possible against osteoporosis?

\begin{tabular}{|l|l|}
\hline Yes & \\
\hline No & \\
\hline I don't know & \\
\hline
\end{tabular}

17) Have you ever been prescribed any medicine against osteoporosis such as alendronic acid, risedronic acid, denosumab or zoledronic acid?

\begin{tabular}{|l|l|}
\hline Yes & \\
\hline No & \\
\hline I don't know & \\
\hline
\end{tabular}

18) If yes: in ........ (year)

19) How long have you used this osteoporosis medicine?

\begin{tabular}{|l|l|}
\hline Less than 3 months & \\
\hline Between 3 months and $1 / 2$ a year & \\
\hline Between $1 / 2$ a year and 1 year & \\
\hline Between 1 year and 3 years & \\
\hline Longer than 3 years & \\
\hline Longer than 5 years & \\
\hline
\end{tabular}


20) Are you using this osteoporosis medicine (still) at the moment?

\begin{tabular}{|l|l|}
\hline Yes & \\
\hline No & \\
\hline I don't know & \\
\hline
\end{tabular}

21) If you do not use this osteoporosis medicine (any more): what are your thoughts on that? (You may tick more than one answer)

\begin{tabular}{|l|l|}
\hline $\begin{array}{l}\text { My doctor / healthcare specialist has not advised me to do that or prescribed } \\
\text { that }\end{array}$ & \\
\hline My doctor / healthcare specialist advised me to stop & \\
\hline $\begin{array}{l}\text { My DEXA scan was good: I do not have osteoporosis and so no increased risk } \\
\text { of bone fractures }\end{array}$ & \\
\hline I got a prescription but I haven't picked it up yet & \\
\hline I would rather not take any medicine & \\
\hline I am afraid of getting side effects from this medicine & \\
\hline $\begin{array}{l}\text { At the moment I am not interested in preventing fractures caused by } \\
\text { osteoporosis }\end{array}$ & \\
\hline I do not believe that this medicine works against preventing fractures & \\
\hline I have enough with calcium tablets and vitamin D & \\
\hline I have a lot of physical exercise and get enough calcium from my food & \\
\hline I cannot afford the extra cost of the medicine. & \\
\hline
\end{tabular}

22) Have you ever been prescribed calcium tablets?

\begin{tabular}{|l|l|}
\hline Yes & \\
\hline No & \\
\hline I don't know & \\
\hline
\end{tabular}

23) Do you take calcium tablet at the moment?

\begin{tabular}{|l|l|}
\hline Yes & \\
\hline No & \\
\hline I don't know & \\
\hline
\end{tabular}

24) Have you ever been prescribed vitamin D?

\begin{tabular}{|l|l|}
\hline Yes & \\
\hline No & \\
\hline I don't know & \\
\hline
\end{tabular}


25) Do you take vitamin D at the moment?

\begin{tabular}{|l|l|}
\hline Yes & \\
\hline No & \\
\hline I don't know & \\
\hline
\end{tabular}

26) How would you judge your general health before the bone fracture in 2016 ?

\begin{tabular}{|l|l|}
\hline Excellent & \\
\hline Very good & \\
\hline Good & \\
\hline Reasonable & \\
\hline Poor & \\
\hline
\end{tabular}

27) How would you judge your health at the moment?

\begin{tabular}{|l|l|}
\hline Excellent & \\
\hline Very good & \\
\hline Good & \\
\hline Reasonable & \\
\hline Poor & \\
\hline
\end{tabular}




\section{Tilburg Frailty Indicator}

Gobbens RJJ, van Assen MALM, Luijkx KG, Wijnen-Sponselee MTh, Schols JMGA. The Tilburg Frailty Indicator: psychometric properties. J Am Med Dir Assoc 2010; 11(5):344-355.

\section{Part A Determinants of frailty}

1. Which sex are you?

2. What is your age?

3. What is your marital status?
0 male 0 female

.........years

0 married/living with partner

0 unmarried

0 separated/divorced

0 widow/widower

0 The Netherlands

0 Former Dutch East Indies

o Suriname

0 Netherlands Antilles

0 Turkey

0 Morocco

0 Other, namely

5. What is the highest level of education you have completed?

0 none or primary education

0 secondary education

0 higher professional or university education 
6. Which category indicates your net monthly household income?

$$
\begin{aligned}
& 0 € 600 \text { or less } \\
& 0 € 601-€ 900 \\
& 0 € 901-€ 1200 \\
& 0 € 1201-€ 1500 \\
& 0 € 1501-€ 1800 \\
& 0 € 1801-€ 2100 \\
& 0 € 2101 \text { or more }
\end{aligned}
$$

7. Overall, how healthy would you say your lifestyle is?

$$
\begin{aligned}
& 0 \text { healthy } \\
& 0 \text { not healthy, not unhealthy } \\
& 0 \text { unhealthy }
\end{aligned}
$$

8. Do you have two or more diseases and/or chronic disorders?

$$
0 \text { yes } 0 \text { no }
$$

9. Have you experienced one or more of the following events during the past year?

- the death of a loved one

0 yes 0 no

- a serious illness yourself

0 yes 0 no

- a serious illness in a loved one

0 yes 0 no

- a divorce or ending of an important intimate relationship

- a traffic accident

0 yes 0 no

- a crime

0 yes 0 no

0 yes 0 no

10. Are you satisfied with your home living environment?

$$
0 \text { yes } 0 \text { no }
$$




\section{Part B Components of frailty}

\section{B1 Physical components}
11. Do you feel physically healthy?
0 yes 0 no

12. Have you lost a lot of weight recently without wishing to do so? ('a lot' is: 6 kg or more during the last six months, or $3 \mathrm{~kg}$ or more during the last month)

$$
0 \text { yes } 0 \text { no }
$$

Do you experience problems in your daily life due to:
13. difficulty in walking?
0 yes 0 no
14. difficulty maintaining your balance?
0 yes 0 no
15. poor hearing?
0 yes 0 no
16. poor vision?
0 yes 0 no
17. lack of strength in your hands?
0 yes 0 no
18. physical tiredness?
0 yes 0 no

\section{B2 Psychological components}

19. Do you have problems with your memory?

0 yes 0 sometimes 0 no

20. Have you felt down during the last month?

0 yes 0 sometimes 0 no

21. Have you felt nervous or anxious during the last month?

22. Are you able to cope with problems well?

0 yes 0 sometimes 0 no

0 yes 0 no

\section{B3 Social components}

23. Do you live alone?

0 yes 0 no

24. Do you sometimes miss having people around you? 0 yes 0 sometimes 0 no 25. Do you receive enough support from other people? 0 yes 0 no 
* The TFI was translated into English using the method of back-translation.

Scoring Part B Components of frailty (range: 0 - 15) (Cut point: 5)

Question 11:

yes $=0$, no $=1$

Question 12 - 18:

no $=0$, yes $=1$

Question 19:

no and sometimes $=0$, yes $=1$

Question 20 and 21:

no $=0$, yes and sometimes $=1$

Question 22:

yes $=0$, no $=1$

Question 23:

no $=0$, yes $=1$

Question 24:

no $=0$, yes and sometimes $=1$

Question 25:

yes $=0$, no $=1$ 


\section{References}

1. Akesson K, Marsh D, Mitchell PJ, McLellan AR, Stenmark J, Pierroz DD, Kyer C, Cooper C (IOF Fracture Working Group). Capture the Fracture ${ }^{\circledR}$ : a Best Practice Framework and global campaign to break the fragility fracture cycle. Osteoporos Int. 2013 24(8):2135-52. doi: 10.1007/ s00198-013-2348-z.

2. Lems WF, Dreinhöfer KE, Bischoff-Ferrari H, Blauth M, Czerwinski E, da Silva J, Herrera A, Hoffmeyer P, Kvien T, Maalouf G, Marsh D, Puget J, Puhl W, Poor G, Rasch L, Roux C, Schüler S, Seriolo B, Tarantino U, van Geel T, Woolf A, Wyers C, Geusens P. EULAR/EFORT recommendations for management of patients older than 50 years with a fragility fracture and prevention of subsequent fractures. Ann Rheum Dis. 2017 May;76(5):802-810. doi: 10.1136/annrheumdis-2016-210289.

3. Eisman JA, Bogoch ER, Dell R, Harrington JT, McKinney RE Jr, McLellan A, Mitchell PJ, Silverman S, Singleton R, Siris E. Making the first fracture the last fracture: ASBMR task force report on secondary fracture prevention. J Bone Miner Res. 2012 Oct;27(10):2039-46. doi: 10.1002/ jbmr.1698.

4. McLellan AR, Gallacher SJ, Fraser M, McQuillian C. The fracture liaison service: success of a program for the evaluation and management of patients with osteoporotic fracture. Osteoporos Int. 2003 Dec;14(12):1028-34.

5. Ganda K, Puech M, Chen JS, Speerin R, Bleasel J, Center JR, Eisman JA, March L, Seibel MJ (2013). Models of care for the secondary prevention of osteoporotic fractures: a systematic review and meta-analysis. Osteoporos Int. 24(2):393-406. doi: 10.1007/s00198-012-2090-y.

6. Luc M, Corriveau H, Boire G, Filiatrault J, Beaulieu MC, Gaboury I. Patient-Related Factors Associated with Adherence to Recommendations Made by a Fracture Liaison Service: A MixedMethod Prospective Study. Int J Environ Res Public Health. 2018 May 9;15(5). pii: E944. doi: 10.3390/ijerph15050944.

7. Swart KMA, van Vilsteren M, van Hout W, Draak E, van der Zwaard BC, van der Horst HE, Hugtenburg JG, Elders PJM. Factors related to intentional non-initiation of bisphosphonate treatment in patients with a high fracture risk in primary care: a qualitative study. BMC Fam Pract. 2018 Aug 23;19(1):141. doi: 10.1186/s12875-018-0828-0. PMID: 30139341

8. Eekman DA, van Helden SH, Huisman AM, Verhaar HJ, Bultink IE, Geusens PP, Lips P, Lems WF. Optimizing fracture prevention: the fracture liaison service, an observational study. Osteoporos Int. 2014 Feb;25(2):701-9. doi: 10.1007/s00198-013-2481-8.

9. van den Berg P, Schweitzer DH, van Haard PM, van den Bergh JP, Geusens PP. Meeting international standards of secondary fracture prevention: a survey on Fracture Liaison Services in the Netherlands. Osteoporos Int. 2015 Sep;26(9):2257-63. doi: 10.1007/s00198-015-3117-y.

10. Khosla S, Hofbauer LC. Osteoporosis treatment: recent developments and ongoing challenges. Lancet Diabetes Endocrinol. 2017 Nov;5(11):898-907. doi: 0.1016/S2213-8587(17)30188-2.

11. Giangregorio L, Thabane L, Cranney A, Adili A, deBeer J, Dolovich L, Adachi JD, Papaioannou A. Osteoporosis knowledge among individuals with recent fragility fracture. Orthop Nurs. 2010 MarApr;29(2):99-107. doi: 10.1097/NOR.0b013e3181d2436c. PMID: 20335769

12. Alami S, Hervouet L, Poiraudeau S, Briot K, Roux C. One Barriers to Effective Postmenopausal Osteoporosis Treatment: A Qualitative Study of Patients' and Practitioners' Views. PLoS One. 2016 Jun 29;11(6):e0158365. doi: 10.1371/journal.pone.0158365. eCollection 2016. PMID: 27355576

13. Ong T, Tan W, Marshall L, Sahota O. The relationship between socioeconomic status and fracture in a fracture clinic setting: data from the Nottingham Fracture Liaison Service. Injury. 2015 Feb;46(2):366-70. doi: 10.1016/j.injury.2014.10.002. 
14. Grover ML, Edwards FD, Chang YH, Cook CB, Behrens MC, Dueck AC. Fracture risk perception study: patient self-perceptions of bone health often disagree with calculated fracture risk. Womens Health Issues. 2014 Jan-Feb;24(1):e69-75. doi: 10.1016/j.whi.2013.11.007. PMID: 24439949

15. Besser SJ, Anderson JE, Weinman J. How do osteoporosis patients perceive their illness and treatment? Implications for clinical practice. Besser SJ, Anderson JE, Weinman J. Arch Osteoporos. 2012;7:115-24. doi: 10.1007/s11657-012-0089-9. PMID: 23225289

16. Raybould G, Babatunde $O$, Evans AL, Jordan JL, Paskins Z. Expressed information needs of patients with osteoporosis and/or fragility fractures: a systematic review. Arch Osteoporos. 2018 May 8;13(1):55. doi: 10.1007/s11657-018-0470-4.

17. Vranken L, Wyers CE, van den Bergh JPW, Geusens PPMM. The Phenotype of Patients with a Recent Fracture: A Literature Survey of the Fracture Liaison Service. Calcif Tissue Int. 2017 Sep;101(3):248258. doi: 10.1007/s00223-017-0284-1.

18. Dutch Institute for Healthcare Improvement CBO (2011) Richtlijn Osteoporose en Fractuurpreventie. www.diliguide.nl/document/1015/file/pdf/. (Dutch) Assessed 14-02-2018

19. Gobbens RJ, van Assen MA, Luijkx KG, Wijnen-Sponselee MT, Schols JMJ. The Tilburg Frailty Indicator: psychometric properties. Am Med Dir Assoc. 2010 Jun;11(5):344-55. doi: 10.1016/j. jamda.2009.11.003.

20. https://www.nza.nl/english Assessed 01-03-2018

21. https://en.nvz-ziekenhuizen.nl/ Assessed 01-03-2018

22. https://werkenmetdbcs.nza.nl/downloadcentrum-ziekenhuiszorg/infomateriaal/ 9156-factsheetdbc-systematiek/file (Dutch). Assessed 01-03-2018

23. https://chipsoft.com/?Source=https\%3A\%2F\%2Fwww\%2Echipsoft\%2Enl\%2F. Assessed 14-02-2018

24. Warriner A ea. Minor, major, low-trauma, and high-trauma fractures: what are the subsequent fracture risks and how do they vary? Curr. Osteoporos Rep. 2011 Sep;9(3):122-8. doi: 10.1007/ s11914-011-0064-1.

25. https://www.vmszorg.nl/wp-content/uploads/2017/11/web_2009.0104_praktijkgids_kwetsbare_ ouderen.pdf (Dutch) assessed 30-12-2018

26. Lötters FJ, van den Bergh JP, de Vries F, Rutten-van Mölken MP. Current and Future Incidence and Costs of Osteoporosis-Related Fractures in The Netherlands: Combining Claims Data with BMD Measurements. Calcif Tissue Int. 2016 Mar;98(3):235-43. doi: 10.1007/s00223-015-0089-z.

27. Boudreau DM, Yu O, Balasubramanian A, Wirtz H, Grauer A, Crittenden DB, Scholes D. A Survey of Women's Awareness of and Reasons for Lack of Postfracture Osteoporotic Care. J Am Geriatr Soc. 2017 Aug;65(8):1829-1835. doi: 10.1111/jgs.14921.

28. Bours SP, van Geel TA, Geusens PP, Janssen MJ, Janzing HM, Hoffland GA, Willems PC, van den Bergh JP. Contributors to secondary osteoporosis and metabolic bone diseases in patients presenting with a clinical fracture. J Clin Endocrinol Metab. 2011 May;96(5):1360-7. doi: 10.1210/ jc.2010-2135. Epub 2011 Mar 16. PMID: 21411547

29. Adler RA. Update on osteoporosis in men. Best Pract Res Clin Endocrinol Metab. 2018 Oct;32(5):759-772. doi: 10.1016/j.beem.2018.05.007.

30. Center JR. Fracture Burden: What Two and a Half Decades of Dubbo Osteoporosis Epidemiology Study Data Reveal About Clinical Outcomes of Osteoporosis. Curr Osteoporos Rep. 2017 Apr;15(2):88-95. doi: 10.1007/s11914-017-0352-5.

31. Clegg A, Young J, Iliffe S, Rikkert MO, Rockwood K. Frailty in elderly people. Lancet. 2013 Mar 2;381(9868):752-62. doi: 10.1016/S0140-6736(12)62167-9.

32. Li G, Thabane L, Papaioannou A, loannidis G, Levine MA, Adachi JD. An overview of osteoporosis 
and frailty in the elderly. BMC Musculoskelet Disord. 2017 Jan 26;18(1):46. doi: 10.1186/s12891017-1403-x.

33. Blain H, Masud T, Dargent-Molina P, Martin FC, Rosendahl E, van der Velde N, Bousquet J, Benetos A, Cooper C, Kanis JA, Reginster JY, Rizzoli R, Cortet B, Barbagallo M, Dreinhöfer KE, Vellas B, Maggi S, Strandberg T; EUGMS Falls and Fracture Interest Group; European Society for Clinical and Economic Aspects of Osteoporosis and Osteoarthritis (ESCEO), Osteoporosis Research and Information Group (GRIO), and International osteoporosis Foundation (IOF). A Comprehensive Fracture Prevention Strategy in Older Adults: The European Union Geriatric Medicine Society (EUGMS) Statement. J Nutr Health Aging. 2016;20(6):647-52. doi: 10.1007/s12603-016-0741-y.

34. Fried LP, Ferrucci L, Darer J, Williamson JD, Anderson G. Untangling the concepts of disability, frailty, and comorbidity: implications for improved targeting and care. J Gerontol A Biol Sci Med Sci. 2004 Mar;59(3):255-63.

35. Theou O, Cann L, Blodgett J, Wallace LM, Brothers TD, Rockwood K. Modifications to the frailty phenotype criteria: Systematic review of the current literature and investigation of 262 frailty phenotypes in the Survey of Health, Ageing, and Retirement in Europe. Ageing Res Rev. 2015 May;21:78-94. doi: 10.1016/j.arr.2015.04.001.

36. Fried LP, Tangen CM, Walston J, Newman AB, Hirsch C, Gottdiener J, Seeman T, Tracy R, Kop WJ, Burke G, McBurnie MA. Frailty in older adults: evidence for a phenotype. Cardiovascular Health Study Collaborative Research Group. J Gerontol A Biol Sci Med Sci. 2001 Mar;56(3):M146-56.

37. Li G, Papaioannou A, Thabane L, Cheng J, Adachi JD. Frailty Change and Major Osteoporotic Fracture in the Elderly: Data from the Global Longitudinal Study of Osteoporosis in Women 3-Year Hamilton Cohort. J. Bone Miner. Res.Volume 31, Issue 4; Pages 718-24

38. Li G, Papaioannou A, Thabane L, Levine MAH, Ioannidis G, Wong AKO, Lau A, Adachi JD. Modifying the Phenotypic Frailty Model in Predicting Risk of Major Osteoporotic Fracture in the Elderly. J Am Med Dir Assoc Volume 18, Issue 5; Pages 414-4199

39. Weycker D, Edelsberg J, Barron R, Atwood M, Oster G, Crittenden DB, Grauer A. Predictors of near-term fracture in osteoporotic women aged $\geq 65$ years, based on data from the study of osteoporotic fractures. Osteoporos Int. 2017 Sep;28(9):2565-2571. doi: 10.1007/s00198-0174103-3.

40. https://www.cbs.nl/en-gb/figures assessed 04-01-2019

41. Steptoe A, Shankar A, Demakakos P, Wardle J. Social isolation, loneliness, and all-cause mortality in older men and women. Proc Natl Acad Sci U S A. 2013 Apr 9;110(15):5797-801. doi: 10.1073/ pnas. 1219686110 .

42. EbertJF, Huibers L, Christensen B, Christensen MB. Paper- or Web-Based Questionnaire Invitations as a Method for Data Collection: Cross-Sectional Comparative Study of Differences in Response Rate, Completeness of Data, and Financial Cost. J Med Internet Res. 2018 Jan 23;20(1):e24. doi: 10.2196/jmir.8353 


$$
4
$$




\section{CHAPTER 4}

\section{Characterization of Fracture Liaison Service Non-Responders after Invitation by Home Visits and Questionnaires.}

Peter van den Berg (1)*, Paul M.M. van Haard (2), Piet P. Geusens (4,5), Joop P. van den Bergh (3,4,5), Dave H. Schweitzer (6).

1. Dept. of Orthopedics and Trauma surgery, Fracture Liaison Service, Reinier de Graaf Hospital, Delft, the Netherlands

2. Dept. of Medical Laboratories, Association of Clinical Chemistry, Reinier the Graaf Hospital, Delft, the Netherlands

3. Dept. of Internal Medicine, VieCuri Medical Centre Noord-Limburg

4. Dept. of Internal Medicine, Subdivision Rheumatology, Maastricht University Medical Center, Maastricht, the Netherlands

5. Hasselt University, Hasselt, Belgium

6. Dept. of Internal Medicine and Endocrinology, Reinier the Graaf Hospital, Delft, the Netherlands

* Corresponding author E-Mail: pberg@rdgg.nl

Tel.: +31 152604926; Fax: +31 152605982 


\section{Disclosures}

Peter van den Berg: no disclosures; Paul M.M. van Haard: no disclosures; Piet P. Geusens: no disclosures; Joop P. van den Bergh: no disclosures; Dave H. Schweitzer: no disclosures.

\section{Conflicts of Interest}

Peter van den Berg, Paul van Haard, Piet Geusens, Joop van den Bergh and Dave Schweitzer declare that they have no conflict of interest.

\section{Acknowledgments}

We are grateful to Mrs. Sabine `t Hart, Mrs. Wil Aarssen and Mrs. Maria van Woerden for their excellent secretarial services.

\section{Contributions}

PVDB, PVH and DHS are responsible for the study design. PVDB and DHS were the authors, supported by PVH, who also performed all statistical analyses. PG and JVDB supported the process as co-authors and with important scientific contributions.

\section{Mini-abstract:}

This study aimed to gain insight in specific characteristics and believes of FLS nonresponders.

Keywords: FLS; Non-respondence; Non-attendance; Home Visit; Osteoporosis; Questionnaire. 


\begin{abstract}
Introduction

The proportion non-responding fracture liaison service (FLS) invitees is high but characteristics of FLS non-responders are unknown.
\end{abstract}

\title{
Patients and Methods
}

We contacted FLS non-responders by telephone to consent with home visit (HV) and to fill in a questionnaire or, if $\mathrm{HV}$ was refused, to receive a questionnaire by post (Q), to gain insight in believes on fracture cause and subsequent fracture risk.

\section{Results}

Out of 716 FLS invitees, 510 attended, 9 declined and 197 did not respond. Of these non-responders, 181 patients were consecutively traced and phoned until 50 consented with HV. 42 declined HV but consented with Q. Excluded were 8 Q-consenters in whom no choice was offered (either HV or Q) and 81 patients who declined any proposition (non-HV|Q). 62\% HV and Q could recall the FLS invitation letter. The fracture cause was differently believed between HV and Q; the fall (96\% versus 79\%, $\mathrm{p}=.02$ ), bad physical condition (36\% versus $2 \%, \mathrm{p}=.0001$ ), dizziness or imbalance (24\% versus Q 7\%, $\mathrm{p}=.03$ ), osteoporosis (16\% versus $2 \%, \mathrm{p}=.02$ ), and increased fracture risk (26\% versus 17\%, NS). Age $\geq 70$, woman and major fracture were significantly associated with HV consent compared to Q (OR 2.7, 2.5 and 2.4, respectively) and HV compared to non-HV|Q (OR 16.8, 5.3 and 6.1).

\section{Conclusion}

FLS non-responders consider fracture risk as low. Note, 50 patients (about 25\%) consented with a home visit after one telephone call, mainly older women with a major fracture. This non-responders subgroup with high subsequent fracture risk is therefore approachable for secondary fracture prevention. 


\section{Introduction}

Osteoporosis care in patients with a recent fracture has been improved by the introduction of the Fracture Liaison Service model (FLS). This hospital initiative is firstly reported by McLellan et al. [1] and as such gradually regarded to be an optimal model of care [2-5]. Today, many FLS facilities experience the issue of low attendance rates being approximately $50 \%$ of all eligible patients $>50$ years [6]. Several factors are considered to contribute in FLS non-attendance i.e. not interested, physically unable to attend such as patients after hip fracture, male gender, frailty, living alone and also lower education [7,8]. Lower education even accounted as independent risk factor and, therefore, points into the direction of anyone's capability of self-reflection and self- management and also into that of health illitteracy $[7,9,10]$. Apart from this, we discovered that flaws in the hospital registration led to 14\% less FLS attendance [7]. A strong cue for attendance is face-to-face contact between patient and health professional in order to convince patients to agree with a FLS visit [7]. Therefore, FLS policy must take care of potential errors in patient registration but also focus on patients ` perspectives and opinions regarding fracture risk and subsequent fracture prevention [7,11-13].

In the current study, we were particularly interested to broaden our insight into the characteristics and believes of FLS non-responders [14-16]. We aimed to contact FLS non-responders by telephone to consent with HV during which they had to complete a questionnaire with help of a FLS health professional if necessary or to consent to fill in a questionnaire which was send by post (Q) in order to study the characteristics and motivations of these patients.

\section{Patients and Methods}

\section{Study design and objectives}

This explorative study was conducted at the FLS of the Reinier de Graaf Hospital, Delft, The Netherlands. The intention of this FLS initiative is to encourage all patients $\geq 50$ years to attend the FLS immediately following a fracture, in line with the Dutch Guideline on Osteoporosis and Falls [17]. After exclusion of patients who were deceased, all following patients were not invited (according to the local FLS protocol): permanent nursing home residents, patients already on anti-osteoporosis treatment (not including calcium or vitamin D) or patients who had a DXA within two years 
before fracture. Two strategies were followed: 1/ personal invitation by the health professional during fracture treatment as mandatory in the local FLS protocol and $2 /$ sending invitation letters to all patients in whom the personal invitation was not made or to those who did not make an FLS appointment after receipt of the letter at 2 months after first admission at the emergency department.

This invitation strategy was performed by monthly screening of all fracture code registrations from the database of the emergency department to identify eligible patients. Data was extracted from the hospital entry registry (ChipSoft Hix 6.1) [18]. Then, retrieved data were used to prepare a mailing list to all eligible patients without a verifiable FLS appointment at 2 months after first attendance at the emergency department. Each letter consisted out of the following items: an invitation to attend and an explanation about osteoporosis and information about appropriate care. For this study, recruitment lasted from 2017/8 to 2018/4. Non-responders were contacted by telephone by one experienced female FLS care health professional 8 weeks after the written invitation. During the phone call patients were asked to consent with a HV to fill in a questionnaire about their drives and motives with regard to health issues. In case of no consent for $\mathrm{HV}$, patients were subsequently asked to consent to fill in the same questionnaire send by mail (Q). In case of no consent for either HV or Q, patients were assigned to a third group (non-HV|Q). According to protocol, patients were phoned until a total of 50 patients had consented with HV. Eight patients were given no choice but Q as completion of HV was achieved. These patients were excluded from analysis. Note, during telephone calls patients were not persuaded to accept our invitation to attend the FLS. This was on purpose in order to prevent people from feeling unsafe. Of all patients, available demographic data were used in the study (age, gender, fracture type and death within one year after fracture) (see Fig 1). After verification of the fracture location by X-Ray, patients were categorized according to the classification of fracture locations proposed by Warriner et al., based on the probability that fractures were associated with osteoporosis: low risk for osteoporosis ranked as minor fractures and higher risk for osteoporosis ranked as major fractures, hipfractures and vertebral fractures [19]. Categorized as minor fractures were clavicle / scapula, scaphoid, metacarpal, neck and head of radius, patella, ankle / malleolus and metatarsal fractures. The definition for major fractures used in the models was a major, vertebral or hip fracture. In more detail, distal radius and lower arm, sub-capital humeral, rib, pelvis and acetabulum, tibia proximal / tibia plateau and calcaneal / tarsal fractures as well as hip and vertebral fractures are classified as major fractures [19]. 
Fig 1. Flowchart of the study

Consecutive fracture patients $\geq 50$ years $\mathrm{N}=945$

(Deceased before FLS invitation $n=14$ )

Remaining $\mathrm{n}=931$

Exclusion for FLS invitation $n=215 / 931$ (24\%)

- Permanently institutionalized $\mathrm{n}=52(6 \%)$

- Being already on antiresorptive treatment $n=33(4 \%)$

- Recent DXA scan $n=22(2 \%)$

- Toe, finger and skull fractures $n=56(6 \%)$

- Living outside the hospital adherence region $n=52(6 \%)$

$\downarrow$\begin{tabular}{l|l|}
$\qquad>\begin{array}{l}\text { Patients eligible for FLS invitation } n=716 / 931(77 \%) \\
510 \text { attenders (71\%) } \\
9 \text { responders but non-attenders, (1\%) } \\
197 \text { non responders (28\%) }\end{array}$ \\
\hline
\end{tabular}

Untraceable non-responders $n=16(8 \%)$

Non-responders available for phone calls $\mathrm{n}=181(92 \%)$

\section{$\downarrow$}

173 could be traced and included for this study*:

Consented with HV $\mathrm{n}=50(29 \%)$

Consented with Q $\mathrm{n}=42(24 \%)$

No consent for HV or Q $\mathrm{n}=81(47 \%)$

Legends

Demographics used from patient charts were Age, Gender M/F, Death and Fracture type. ${ }^{*} \mathrm{n}=8$ were excluded for this study (received no request for HV)

\section{Questionnaire}

The questionnaire for HV and Q patients highlighted three domains: Demographics, Tilburg Frailty Indicator (TFI) [20] and extrinsic/intrinsic motivations for the decision not to attend and personal arguments to abstain from attending, as formerly used in other studies [7,11-16]. The TFI (a validated indicator of Frailty) ranges from 1 to 15 (Frailty: $\geq$ 5) [20]. Patients' own judgment of their personal health was analyzed binary according to a score of 1-6 as 'poor' and 7-10 as 'good'. Extrinsic motivations were considered to arise from information by clinical professionals, for example the inclination to follow a doctor's or plaster cast nurses ' advice or to follow the instructions by the medical staff of the FLS. Intrinsic motivations were considered to be entered exclusively by selfreflection i.e. anyone's personal believes to strive for a better bone health $[7,9,16]$. 


\section{Aim}

The aim of the study was to make an inventory of characteristics and believes of 50 FLS non-responders who consented with HV and to analyze factors associated with consent for $\mathrm{HV}$ or Q.

\section{Statistical Analysis}

Data were analyzed using Statgraphics Centurion software (Version 17.2.05 for MSWindows; Statpoint Inc., Warrenton, VA, USA) and using R (2018, The R Foundation for Statistical Computing Platform, version 3.5.3). If numerical data could not be fitted with a Gaussian distribution (Shapiro\&Wilk\&Royston test or Micceri Normality function (in R) their mean of ranks or medians were compared using the Wilcoxon rank-sum test after checking for equal distributions using the Kolmogorov\&Smirnov test. Analyses were further performed on dichotomized age ( $<70$ or $\geq 70$ year), gender and on all the (often binominal) variables of the questionnaire. In this study age is a variable with multiple different integer values; we transformed it (according to the Dutch VMS) [21] so that the new variable has only 2 different values: $<70$ or $\geq 70$ years. Associations were assessed by crosstabulation, using as dependent variables HV and Q. After bivariate crosstabulations, a multivariate logistic regression model was fitted to identify any possible association between the binary outcome variable HV and Q and various independent predictor variables i.e. demographics such as age, gender, education, income and physical conditions. Any association was assessed by direction and absolute value of adjusted Pearson residuals (resembling z-scores). Evidence of any association in the population from which the sample was drawn was assessed with the unconditional, uncorrected Pearson's Chi-Square test, applying Monte Carlo sampling (10,000 resamplings) and if significant, measured using Odds Ratios and 95\% Confidence Intervals. Multivariate Odds Ratios were estimated by logistic regression, with variable $\mathrm{HV}$ and Q as dependent outcome and Frailty (TFI dichotomized); age (numerical) and gender are included, and education, income and physical conditions as independent variables after exclusion of those independent variables that were not significant in the univariate analysis and after testing for interaction between variables. Collinearity was analyzed using R's Condition Index applying a variance inflation factor (VIF) $>2.5$ and at least twice an Index $>.5$ ). Where applicable, 95\% Confidence Intervals and correlation coefficients $>.5$ were used. A p-value $<.05$ was considered statistically significant. 


\section{Ethics}

The study was carried out in accordance with the declaration of Helsinki and the guidelines of the International Conference on Harmonization Good Clinical Practice (GCP) after a certificate of no objection approved by the regional Medical Ethical Review Board (METC Zuidwest Holland) no. NL 17.108.

\section{Results}

From 945 consecutive patients with a recent fracture, 229 were not invited at the FLS: 14 patients (1\%) deceased shortly after fracture, 52 (6\%) for permanent residence in nursery care, 33 (4\%) for priory initiated anti-osteoporosis treatment and 22 (3\%) because they had a DXA scan 24 months prior to this study, 56 (6\%) because of finger, toe and skull fractures and 52 patients (6\%) who were untraceable to our systems because of their residence outside the region of the hospital. Of the 716 invitees, 510 (72\%) attended the FLS, 9 patients (1\%) responded but deliberately abstained from attending (FLS responders) and the remaining 197 patients (27\%) did not respond to the invitation.

The analysis of this study was focused on the 197 non-responders. Of these patients, 181 could be traced and called, 16 patients could not be traced because of a no valid home address. None of these patients had a minor fracture, 4 had a major fracture, 9 had a hip fracture and 3 had vertebral fractures. During the inclusion period to complete assignment of 50 patients for $\mathrm{HV}$, another 42 patients declined $\mathrm{HV}$ but consented to fill in a questionnaire send by post (Q) and 81 patients declined both HV and Q (the so called non-HV|Q group). For the completion of this study a total of 173 patients was called, see Fig.1. The remaining eight patients who were not given a choice other than to give permission for $\mathrm{Q}$ were excluded from the analysis because a HV was never offered to them. By April 2018, we finalized the recruitment of 50 patients for HV. Meanwhile 42 agreed with Q and 81 had declined $H V$ as well as Q (the non-HV|Q group). 
Table 1. Characteristics of FLS non-responders who consented with Home visits or Questionnaires.

Home Visit group Questionnaire group $\mathrm{n}=50(54 \%) \quad \mathrm{n}=42(46 \%)$

\section{Demographics}

Age at Fracture: median (min, max)

All: no.: median (min, max)

Women: no.: median (min, max)

Men: no.: median (min,max)

Fracture type

Minor fracture

Major Fracture

Hip Fracture

Vertebral Fracture

Education

Primary/secondary school vs.

High school/University

Country of birth

The Netherlands

Indonesia

Surinam

Income (in € per month)

Low/Normal: $(€ 601-€ 1200) /(€ 1200-€$

1800)

High ( $\geq € 2100)$

No response

Marital status

Living together (married/shared living)

Not married/Divorced/Widow/Widower

Are you satisfied with your living/housing environment?

Yes

No
$81(58,101)$

$\mathrm{n}=50: 81(58,101)$

$n=42: 81(58,101)$

$n=8: 83(65,89)$

$6(12 \%)$

$30(60 \%$

$8(16 \%)$

$6(12 \%)$

47 (94\%)

$3(6 \%)$

49 (98\%)

$1(2 \%)$

0

$36(72 \%)$

$3(6 \%)$

11 (22\%)

26 (52\%)

$24(48 \%)$
$63(50,93)$

$n=42: 63(50,93)$

$n=22: 60(51,93)$

$n=20: 63(50,88)$

$23(55 \%)$

$17(40 \%)$

$2(5 \%)$

29 (69\%)

$13(31 \%)$

39 (93\%)

$2(5 \%)$

$1(2 \%)$

$23(55 \%)$

$13(31 \%)$

$6(14 \%)$

$23(55 \%)$

$19(45 \%)$
47 (94\%)
$3(6 \%)$
$42(100 \%)$
0

Use of Calcium, Vitamin D supplementation and/or Osteoporosis medication

Use of calcium tablets?

\begin{tabular}{lll} 
Yes & $8(16 \%)$ & $6(14 \%)$ \\
No & $42(84 \%)$ & $36(86 \%)$ \\
$\begin{array}{ll}\text { Use of Vitamin D? } \\
\text { Yes }\end{array}$ & \\
No & $24(48 \%)$ & $15(36 \%)$ \\
$\begin{array}{l}\text { Do you already take antiresorptive medication? } \\
\text { Yes }\end{array}$ & $27(52 \%)$ \\
\hline
\end{tabular}




\section{Home Visit group Questionnaire group \\ $\mathrm{n}=50(54 \%) \quad \mathrm{n}=42(46 \%)$}

\section{Patient opinions}

What caused your fracture:

Osteoporosis (yes/no; \%)

The fall (yes/no, \%)

$\begin{array}{lllll}p=.02 & 8(16 \%) & 42(84 \%) & 1(2 \%) & 41(98 \%) \\ p=.01 & 48(96 \%) & 2(4 \%) & 33(79 \%) & 9(21 \%) \\ \text { NS } & 35(70 \%) & 15(30 \%) & 28(67 \%) & 14(33 \%) \\ p=.0001 & 18(36 \%) & 32(64 \%) & 1(2 \%) & 41(98 \%) \\ p=.03 & 12(24 \%) & 38(76 \%) & 3(7 \%) & 39(93 \%)\end{array}$

The accident (yes/no, \%)

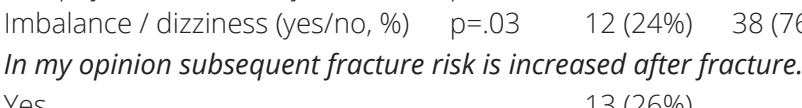

Yes

$18(36 \%)$

$7(17 \%)$

No

$19(38 \%) \quad 13(31 \%)$

$22(52 \%)$

Do not know

Perceived advice to attend the FLS

Perceived advice to attend the FLS by letter 34 (68\%)

$23(55 \%)$

$=$ Yes

Perceived advice to attend the FLS by letter 16 (32\%)

$19(45 \%)$

$=$ No

Taking interest in Bone Quality

Yes

$22(44 \%)$

$14(33 \%)$

No/Somewhat

$28(56 \%)$

$28(67 \%)$

\section{Various aspects of health and frailty}

How healthy is your lifestyle?

Healthy

$31(62 \%)$

$24(57 \%)$

Not healthy

$19(38 \%)$

$18(43 \%)$

Self-reported Level of Health

Good

$25(50 \%)$

$32(76 \%)$

Poor

$25(50 \%)$

$10(24 \%)$

Do you suffer from 2 or more chronic diseases?

Yes

$17(34 \%)$

$12(29 \%)$

No

$33(66 \%)$

$30(71 \%)$

Do you take 4 or more tablets every day?

Yes

$25(50 \%)$

$7(17 \%)$

No

$25(50 \%)$

$35(83 \%)$

Frailty (Tilburg Frailty Indicator scores)

TFI score $\geq 5$ (frail)

$23(46 \%)$

$13(31 \%)$

TFI score $<5$ (not frail)

$27(54 \%)$

$29(69 \%)$

Parental hip Fracture

Yes

$6(12 \%)$

$6(14 \%)$

No

$44(88 \%)$

$36(86 \%)$

Legends: Results are presented as median (min, max) or no. (\%). 
Table 2. Significant univariate associations to consent with Home Visit (HV) versus Questionnaire (Q).

\begin{tabular}{llll}
\hline Factors & OR & $95 \% \mathrm{Cl}$ & $p$-value \\
\hline Age $\geq 70$ year & 17.3 & $6.03 ; 49.7$ & $<.001$ \\
Woman & 4.77 & $1.81 ; 12.6$ & .001 \\
Low Income & 6.78 & $1.74 ; 26.4$ & .003 \\
Self-rated low quality of life after fracture & 4.26 & $1.59 ; 11.4$ & .003 \\
Loss of weight after fracture & 3.09 & $1.09 ; 8.78$ & .03 \\
Difficulty in walking & 3.97 & $1.58 ; 9.99$ & .003 \\
Difficulty maintaining your balance & 6.83 & $2.31 ; 20.2$ & $<.001$ \\
Poor hearing & 7.97 & $2.16 ; 29.4$ & $<.001$ \\
Lack of strength in your hands & 3.81 & $1.27 ; 11.5$ & .013 \\
Age $\geq 70$ years and no frailty (TFI $\geq 5)$ & 19.2 & $3.6 ; 102.0$ & $<.001$ \\
Major fractures (no hip or vertebral fractures) & 2.89 & $1.2 ; 6.94$ & 0.02 \\
All Major fractures (all major including hip and vertebral & 4.27 & $1.88 ; 51.59$ & 0.04 \\
fractures) & & & \\
\hline
\end{tabular}

Legends:

OR: Odds Ratio; 95\%Cl: 95\% Confidence Interval for population Odds Ratio, $p$-value $<.05$ is considered significant.

\section{The recalls of patient information in HV or Q patients.}

None of the HV and Q patients could recall any face-to-face patient information in the hospital during time of fracture treatment including advice to attend the FLS. Receipt of an FLS invitation letter was recalled by $68 \%$ of HV versus 55\% of Q patients ( $p=.002$ ).

\section{Factors associated with consent for HV or Q}

The proportion of patients that perceived a poor physical condition as the main cause of fracture was significantly higher in the HV compared to the Q group (36\% and 2\%, $p=0.0001)$. The proportion of patients with a "poor" self-reported health was also significantly higher in HV than Q (50\% vs 24\%, $p=.001)$.

$H \vee$ and Q patients considered falls, the accident, bad physical condition and dizziness or imbalance as main cause of recent fracture. In addition, the main cause of fracture was differently believed between $\mathrm{HV}$ and Q; the fall: 96\% versus 79\%, $\mathrm{p}=.02$, bad physical condition: $36 \%$ versus $2 \%, p=.0001$, dizziness or imbalance: $24 \%$ versus $7 \%, \mathrm{p}=.03$, while for osteoporosis it was $16 \%$ in $\mathrm{HV}$ versus $2 \%$ in $\mathrm{Q}, \mathrm{p}=.02$ and the belief that subsequent fracture risk was increased; $26 \%$ versus $17 \%$, respectively (NS). There was no difference in patients ' reports about have more than 2 chronic 
diseases or using more than 4 tablets per day, see Table 1.

According to univariate analysis HV patients were older (age $\geq 70$ years; OR 17.3), with a higher contribution of women (OR 4.77) and more major fractures (OR 4.27). HV patients reported lower income more frequently (OR 6.78) as well as quality of life (OR 4.26) and weight loss after fracture (OR 3.09). Finally, more HV patients had walking difficulties (OR 3.97) and difficulties in maintaining balance (OR 6.83), more frequent hearing loss (OR 7.97) and loss of grip strength (OR 3.81). In both HV and Q there was a moderate frailty prevalence and no significant difference between groups according to TFI (Frailty: $\geq 5$ ). Only significant univariate associations to consent with HV versus Q are shown in Table 2.

In a multivariate model, three factors remained significantly associated with consent for HV versus Q: age $\geq 70$ years (OR: 16.8), gender (women, OR: 5.3) and major fractures (OR 6.1); the same three factors were associated with consent for HV versus non-HV|Q: (OR 2.7, 2.5 and 2.4, respectively). Age < 70 years and minor fractures (OR 3.2 and 5.3, respectively) were associated to consent with Q versus non-HV|Q (Table 3).

Table 3. Significant multivariate associations to consent with HV versus Q.

\begin{tabular}{lll}
\hline Factors $-H V(n=50)$ versus $Q(n=42)$ & OR $(95 \% \mathrm{Cl})$ & $p$ value \\
\hline Age $\geq 70$ & $16.8(5.0 ; 56.7)$ & $<.001$ \\
Women & $5.3(1.5 ; 19.2)$ & .008 \\
Major Fractures & $6.1(1.7 ; 22.3)$ & .0045 \\
\hline
\end{tabular}

Legends:

Multivariate associations in Age (dichotomized at $\geq 70$ or $<70$ ), Gender and Fracture Type. Factors were first analysed of association with each pair of groups using crosstabulation, using adjusted standardized residuals and Chi-square/Fisher Exact tests $p$ value for significance and Odds Ratio for measure of strength. OR: Logistic Regression Odds Ratio; 95\%Cl: 95\% Confidence Interval for population Odds Ratio; $p$ value <.05 is considered significant. 


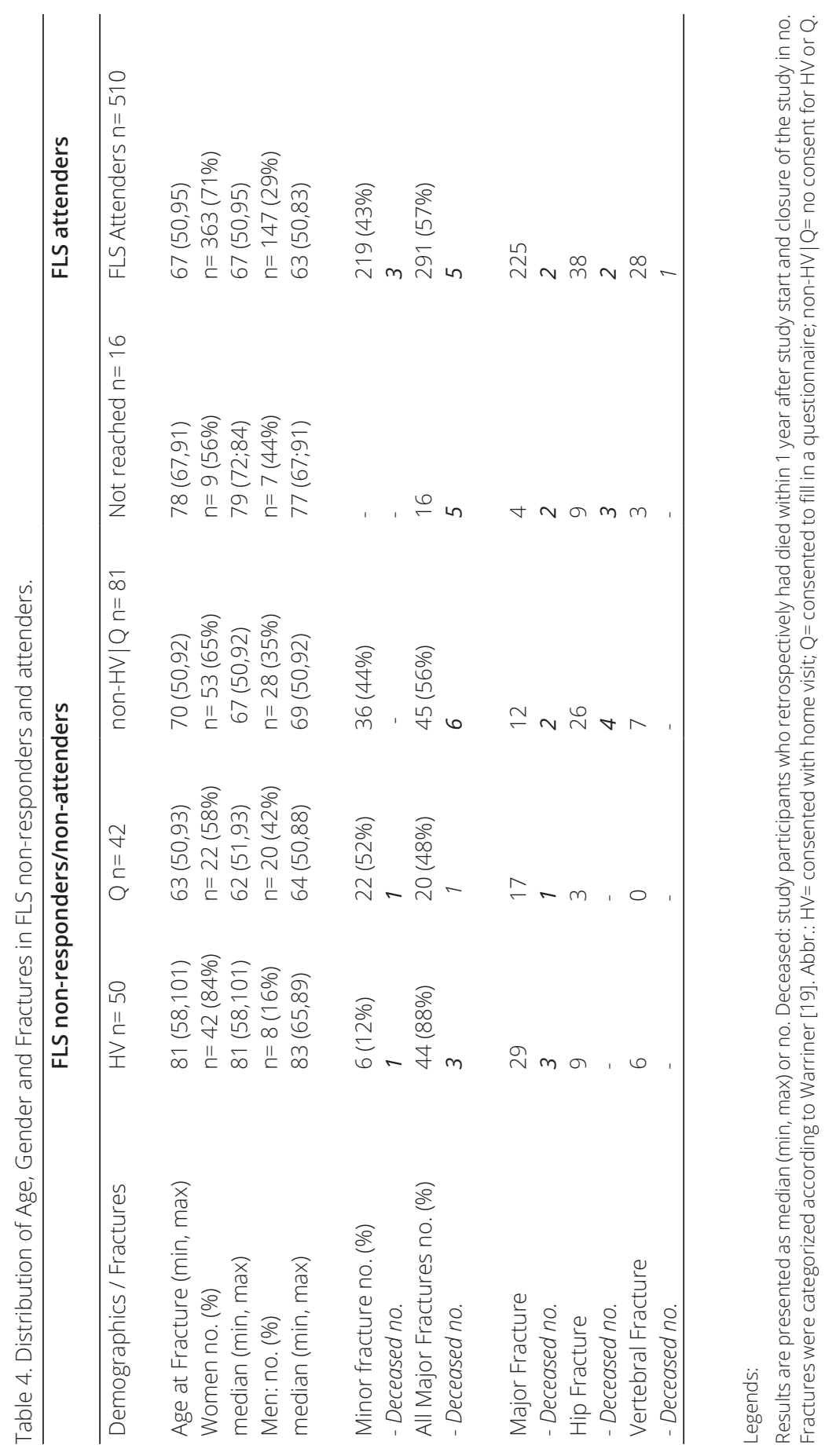




\section{Distribution of fractures among FLS non-responders and the patients who attended the FLS.}

Distribution according to fracture type (major fractures including hip and vertebral fractures versus minor fractures) was compared between FLS attenders and traceable FLS non-responders (Table 4).

The proportion of patients with major fractures in FLS attenders and traceable nonresponders was similar 291/510 (57\%) and 109/173 (63\%). The proportion of major fractures was significantly higher in HV than in $\mathrm{Q}(\mathrm{p}<.0001)$ and non-HV|Q $(p=$ .0001). In the latter two groups minor and major fracture proportions were similar.

\section{Deceased patients}

Several patients with major fractures died within 12 months after initiation of the study; 3 patients in $\mathrm{HV}$ and 1 in Q), 6 patients in non-HV|Q, 5 were deceased in not-reached patients and 5 were deceased in FLS attenders. In minor fractures it was 1 patient in HV and 1 patient in Q and 3 patients after minor fracture in the FLS attending group. All of the 16 untraceable individuals were elderly patients and 12 patients in this group had died within 12 months post-fracture.

\section{Discussion}

This study was specifically designed to characterize patients who did not respond to FLS invitation after a recent fracture and showed that it is feasible to trace and contact more than $90 \%$ of non-responders by one phone call of whom more than $25 \%$ agreed with a home visit, especially women of 70 years or older who sustained a major fracture. They primarily considered a fall, their bad physical condition, dizziness or balance problems as the main cause of the recent fracture. Only one in five believed that subsequent fracture risk was increased, and a small proportion considered osteoporosis as underlying risk factor for subsequent fractures. As far as we know the characteristics of FLS non responders have not been studied before by home visits and questionnaires. Therefore, the current study design differs entirely from an earlier study by our group comparing personal opinions, drives and motives of patients who were willing to share details of their decision to attend or not attend the FLS [7].

In this study, 931 fracture patients were identified of whom 716 were eligible for FLS 
invitation. According to daily FLS protocol all of them should have received face-to-face invitation to attend the FLS (at any time during fracture treatment). Besides, patients who did not reply within 2 months had received a FLS invitation letter. Remarkably, most FLS non-attenders were non-responders to invitation $(n=197)$ and there were only 9 responders who informed us that they refrained from FLS attendance after receiving the FLS invitation letter.

None of the HV or Q assigned patients could remember information face-to-face given by the health professional during fracture treatment meant to remind fracture patients about the urgency to attend the FLS (personal patient information is mandatory according to the local FLS protocol). It is conceivable that this information was not or insufficiently given since all patients of both groups were unanimous on the idea of lack of any given face-to-face patient information, while receipt of the FLS invitation letter was recalled by $68 \%$ of $\mathrm{HV}$ and $55 \%$ of Q patients. In addition, our FLS invitation letter was not designed to ask patients to inform our department if they were not willing or able to attend our FLS. It is emphasized that health illiteracy and the consequent incapability to properly understand the content of written information, albeit not tested in the current study, has been reported up to $40 \%$ in the elderly population $[9,10]$. These findings point at the importance for adequate FLS invitation strategies.

There are several studies reporting on clinical characteristics of FLS attenders but published data on FLS non-responders are limited. A telephone questionnaire study from Australia compared the 2-year outcome of FLS attenders with FLS non-attenders showing that FLS attenders had fewer new fractures and were more likely to be on treatment for bone fragility [22]. A similarly designed Dutch study showed also significant lower mortality and 56\% lower subsequent fracture rate in FLS attenders [23]. Similar results were also found in a Norwegian literature review [24]. Besides these outcome differences between FLS attenders and non-attenders some studies evaluated the reasons of differences in FLS attendance among different centers. The first report on this issue albeit in a limited number of centers showed that attendance varied widely, between 20-89\%, together with a high variability in patient selection for FLS invitation [25]. In a study performed in the Netherlands, high compliance with the Capture the Fracture Framework Standards was shown in 24 analyzable FLSs. This study showed in particular that FLS attendance occurred in approximately half of all fracture patients [6].

Obtaining consent was time consuming and approximately half patients declined 
to consent for participation. Remarkably, most HV consenters hardly needed any persuasion, while it took eight weeks until all questionnaires were returned by $\mathrm{Q}$ patients. This difference may be explained by stronger concerns about health issues and fracture risk in the HV group compared to Q. Another study of the FLS found that older patients reported less mobility and more dependency on their caregivers for transportation to the hospital [8]. We speculate therefore that older patients consider a home visit as a solution for their inability to attend the FLS.

There were also similarities between both groups ( $\mathrm{HV}$ and Q) noteworthy to report. i.e. a similar low frailty prevalence (according to the TFI, frailty: $\geq 5$ ) and a similar believed major reasons of fracture i.e. the fall and accident. Another similar characteristic (39\% and $31 \%$, respectively) was the low proportion of knowledge of patients concerning increased subsequent fracture risk in agreement with previous reports $[7,9,15,16]$. ASBMR, IOF, EULAR and EUGMS fully endorse the importance of secondary fracture prevention and FLS care is considered the most optimal approach in this respect [2-5]. To optimize FLS care according to this vision the issue of attendance needs full attention.

This study has several weaknesses. 1/ the study is an explorative study and therefore not based on preliminary determined statistical power. The outcome does not allow generalization outside this region and to other countries. 2/ Age was dichotomously analyzed (< or $\geq 70$ years), threshold proposed by the Dutch VMS authority (Safety Management System) and commonly used for patient safety issues in hospital care. [21]. Dichotomizing data can lower power in study outcomes. 3/ we have no information on the exact number of patients who did or did not receive faceto-face patient information during fracture treatment encouraging them to attend the FLS.

In conclusion, a high proportion of FLS non-responders who participated in HV or Q consider subsequent fracture risk to be low. Nevertheless, 50 patients (about 25\% of FLS non-responders) consented with a home visit after one telephone call, mainly elderly women with a major fracture. These patients have a high subsequent fracture risk and are approachable for evaluation. The encountered approachability of FLS non-responders indicates that innovative strategies in optimizing FLS invitation can improve secondary fracture prevention care. 


\section{References}

1. McLellan AR, Gallacher SJ, Fraser M, McQuillian C. The fracture liaison service: success of a program for the evaluation and management of patients with osteoporotic fracture. Osteoporos Int. 2003 Dec;14(12):1028-34.

2. Akesson K, Marsh D, Mitchell PJ, McLellan AR, Stenmark J, Pierroz DD, Kyer C, Cooper C (IOF Fracture Working Group). Capture the Fracture®: a Best Practice Framework and global campaign to break the fragility fracture cycle. Osteoporos Int. 2013 24(8):2135-52. doi: 10.1007/ s00198-013-2348-z.

3. Lems WF, Dreinhöfer KE, Bischoff-Ferrari H, Blauth M, Czerwinski E, da Silva J, Herrera A, Hoffmeyer P, Kvien T, Maalouf G, Marsh D, Puget J, Puhl W, Poor G, Rasch L, Roux C, Schüler S, Seriolo B, Tarantino U, van Geel T, Woolf A, Wyers C, Geusens P. EULAR/EFORT recommendations for management of patients older than 50 years with a fragility fracture and prevention of subsequent fractures. Ann Rheum Dis. 2017 May;76(5):802-810. doi: 10.1136/annrheumdis-2016-210289.

4. Eisman JA, Bogoch ER, Dell R, Harrington JT, McKinney RE Jr, McLellan A, Mitchell PJ, Silverman S, Singleton R, Siris E. Making the first fracture the last fracture: ASBMR task force report on secondary fracture prevention. J Bone Miner Res. 2012 Oct;27(10):2039-46. doi: 10.1002/jbmr.1698.

5. Blain H, Masud T, Dargent-Molina P, Martin FC, Rosendahl E, van der Velde N, Bousquet J, Benetos A, Cooper C, Kanis JA, Reginster JY, Rizzoli R, Cortet B, Barbagallo M, Dreinhöfer KE, Vellas B, Maggi S, Strandberg T; EUGMS Falls and Fracture Interest Group; European Society for Clinical and Economic Aspects of Osteoporosis and Osteoarthritis (ESCEO), Osteoporosis Research and Information Group (GRIO), and International osteoporosis Foundation (IOF). A Comprehensive Fracture Prevention Strategy in Older Adults: The European Union Geriatric Medicine Society (EUGMS) Statement. J Nutr Health Aging. 2016;20(6):647-52. doi: 10.1007/s12603-016-0741-y.

6. van den Berg P, Schweitzer DH, van Haard PM, van den Bergh JP, Geusens PP. Meeting international standards of secondary fracture prevention: a survey on Fracture Liaison Services in the Netherlands. Osteoporos Int. 2015 Sep;26(9):2257-63. doi: 10.1007/s00198-015-3117-y.

7. van den Berg P, van Haard PMM, Geusens PP, van den Bergh JP, Schweitzer DH. Challenges and opportunities to improve fracture liaison service attendance: fracture registration and patient characteristics and motivations. Osteoporos Int. 2019 May 25. doi: 10.1007/s00198-019-05016-4.

8. Eekman DA, van Helden SH, Huisman AM, Verhaar HJ, Bultink IE, Geusens PP, Lips P, Lems WF. Optimizing fracture prevention: the fracture liaison service, an observational study. Osteoporos Int. 2014 Feb;25(2):701-9. doi: 10.1007/s00198-013-2481-8.

9. Raybould G, Babatunde O, Evans AL, Jordan JL, Paskins Z. Expressed information needs of patients with osteoporosis and/or fragility fractures: a systematic review. Arch Osteoporos. 2018 May 8;13(1):55. doi: 10.1007/s11657-018-0470-4.

10. Heijmans M, Waverijn G, Rademakers J, van der Vaart R, Rijken M. Functional, communicative and critical health literacy of chronic disease patients and their importance for self-management. Patient Educ Couns. 2015;98(1):41-48.

11. Giangregorio L, Thabane L, Cranney A, Adili A, deBeer J, Dolovich L, Adachi JD, Papaioannou A. Osteoporosis knowledge among individuals with recent fragility fracture. Orthop Nurs. 2010 MarApr;29(2):99-107. doi: 10.1097/NOR.0b013e3181d2436c. PMID: 20335769

12. Grover ML, Edwards FD, Chang YH, Cook CB, Behrens MC, Dueck AC. Fracture risk perception study: patient self-perceptions of bone health often disagree with calculated fracture risk. Womens Health Issues. 2014 Jan-Feb;24(1):e69-75. doi: 10.1016/j.whi.2013.11.007. PMID: 24439949

13. Alami S, Hervouet L, Poiraudeau S, Briot K, Roux C. One Barriers to Effective Postmenopausal Osteoporosis Treatment: A Qualitative Study of Patients' and Practitioners' Views. PLoS One. 2016 
Jun 29;11(6):e0158365. doi: 10.1371/journal.pone.0158365. eCollection 2016. PMID: 27355576

14. Ong $\mathrm{T}$, Tan $\mathrm{W}$, Marshall $\mathrm{L}$, Sahota $\mathrm{O}$. The relationship between socioeconomic status and fracture in a fracture clinic setting: data from the Nottingham Fracture Liaison Service. Injury. 2015 Feb;46(2):366-70. doi: 10.1016/j.injury.2014.10.002.

15. Boudreau DM, Yu O, Balasubramanian A, Wirtz H, Grauer A, Crittenden DB, Scholes D. A Survey of Women's Awareness of and Reasons for Lack of Postfracture Osteoporotic Care. J Am Geriatr Soc. 2017 Aug;65(8):1829-1835. doi: 10.1111/jgs.14921.

16. Besser SJ, Anderson JE, Weinman J. How do osteoporosis patients perceive their illness and treatment? Implications for clinical practice. Besser SJ, Anderson JE, Weinman J. Arch Osteoporos. 2012;7:115-24. doi: 10.1007/s11657-012-0089-9. PMID: 23225289

17. Dutch Institute for Healthcare Improvement CBO (2011) Richtlijn Osteoporose en Fractuurpreventie. www.diliguide.nl/document/1015/file/pdf/. (Dutch) Assessed 14-02-2018

18. https://chipsoft.com/?Source=https\%3A\%2F\%2Fwww\%2Echipsoft\%2Enl\%2F. Assessed 14-02-2018

19. Warriner A ea. Minor, major, low-trauma, and high-trauma fractures: what are the subsequent fracture risks and how do they vary? Curr. Osteoporos Rep. 2011 Sep;9(3):122-8. doi: 10.1007/ s11914-011-0064-1.

20. Gobbens RJ, van Assen MA, Luijkx KG, Wijnen-Sponselee MT, Schols JMJ. The Tilburg Frailty Indicator: psychometric properties. Am Med Dir Assoc. 2010 Jun;11(5):344-55. doi: 10.1016/j. jamda.2009.11.003.

21. https://www.vmszorg.nl/wp-content/uploads/2017/11/web_2009.0104_praktijkgids_kwetsbare_ ouderen.pdf (Dutch) assessed 30-12-2018

22. Van der Kallen J, Giles M, Cooper K, Gill K, Parker V, Tembo A, Major G, Ross L, Carter J. A fracture prevention service reduces further fractures two years after incident minimal trauma fracture. Int J Rheum Dis. 2014 Feb;17(2):195-203. doi: 10.1111/1756-185X.12101.

23. Huntjens KM, van Geel TA, van den Bergh JP, van Helden S, Willems P, Winkens B, Eisman JA, Geusens PP, Brink PR. Fracture liaison service: impact on subsequent nonvertebral fracture incidence and mortality. J Bone Joint Surg Am. 2014 Feb 19;96(4):e29. doi: 10.2106/JBJS.L.00223.

24. Andreasen C, Solberg LB, Basso T, Borgen TT, Dahl C, Wisløff T, Hagen G, Apalset EM, Gjertsen JE, Figved W, Hübschle LM, Stutzer JM, Elvenes J, Joakimsen RM, Syversen U, Eriksen EF, Nordsletten L, Frihagen F, Omsland TK, Bjørnerem $\AA$. Effect of a Fracture Liaison Service on the Rate of Subsequent Fracture Among Patients With a Fragility Fracture in the Norwegian Capture the Fracture Initiative (NoFRACT): A Trial Protocol. JAMA Netw Open. 2018 Dec 7;1(8):e185701. doi: 10.1001/jamanetworkopen.2018.5701.

25. Vranken L, Wyers CE, van den Bergh JPW, Geusens PPMM. The Phenotype of Patients with a Recent Fracture: A Literature Survey of the Fracture Liaison Service. Calcif Tissue Int. 2017 Sep;101(3):248-258. doi: 10.1007/s00223-017-0284-1. 


$$
5
$$




\section{CHAPTER 5}

\section{First Quantification of Calcium Intake from Calcium-Dense Dairy Products in Dutch Fracture Patients (The Delft Cohort Study)}

Peter van den Berg (1), Paul M.M. van Haard (2), Joop P. van den Bergh (3), Dieu Donné Niesten (4), Maarten van der Elst (5), Dave H. Schweitzer (6)*.

1. Dept. of Orthopedics and Surgery, Reinier de Graaf Hospital, Delft, The Netherlands.

2. Dept. Medical Laboratories/Diagnostic Centre SSDZ, Reinier de Graaf Hospital, Association of Clinical Chemistry, Delft, The Netherlands.

3. Dept. of Internal Medicine, VieCuri Medical Centre Noord-Limburg and Department of Internal Medicine, Subdivision Rheumatology, Maastricht University Medical Centre, Maastricht, The Netherlands.

4. Dept. of Orthopaedics, Reinier de Graaf Hospital, Delft, The Netherlands.

5. Dept. of Surgery, Reinier de Graaf Hospital, Delft, The Netherlands.

6. Dept. of Internal Medicine, Reinier de Graaf Hospital, Delft, The Netherlands.

${ }^{*}$ Corresponding author: Dave H. Schweitzer, Dept. of Internal Medicine, Reinier de Graaf Hospital, Reinier de Graafweg 3-11, 2625AD Delft, The Netherlands; E-mail: schweitzdh@rdgg.nl; Tel.: +31 703401106; Fax: +31 703401103 
Abstract: Recommendations for daily calcium intake from dairy products are variable and based on local consensus. To investigate whether patients with a recent fracture complied with these recommendations, we quantified the daily dairy calcium intake including milk, milk drinks, pudding, yoghurt and cheese in a Dutch cohort of fracture patients and compared outcomes with recent data of a healthy US cohort (80\% Caucasians). An observational study analyzed dairy calcium intakes of 1526 female and 372 male Dutch fracture patients older than 50. On average, participants reported three dairy servings per day, independently of age, gender or population density. Median calcium intake from dairy was 790 mg/day in females and males. Based on dairy products alone, $11.3 \%$ of women and $14.2 \%$ of men complied with Dutch recommendations for calcium intake (adults $\leq 70 \mathrm{yrs}: 1100$ mg/day and >70 yrs: $1200 \mathrm{mg}$ /day). After including $450 \mathrm{mg}$ calcium from basic nutrition, compliance raised to $60.5 \%$ and $59.1 \%$ respectively, compared to $53.2 \%$ in the U.S. cohort. Daily dairy calcium intake as not associated with femoral neck BMD T-scores or FRAX risk scores for major fracture or hip fracture. However, sub analyzing the male cohort these associations were weakly negative. The prevalence of maternal hip fracture was a factor for current fracture risks, both in women and men. While daily dairy calcium intakes of Dutch fracture patients was were well below the recommended dietary intake, they were comparable to intakes in a healthy U.S. cohort. This questions recommendations for adding more additional dairy products to preserve adult skeletal health, particularly when sufficient additional calcium is derived from adequate non-dairy nutrition.

Keywords: Calcium-Dense Food; Dairy products; Fracture Liaison Service; FRAX. 


\section{Introduction}

In 1993, the U.S. Food and Drug Administration authorized a health claim for foods and supplements related to calcium to prevent osteoporosis. In January 2010, the health claim was expanded for the combination of calcium and vitamin D supplements. (FDA 21CFR101.72) This claim raises questions about the amount of calcium that should be recommended to the adult population [1]. Today, the Recommended Dietary Intake (RDI) for calcium, meaning the average daily level of intake sufficient to meet the nutrient requirements of healthy individuals, is $1200 \mathrm{mg}$ for individuals older than 50 yrs in the US (Food Guide Pyramid FGP, US Department of Agriculture) [2]. In the Netherlands, RDI for total daily calcium intake is quite similar to that in the US: 1100 mg for the age category 51-69 yrs and $1200 \mathrm{mg}$ for people older than $70 \mathrm{yrs}$. Based on the US recommendation, the number of recommendable calcium-dense servings should be four per day [2,3], which is more than the actual average consumption in the Netherlands as well as in the USA. While extra intake of dairy servings would seem the most straightforward way to increase calcium intake, it is questionable whether it is beneficial for bone health to use more dairy servings than those taken according to cultural habits and traditions. Over-nutrition of dairy products may cause maldigestion and malabsorption, which may overrule beneficial effects of calcium intake. Besides, it is unclear how traditional use of liquid milk and milk products relates to bone mineral density (BMD) and fracture risk during adulthood.

Public health authorities [4] claim that actual calcium intake is 25 percent lower in Europe than in the U.S. Although a large part of the agricultural activities in the Netherlands is dedicated to milk production and processing, the average Dutch consumption of liquid milk and milk products per capita in $\mathrm{kg} / \mathrm{year}$ is estimated to be 83.5, while it is 85.1 on average in 27 other European countries and 111.4 in the U.S. [5]. According to the Dutch National Food Consumption Survey (DNFCS 2007-2010), the median habitual total calcium intake per day (51-69yrs; P50) in Dutch men is 1109 mg calcium and in women $985 \mathrm{mg}$ [6].Non-dairy food sources contribute $42 \%$ of total calcium content in daily nutrition [6].

Since dairy products consumption per capita in $\mathrm{kg} / \mathrm{year}$ in the Netherlands compares well with the average in North-Western Europe, we were interested in comparing calcium intake in the Dutch adult population with that of an U.S. cohort of more than 80\% Caucasians, which was extracted from the Continuing Survey of Food Intake by Individuals, 1994-96, 1998, (CSFII) and the National Health and Nutrition Examination 
Survey, 1999-2000 (NHANES). We wondered whether the CSFII en NHANES reports would agree with the number of daily servings taken by Dutch individuals.

In order to answer this question, we conducted the present study at the Fracture Liaison Service (FLS) of the Reinier de Graaf Group of Hospitals in The Netherlands. Our primary research goals were to determine the number of daily servings of dairy products in a Dutch cohort of fracture patients after partitioning for age and gender, but also for population density; to correlate daily calcium intake from dairy products with femoral neck BMD T-scores and 10-year probability of major fracture or hip fracture; and to compare intakes with another, mainly Caucasian cohort in the U.S., consisting of patients without reported fracture. We further questioned whether the total amount of calcium from both daily basic nutrition and daily dairy consumption is appropriate for fulfilling Dutch recommendations for total calcium intake.

\section{Experimental Section}

\section{Patients and methods}

This prospective observational study was conducted at the Fracture Liaison Service (FLS) of the Reinier the Graaf Group of Hospitals, Delft (The Netherlands). The FLS is organized according to a previously reported concept [7-9]. We included women and men of 50 yrs and older with a recent fracture. These patients were evaluated by means of a structured diagnostic work up, including a detailed questionnaire regarding their daily calcium intake from dairy and a Dual Energy X-Ray Absorptiometry (DXA) measurement for femoral neck BMD T-scores. Each patient received a scan, with the exception of those who were already known with osteoporosis evidenced by older DXA measurements or with prevalent vertebral fractures evidenced by previous spinal radiographs. Patients using prescribed calcium and/or bisphosphonates were excluded.

Calcium intake was assessed using a validated Dutch questionnaire on Daily Calcium Intake (DCl-Holland), which was developed by Het Rijksinstituut voor Volksgezondheid en Milieu (National Institute for Public Health and the Environment, RIVM), Bilthoven, the Netherlands; see: NEVO-online.rivm.nl [4]. The DCI-Holland calculated the calcium content of food categories such as meat, fish, poultry, eggs, vegetables, fruits, potatoes, pasta, and milk products. According to the DCl-Holland, the average calcium content is $270 \mathrm{mg}$ in one glass of milk (200 ml), $400 \mathrm{mg}$ in one glass of calcium-enriched 
milk, and $240 \mathrm{mg}$ in one serving of yoghourt or pudding (200 ml). Non-dairy food contributes (as median) $430 \mathrm{mg}$ calcium in females and $443 \mathrm{mg}$ calcium in males, based on the habitual intake distribution at P50 of calcium food sources by the Dutch population aged 51-69 yrs, weighted for socio-demographic factors, season and day of the week.

Patients were recruited from the Emergency Department or were outpatients of the departments of Trauma surgery or Orthopaedic surgery. Each patient was asked to fill in a questionnaire that included questions about calcium intake from dairy nutrition categorized per product type (milk, calcium-enriched milk, yoghurt, pudding, cheese) as mentioned in the DCl-Holland. We estimated total daily dairy calcium intake using the number of glasses of milk or yoghourt/pudding servings. The calcium intake of cheese products was dichotomized (Yes/No). The intake of calcium from cheese products was calculated as half the amount in a glass of milk. The questionnaire also included the WHO Fracture Assessment Tool (FRAX) for evaluating fracture risks [10] and additional questions regarding age at menopause, daily exercise and sports habits. Calcium intake from dairy nutrition, per serving, was calculated using the formula of Fulgoni [2], one serving representing $250 \mathrm{mg}$ calcium, according to the Dutch Standard (DCl-Holland).

FRAX risk scores were calculated according to the Dutch FRAX algorithm [11]. Osteoporosis was defined as a T-score $\leq-2.5 *$ SD (SD=standard deviation) at either total hip, femoral neck or lumbar spine, normal BMD as a T-score $\geq-1$ *SD at all three locations and osteopenia as a T-score between -1*SD and -2.5*SD.

In patients with a T-score less than $-2 *$ SD, additional laboratory assessments and radiographs of lumbar and thoracic spine were performed, according to protocol. Vertebral fractures were scored according to the semi-quantitative method of Genant et al.. A vertebral fracture was defined as an infraction of at least $25 \%$ reduction in anterior, middle and/or posterior height and a reduction in area by 20-40\% [12].

Analyses were performed on 5 age decades (50-59, 60-69, 70-79, 80-89 and 90-100 yrs), gender, and on 5 (Dutch) population density categories (1: 21-250, 2: 250-500, 3: 500-1000, 4: 1000-2500 and 5: 2500-5976 inhabitants per square kilometres (source: Dutch National Atlas of Public Health; see: www.zorgatlas.nl.)[13].

Data were analysed using Statgraphics Centurion XVI software (Version 16.2.4 for MSWindows; Statpoint, Inc., VA, USA). Multiple-variable correlation analysis was applied after partitioning of data by gender. Wilcoxon\&Mann\&Whitney rank-sum test was 
applied to compare medians of numerical variables with respect to gender. Mood's Median and Kruskall\&Wallis tests were applied to genders in order to compare numerical variables between the categories of the diagnosis variable (normal, osteopenia, osteoporosis). Variance Components Analysis was applied, using fracture frequency as a dependent variable and relevant numerical variables as factors in order to assess their contribution to total variation in fracture frequency. To estimate odds ratios in genders, logistic regression with backward factor selection (p-to-enter .05; p-to-remove .05) was applied, with maternal hip fracture as dependent variable (Yes=1; No=0) and all numerical and dichotomous categorical variables as factors. Non-parametric correlations were then assessed again between final numerical factors of the best logistic regression model. Where applicable, 95\% Confidence intervals were used and a p-value < .05 was considered statistically significant at the 95\% confidence level. The study was approved by the Medical Review Board (METCZuid Holland), The Netherlands.

\section{Results}

From March 2008 to November 2011, we included 1526 women and 372 men of 50 yrs and older with a recent fracture. All patients were Caucasians. Of these patients, 1451 women and 349 men received a Dual Energy X-Ray Absorptiometry (DXA: Hologic QDR 4500 C) of total hip, femoral neck and lumbar spine and had a consultation at the outpatient clinic with a specialised nurse practitioner. Relevant complete data were obtained from all 1898 patients who were originally included, and demographics are listed in Table 1 and 2. Calculated daily dairy calcium intakes in genders are graphically represented in Figure 1 and the distribution of genders into age decades is listed in table 3.

Table 1. Demographic data of a Dutch cohort after a recent fracture

\begin{tabular}{|c|c|c|c|c|c|}
\hline Sex & Numbers & Age & $\begin{array}{l}\text { \% Osteoporosis } \\
\text { (T-score<- } \\
2.5 * \text { SD) }\end{array}$ & $\begin{array}{l}\text { FRAX,\% } \\
\text { (for major } \\
\text { fracture) }\end{array}$ & $\begin{array}{l}\text { FRAX,\% } \\
\text { (for hip } \\
\text { fracture) }\end{array}$ \\
\hline Women & 1526 & 66 (50-96) & 13.6 & $11.0(2.4-90.0)$ & $2.6(0.0-73.0)$ \\
\hline Men & 372 & 65 (50-90) & 6.2 & $7.5(1.6-41.0)$ & $2.7(0.1-37.0)$ \\
\hline
\end{tabular}

Fracture Assessment Tool (FRAX) was used to estimate FRAX risk scores for major osteoporotic fracture or hip fracture. Data were not normally distributed and are given as Median (Range). 
Table 2. Variables of a Dutch cohort after a recent fracture

\begin{tabular}{|c|c|}
\hline Variables & Data \\
\hline \multicolumn{2}{|l|}{ Sex } \\
\hline Women & 0 \\
\hline Men & 1 \\
\hline \multicolumn{2}{|l|}{ Age decades } \\
\hline $50-59$ yrs & 1 \\
\hline $60-69$ yrs & 2 \\
\hline $70-79$ yrs & 3: \\
\hline $80-89$ yrs & 4: \\
\hline $90-100$ yrs & 5 \\
\hline Age at menopause & age (yrs), women only \\
\hline \multicolumn{2}{|l|}{ Population density } \\
\hline category 1 & 21-250 inhabitants $/ \mathrm{km}^{2}$ \\
\hline category 2 & 250-500 inhabitants/ km² \\
\hline category 3 & 500-1000 inhabitants/ km² \\
\hline category 4 & 1000-2500 inhabitants $/ \mathrm{km}^{2}$ \\
\hline category 5 & 2500-5967 inhabitants/ km² \\
\hline \multicolumn{2}{|l|}{ Dairy calcium intake } \\
\hline per serving milk & 270 mg calcium \\
\hline per serving yoghourt & 240 mg calcium \\
\hline per serving cheese & 160 mg calcium \\
\hline \multicolumn{2}{|l|}{ Currently smoking } \\
\hline No & 0 \\
\hline Yes & 1 \\
\hline \multicolumn{2}{|l|}{ Alcohol } \\
\hline$\geq 3$ servings per day & 1 \\
\hline$\leq 2$ servings per day & 0 \\
\hline \multicolumn{2}{|c|}{ Current use of corticosteroids } \\
\hline No & 0 \\
\hline Yes & 1 \\
\hline
\end{tabular}




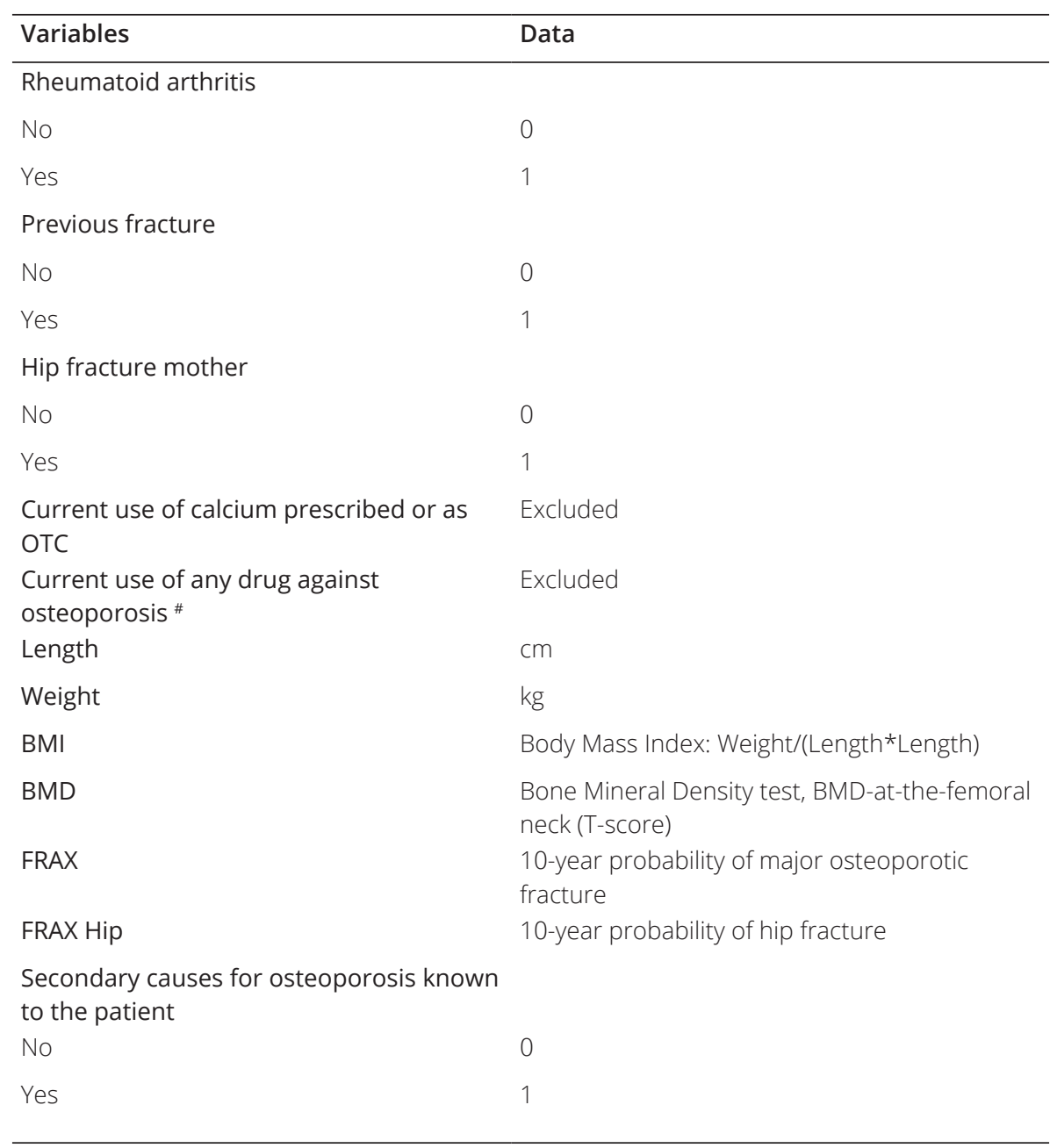

Legends:

OTC: Over-The-Counter available drugs not prescribed by a physician." Any drug against osteoporosis i.e. bisphosphonates, estrogens or Selective Estrogen Receptor Modulators 
Fig 1. Distributions of daily calcium intake (mg/day) from dairy products in women and men.

Histogram Females

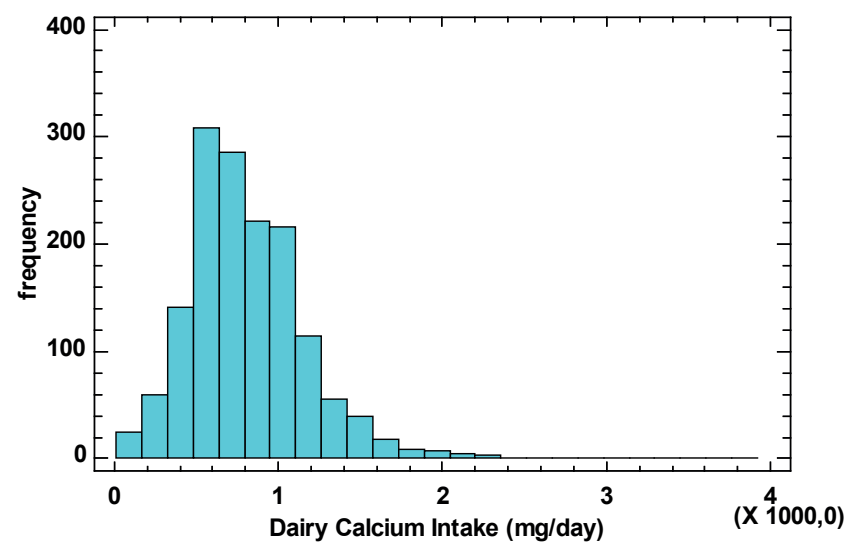

Histogram Males

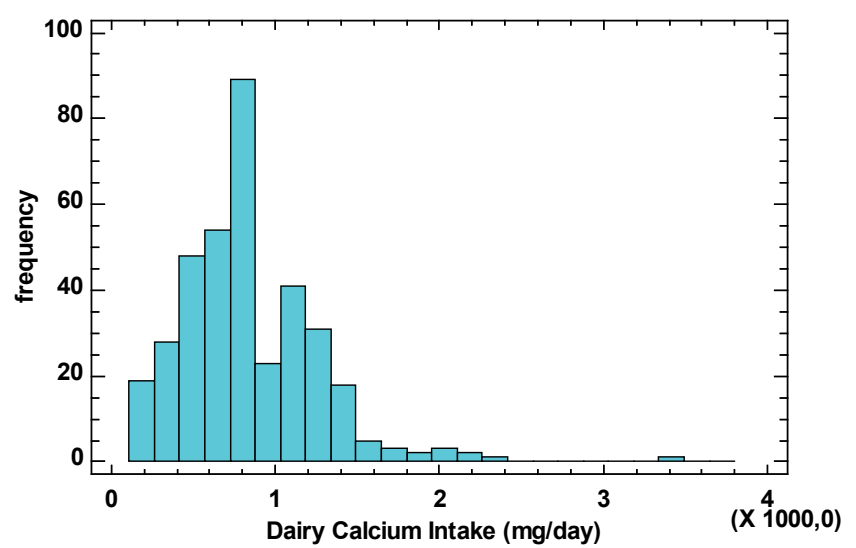

This study included more women than men, but genders were distributed equally over age decades, as is demonstrated in Table 2. 
Table 3. Distribution of 1898 patients into 5 age decades (range 50-100 yrs).

\begin{tabular}{llll}
\hline Age (yrs) & Women & Men & Ratio of genders \\
& W (N=1526) & M (N=372) & F/M \\
\hline $50-59$ & $399(26.1)$ & $113(30.4)$ & 3.5 \\
$60-69$ & $528(34.6)$ & $125(33.6)$ & 4.2 \\
$70-79$ & $428(28.0)$ & $96(25.8)$ & 4.5 \\
$80-89$ & $161(10.6)$ & $37(10.0)$ & 4.4 \\
$90-100$ & $10(0.7)$ & $1(0.2)$ & 10.0. \\
\hline
\end{tabular}

Legends: Data for women and men per age decade are given in numbers of patients and percentage of patients (\%).

Overall, we found no significant difference in calcium intakes from dairy food products between women and men (median 790 (range 0-4360) and 790 (0-3435) mg/day, respectively, $p=.80$ ). The dairy calcium intake was also expressed as numbers of servings per day, which were similar for each age decade except for those patients who were older than 80 yrs (Table 4). Numbers of servings did not differ between genders, nor between female and male cohorts compared for population density categories (Table 5).

Table 4. Number of daily servings of dairy products in females and males distributed into 5 age decades

\begin{tabular}{lll}
\hline $\begin{array}{l}\text { Age } \\
\text { (yrs) }\end{array}$ & $\begin{array}{l}\text { Women } \\
\text { (N=1526) }\end{array}$ & Servings/day \\
\hline $50-59$ & $399(26.1)$ & $3(0-9)$ \\
$60-69$ & $528(34.6)$ & $3(0-15)$ \\
$70-79$ & $428(28.0)$ & $3(0-13)$ \\
$80-89$ & $161(10.6)$ & $3(0-8)$ \\
$90-100$ & $10(0.7)$ & $3(2-4)$ \\
\hline Age & Men & Servings/day \\
(yrs) & (N=372) & $3(0-15)$ \\
\hline $50-59$ & $113(30.4)$ & $3(0-9)$ \\
$60-69$ & $125(33.6)$ & $3(0-8)$ \\
$70-79$ & $96(25.8)$ & $3(1-5)$ \\
$80-89$ & $37(10.0)$ & 1 \\
$90-100$ & $1(0.2)$ & \\
\hline
\end{tabular}

Legends: Data for women and men per age decade are given in numbers of patients having completed the questionnaire and in percentage of patients (\%). Data for number of servings were not normally distributed and are given as median (range). 
Table 5. Number of daily servings of dairy products in women and men grouped by population density

\begin{tabular}{lll}
\hline Population Density Category $\left(\right.$ Inhabitants per $\left.\mathrm{Km}^{2}\right)$ & Women $(\mathrm{N}=1526)$ & Servings/day \\
\hline $2(250-500)$ & $98(6.4)$ & $3(1-10)$ \\
$3(500-1000)$ & $5(0.3)$ & $4(3-5)$ \\
$4(1000-2500)$ & $565(37.0)$ & $3(0-9)$ \\
$5(2500-5976)$ & $858(56.3)$ & $3(0-15)$ \\
\hline Population Density Category (Inhabitants per $\left.\mathrm{Km}^{2}\right)$ & Men (N=372) & Servings/day \\
\hline $2(250-500)$ & $19(5.1)$ & $3(1-6)$ \\
$3(500-1000)$ & $2(0.5)$ & $4(3-5)$ \\
$4(1000-2500)$ & $156(41.9)$ & $3(0-15)$ \\
$5(2500-5976)$ & $195(52.5)$ & $3(0-9)$ \\
\hline
\end{tabular}

Legends:

Inhabitants per $\mathrm{Km}^{2}$ per category was defined according to www.zorgatlas.nl [13]. Category 1 was not represented in the study region. Data for women and men per population density category are given in numbers of patients and in percentage of patients (\%).Data for number of servings were not normally distributed and are given as median (range).

Most women and men were osteopenic and used 500 -1000 mg calcium calculated from total dairy product intake per day. No significant differences in patients in both genders were found for dairy intake nor for DXA T-scores normal BMD, osteopenia or osteoporosis (Table 6).

Table 6. Stratified Calcium intakes from dairy products in women and men grouped by Dual Energy X-Ray Absorptiometry (DXA) T-scores

\begin{tabular}{|c|c|c|c|}
\hline \multirow[t]{3}{*}{ Dairy Calcium intake (mg/day) } & \multicolumn{3}{|c|}{ Women $(\mathrm{N}=1451)$} \\
\hline & \multicolumn{3}{|c|}{ DXA T-score (*SD) } \\
\hline & $\geq-1$ & -1.0 to -2.5 & $\leq-2.5$ \\
\hline$<500$ & $42(2.9)$ & $141(9.7)$ & $49(3.4)$ \\
\hline $500-1000$ & $182(12.5)$ & $445(30.7)$ & $152(10.5)$ \\
\hline $1000-1500$ & $87(6.0)$ & $228(15.7)$ & $59(4.1)$ \\
\hline $1500-2000$ & $12(0.8)$ & $34(2.3)$ & $6(0.4)$ \\
\hline$\geq 2000$ & $4(0.3)$ & $7(0.5)$ & $3(0.2)$ \\
\hline \multirow[t]{3}{*}{ Dairy Calcium intake (mg/day) } & \multicolumn{3}{|c|}{ Men $(\mathrm{N}=349)$} \\
\hline & \multicolumn{3}{|c|}{ DXA [T-score (*SD)] } \\
\hline & $\geq-1$ & -1.0 to -2.5 & $\leq-2.5$ \\
\hline$<500$ & $12(3.4)$ & $37(10.6)$ & $9(2.6)$ \\
\hline $500-1000$ & $53(15.2)$ & $118(33.8)$ & $14(4.0)$ \\
\hline $1000-1500$ & $21(6.0)$ & $62(17.8)$ & $6(1.7)$ \\
\hline $1500-2000$ & $2(0.6)$ & $9(2.6)$ & $0(0.0)$ \\
\hline$\geq 2000$ & $0(0.0)$ & $6(1.7)$ & $0(0.0)$ \\
\hline
\end{tabular}

Legends: There were no significant differences between calcium intake from dairy per DXA T-score category, neither within gender nor between genders. 
Median (range) FRAX 10-year probability for major osteoporotic fracture was significantly higher in women than in men (11.0\% (2.4 - 90.0) and 7.5\% (1.6 - 41.0) respectively, $p<.05$ ). 10-year probability of hip fracture (median(range)) was not significantly different between genders (2.6\% (0.0 - 73.0) in women and 2.7\% (0.1 37.0) in men, respectively).

In men (Figure 2), dairy calcium intake showed a weak but significant negative correlation with the 10-year FRAX probability of major fracture as well as of hip fracture (Rho: -.13 and -.14 , respectively, $p<.01$ ), but no significant correlation with age, height, Body Mass Index (BMI), weight or BMD at the femoral neck. In females we found no significant correlation between dairy calcium intake and the variables mentioned, nor with 'age at menopause'.

Logistic regression analysis disclosed ‘maternal hip fracture`as a dependent variable. This was not found for any of the other variables like age, BMI, age at menopause (women only), population density, dairy calcium intake, more than one fracture prior to analysis, currently smoking, currently glucocorticoids use, rheumatoid arthritis, secondary causes for osteoporosis known to the patient, alcohol use (either $\leq 2$ or $\geq 3$ servings), BMD at the femoral neck, 10-year probability of osteoporotic major fracture, and 10-year probability of hip fracture. In women, logistic regression showed a weak relationship between 'maternal hip fracture ' and the independent variables (factors) BMD-at-the-femoral neck, 10-year probability of osteoporotic major fracture, 10-year probability of hip fracture, BMI, height, weight, Alcohol use=0, currently smoking=No. In men, logistic regression showed a strong relationship between 'maternal hip fracture' and the independent variables BMD at the femoral neck, 10-year probability of osteoporotic major fracture, 10-year probability of hip fracture, $\mathrm{BMI}$, and Prednisone $=0$. 
Fig 2. Relationship between daily dairy calcium intake and 10-year FRAX probability of osteoporotic major fracture or hip fracture in men.

10-year FRAX probability of os teoporotic major fracture in Men

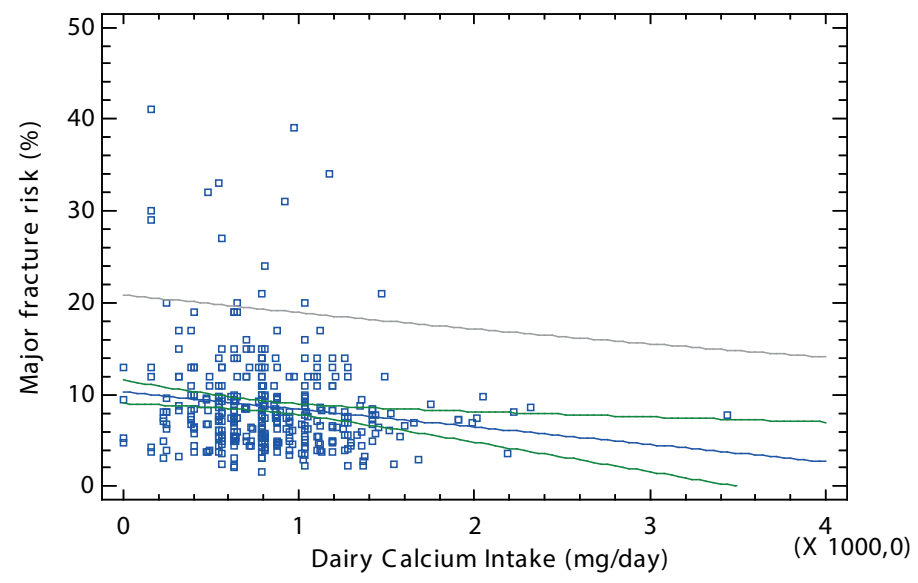

10-year FRAX probability of hip fracture in Men

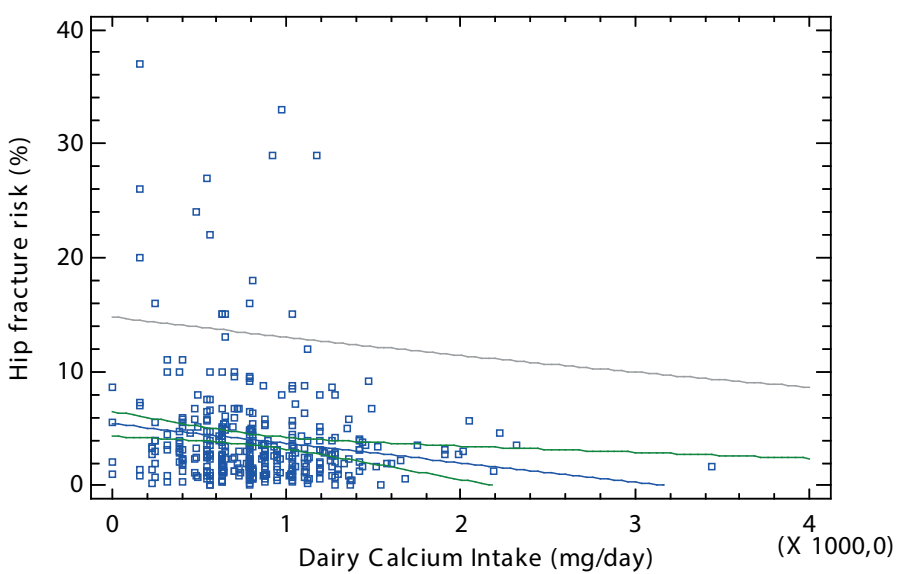




\section{Comparison between the current Dutch cohort and a cohort from the U.S.}

The percentage of patients fulfilling the recommended total calcium intake of $>1100 \mathrm{mg} /$ day ( $\leq 69 \mathrm{yrs}$ ) or > $1200 \mathrm{mg} /$ day (>70 yrs) depends on the total amount of calcium in Dutch basic nutrition. In this study, this would mean that focusing on dairy intake alone, just $11.3 \%$ of the women and $14.2 \%$ of the men complied with Dutch recommendation. However, assuming that Dutch basic non-dairy nutrition provides $42 \%$ of the total daily calcium intake (P50= $450 \mathrm{mg}$ ) [6], our findings mean that $60.5 \%$ of women and $59.1 \%$ of men complied with Dutch recommendations for nutritional calcium intake. U.S. data from the group of Fulgoni [2] showed a mean calcium intake of $674 \pm 6 \mathrm{mg} /$ day from dairy products for both women and men older than $50 \mathrm{yrs} ; 15.2 \%$ of both women and men complied with U.S. recommendations for nutritional calcium intake. Moreover, U.S. non-dairy nutrition was estimated to contain 250-475 mg calcium, and complemented with 2.93 dairy servings this would imply that $53.2 \%$ of this group complied with U.S. recommendations for calcium from dailynutrition [3].

\section{Discussion}

The current study shows that calcium intake from dairy products in a Dutch cohort of Caucasians with a recent fracture was well below the Dutch RDI of $1100 \mathrm{mg}$ for individuals between 50 and 70 yrs and of 1200 mg for older people. There were no differences in dairy calcium intake between age decades, genders or population density categories. In contrast to women in men there was a weak but significantly negative correlation between dairy calcium intake and 10-year probability of major fracture and hipfracture. Importantly, the present study showed that prevalence of 'maternal hip fracture ' was a factor for current fracture risk, both in women and men.

In spite of the fact that the esteemed calcium intake is lower in most European countries than in the US [2], there were no significant differences between our cohort of fracture patients and a comparable non-fracture cohort from the U.S. in terms of dairy calcium intake (expressed as the consumed amount of calcium or as daily number of servings).

The current study demonstrated that only $11.3 \%$ of women and $14.2 \%$ of men comply with Dutch recommendations for daily calcium intake from dairy products. However, a different picture emerges after adding $450 \mathrm{mg}$ calcium from basic nutrition $[4,6]$. 
Nevertheless, even in this scenario, 39.1\% of women and $37.4 \%$ of men still do not comply with Dutch recommendations (i.e. consume less calcium than recommended). We emphasize that our choice for $450 \mathrm{mg}$ calcium from non-dairy nutrition was based on previously published data by the Dutch National Institute for Public Health and the Environment (RIVM) [6]. These estimates are clearly higher compared with those made by Heaney [14] and documented in the Clinician's Guide to Prevention and Treatment of Osteoporosis by the National Osteoporosis Foundation (NOF) i.e. $250 \mathrm{mg}$ per day [15].

Whether this non-compliance with Dutch recommendations should be considered a health risk is debatable, since there is no uniformity amongst countries in the recommendation of calcium intake from dairy products or supplements. The Dutch daily recommendations for adults are similar to those in the U.S. i.e. men 50 - 70 years: 1000 mg, women > 50 years and men > 71: 1200 mg calcium per day (NOF Clinician's guide). For Australia and New Zealand recommendations are 1300 mg, for the UK 700 mg and for Scandinavian countries $800 \mathrm{mg}$. What calcium intake is optimal for skeletal health in adults remains an unresolved issue [16-20] For example, daily calcium intake in Asian and African countries is about a third of that in Western countries [21], and in Japan it is no more than 400-500 mg/day [2].

The current study found weak but significant negative correlations between dairy calcium intake and 10-year probability of major fracture and 10-year probability of hip fracture in the male cohort. This implies that males with the lowest calcium intake are at highest risk for fracture.

These data agree with the age-adjusted incidence rates of hip fractures around the world, which show a negative association with calcium intake by country and hip fracture rates $[17,23,26,27]$. However several other cohort studies in middle-aged and older Caucasian women and men found no proof of beneficial effects of dairy in reducing hip fractures [21,23-25]. Finally, a recent study by Feskanich et al. has shown that the highest hip fracture risk in men appeared to be in those individuals who had consumed most dairy products during their teenage years [22].

The different outcomes of studies with regard to effects of dairy consumption and osteoporotic fractures are confusing, but they may possibly be explained by dual mode effects of dairy consumption and the incidence of osteoporotic fractures. This phenomenon has been previously shown in the prospective longitudinal mammography cohort from sweden analysing the cumulative intake of dietary 
calcium study amongst 61.433 participants [21]. Primary outcome measures were incident fractures of any type and hip fracture (6\% during 19 years of follow-up). From these large amount of data it appeared that the risk of low calcium intake in the lowest quintile was associated with an increased fracture risk (for all as well as hip fractures). Oppositely, in the highest quintile of calcium intake there was an increased risk but only for hip fractures. Moreover, the investigators showed a multivariable adjusted spline curve for relation between cumulative average intake of dietary calcium and time to first hip fracture suggesting a protective effect for dairy calcium intake amounting to $800 \mathrm{mg}$ per day, whereas, a fracture-promoting effect for intakes exceeding $800 \mathrm{mg}$ of dietary calcium. In other words, it seems that the beneficial effects of dairy calcium intake followed a U-shaped pattern with calcium dose [21].

The variability of consumption of dairy products around the globe can be explained both by historical/cultural food aspects and biological variations, such as differences in intestinal lactase expression in populations. Lactase expression at infancy is universal, but in most mammals its activity declines after the age of weaning. Lactase activity in humans, however, is variable. Although most populations of the world have a low prevalence of lactase persistence, Northern European populations tend to have a high preservation of intestinal lactase expression, while it is least among Asians [27]. Combined databases of non-cohort studies have shown that lactose intolerance and malabsorption are clearly less prevalent among individuals of Northern European descent than in African American, Hispanic, Asian and American Indian populations [28].

While lactose intolerance can be a barrier to milk consumption, it has been shown that at least $240 \mathrm{ml}$ of whole or skimmed milk per day (containing appr. $37.5 \mathrm{~g}$ lactose) may be consumed by lactose maldigesters without experiencing adverse symptoms, especially if amounts are divided into smaller doses taken throughout the day $[29,30]$. Most individuals with lactose intolerance can tolerate up to $12 \mathrm{~g}$ of lactose in a single dose, though symptoms will become more prominent at doses above $12 \mathrm{~g}$ and appreciably so after $25 \mathrm{~g}$ of lactose; $50 \mathrm{~g}$ will induce symptoms in the vast majority of lactose intolerant individuals [28].

While U.S. authorities support supplemental milk feeding programs [29] it is in this respect remarkable to note that three servings of dairy products, uniform among adult populations of North-Western European descent, regardless of age, gender or population density, the latter at least in the Netherlands. Recommending more 
than three daily dairy servings to protect adult bone in North-Western European populations does not seem to have any scientific grounds.

An important finding of the present study is that prevalence of maternal hip fracture was a outcome variable for current fracture risks, both in men and women. These findings are in line with the publication and data of Lalmohamed [11] who investigated and calibrated the Dutch version of the FRAX algorithm. Our calculations were based on logistic regression models applying numeric as well as dichotomized variables (i.e. smoking, alcohol use, prednisone use, rheumatoid arthritis) and applying the FRAX algorithm in a fracture cohort. Our data indicate that genetics may play a more prominent role in osteoporotic fractures, independently of gender. Moreover, when calibrating FRAX for our Dutch cohort, we also found that maternal hip fracture accounted for the greatest increase in 10-year fracture probability.

A possible limitation of our study is that the Dutch data were obtained from patients who sustained a fracture, while the U.S. data were obtained from healthy individuals. It may be argued that a recent fracture may bias memorized daily dairy intakes. Another limitation of our study might be the fact that we did not focus on the vitamin D levels. These assays were not systematically performed in the included patients.

\section{Conclusions}

We have shown that Dutch fracture patients are used to taking on average three servings of dairy products per day, containing approximately $750 \mathrm{mg}$ of calcium, plus an estimated $450 \mathrm{mg}$ extra calcium from basic nutrition. There were no differences in daily dairy intake between age cohorts, genders or population densities. While daily dairy calcium intakes of Dutch fracture patients were well below the recommended dietary intake, they were comparable to healthy U.S. cohorts composed of mainly Caucasians. This questions recommendations to use additional amounts of dairy products to preserve adult skeletal health, particularly when sufficient additional calcium is derived from adequate non-dairy basic nutrition. 
Chapter 5

\section{Acknowledgments}

The authors are grateful to Mrs. Wil Aarssen and Mrs. Sabine 't Hart for their excellent secretarial services, to Mr. Luc Huijskes for support with programming the MS Access database and to Mrs. Lisette van Hulst for her critical linguistic advice.

\section{Conflicts of Interest}

The authors declare no conflict of interest. 


\section{References}

1. Cho K, Cederholm T, Lökk J. Calcium intake in elderly patients with hip fractures. Food Nutr Res. 2008; 52. doi: 10.3402/fnr.v52i0.1654

2. Fulgoni VL 3rd, Huth PJ, DiRienzo DB, Miller GD. Determination of the optimal number of dairy servings to ensure a low prevalence of inadequate calcium intake in Americans. J Am Coll Nutr. 2004; 23(6):651-9.

3. Beasley JM, LaCroix AZ, Neuhouser ML, Huang Y, Tinker L, Woods N, Michael Y, Curb JD, Prentice RL. Protein intake and incident frailty in the women's health initiative observational study. J Am Geriatr Soc. 2010; 58(6):1063-71.

4. National Institute for Public Health and the Environment RIVM. NEVO-tabel: Nederlands Voedingsstoffenbestand 2006/ Stichting Nederlands Voedingsstoffenbestand. 2006. Den Haag: Voedingscentrum. Internet: http://www.rivm.nl/Onderwerpen/Onderwerpen/N/Nederlands_ Voedingsstoffenbestand/Publicaties 2006.

5. Dutch Dairy Board. Kerncijfers belangrijkste zuivellanden 2010. Internet: http://www.prodzuivel. nl/pz/productschap/publicaties/Kerncijfers/Kerncijfers_belangrijkste_zuivellanden.htm (2010)

6. National Institute for Public Health and the Environment RIVM. Dutch National Food Consumption Survey 2007-2010: Diet of children and adults aged 7 to 69 years. Internet: http://www.rivm.nl/ Bibliotheek/Wetenschappelijk/Rapporten/2011/oktober/Dutch_National_Food_Consumption_ Survey_2007_2010_Diet_of_children_and_adults_aged_7_to_69_years

7. Dutch Institute for Healthcare Improvement CBO. Richtlijn Osteoporose en Fractuurpreventie. http:// www.cbo.nl/Downloads/1318/Definitieve\%20richtlijn\%200steoporose\%2028-04-2011 (2011)

8. McLellan AR, Gallacher SJ, Fraser M, McQuillian C. The fracture liaison service: success of program for the evaluation and management of patients with osteoporotic fracture. Osteoporos Int. 2003; 14(12):1028-34.

9. Hegeman $J \mathrm{H}$, Oskam J, van der Palen J, Ten Duis HJ, Vierhout PA.The distal radial fracture in elderly women and the bone mineral density of the lumbar spine and hip. J Hand Surg Br. 2004; 29(5):473-6.

10. Kanis JA, Johnell O, Oden A, Johansson H, McCloskey E. Frax and the assessment of fracture probability in men and women from the UK. Osteoporos Int.2004; 19(4):385-97.

11. Lalmohamed A, Welsing PMJ, Lems WF, Jacobs JWG, Kanis JA, Johansson H, De Boer A, De Vries F. The Calibration of FRAX $® 3.1$ to the Dutch population with data on the epidemiology of hip fractures. Osteoporos Int. 2012 23:861-899 DOI 10.1007/s00198-011-1852-2

12. Genant HK, Wu CY, van Kuijk C, Nevitt MC. Vertebral fracture assessment using a semiquantitive technique. J Bone Miner Res. 1993 ;8(9):1137-48.

13. Dutch National Atlas of Public Health. Bevolkingsdichtheid per gemeente. Internet: http:// www.zorgatlas.nl/beinvloedende-factoren/demografie/groei-en-spreiding/bevolkingsdichtheidper-gemeente\#breadcrumb 2010

14. Heaney RP. Calcium, dairy products and osteoporosis. J Am Coll Nutr. 2000 Apr;19(2 Suppl): 83S-99S.

15. National Osteoporosis Foundation. Clinician's Guide to Prevention and Treatment of Osteoporosis. Washington, DC: National Osteoporosis Foundation; 2014

16. Zhong Y, Okoro CA, Balluz LS Association of Total calcium and dietary protein intakes with fractures risk in postmenopausal women: the 1999-2002 National Health and Nutrition Examination Survey (NHANES). Nutrition. 2009; 25(6):647-54.

17. Prentice A. Diet, Nutrition and the prevention of Osteoporosis. Public Health Nutr. 2004; 7(1A):227-43. 
18. Tang BM, Eslick GD, Nowson C, Smith C, Bensoussan A. Use of calcium or calcium in combination with vitamin D supplementation to prevent fractures and bone loss in people aged 50 years or older: a meta-analysis. Lancet. 2007; 370(9588):657-66.

19. Heaney RP. Dairy and bone health. J Am Coll Nutr. 2009; 28 Suppl 1:82S-90S.

20. Surdykowski AK, Kenny AM, Insogna KL, Kerstetter JE. Optimizing bone health in older adults: the importance of dietary protein. Aging health. 2010; 6(3):345-357.21. Warensjö E, Byberg L, Melhus H, Gedeborg R, Mallmin H, Wolk A, Michaëlsson K. Dietary calcium intake and risk of fracture and osteoporosis: prospective Iongitudinal cohort study. BMJ. 2011; 342:d1473. doi: 10.1136/bmj.d1473.

21. Warensjö E, Byberg L, Melhus H, Gedeborg R, Mallmin H, Wolk A, Michaëlsson K. Dietary calcium intake and risk of fracture and osteoporosis: prospective longitudinal cohort study. BMJ. 2011; 342:d1473. doi: 10.1136/bmj.d1473.23.

22. Feskanich D, Bischoff-Ferrari HA, Frazier AL, Willett WC. Milk consumption during teenage years and risk of hip fractures in older adults. MA Pediatr. 2014 Jan;168(1):54-60. doi: 10.1001/ jamapediatrics.2013.3821

23. Bischoff-Ferrari HA, Dawson-Hughes B, Baron JA, Burckhardt P, Li R, Spiegelman D, Specker B, Orav JE, Wong JB, Staehelin HB, ea. Calcium intake and hip fractures in men and women: a metaanalysis of prospective cohort studies and randomised controlled trails. Am J Clin Nutr. 2007; 86(6):1780-90.

24. Feskanich D, Willett WC, Colditz GA. Calcium, Vitamin D, milk consumption, and hip fractures: a prospective study among postmenopausal women. Am J Clin Nutr. 2003; 77(2):504-11.

25. Cheng SY, Levy AR, Lefaivre KA, Guy P, Kuramoto L, Sobolev B. Geographic trends in incidence of hip fractures: a comprehensive literature review. Osteoporos Int. 2011; 22(10):2575-86.

26. Bischoff-Ferrari HA, Dawson-Hughes B, Baron JA, Kanis JA, Orav EJ, Staehelin HB, Kiel DP, Burckhardt P, Henschkowski J, Spiegelman D, ea. Milk intake and risk of hip fracture in men and women: a meta analysis of prospective cohort studies. J Bone Miner Res. 2011; 26(4):833-9. doi: 10.1002/jbmr.279.

27. Wilt TJ, Shaukat A, Shamliyan T, Taylor BC, MacDonald R, Tacklind J, Rutks I, Schwarzenberg SJ, Kane RL, and Levitt M. Lactose Intolerance and Health. No. 192 (Prepared by the Minnesota Evidence-based Practice Center under Contract No. HHSA 290-2007-10064-I.) AHRQ Publication No. 10-E004. Rockville, MD. Agency for Healthcare Research and Quality. February 2010.

28. Swallow DM. Genetics of lactase persistence and lactose intolerance. Annu Rev Genet. 2003; 37:197-219.

29. Scrimshaw NS, Murray EB. The acceptability of milk and milk products in populations with a high prevalence of lactose intolerance. Am J Clin Nutr. 1988 Oct;48(4 Suppl):1079-159. Chapter 5:Experimental and field observations of lactose and milk acceptability. Am J Clin Nutr 1988 48:1110S-1117S

30. Suarez FL, Adshead J, Furne JK, Levitt MD. Lactose maldigestion is not an impediment to the intake of 1500 mg calcium daily as dairy products. Am J Clin Nutr 1998; 68(5):1118-22. 
Quantification of Calcium Intake from Calcium-Dense Dairy Products 


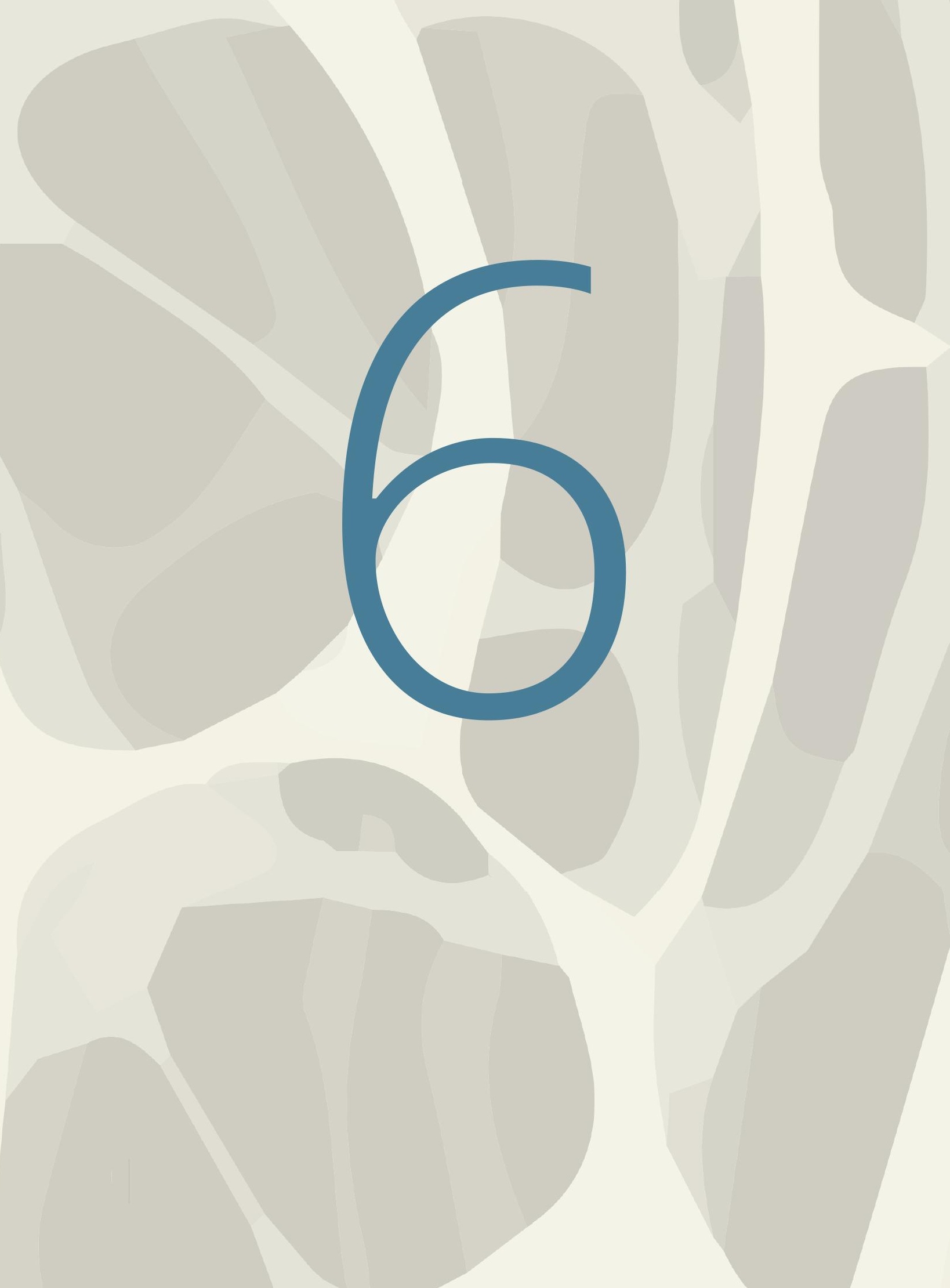




\section{CHAPTER 6}

\section{The use of Pulse-Echo Ultrasound in women with a recent non-vertebral fracture to identify those without osteoporosis and/or a subclinical vertebral fracture: a pilot study}

Peter van den Berg (1)*, Dave H. Schweitzer (2), Paul M.M. van Haard (3), Piet P. Geusens (4), Joop P. van den Bergh (5).

1. Dept. of Orthopedics and Surgery, Fracture Liaison Service, Reinier de Graaf Hospital, Delft, the Netherlands

2. Dept. of Internal Medicine and Endocrinology, Reinier the Graaf Hospital, Delft, the Netherlands

3. Dept. of Medical Laboratories, Association of Clinical Chemistry, Reinier the Graaf Hospital, Delft, the Netherlands

4. Dept. of Internal Medicine, Subdivision Rheumatology, Maastricht University Medical Center, Maastricht, the Netherlands and Hasselt University, Hasselt, Belgium

5. Dept. of Internal Medicine, VieCuri Medical Centre Noord-Limburg, Venlo, the Netherlands.

* Corresponding author E-Mail: pberg@rdgg.nl

Phone: + 31 152604926; Fax: + 31152605982 


\section{Disclosures}

Peter van den Berg: $\quad$ no disclosures.

Dave H. Schweitzer: no disclosures.

Paul M.M. van Haard: $\quad$ no disclosures.

Piet P. Geusens: no disclosures.

Joop P. van den Bergh: $\quad$ no disclosures.

\section{Conflicts of Interest:}

Peter van den Berg, Dave Schweitzer Paul van Haard, Piet Geusens, and Joop van den Bergh declare that they have no conflict of interest.

\section{Acknowledgments}

We are grateful to Mrs. Jeanette Kat for the P-EU measurements and to Mrs. Wil Aarssen and Mrs. Maria van Woerden for their excellent secretarial services. We thank Bindex® (Bone Index Finland Oy, Kuopio, Finland) for making the device available for the study.

\section{Contributions}

PVDB, DHS and PVH are responsible for the study design. PVDB and DHS were the authors, strongly supported by PVH, who also performed all statistical analyses. PG and JVDB supported the process with important scientific contributions and as co-authors.

\section{Mini abstract:}

A pilot study on the use of P-EU to identify patients without osteoporosis and/or a subclinical vertebral fracture after a recently sustained non-vertebral fracture (NVF). Keywords: DXANFA; FLS; Non-vertebral fracture; Osteoporosis; Subclinical Vertebral Fracture; Pulse-Echo Ultrasound. 


\begin{abstract}
Introduction

Screening with portable devices at emergency departments or plaster rooms could be of interest to limit referrals for Dual X-Ray Absorptiometry (DXA) and Vertebral Fracture Assessment (VFA). We calculated the number of negative tests for osteoporosis and/ or subclinical vertebral fractures (VFs) using Pulse-Echo Ultrasonometry (P-UE) at different thresholds.
\end{abstract}

\title{
Patients and Methods
}

In this cross-sectional study, 209 consecutive women of 50-70 years with a recent non-vertebral fracture (NVF) were studied at the Fracture Liaison Service (FLS) of one hospital. All women received DXANFA and P-EU (Bindex®) assessments. Various P-EU thresholds (based on the Density Index (DI, $\left.\mathrm{g} / \mathrm{cm}^{2}\right)$ ) were analyzed to calculate the best balance between true negative (indeed no osteoporosis and/or subclinical VF) and false negative tests (osteoporosis and/or subclinical VF according to DXA/VFA).

\section{Results}

83 women had osteoporosis (40\%) and 17 women at least one VF (8\%). Applying the manufacturer's recommended P-EU threshold (DI 0.844g/ $\left.\mathrm{cm}^{2}\right)$ being their proposed cut-off for not having hip osteoporosis resulted in 77 negative tests (37\%, 31\% true negative and $6 \%$ false negative tests). A DI of $0.896 \mathrm{~g} / \mathrm{cm}^{2}$ resulted in 40 negative tests (19.3\%) (38 true negative (18.3\%) and 2 false negative tests (1.0\%).

\section{Conclusion}

The application of P-EU enables the identification of a substantial proportion of women with recent non-vertebral fractures at the FLS who would not need a DXA/ VFA referral because they had no osteoporosis and/or subclinical vertebral fractures. The most conservative P-EU threshold resulted in 18.3\% true negative tests verified by DXANFA against $1 \%$ false negative test results. 


\section{Introduction}

The burden of Osteoporotic fractures increases worldwide due to aging and the contribution of the subsequent in part preventable fractures [1-3]. Osteoporotic fractures not only represent a large disease burden but it is also associated with increased mortality $[4,5]$. Secondary fracture prevention care is considered to be best organized at a Fracture Liaison Service (FLS) [6] and this is therefore propagated by the International Osteoporosis Foundation, the ASBMR and EULAR/EFORT [1,3,7]. However, a substantial work-up and treatment gap still remains due to limited or even low attendance rates [8]. Lack of recalled patient information (extrinsic motivation) and lack of patient's interest into personal health issues (intrinsic motivation) have been shown to be major clues for FLS non-attendance [9-12]. Screening for the presence of osteoporosis with peripheral devices in patients with a fracture intending to improve the proportion of patients that get further analyzed and treated with anti - osteoporosis medication has been previously highlighted, but did not yet result in guidelines worldwide [12]. Fast track diagnosis and treatment shortly after the index fracture could be efficacious regarding subsequent fracture risk reduction in any fracture patient $>50$ years [13]. Because of the imminent subsequent fracture risk $[14,15]$ it could be of added value to use a mobile peripheral screening imaging technique shortly after index fracture during fracture treatment procedures, on the one hand to rule out patients with a "negative" screening test for having osteoporosis or prevalent subclinical VFs in order to reduce the number of DXA and VFA measurements and, on the other hand to motivate, hence rule in, those with a "positive" screening test for further assessment at the FLS.

Screening at emergency departments and plaster rooms may be achievable and advantageous with peripheral portable non-ionizing ultrasound devices. Accuracy of quantitative ultrasound (QUS) in diagnosing osteoporosis as found by DXA has been reported in a number of studies $[16,17]$. In a meta-analysis that explored the usability of QUS as a pre-screen stratification tool for assessment of osteoporosis on DXA of the spine and hip showed a wide range of supposed DXA scan savings ranging from 3 to $69 \%$ at the expense of false negative tests ranging from 0 to 12\%, depending on the screening strategy and study characteristics, device, measured variable and cut-off values $[18,19]$. In contrast to QUS, P-EU (Bindex®) measurements are performed at the proximal tibia and measures mainly cortical bone properties. In earlier studies, the P-EU outcomes showed reproducible a good and significant correlation coefficient, between $r=0.86$ and $r=0.89$ with BMD at the femoral neck 
$[20,21]$. Diagnostic accuracy studies using this device at a single site showed a specificity of $82 \%$ and a sensitivity of $80 \%$ for detection of osteoporosis at the femoral neck or total hip [22,23].

According to our knowledge there are no data published on prescreening with QUS and/or P-EU in FLS cohorts and there are also no studies prescreening P-EU to predict subclinical VFs [16-18]. The rationale to use ultrasound to predict BMD - a different technique - is based on significant fracture prediction for both techniques [20-23]. However, DXANFA is the golden standard. Efficient and safe prediction of a negative test (i.e. low numbers of false negative tests) was held to be feasible in 50-70 year old women with reference to subclinical vertebral fractures of $11 \%<70$ years versus $23 \%$ $>70$ years. $[24,25]$. Besides, most data reported is in heterogeneous cohorts with or without previous fractures [20,22].

Recently a handheld CE approved Pulse-Echo Ultrasonometer device (P-EU Bindex $\left.{ }^{\circledR}\right)$ that measures cortical thickness (CTh) has been developed. The application of the P-EU Bindex ${ }^{\circledR}$ is based on the Density Index (DI), a composite value for sonographically measured cortical thickness (CTh) adjusted for age and body mass index (BMI) [2022]. High prediction was reported for a DI threshold of $0.844 \mathrm{~g} / \mathrm{cm}^{2}$ to differentiate BMD femoral neck t-scores below or above - 2.5*SD [22]. The NICE guideline on osteoporosis care recommends FRAX for fracture risk assessment [26,27]. In case of a calculated risk above the threshold for intervention a DXA including VFA is recommended. However, NICE leaves the application of Bindex® optional providing that it becomes adopted into NHS guidelines. In that scenario Bindex could be used after FRAX as an adjunct tool to screen before DXA referral [27].

We aimed to study the number of avoidable DXANFA referrals applying different P-EU cut-off levels for DI. The approach was to calculate the proportion of DXANFA scan savings based on the calculated true as well as false negative tests per DI threshold in parallel. The study was performed in 50-70 year old women who recently sustained a traumatic or non-traumatic NVF, a group considered to be at relative low risk of osteoporosis and subclinical VFs. [24,25].

\section{Patients and methods}

A total of 591 consecutive women with a recent NVF and between 50 and $70 \mathrm{yr}$. were identified between September $1^{\text {st }} 2016$ and June 30 2017 at the emergency 
department and plaster room of the Reinier de Graaf Hospital, Delft, The Netherlands. After exclusion of women with toe, finger and skull fractures, all women (except for women with fractures due to high velocity traumata) were invited to attend the FLS both after exchanging patient information at the emergency and plaster room or outpatient clinic and in case of no attendance within 1 month by written invitation. As a pilot we studied women between 50-70 years after recent fracture expecting their risk on osteoporosis and non-clinical vertebral fractures to be low [24,25]. For this study we excluded patients with clinical VFs since treatment is started in these patients regardless of the DXA outcome, according to the Dutch guideline [28].

DXA and Vertebral Fracture Assessments (VFA) were standard clinical procedures in all FLS patients. For this study, women were separately asked permission for a P-EU (Bindex®) measurement. Patients and health care professionals had no insight in the outcome at the time of this measurement. Anti-osteoporosis treatment was recommended according to the Dutch guidelines (the presence of osteoporosis and/ or a grade II/III subclinical prevalent VF) [28].

Index fractures were categorized in non-vertebral/non-hip minor, non-vertebral/nonhip major, hip and VFs according to Warriner [29].

The study was carried out in accordance with Good Clinical Practice (GCP; Medical Ethical Review Board: METC Zuidwest Holland; approval 16.190).

\section{DXA and VFA}

Patients had a DXAVFA measurement (Hologic Discovery QDR®) at the lumbar spine, total hip and femoral neck and a VFA. Osteoporosis was defined according to the WHO as a t-score $\leq-2.5$ *SD at the femoral neck, total hip or lumbar spine. Prevalent subclinical VF severity was graded according the classification of Genant i.e., grade I (mild) $\geq 20 \%-<$ $25 \%$, grade II (moderate) $\geq 25 \%-<40 \%$ and grade III (severe) $>40 \%$ height loss [30].

\section{P-EU (Bindex $囚)$}

P-EU (Bindex ${ }^{\circledR}$; Bone Index Finland, Kuopio, Finland) was used for this study [20-22]. Cortical Thickness (CTh) was calculated by multiplying the time of flight between the ultrasound echoes from the periosteal and endosteal surfaces by the speed of sound (SOS) [31]. According to manufacturers' recommendation, CTh is measured at onethird of the proximal tibia, meaning a third of the distance from the knee joint space 
to the medial malleolus. First, the participant was asked to bend the knee in order to palpate the knee joint. The leg was returned to a flat position while keeping contact with the medial knee joint gap. The joint was marked using a ball pen. Then the ruler was held next to the lower leg with the lower end at the most distal side of the medial malleolus. We used a manufacturer's ruler to indicate the measuring exactly at one third of the tibia length. Echo gel was applied at this site and the transducer was moved over the tibia in a slight angle. This movement was repeated five times to obtain five valid signals. All measurements were performed by the same operating technician who was trained by the manufacturer. These 5 results were averaged, computed further in the software (Bindex ${ }^{\circledR}$ software v2.0) using CTh, age, weight and height. Density Index (DI) g/ $\mathrm{cm}^{2}$ ) was calculated with Bindex® software [20-22]. After two days training of the local operating technician by the manufacturer the inter-rater agreement between the manufacturer's instructor and the local operator was tested (Inter Rater Reliability - IRR) was 87\% (R^2=0.8716, CV=3.2\%) measuring 16 patients, which reflects a high agreement [32].

\section{Aims of the Study}

We studied various P-EU cut-off levels to determine the proportion of women with a true negative P-EU test for having no osteoporosis at femoral neck, total hip or lumbar spine and/or a subclinical VF with the consequent proportion of women with a false negative P-UE test i.e. the confirmed presence of osteoporosis or at least one subclinical prevalent VF according to DXANFA. The first step in this research was to study the manufacturer 's recommended P-EU (Bindex) DI score of $\geq 0.844 \mathrm{~g} / \mathrm{cm}^{2}$ that was originally developed and tested for osteoporosis at the hip and femoral neck. The second step was to determine the P-EU DI threshold with the highest proportion of true negative tests at the expense of the lowest proportion of false negative tests.

\section{Statistical methods}

Statistical analyses were performed using StatGraphics Centurion software (Version 17.2.05 for MS-Windows; Statpoint, Inc., Warrenton, VA, USA) and R (2018, The R Foundation for Statistical Computing Platform, version 3.5) [33]. All DXA and VFA scores were dichotomized being Yes $=1$ (t-score $\leq-2.5 * \mathrm{SD}$ and/or at least one prevalent VF $\geq$ $25 \%$ and $\mathrm{No}=0$ (t-score $>-2.5 * \mathrm{SD}$ and no prevalent $\mathrm{VF} \geq 25 \%$ ). 
The Wilcoxon-Mann-Whitney rank-sum test was used to compare two groups formed by censoring via DXA Spine, Total Hip and Femoral Neck (osteoporosis and osteopenia/ normal) and dichotomized DI as outcome variable. The Kruskall-Wallis test was used to compare these groups among the various numerical variables DI and DXA spine, DXA total hip and femoral neck t-scores. Pearson's Chi Square test or Fisher's Exact Probability test were used to examine the significance of the association between dichotomized DI and dichotomized DXA total hip, DXA femoral neck, DXA lumbar spine, DI t-scores and Genant classifications. OR and 95\% CI were calculated to assess the effect size of a significant association. The diagnostic accuracies of varying DI threshold levels to predict t-score defined osteoporosis and/or subclinical VF grade II and III were analyzed performing ROC analyses aiming to find DI threshold values corresponding with AUC > 80\%.

Spearman's rank correlations were calculated between DXA lumbar spine, femoral neck and total hip, DI t-scores and Genant classification vs. numerical DI as outcome variable before establishing the most adequate logistic regression model, as well as for the interpretation of the Inter-rater reliability. Collinearity and interactions were analyzed using R and judged by interpretation of VIF, Condition Indices and interaction trees and plots. Receiver Operator Curve (ROC) analyses were performed using library pROC in R aiming to achieve an Area under the ROC curve (AUC=auroc) > 80\% [34].

The best DI threshold (method Youden), all other thresholds and adhering diagnostics like sensitivity, specificity, NPV, PPV and their respective $95 \% \mathrm{Cl}$ were calculated by bootstrapping using typically 10,000 replicates to obtain good estimates of statistics and adequate significant figures [35].

For the calculation of the proportion of correctly and incorrectly non-referred women for DXANFA, we calculated by tabulation the number of women who are above or below a specific threshold DI (g/cm^2) and had a dichotomous score in DXAVFAALL and related that number to $N$ (the total number of women). P-value $<.05$ was considered statistically significant at the $95 \%$ confidence level. 


\section{Results}

Of a total of 591 consecutive women with a NVF we excluded 122 women with finger, toe, and skull fractures (fig 1). Therefore, 469 patients were invited at the FLS resulting in 263 attenders (56\%) and 206 FLS non-attenders (44\%). After exclusion of 54 women (18 with a clinical VF, 9 no informed consent, 20 with unreadable or incomplete data, 7 not accessible for P-UE measurement), the study population consisted out of 209 women. Patient characteristics are provided in table 1. Median age was $62.2 \pm 6.0$ years, 19 women (9\%) had a hip fracture, 94 (45\%) a non-vertebral/non-hip major fracture and 96 (46\%) a non-vertebral/non-hip minor fracture. Osteoporosis was present in 83 women (40\%) and/or at least one prevalent subclinical VF was present in 10 women while 7 women had a VF without osteoporosis. 73 women (35\%) had osteoporosis but no prevalent subclinical VFs.

Table 1.

Characteristics of 209 women, 50-70 years old, with a recent Non-Vertebral Fracture at the FLS

\begin{tabular}{|c|c|c|c|c|}
\hline \multirow{2}{*}{ Age (yr) } & \multirow{2}{*}{$\begin{array}{l}\text { Number (\%) } \\
209(100 \%)\end{array}$} & \multirow{2}{*}{$\begin{array}{l}\text { Median } \\
62.2\end{array}$} & \multicolumn{2}{|c|}{ Range (min/max) } \\
\hline & & & 50 & 70 \\
\hline Osteoporosis & $83(40 \%)$ & & & \\
\hline Osteopenia & $92(44 \%)$ & & & \\
\hline Normal BMD & $34(16 \%)$ & & & \\
\hline \multicolumn{5}{|c|}{ At least one Prevalent VF (Genant grade II/III) } \\
\hline Grade $\|(\geq 25 \%$ but $\leq 40 \%)$ & $13(6 \%)$ & & & \\
\hline Grade III (> 40\%) & $4(2 \%)$ & & & \\
\hline Hip fracture* & $19(9 \%)$ & & & \\
\hline \multicolumn{5}{|l|}{ Major fractures* $n=94$ (45\%) } \\
\hline - Distal radius and lower arm & $52(55 \%)$ & & & \\
\hline - Sub-capital humerus & $16(17 \%)$ & & & \\
\hline - Rib & $6(6 \%)$ & & & \\
\hline - Pelvis and Acetabulum & $6(6 \%)$ & & & \\
\hline - Tibia proximal / plateau & $10(11 \%)$ & & & \\
\hline - Calcaneal / tarsal & $10(11 \%)$ & & & \\
\hline \multicolumn{5}{|l|}{ Minor fractures* $n=96$ (46\%) } \\
\hline - Clavicle / scapula & $6(6 \%)$ & & & \\
\hline - Scaphoid & $7(7 \%)$ & & & \\
\hline - Metacarpal & $12(13 \%)$ & & & \\
\hline - Radius neck / head & $9(9 \%)$ & & & \\
\hline - Patella & $7(7 \%)$ & & & \\
\hline - Ankle / malleolus & $25(26 \%)$ & & & \\
\hline - Metatarsal & $18(19 \%)$ & & & \\
\hline Age at menopause (self-reported; yr.) & & 50 & 41 & 61 \\
\hline DXA femoral neck t-score (SD) & & -1.9 & -4.4 & +1.3 \\
\hline DXA total hip t-score (SD) & & -1.6 & -5.2 & +2.4 \\
\hline DXA t-score lumbar spine (SD) & & -1.6 & -5.2 & +2.4 \\
\hline
\end{tabular}




\begin{tabular}{lllll}
\hline & Number (\%) & Median & Range (min/max) \\
\hline Cortical Thickness (CTh) (mm) & & 2.1 & 1 & 2.3 \\
Density Index (DI) (g/cm²) & & 0.82 & 0.667 & 1.183 \\
Density Index t-score (SD) & & -1.6 & -3.4 & +2.7 \\
BMI (kg / cm*cm) & & 21.8 & 16.1 & 23.1 \\
Weight (kg) & & 68 & 45 & 130 \\
Height (cm) & $44(19 \%)$ & & & 188 \\
Smoking (Yes) & $33(15 \%)$ & & & \\
Alcohol (> 2 U/daily) & $53(23 \%)$ & & & \\
Previous fracture(s): Yes (self-reported) & $23(10 \%)$ & & & \\
Previous fall: Yes (self-reported) & $23(10 \%)$ & & & \\
Parental hip fracture (mother: Yes) & $9(4 \%)$ & & & \\
Parental hip fracture (father: Yes) & $11(5 \%)$ & & & \\
Rheumatoid arthritis (existing) & $9(4 \%)$ & & & \\
Diabetes (existing) & $2(1 \%)$ & & & \\
Hyperthyroidism (existing) & $16(7 \%)$ & & & \\
COPD & $105(46 \%)$ & 68 & 18 & \\
Vitamin D supplementation (Yes). Nr. conc. nmol/l) & & & & \\
\hline
\end{tabular}

Legends:

* Fractures were categorized according to Warriner [20]

Fig 1. Flowchart of the current study

591 consecutive women with a recent non-vertebral fracture

Exclusion of toe, finger and skull fractures $n=122(20 \%)$

$469(77 \%)$ were invited for FLS

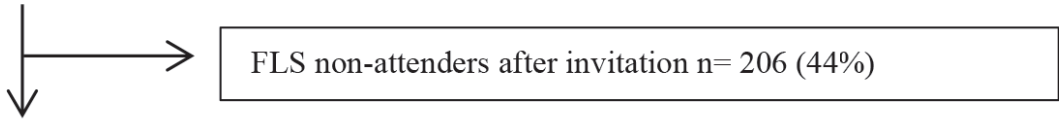

FLS attenders referred for DXA/VFA and P-EU (Bindex $\left.{ }^{\circledR}\right) n=263(56 \%)$

\begin{tabular}{|l|l|} 
Clinical vertebral fractures on presentation $\mathrm{n}=18(7 \%)$ \\
No informed consent $\mathrm{n}=9(3 \%)$ \\
Incomplete data $\mathrm{n}=20(8 \%)$ \\
Not accessible for P-UE $\mathrm{n}=7(3 \%)$
\end{tabular}

Final analysis in 209 women (79\%). 
Applying the manufacturer 's standard P-EU threshold (DI $0.844 \mathrm{~g} / \mathrm{cm}^{2}$ ) resulted in 130 women with a $\mathrm{DI} \leq 0.844 \mathrm{~g} / \mathrm{cm}^{2}(62 \%)$ and 79 with women with a $\mathrm{DI}>0.844$ (38\%). Odds Ratios of a DI $\geq 0.844 \mathrm{~g} / \mathrm{cm}^{2}$ for not having osteoporosis at the femoral neck, total hip or lumbar spine and for not having osteoporosis or subclinical VFs, respectively, are presented in table 2 .

Table 2. Odds Ratio's (OR) using manufacturer's Density Index (DI) $\geq 0.844 \mathrm{~g} / \mathrm{cm}^{2}$ to exclude for osteoporosis and/or subclinical vertebral fractures in 209 women who sustained a recent nonvertebral fracture.

\begin{tabular}{llll}
\hline DXA per site & p-value & $95 \% \mathrm{Cl}$ & OR \\
\hline DXA femoral neck & $<.001$ & $7.46 ; 61.76$ & 21.47 \\
DXA total hip & $<.001$ & $3.43 ; 38.31$ & 11.47 \\
DXA spine & $<.001$ & $3.69 ; 25.14$ & 9.68 \\
DXA ALL sites & $<.001$ & $2.69 ; 10.23$ & 5.25 \\
DXA all sites including subclinical vertebral fractures & & & \\
$\begin{array}{l}\text { DXA ALL sites } \\
\text { (including subclinical vertebral fractures Grade II and III) }\end{array}$ & $<.001$ & $2.54 ; 9.61$ & 4.94 \\
\hline
\end{tabular}

Legends:

DI measures $\left(\mathrm{g} / \mathrm{cm}^{2}\right)$ in women with and without osteoporosis (dichotomized $\mathrm{DI} \geq 0.844: 0$ and $1 \mathrm{resp}$.). DXA measures were dichotomized for osteoporosis (t-score $\leq-2.5 *$ SD: 1 ) at least at one of the DXA sites (femoral neck, total hip and spine) and/or grade II and III prevalent vertebral fractures. OR: Odds Ratio; 95\%Cl: 95\% Confidence Interval. $p$-value $<.05$ is considered significant.

The diagnostic accuracy of DI thresholds for any combined DXANFA outcome according to the ROC analyses are presented in table 3. The ROC diagnostic accuracy analysis of P-EU (Bindex®) is depicted in figure 2 . 
Fig 2. ROC curves

Fig. A ROC curves: Three DXA-based predictors vs. dichotomized Bindex® Density Index predictors.

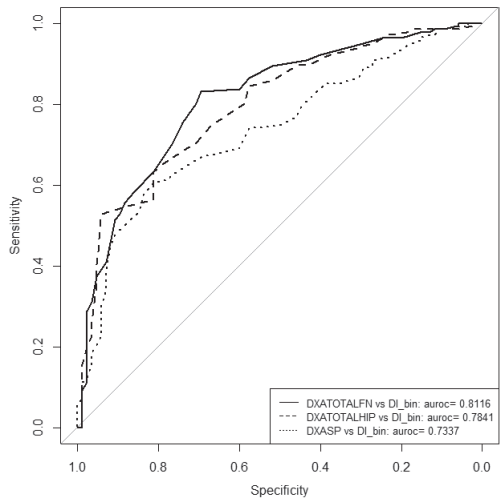

Legends:

The area under each ROC curve (i.e. auroc) quantifies the overall ability of each "diagnostic test" to discriminate between women (50-70 yr.) with suspicion of osteoporosis (dichotomized DI $\leq 0.844$ ) and those without osteoporosis (dichotomized $\mathrm{DI}>0.844$ ). From the three curves it can be seen that the 3 predictors may be able to discriminate between the two groups of women. The $95 \%$ Confidence Intervals of the aurocs are not significantly different between Femoral Neck (auroc: 0.8116, 95\% Cl: 0.7506-0.8726) and Total hip (auroc: 0.7841, 95\% Cl: 0.7209-0.8473) and between Total hip and Lumbar Spine (auroc: 0.7337, 95\% Cl: 0.6656-0.8017). However, aurocs of Femoral Neck and Lumbar spine are significantly different (bootstrap method; p-value .02).

Fig. B ROC curve: Density Index (numerical) vs. Fig. C ROC curve: Density Index (numerical) vs. dichotomized DXA ALL sites

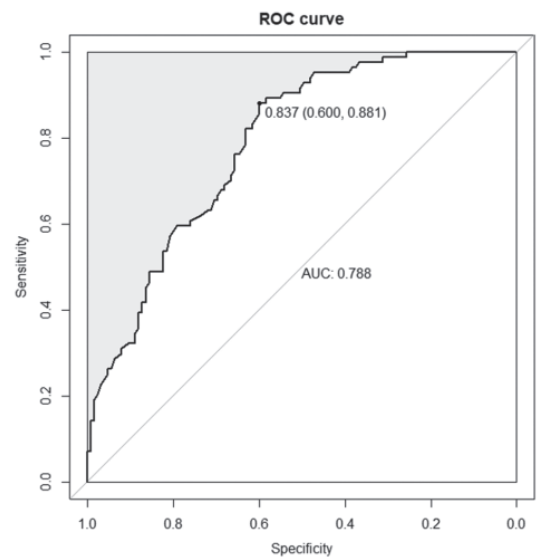
dichotomized DXAVFAALL sites including al subclinical vertebral fractures grade II and III

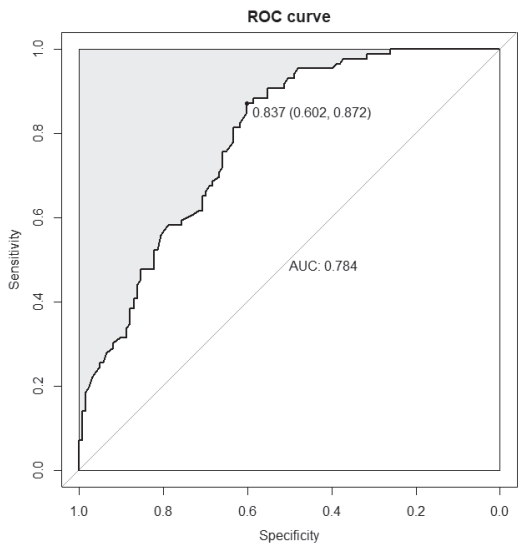

Legends Fig. B and C:

The area under the ROC curve (i.e. auroc) quantifies the overall ability of the "diagnostic test" DI to discriminate between women (50-70 yr.) with and without osteoporosis and clinical vertebral fractures with DXAVFA ALL sitesbased absence of osteoporosis with and without vertebral fractures grade II and III. Each point on the ROC curve represents a sensitivity/specificity pair corresponding to a particular decision threshold of the respective predictor. 
Table 3. Calculated Bindex Density Index (DI) cut-off for achieving the optimal AUCs according to DXA with or without subclinical Grade II and III on VFA, using ROC analyses.

\begin{tabular}{llllll}
\hline DXA sites & $\begin{array}{l}\text { DXAVFAALL } \\
\text { including } \\
\text { VFs Grade II/III }\end{array}$ & $\begin{array}{l}\text { DXA ALL } \\
\text { sites }\end{array}$ & $\begin{array}{l}\text { DXA } \\
\text { Lumbar } \\
\text { Spine (L1-4) }\end{array}$ & $\begin{array}{l}\text { DXA } \\
\text { Femoral } \\
\text { Neck }\end{array}$ & $\begin{array}{l}\text { DXA } \\
\text { Total hip }\end{array}$ \\
\hline Optimal DI Cut-off & 0.837 & 0.837 & 0.822 & 0.812 & 0.837 \\
AUC (= auroc) & 0.7844 & 0.7878 & 0.7337 & 0.7841 & 0.8116 \\
Specificity (\%) & 60.2 & 60.0 & 59.4 & 63.5 & 59.9 \\
Sensitivity (\%) & 87.2 & 88.1 & 81.5 & 78.6 & 92.5 \\
NPV (\%) & 87.1 & 88.2 & 90.2 & 92.2 & 93.6 \\
PPV (\%) & 60.5 & 59.7 & 41.1 & 35.1 & 55.6 \\
\hline
\end{tabular}

Legends:

Optimal DI cut-offs (numerical, g/cm2) are obtained from Receiver Operator Curve (ROC) analyses. Auroc: Area under the Receiver Operator Curve. NPV: Negative predictive value. PPV: positive predictive value. The calculated optimal DI cut-off agreed with that of the manufacturers recommended cut-off.

Table 4 shows the number and proportion of true negative and false negative tests for a range of DI thresholds including that formulated by the manufacturer (from 0.844 to $0.896 \mathrm{~g} / \mathrm{cm} 2)$. Use of the manufacturer's recommended DI cut-off of $\geq 0.844$ $\mathrm{g} / \mathrm{cm} 2$ resulted in 77/209 true negative (37.8\%) and 12 (5.8\%) false negative tests. The lowest proportion of false negative tests was achieved at a DI of $0.896 \mathrm{~g} / \mathrm{cm} 2$ being true negative in 38 women (18.3\%) and false negative in 2 women (1\%) in whom one with a subclinical VF and one women with osteoporosis but no subclinical VF. 
Table 4. Proportion of true positive and false negative tests in women 50-70 year for not having osteoporosis and/or prevalent morphometric vertebral fractures according to different Density Index (DI) cut-offs.

\begin{tabular}{|c|c|c|c|c|c|c|c|c|}
\hline \multicolumn{5}{|c|}{ True negative and false negative tests } & \multicolumn{4}{|c|}{ Test characteristics. } \\
\hline $\begin{array}{l}\text { Measured } \\
\text { DI }\end{array}$ & $\begin{array}{l}\text { True } \\
\text { negative } \\
(\mathrm{nr} .)\end{array}$ & $\begin{array}{l}\text { True } \\
\text { negative } \\
(\%)\end{array}$ & $\begin{array}{l}\text { False } \\
\text { negative } \\
(\mathrm{nr} .)\end{array}$ & $\begin{array}{l}\text { False } \\
\text { negative } \\
(\%)\end{array}$ & NPV (\%) & $\begin{array}{l}\text { PPV } \\
(\%)\end{array}$ & $\begin{array}{l}\text { Specificity } \\
(\%)\end{array}$ & $\begin{array}{l}\text { Sensitivity } \\
(\%)\end{array}$ \\
\hline 0.844 & 65 & 31.3 & 12 & 5.8 & 84.40 & 58.80 & 54.60 & 86.50 \\
\hline 0.846 & 65 & 31.3 & 11 & 5.3 & 85.50 & 59.10 & 54.60 & 87.60 \\
\hline 0.848 & 63 & 30.3 & 11 & 5.3 & 85.10 & 58.20 & 52.90 & 87.60 \\
\hline 0.851 & 60 & 28.8 & 11 & 5.3 & 84.50 & 56.90 & 50.40 & 87.60 \\
\hline 0.854 & 60 & 28.8 & 10 & 4.8 & 85.70 & 57.20 & 50.40 & 88.80 \\
\hline 0.855 & 59 & 28.4 & 9 & 4.3 & 86.80 & 57.10 & 49.60 & 89.90 \\
\hline 0.857 & 58 & 27.9 & 9 & 4.3 & 86.60 & 56.70 & 48.70 & 89.90 \\
\hline 0.860 & 57 & 27.4 & 9 & 4.3 & 86.40 & 56.30 & 47.90 & 89.90 \\
\hline 0.862 & 57 & 27.4 & 8 & 3.8 & 87.70 & 56.60 & 47.90 & 91.00 \\
\hline 0.864 & 56 & 26.9 & 7 & 3.4 & 88.90 & 56.60 & 47.10 & 92.10 \\
\hline 0.866 & 54 & 26.0 & 7 & 3.4 & 88.50 & 55.80 & 45.40 & 92.10 \\
\hline 0.868 & 52 & 25.0 & 7 & 3.4 & 88.10 & 55.00 & 43.70 & 92.10 \\
\hline 0.870 & 51 & 24.5 & 7 & 3.4 & 87.90 & 54.70 & 42.90 & 92.10 \\
\hline 0.872 & 49 & 23.6 & 7 & 3.4 & 87.50 & 53.90 & 41.20 & 92.10 \\
\hline 0.875 & 47 & 22.6 & 7 & 3.4 & 87.00 & 53.20 & 39.50 & 92.10 \\
\hline 0.876 & 46 & 22.1 & 7 & 3.4 & 86.80 & 52.90 & 38.70 & 92.10 \\
\hline 0.879 & 45 & 21.6 & 6 & 2.9 & 88.20 & 52.90 & 37.80 & 93.30 \\
\hline 0.881 & 44 & 21.2 & 6 & 2.9 & 88.00 & 52.50 & 37.00 & 93.30 \\
\hline 0.883 & 43 & 20.7 & 5 & 2.4 & 89.60 & 52.50 & 36.10 & 94.40 \\
\hline 0.884 & 41 & 19.7 & 5 & 2.4 & 89.10 & 51.90 & 34.50 & 94.40 \\
\hline 0.886 & 41 & 19.7 & 3 & 1.4 & 93.20 & 52.40 & 34.50 & 96.60 \\
\hline 0.890 & 40 & 19.2 & 3 & 1.4 & 93.00 & 52.10 & 33.60 & 96.60 \\
\hline 0.893 & 39 & 18.8 & 3 & 1.4 & 92.90 & 51.80 & 32.80 & 96.60 \\
\hline 0.895 & 38 & 18.3 & 3 & 1.4 & 92.70 & 51.50 & 31.90 & 96.60 \\
\hline 0.896 & 38 & 18.3 & 2 & 1.0 & 95.00 & 51.80 & 31.90 & 97.80 \\
\hline
\end{tabular}

Legends:

True Negative and False Negative tests in women 50-70 year not having osteoporosis and/or grade II or III vertebral fractures by application of various (higher) DI cut-offs. DI cut-offs are obtained from Receiver Operator Curve (ROC) analyses in DXAVFAALL. NPV: negative predictive value. PPV: positive predictive value. 


\section{Discussion}

In this cross-sectional pilot study we showed outcome results of several P-UE DI thresholds (including the cut-off DI $(0.844 \mathrm{~g} / \mathrm{cm} 2)$ as recommended by the manufacturer. The proportions of true negative and false negative tests were calculated to get a first notion about potential DXANFA non-referrals because of no suspicion of osteoporosis and/or a subclinical vertebral fracture on VFA in parallel with proportions of false negative results down to $1 \%$. The results are relevant since there are no previous studies performed in high risk FLS patients that focused on screening with peripheral ultrasound technology showing a 18.3\% proportion of true negative tests (indeed no osteoporosis and/or prevalent subclinical VFs grade II/III).

Previous studies were limited in reporting the accuracy of peripheral ultrasound devices with a more general approach to find optimal cut-off thresholds for 'osteoporosis' based on central DXA, but not to additionally diagnose those patients with a subclinical VF. In this context it has been shown that the diagnostic inaccuracy of ultrasound techniques mostly using ROCs ranged from 0 to $12.4 \%$ with DXA savings from 3 up to 69\% [16-18,20,21].

In this study, Bindex® showed a good diagnostic accuracy for DXA-defined femoral neck osteoporosis (AUC >0.81) and a fair accuracy for DXA measurements at the lumbar spine and total hip and for the combination of the three locations and subclinical VFs $\geq 25 \%$ (Table 2 and 3, Fig. 2). ROC analysis comparing P-UE versus DXA/ VFA outcomes showed an optimal AUC of $78.4 \%$ at a DI of $0.837 \mathrm{~g} / \mathrm{cm}^{2}$, which is almost equivalent to manufacturers' recommended DI $0.844 \mathrm{~g} / \mathrm{cm}^{2}$. However, the aim of the study was not to test accuracy of P-UE but to identify a specific DI threshold that covers optimal balance between true negative and false negative test results as compared to the results generated by DXANFA. The lowest DI threshold reported here was the manufacturers' recommended DI of $0.844 \mathrm{~g} / \mathrm{cm}^{2}$ followed by a range of higher DI cut-off steps up to $0.896 \mathrm{~g} / \mathrm{cm} 2$. Using the composite DXA at all sites/ VFA measure (DXAVFAALL; see table 3 ) a calculated range of true negative and false negative results is shown in table 4 . In this single center FLS cross-sectional study and according to current definition we found true and false test negative outcomes to be optimally balanced at a DI cut-off of $0.896 \mathrm{~g} / \mathrm{cm} 2$. By doing so, we found $18.3 \%$ true negative and $1 \%$ false negative P-UE tests. This higher DI as compared to recommendation enables safely the identification of a substantial proportion of women who may be in no need for DXANFA referral. However, prospective studies 
are further needed. This pilot study was performed in a small FLS group of women among 50 to 70 years of age, assuming that the prevalence of subclinical VFs was not very high in this group of women and that it therefore could be of additional value to perform screening with a peripheral device in this group of women. By doing so, the prevalence of osteoporosis was $40 \%$ and of one or more subclinical VFs $8 \%$, which is similar to previous Dutch studies and also to a UK cohort $[15,24,36]$.

It is of note that the attendance rate in most FLSs is only around $50 \%$ of all patients with a fracture regardless of face-to-face patient information and of FLS invitations by letter afterwards $[8,36]$. Besides the fact that $18.3 \%$ of women had a true negative test based on DI of $0.896 \mathrm{~g} / \mathrm{cm} 2$ and may be confidently not in need for DXA/VFA, there may be another advantageous aspect of immediate post-fracture screening with a mobile device. A 'positive' Bindex test could promote the awareness for having a condition in order to motivate them for further assessment at the FLS. In fact, of the women with a DI $\leq 0.896 \mathrm{~g} / \mathrm{cm} 2,50 \%$ had osteoporosis and/or a VF. Screening may, therefore, be promising to encourage a proportion of individuals to attend the FLS, who would have decided otherwise not to attend the FLS [8]. This easy to operate hand-held non-ionizing tool offers an important opportunity as it can be used during the early stages of fracture care, being the optimum moment when the patient realizes that there might be a problem with skeletal health.

This study has several limitations. First, it was conducted in a small group of women of 50-70 years and not among older women and men. FLS attendance was again confirmed to be low. Therefore, the results cannot be extrapolated to elderly women or men. Second, the percentage of osteoporosis was higher than expected. Third, the number of subclinical VFs was smaller than expected, the prevalence of grade II and III VFs increases with age $[24,25]$. This low number as found may be a confounder in the interpretation of the results. However, the higher the prevalence of patients with osteoporosis or subclinical VFs, the lower will be the proportion of subjects that is correctly excluded for DXANFA referral. Secondly, data were obtained from FLS attenders and not from FLS non-attenders. FLS attenders who were requested to consent with a scientific study are probably different from FLS non-attenders [36]. Since this study was post-hoc analyzed this discrepancy may have caused selection bias. Therefore, further studies in a complete consecutive cohort of patients of 50 years and older including men with a recent fracture are needed. In addition, it has to be further studied whether the screening approach would result in a higher FLS attendance. Finally, this is a single-FLS study; comparisons with and experiences from other FLS centers are still needed. 
In conclusion, based on specific P-EU thresholds, a substantial proportion of women between 50 and 70 years with a recent NVF could confidently not be referred for further assessment with DXANFA. Moreover the strategy of immediate screening during post-fracture care may help to improve FLS attendance and DXANFA testing in patients with a positive screening outcome. 


\section{References}

1. Akesson K, Marsh D, Mitchell PJ, McLellan AR, Stenmark J, Pierroz DD, Kyer C, Cooper C (IOF Fracture Working Group). Capture the Fracture ${ }^{\circledR}$ : a Best Practice Framework and global campaign to break the fragility fracture cycle. Osteoporos Int. 2013 24(8):2135-52. doi: 10.1007/ s00198-013-2348-z.

2. Javaid MK, Kyer C, Mitchell PJ, et al (2015) Effective secondary fracture prevention: implementation of a global benchmarking of clinical quality using the IOF Capture the Fracture ${ }^{\circledR}$ Best Practice Framework tool. Osteoporos Int 26:2573-2578 . doi: 10.1007/s00198-015-3192-0.

3. Eisman JA, Bogoch ER, Dell R, Harrington JT, McKinney RE Jr, McLellan A, Mitchell PJ, Silverman $\mathrm{S}$, Singleton R, Siris E. Making the first fracture the last fracture: ASBMR task force report on secondary fracture prevention. J Bone Miner Res. 2012 Oct;27(10):2039-46. doi: 10.1002/ jbmr.1698.

4. Hauger AV, Bergland A, Holvik K, Ståhle A, Emaus N, Strand BH. Osteoporosis and osteopenia in the distal forearm predict all-cause mortality independent of grip strength: 22-year follow-up in the population-based Tromsø Study. Osteoporos Int. 2018 Nov;29(11):2447-2456. doi: 10.1007/ s00198-018-4653-z.

5. Bliuc D, Alarkawi D, Nguyen T V, et al. Risk of Subsequent Fractures and Mortality in Elderly Women and Men with Fragility Fractures with and without Osteoporotic Bone Density: The Dubbo Osteoporosis Epidemiology Study. J Bone Miner Res 2015 30:637-646 . doi: 10.1002/jbmr.2393.

6. McLellan AR, Gallacher SJ, Fraser M, McQuillian C. The fracture liaison service: success of a program for the evaluation and management of patients with osteoporotic fracture. Osteoporos Int. 2003 Dec;14(12):1028-34.

7. Lems WF, Dreinhöfer KE, Bischoff-Ferrari H, Blauth M, Czerwinski E, da Silva J, Herrera A, Hoffmeyer P, Kvien T, Maalouf G, Marsh D, Puget J, Puhl W, Poor G, Rasch L, Roux C, Schüler S, Seriolo B, Tarantino U, van Geel T, Woolf A, Wyers C, Geusens P. EULAR/EFORT recommendations for management of patients older than 50 years with a fragility fracture and prevention of subsequent fractures. Ann Rheum Dis. 2017 May;76(5):802-810. doi: 10.1136/annrheumdis-2016-210289.

8. van den Berg P, Schweitzer DH, van Haard PMM, van den Bergh JP, Geusens PP. Meeting international standards of secondary fracture prevention: a survey on Fracture Liaison Services in the Netherlands. Osteoporos Int. 2015 Sep;26(9):2257-63. doi: 10.1007/s00198-015-3117-y.

9. Eekman DA, van Helden SH, Huisman AM, Verhaar HJ, Bultink IE, Geusens PP, Lips P, Lems WF. Optimizing fracture prevention: the fracture liaison service, an observational study. Osteoporos Int. 2014 Feb;25(2):701-9. doi: 10.1007/s00198-013-2481-8.

10. Luc M, Corriveau H, Boire G, Filiatrault J, Beaulieu MC, Gaboury I. Patient-Related Factors Associated with Adherence to Recommendations Made by a Fracture Liaison Service: A MixedMethod Prospective Study. Int J Environ Res Public Health. 2018 May 9;15(5). pii: E944. doi: 10.3390/ijerph15050944.

11. Giangregorio L, Thabane L, Cranney A, Adili A, deBeer J, Dolovich L, Adachi JD, Papaioannou A. Osteoporosis knowledge among individuals with recent fragility fracture. Orthop Nurs. 2010 MarApr;29(2):99-107. doi: 10.1097/NOR.0b013e3181d2436c. PMID: 20335769.

12. Grover ML, Edwards FD, Chang YH, Cook CB, Behrens MC, Dueck AC. Fracture risk perception study: patient self-perceptions of bone health often disagree with calculated fracture risk. Womens Health Issues. 2014 Jan-Feb;24(1):e69-75. doi: 10.1016/j.whi.2013.11.007. PMID: 24439949.

13. Drew, A. Judge, C. Cooper, M. K. Javaid, A. Farmer, and R. Gooberman-Hill. Secondary prevention of fractures after hip fracture: a qualitative study of effective service delivery. Osteoporos Int. 
2016; 27: 1719-1727. doi: 10.1007/s00198-015-3452-z.

14. Johansson H, Siggeirsdóttir K, Harvey NC, Odén A, Gudnason V, McCloskey E, Sigurdsson G, Kanis JA. Imminent risk of fracture after fracture. Osteoporos Int. 2017 Mar;28(3):775-780. doi: 10.1007/s00198-016-3868-0.

15. van der Velde RY, Wyers CE, Geusens PPMM, van den Bergh JPW, de Vries F, Cooper C, van de Staa TP, Harvey NC. Incidence of subsequent fractures in the UK between 1990 and 2012 among individuals 50 years or older. Osteoporos Int. 2018 Nov;29(11):2469-2475. doi: 10.1007/s00198018-4636-0.

16. Pisani P, Renna MD, Conversano Casciaro E, Muratore M, Quarta E, Paola MD, Casciaro S. Screening and early diagnosis of osteoporosis through $\mathrm{X}$-ray and ultrasound based techniques. World J Radiol. 2013 Nov 28;5(11):398-410. doi: 10.4329/wjr.v5.i11.398.

17. Holmberg T, Bech M, Gram J, Hermann AP, Rubin KH, Brixen K. Point-of-Care Phalangeal Bone Mineral Density Measurement Can Reduce the Need of Dual-Energy X-Ray Absorptiometry Scanning in Danish Women at Risk of Fracture. Calcif Tissue Int. 2016 Mar;98(3):244-52. doi: 10.1007/s00223-015-0084-4.

18. Thomsen K, Jepsen DB, Matzen L, Hermann AP, Masud T, Ryg J. Is calcaneal quantitative ultrasound useful as a prescreen stratification tool for osteoporosis? Osteoporos Int. 2015 May;26(5):145975. doi: 10.1007/s00198-014-3012-y.

19. Hans D, Baim S. Quantitative Ultrasound (QUS) in the Management of Osteoporosis and Assessment of Fracture Risk.J Clin Densitom. 2017 Jul - Sep;20(3):322-333. doi: 10.1016/j. jocd.2017.06.018

20. Karjalainen JP, Riekkinen O, Töyräs J, et al. Multi-site bone ultrasound measurements in elderly women with and without previous hip fractures. Osteoporos Int 2012 23:1287-95 . doi: 10.1007/ s00198-011-1682-2.

21. Karjalainen JP, Riekkinen $O$, Töyräs J, Jurvelin JS, Kröger $H$. New method for point-of-care osteoporosis screening and diagnostics. Osteoporos Int. 2016 Mar;27(3):971-977. doi: 10.1007/ s00198-015-3387-4.

22. Schousboe JT, Riekkinen O, Karjalainen J. Prediction of hip osteoporosis by DXA using a novel pulse-echo ultrasound device. Osteoporos Int 2017 28:85-93. doi: 10.1007/s00198-016-3722-4.

23. Schneider J, Ramiandrisoa D, Armbrecht G, Ritter Z, Felsenberg D, Raum K, Minonzio JG. In Vivo Measurements of Cortical Thickness and Porosity at the Proximal Third of the Tibia Using Guided Waves: Comparison with Site-Matched Peripheral Quantitative Computed Tomography and Distal High-Resolution Peripheral Quantitative Computed Tomography. Ultrasound Med Biol. 2019 May;45(5):1234-1242. doi: 10.1016/j.ultrasmedbio.2019.01.008.

24. van der Velde RY, Bours SPG, Wyers CE, Lems WF, Geusens PPMM, van den Bergh JPW. Effect of implementation of guidelines on assessment and diagnosis of vertebral fractures in patients older than 50 years with a recent non-vertebral fracture. Osteoporos Int. 2017 Oct;28(10):30173022. doi: 10.1007/s00198-017-4147-4.

25. Lötters FJ, van den Bergh JP, de Vries F, Rutten-van Mölken MP. Current and Future Incidence and Costs of Osteoporosis-Related Fractures in The Netherlands: Combining Claims Data with BMD Measurements. Calcif Tissue Int. 2016 Mar;98(3):235-43. doi: 10.1007/s00223-015-0089-z.

26. https://www.sheffield.ac.uk/FRAX/ Assessed 10-11-2019.

27. https://www.nice.org.uk/advice/mib106/resources/bindex-for-investigating-suspectedosteoporosis-pdf-2285963217659077 Assessed 10-11-2019.

28. Dutch Institute for Healthcare Improvement CBO (2011) Richtlijn Osteoporose en Fractuurpreventie. www.diliguide.nl/document/1015/file/pdf/. (Dutch) Assessed 14-02-2019. 
29. Warriner A ea. Minor, major, low-trauma, and high-trauma fractures: what are the subsequent fracture risks and how do they vary? Curr. Osteoporos Rep. 2011 Sep;9(3):122-8. doi: 10.1007/ s11914-011-0064-1.

30. Genant HK, Jergas M, Palermo L, et al. Comparison of semiquantitative visual and quantitative morphometric assessment of prevalent and incident vertebral fractures in osteoporosis. J Bone Miner Res 2009 11:984-996 . doi: 10.1002/jbmr.5650110716.

31. Eneh CT, Malo MK, Karjalainen JP, Liukkonen J, Töyräs J, Jurvelin JS. Effect of porosity, tissue density, and mechanical properties on radial sound speed in human cortical bone. Med Phys. 2016 May;43(5):2030. doi: 10.1118/1.4942808.

32. Hallgren KA. Computing Inter-Rater Reliability for Observational Data: An Overview and Tutorial. Tutor Quant Methods Psychol. 2012;8(1):23-34

33. R Development Core Team (version 3.5.2; 2018). R: A language and environment for statistical computing. R Foundation for Statistical Computing, Vienna, Austria. ISBN 3-900051-07-0, URL http://www.R-project.org.

34. DeLong ER, DeLong DM, Clarke-Pearson DL. Comparing the areas under two or more correlated receiver operating characteristic curves: a nonparametric approach. Biometrics (1988) 44, 837-845.

35. Youden, W.J. Index for rating diagnostic tests. Cancer 1950 3: 32-35. doi:10.1002/1097-0142; 3:1<32::aid-cncr2820030106>3.0.co;2-3.

36. van den Berg P, van Haard PMM, Geusens PP, van den Bergh JP, Schweitzer DH. Challenges and opportunities to improve fracture liaison service attendance: fracture registration and patient characteristics and motivations. Osteoporos Int. 2019 May 25. doi: 10.1007/s00198-019-05016-4. 
The use of Pulse-Echo Ultrasound in women with a recent non-vertebral fracture 



\section{CHAPTER 7}

\section{A dedicated Fracture Liaison Service telephone program and use of bone turnover markers for evaluating one-year persistence with Oral Bisphosphonates}

Peter van den Berg (1)*, Paul M.M. van Haard (2), Eveline van der Veer (3), Piet P. Geusens (4), Joop P. van den Bergh (5), Dave H. Schweitzer (6).

1. Dept. of Orthopedics and Surgery, Fracture Liaison Service, Reinier de Graaf Hospital, Delft, the Netherlands.

2. Dept. of Medical Laboratories, Association of Clinical Chemistry, Reinier the Graaf Hospital, Delft, the Netherlands

3. Laboratory Medicine, University Medical Centre, Groningen, the Netherlands

4. Dept. of Internal Medicine, Subdivision Rheumatology, Maastricht University Medical Center, Maastricht, the Netherlands and Hasselt University, Hasselt, Belgium

5. Dept. of Internal Medicine, VieCuri Medical Centre Noord-Limburg and Dept. of Internal Medicine, Subdivision Rheumatology, Maastricht University Medical Center, Maastricht, the Netherlands

6. Dept. of Internal Medicine and Endocrinology, Reinier the Graaf Hospital, Delft, the Netherlands.

* Corresponding author E-Mail: pberg@rdgg.nl

Tel.: +31 152604926; Fax: +31 152605982

Keywords: Alendronate, Capture the Fracture® Best Practice Framework, Medication dispensation, s-CTX, P1NP, Pharmacy Deliveries. 


\title{
Mini-abstract
}

Telephone call intervention did not improve alendronate persistence in FLS patients in this study. A bone turnover marker cut-off point for alendronate persistence is proposed for individual FLS patients.

\begin{abstract}
Introduction

A Fracture Liaison Service (FLS) aims to prevent subsequent fractures, which should include improving patients' persistence with prescribed oral bisphosphonates. We studied the influence of telephone calls and the predictive value of changes in bone turnover markers (BTMs) for evaluating persistence with alendronate.
\end{abstract}

\section{Methods}

Postmenopausal women with a recent fracture and osteoporosis who started alendronate were randomized to receive three Phone Calls (PC) (after 1, 4 and 12 months) or No Phone Calls (no PC). S-CTX and PINP were measured at baseline and after 3, 6, 9 and 12 months. As a reference group, thirty postmenopausal osteopenic patients with a recent fracture were analyzed as well. Persistence was assessed using the Dutch National Switch Point Pharmacies-GPs database and cross-referenced with PC, no PC and BTM changes. Cut-off values of BTMs were calculated based on least significant change (LSC) and also on underrunning median values of the untreated osteopenic postmenopausal reference group with a recent fracture.

\section{Results}

Out of 119 patients, 93 (78\%) completed 12 months follow-up (45 PC and 48 No PC). Mean age was 69 years. Persistence was similar in PC and no PC participants. The cut-off value $>29 \%(<415 \mathrm{ng} / \mathrm{L})$ as LSC of s-CTX and $>36 \%(<53,1 \mu \mathrm{g} / \mathrm{L})$ as LSC of PINP was determined optimally showing alendronate persistence after one year (being 93 and $88 \%$ respectively). 


\section{Conclusions}

In this context, telephone calls did not improve persistence. In around 90\% of patients, one-year alendronate persistence was confirmed by achieving LSC of S-CTX and of PINP at 12 months.

\section{Conflicts of Interest.}

Peter van den Berg, Paul van Haard, Eveline van der Veer, Piet Geusens, Joop van den Bergh, and Dave Schweitzer declare that they have no conflict of interest.

\section{ACKNOWLEDGMENTS}

The authors are grateful to Lisette van Hulst for her critical linguistic advice, to Wil Aarssen, Erica Smit and Tina Polko for their excellent secretarial services, to Luc Huijskes for his support with programming the study database and to Hannette Kamminga at the UMCG Laboratory. This study was funded by an unrestricted grant of Novartis.

\section{Introduction}

The Fracture Liaison Service (FLS) is advocated as the most appropriate approach for secondary fracture prevention in patients with osteoporosis [1,2]. Besides successful prevention of subsequent fractures, FLS activities have been shown to reduce mortality [3]. The FLS concept and its necessity were first reported by the Glasgow group $[4,5]$. The concept includes full diagnostic evaluation with a focus on detecting underlying disorders and determining the appropriate tailor-made treatment. The International Osteoporosis Foundation (IOF) introduced the Capture The Fracture ${ }^{\circledR}$ (CtF) Best Practice Framework (BPF), which consists of 13 standards for evaluating the performance of any FLS, however not including telephone intervention nor taking lab samples for BTMs.[6]. The current study pertains to BPF standard 12, i.e. to ascertaining what processes are in place to ensure that long-term management of fracture risk is reliably provided [6].

Recently, inventories on CtF criteria analyzed FLS qualities worldwide [7-9], and our own group reported nationwide on 24,418 Dutch patients [10]. The principal weakness was an FLS attendance of 49\% [10]. Notably, all recent fracture patients older than 
50 received invitations for follow-up in line with the Dutch Guideline on Osteoporosis and Falls [11]. Besides low numbers of patients attending, a second concern is the low persistence with treatments. In the Netherlands, a nationwide survey of medication dispensation showed up to $40 \%$ persistence for anti-osteoporosis medication during 12 months [12]. These findings were obtained from the medication dispensation database on osteoporosis medication, which was generated by IMS Health based on Dutch nationwide data of most pharmacies' sales to patients. Contrarily, a recent study indicated a much higher persistence of $75 \%$ in patients with a recent fracture [13]. Therefore, we hypothesized that persistence in recently fractured patients may be improved by means of telephone calls during the first year of follow-up. Telephone initiatives to improve persistence with bisphosphonates have been tested previously, yet not in patients attending FLS [14-26] (Table 1).

In this study, the primary objective was to compare the effect of a dedicated telephone call intervention with standard FLS care on persistence with bisphosphonates at 12 months. The secondary objective was to analyze if BTMs are markers of persistence verified by pharmacy deliveries in LSP. 


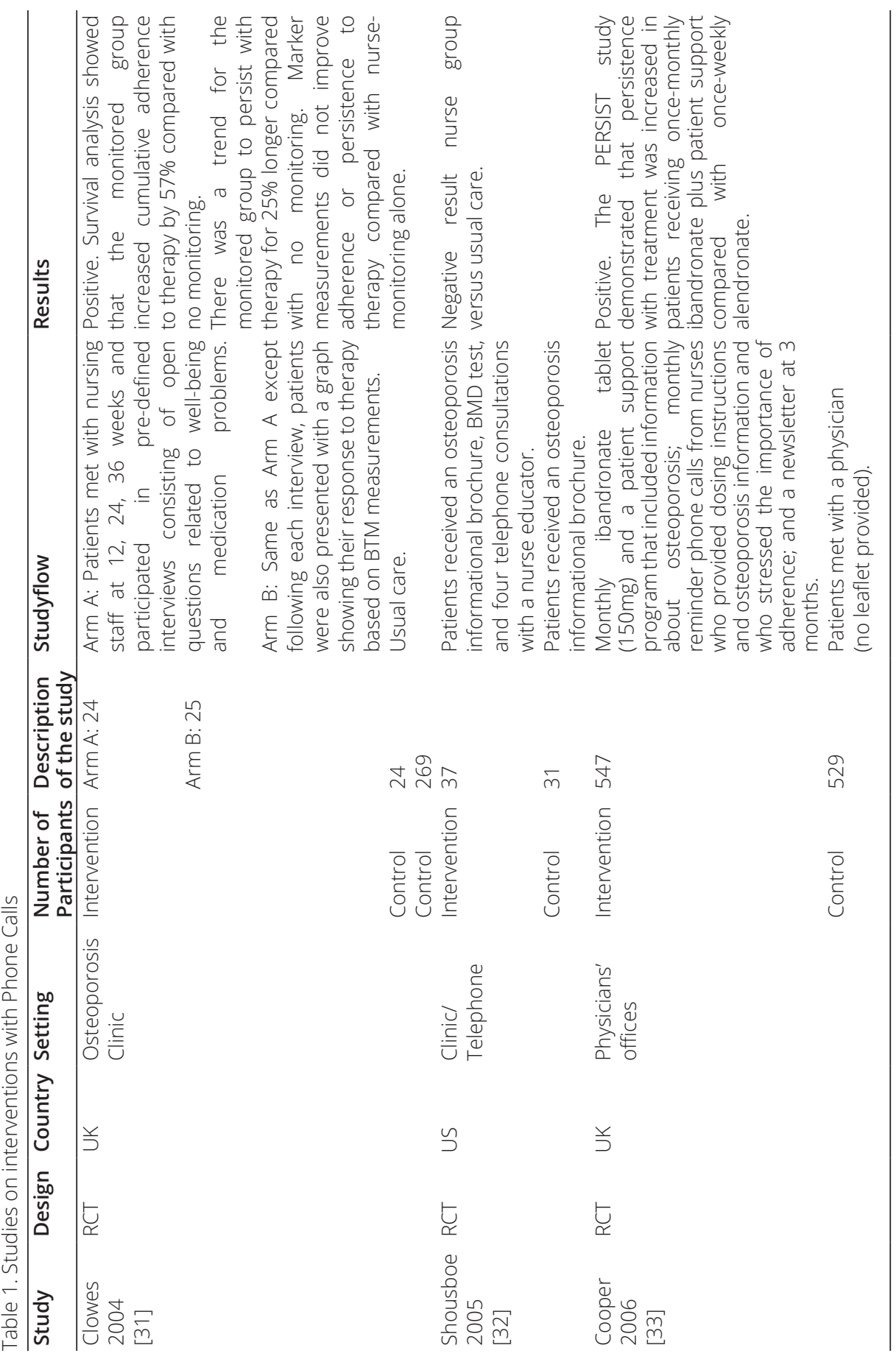




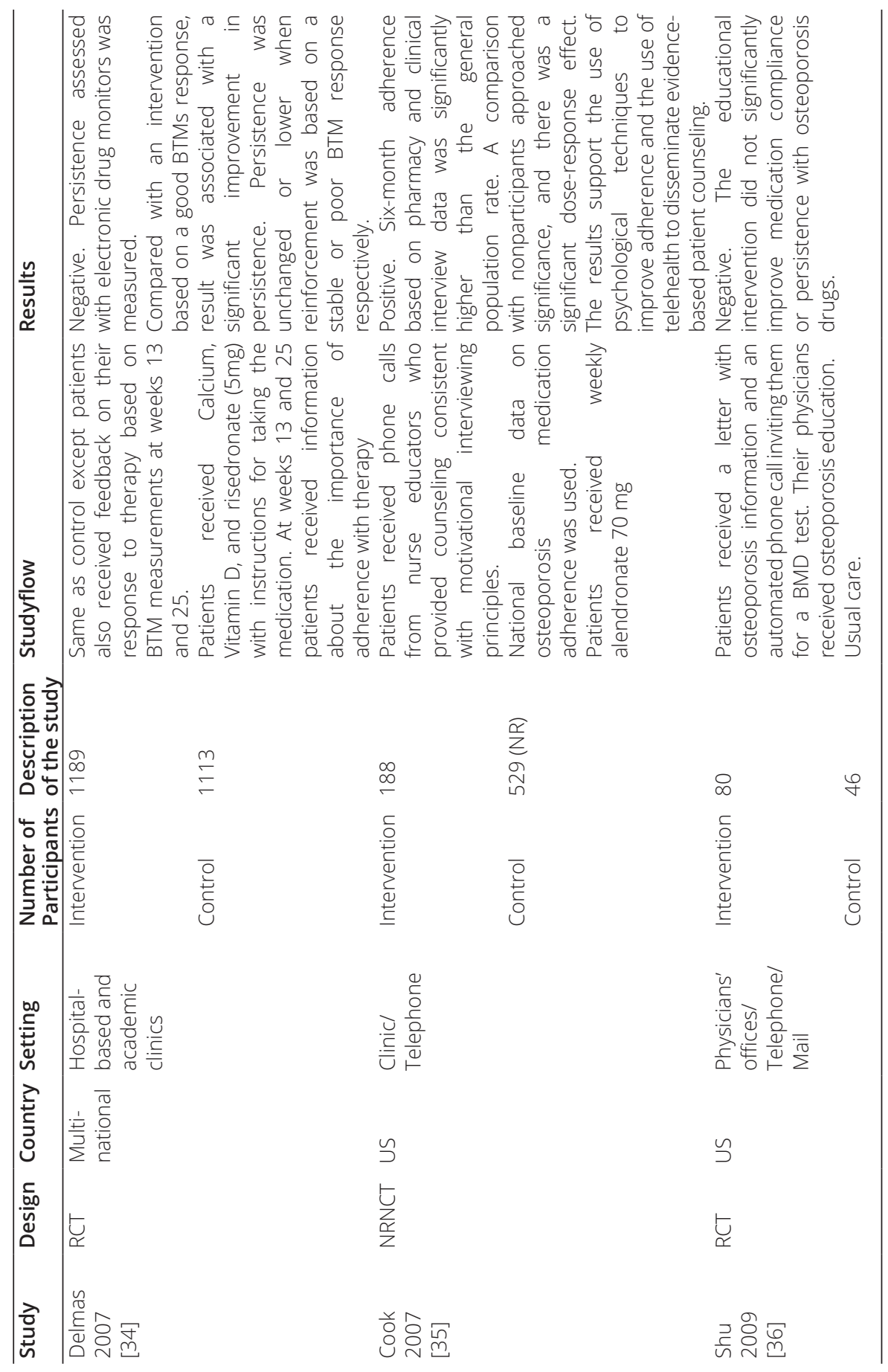




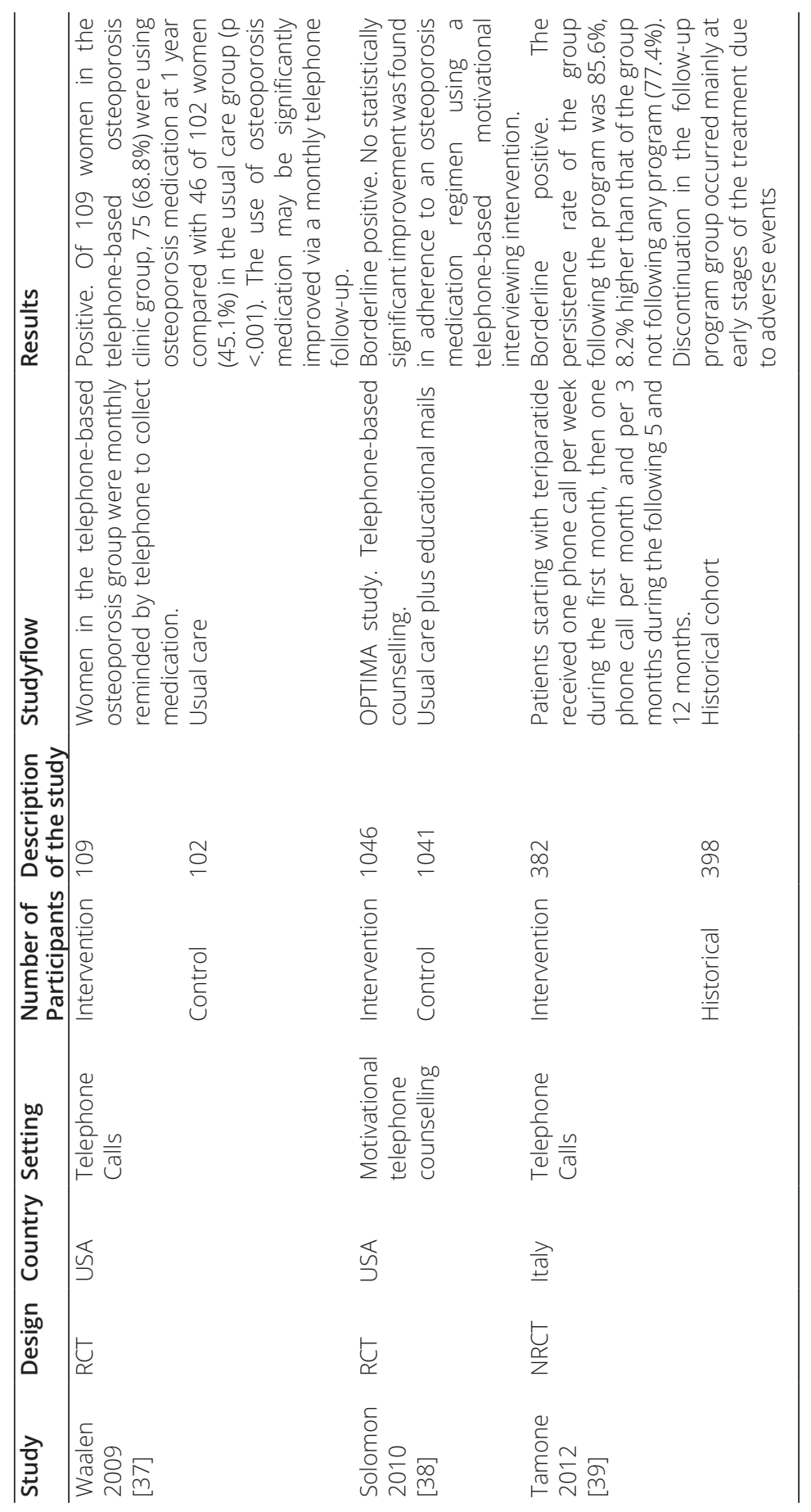




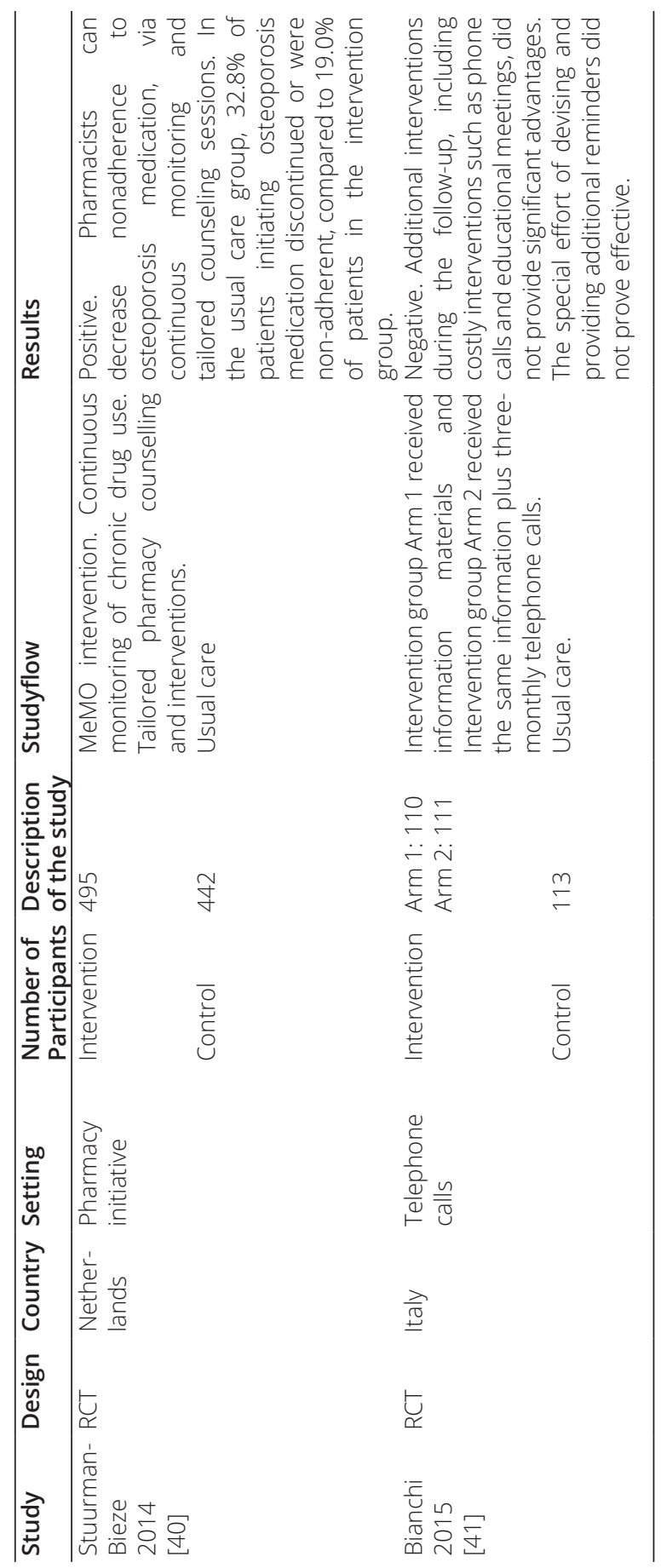




\section{Patients and methods}

\section{Study procedure}

Consecutive female patients who attended the FLS due to a recent non-vertebral or clinical vertebral fracture were included if they were 50 years or older. In each patient, treatment was initiated in line with the Dutch Guideline on Osteoporosis and Falls [11]. This guideline recommends treatment in case of a T-score of - 2.5 *SD or less, or a T-score between -1.0 and 2.5*SD and prevalent vertebral fractures on Vertebral Fracture Assessment (VFA). Patients were excluded in case of metabolic bone disorders. Vitamin D deficiency without secondary hyperparathyroidism was not an exclusion criterion.

All patients with osteoporosis and osteopenia received FLS standard care, including lifestyle and nutrition education according to the Dutch National Guideline [11]. Patients with vitamin D deficiency $(<50 \mathrm{nmol} / \mathrm{l})$ were prescribed a daily dose of calcium (500 mg) and vitamin D3 (800 IU)[11]. Each patient received alendronate 70 mg once weekly.

After obtaining informed consent, patients who agreed to participate in the study were randomized to either Phone Calls intervention (PC) or no Phone Calls (No PC). Besides, we selected a reference group of thirty postmenopausal osteopenic patients with a recent fracture to observe the course of BTMs during fracture repair. In all patients in the randomized groups and in the reference group, blood was drawn for BTM assessment at study start and after 3, 6, 9, and 12 months. Patients in the PC group were called after 1, 4 and 12 months. All telephone calls were made by the same experienced FLS nurse. These calls were particularly meant to remind patients not to forget medication and to exchange views about side effects. In case of clear evidence of drug intolerance, patients were withdrawn from the study and alternative treatments were offered. 
Fig 1. Study Flowchart

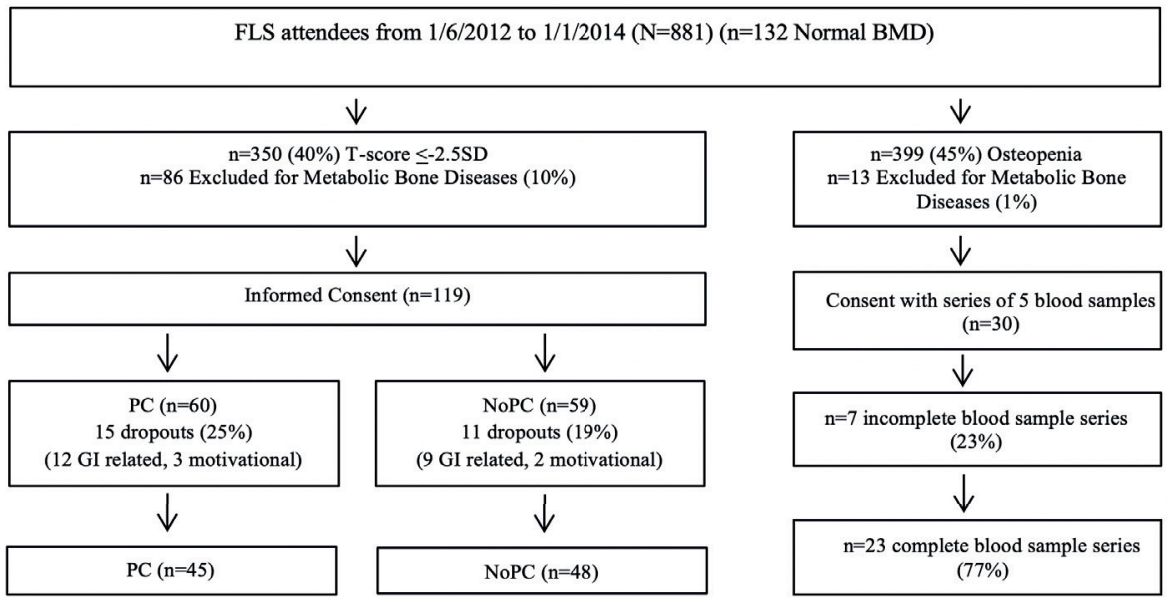

\section{Bone density measurement and VFA}

A patient was diagnosed with osteoporosis if she fulfilled the WHO criteria for osteoporosis (a T-score of $\leq-2.5 S D$ at the total hip, femoral neck or lumbar spine) or if she had had at least one vertebral fracture and a loss of height of more than $25 \%$ on radiography or of more than 40\% on VFA, according to Genant's classification [27]. Criteria for osteopenia were a T-score between -1.0 and - 2.5SD at the lumbar spine and/or hip and no morphometric abnormalities (Hologic DXA equipment, Hologic Discovery QDR Series).

\section{Bone Turnover Markers (BTMs)}

P1NP was measured by means of radioimmunoassay (RIA; Orion Diagnostica, Espoo, Finland), and S-CTX by means of electrochemiluminescence immunoassay (ECLIA; Elecsys 2010 Roche Mannheim, Germany). Fasting serum samples were stored frozen at $-20^{\circ} \mathrm{C}$ within one hour after blood sampling until analysis. P1NP and S-CTX were assayed and expressed in concentrations and in z-scores, using a Dutch Reference Values Group (350 women older than 50) [28]. Blood collection took place at baseline (study start) and after 3, 6, 9 and 12 months, and all samples were finally sent off as one batch for analysis at the laboratory of the University Medical Centre, Groningen, the Netherlands. 


\section{Evaluation of persistence with alendronate based on the Dutch National Exchange}

\section{Point Pharmacies-GPS. (LSP)}

After study completion, dispensation data of all participants were collected from the Dutch Landelijk Schakel Punt (LSP), translated in English as National Exchange Point Pharmacies-GPs.) [29] after verifying whether each patient had consented to the use of personalized data stored in this database. Since patients in the Netherlands are encouraged to store their identifiable healthcare and pharmacy data in the LSP, this database offers accurate information on prescriptions and data on deliveries, including the name of the pharmacy, the date of prescription, the number of prescribed tablets, the prescriber and the dosage regimen. Thus far, nationwide more than 11 million Dutch citizens (which is over $70 \%$ of the population) consented to giving access to LSP. Pharmacy staff are legally bound to request informed consent regarding the review of individual dispense data.

\section{Statistics}

Data were analyzed using Statgraphics Centurion XVII software (Version 17.1.08 for MS-Windows; Statpoint, Inc., Warrenton, VA, USA).

A power analysis was conducted using G*Power software (Germany, version 3.1) to determine the number of patients needed in this study. Two groups of women would have bisphosphonates prescribed. Sample sizes per group were estimated a priori for two-sided significance level alpha $=.05$ and Power $=80 \%$ using Fisher's exact test for unequal proportions in two independent groups. Proportions of patients (= \% medication compliant) with phone calls versus no phone calls were compared in the analysis: the first proportion was 40\% (no phone calls) and the second proportion was 70\% (phone calls). Compliancy was scored by calculating the biologically and statistically significant decrease (so-called Least Significant Change) in the two serum BTMs. The output indicated that 42 patients would be needed in each group to have a power of $80 \%$. These numbers were corrected by $15 \%$ both for non-parametric statistical tests and Losts-to-Follow-up: the final numbers of patients estimated were (rounded up) 50 per group. 


\section{Comparison of Phone Call (PC) vs. No Phone Call (No PC) intervention effects on}

\section{persistence}

We used a logistic regression model comparing the binominal variable Intervention $(P C=1 ;$ No $P C=0)$ and persistence with alendronate at 12 months (LSP Yes vs. No) as a binary outcome variable. Besides least significant change (LSC), other censors were studied using data from the reference group after showing statistical feasibility of pooling. The outcomes of LSC and censors applied in our FLS patients were compared to the LSC criterion proposed by the IOF/ECTS Working Group [30]. BTM levels and both the age- and gender-adjusted near-Gaussian z-scores were analyzed. BTMs and LSP results were analyzed separately according to time since fracture, study start and a fixed time of 180 days (as time outcome variables). For this, linear models were used analyzing BTMs at various time points with the fracture codes as categorical factors. Since the outcomes at these various timepoints were similar, we only report those at 180 days after fracture (see Fig.2). Measuring data of the reference group were repeated at the various time points and pooled for further analysis. Statistical changes between the BTM level or z-score at study start before treatment and after alendronate treatment were analyzed in order to find medication-compliant BTM measures in accordance with LSP Yes or No. The binominal censors explored were LSC, underrunning the Median estimates (< Median; abbr. MedREF) from the pooled BTM levels of the reference Group as previously described [31] and underrunning the calculated outcome BTM level of the Median after correction for outliers (< Median Absolute Deviation; abbr. MedMAD) [32]. Since near-Gaussian distribution was observed and tested for the BTM levels of the reference group at the various points in time, we applied a consistency factor of 1.4826. For this study, we used LSCs (95\% confidence, 2-sided) as previously reported for another Dutch cohort, i.e. Z-scores of 36\% for P1NP and 29\% for s-CTX [33]. Logistic regression was applied to estimate odds ratios and their 95\% confidence intervals, using completed medication dispensation at 12 months (LSP Yes or No) and BTMs and PC and No PC and the separate persistence parameter for both P1NP and s-CTX Yes=1;No=0) and fractures. Where applicable, a p-value of $p<.05$ was considered statistically significant at the 95\% confidence level. 


\section{Ethics}

The study with number NL 35164.098.11 was approved by the regional Medical Ethical Review Board (METC Zuidwest Holland) and was carried out in accordance with the declaration of Helsinki and the guidelines of the International Conference on Harmonization Good Clinical Practice (GCP). Written informed consent was obtained from all participants included in the study and in the reference group.

\section{Results}

From June 2012 to January 2014, 881 postmenopausal women that attended the FLS of the Reinier de Graaf Gasthuis, Delft, the Netherlands were evaluated: 350 (40\%) with osteoporosis, 399 (45\%) with osteopenia and 132 (15\%) with a normal T-score. Of the 350 osteoporotic patients, 119 (34\%; mean age 69.5yrs (range 5386)) consented to participate in our telephone intervention study. After withdrawal for several reasons, 45 completed the study in the PC group and 48 in the No PC group. Obviously, reasons for dropping-out were known in the PC group (12 patients dropped out for $\mathrm{Gl}$ reasons and 3 patients dropped out for motivational issues). In each case, dropping out did occur within the first 4 months of the study based on self-reporting. Other non-oral osteoporosis treatments were offered and accepted by 6 patients. In the NoPC group dropping out was registered in LSP at 12 months (LSP does not include documentation about the cases who dropped out from the study). Subsequently none of these patients received other osteoporosis medication.

Of 30 osteopenic reference group patients, 23 gave the adequate number of blood samples according to study protocol, see Fig 1. Base-line characteristics of all participants are listed in Table 2. 
Fig. 2 (2.1 - 2.6) P1NP and s-CTX z-scores versus Time Period 180 days post-fracture.

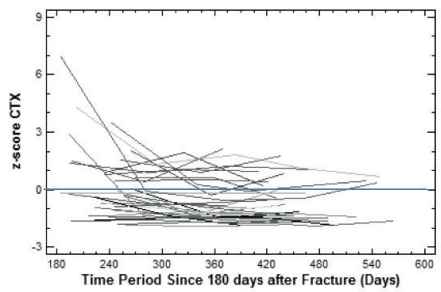

2.1 PC group

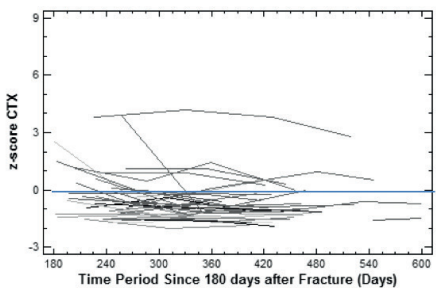

2.3 No PC group

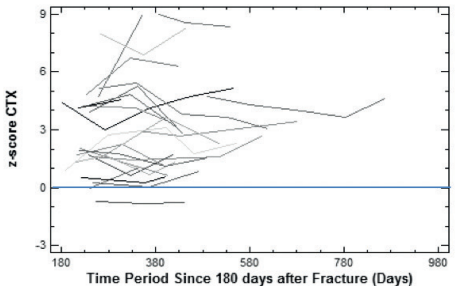

2.5 Reference group

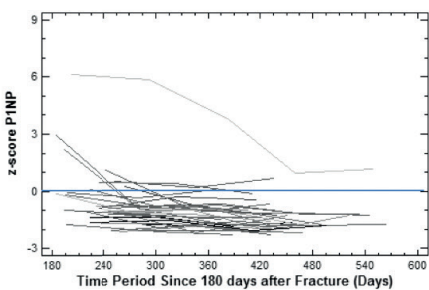

2.2 PC group

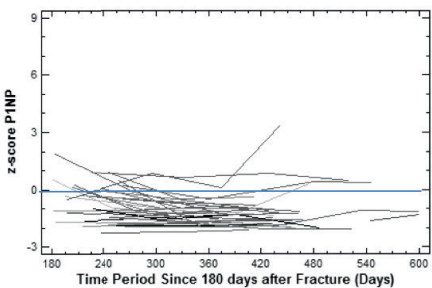

2.4 No PC group

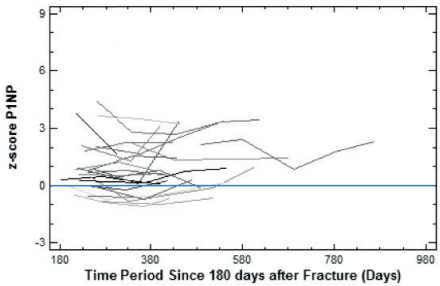

2.6 Reference group

Legenda:

Scatterplots of P1NP and s-CTX z-scores depicted at 180 days post-fracture. Each line represents an individual patient. Data of the PC group and the No PC group on alendronate are depicted in the upper panels (2.1 and 2.2) resp. the middle panels (2.3 and 2.4). Data of the post-menopausal reference group without alendronate therapy are depicted in the lower panels (2.5 and 2.6), Lines at $z$-Score $=0.0$ show the mean of the applied parametric 95\% Reference Interval. 


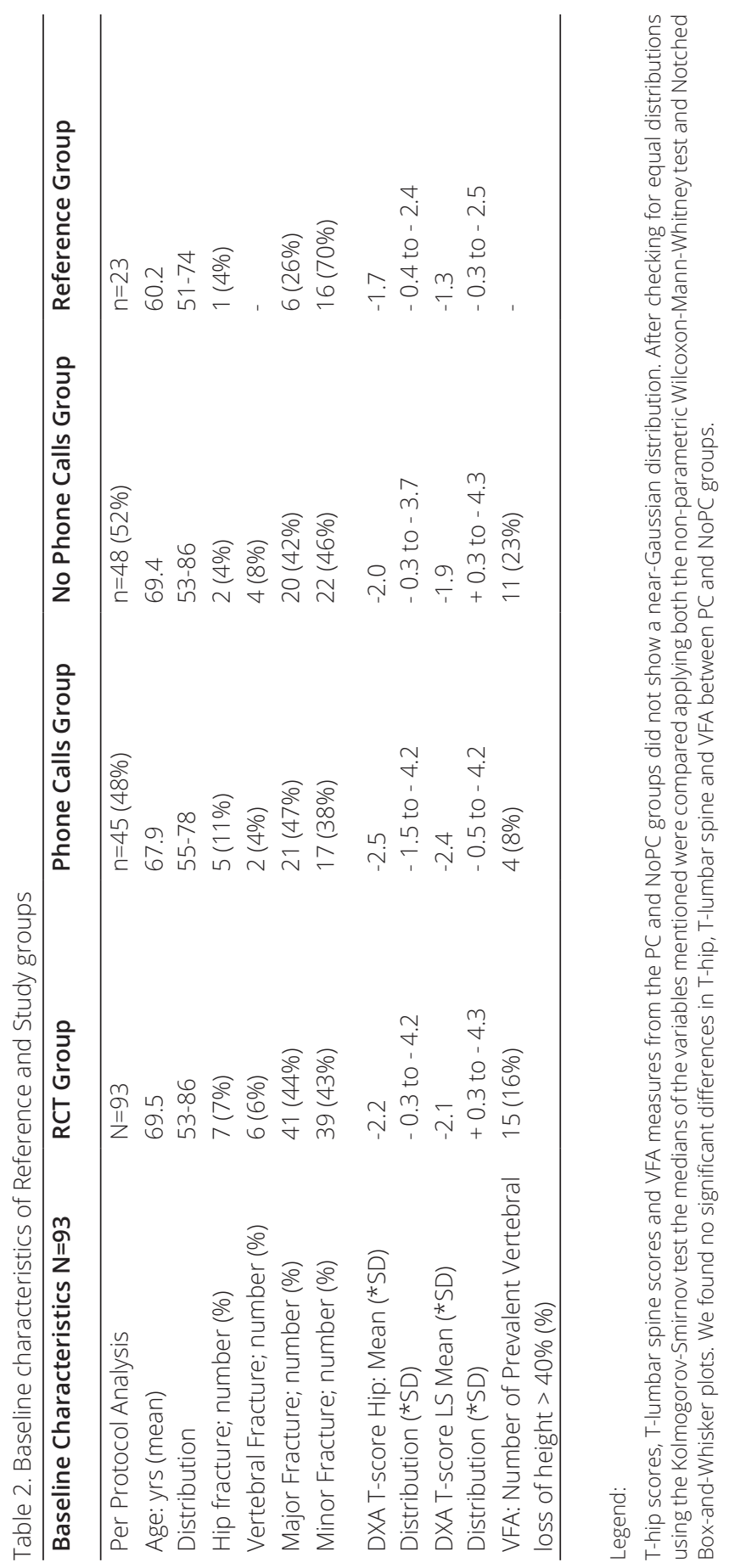




\section{$P C$ versus No $P C$}

Censors indicate significant bisphosphonate-induced lowering of the respective BTMs and were described as proportions at each point in time using Intention-To-Treat (ITT) $(n=119)$ and Per Protocol (PP) ( $n=93)$ analyses. LSP analysis according to ITT revealed: LSP PC: $71.2 \%$ and No PC: $67.9 \%$ ( $p>0.05)$.

Moreover, the 93 patients who completed the study (PP) also showed no significant difference in LSP between the PC group and the no PC group (PC: $75 \%$ and No PC: $76 \%, p>0.05)$.

\section{Bone Turnover Markers and LSP}

Logistic regression using the binominal variable intervention PC and No PC disclosed no significant relationship between intervention and LSP Yes or No, thus allowing data from both interventions to be combined ( $n=93)$. In this group analysis, we found an LSP Yes in more than 85\% (range 85-94) of those patients who had a P1NP decrease of more than 36\% LSC and an LSP Yes in nearly 100\% of those who had an S-CTX decrease of more than 29\% LSC. Looking for a single optimal BTM for persistence prediction, we compared previously reported LSCs and two other censors: Median of Reference group (MedREF) and Median Absolute Deviation of Reference group (MedMAD). (see Table 3). 


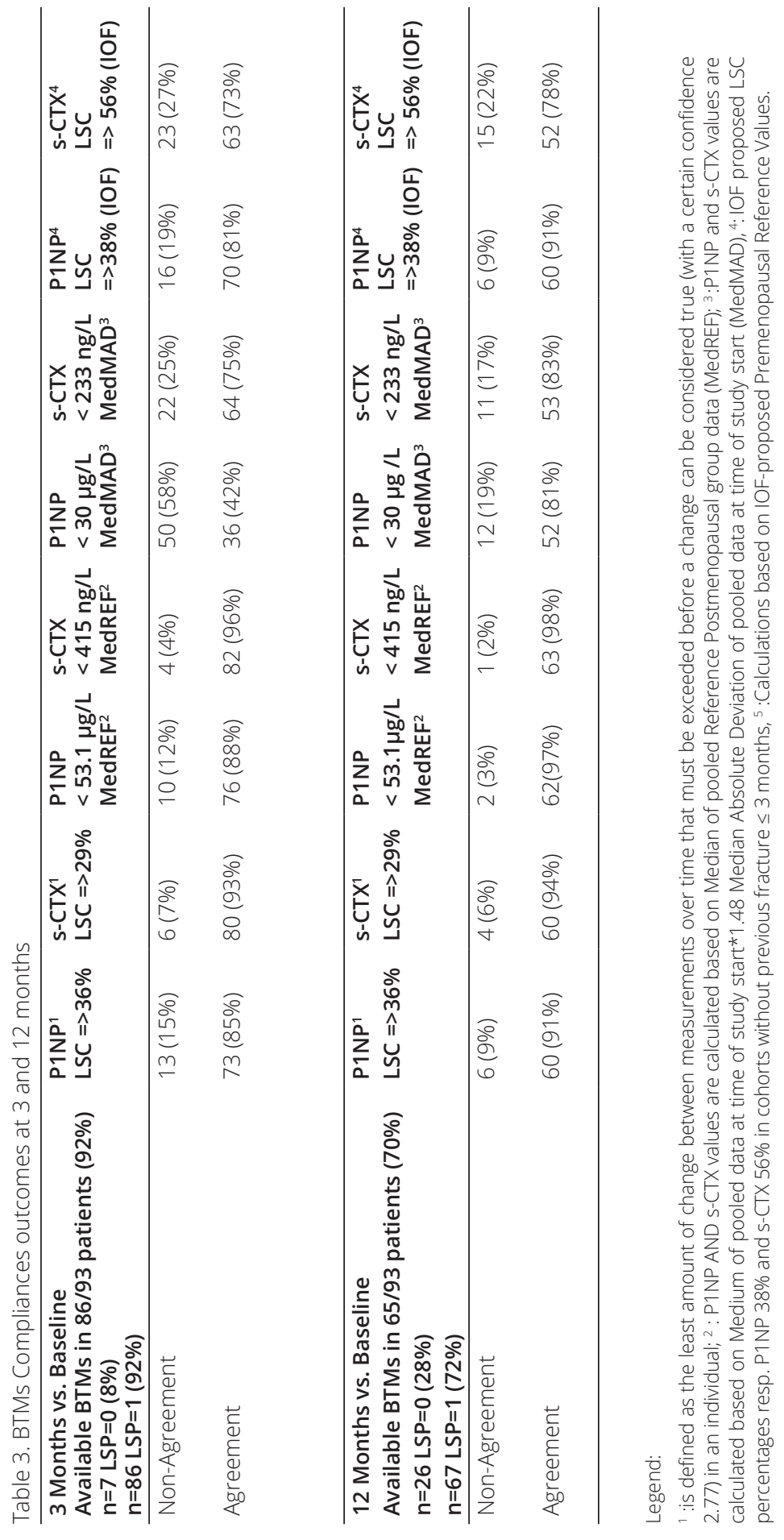


Listed data represent optimal LSC cut-off values for alendronate persistence at 12 months according to LSP for P1NP and S-CTX. The outcomes P1NP and S-CTX levels were expressed as identifiable patient numbers (Yes/No). Censors were expressed at 3 and 12 months after study start. Besides the data obtained in the current study, IOF recommended cut-off values were also listed (see Table 3) [30,34]. The results for PINP and s-CTX at 3,6,9 months are comparable with the 12 month results (data not shown). Using underrunning median values obtained from the reference group led to similar results, but only with use of the MedREF censor.

\section{Discussion}

In this study, we found no favorable effects of a dedicated telephone call intervention on standard care regarding persistence with bisphosphonates at 12 months. Note that this study was executed and analyzed within an FLS setting, which to our knowledge has not been studied before. This study as a whole encompasses real-life FLS practice with or without telephone calls and also BTMs for monitoring medication persistence per individual patient.

We were able to study persistence with BTMs for the analysis of identifiable pharmacy deliveries in the early post-fracture phase and at one-year follow-up. BTMs in the first 3 months post-fracture are notoriously hard to interpret because of the bias caused by fracture repair in this phase. As we are interested in the effects of treatment in that early post-fracture phase, we studied BTMs in the randomized study groups on alendronate and as a surplus in a group of postmenopausal osteopenic women (as a non-treated reference group) reflecting the natural course of BTMs post-fracture.

To substantiate BTMs and the pharmacy deliveries in the analysis of individual persistence, we cross-referenced the identifiable patients in our study groups to a Dutch exchange system on pharmacy deliveries (LSP). This system enables the exchange of healthcare data on pharmacy deliveries among authorized health care staff. First of all, the LSP system offers an overview of prescribed medication, but secondly it generates monitoring facilities of persistence, as nationwide more than 11 million Dutch citizens (which is over 70\% of the population) consented to giving healthcare staff access to their personal LSP data.

At the end of this study we found out firstly that telephone support of patients with an alendronate prescription after a recent fracture is not of importance regarding 
persistence, which was about 75\% (after exclusion of 26 patients who stopped taking bisphosphonates due to Gl-related complaints or motivational issues) in both the PC and the no PC groups at one year. This finding differs entirely from the persistence of $40 \%$ that was previously reported by Netelenbos and Geusens [12]. However, their study was based on the general osteoporotic population-based pharmacy deliveries of alendronate and is not a reflection of those patients starting alendronate soon after sustaining a fracture. Moreover, this difference in persistence could also be explained by the less intensive supervision of patients outside the closely monitored conditions of an RCT. Our findings are in line with the persistence of 74 to $88 \%$ found in the study on osteoporosis medication and persistence of Klop [13], who provided more differentiated data on persistence, taking a recent fracture into account as a discerning variable.

Although telephone interventions did not influence persistence in our study, an important favorable effect of these phone calls was that patients who stopped taking alendronate were identified at an early stage. Of the patients who recently started taking alendronate and then stopped, the majority reported GI side effects as reason for stopping this medication. Any undetected cessation of alendronate therapy should be considered an FLS failure, which might be prevented by telephone calls at an early stage and offering alternatives, such as liquid or non-oral medication.

Alendronate persistence is crucial in the long-term treatment for osteoporosis patients. Medication persistence in general regarding chronic conditions is reported to be low, and the World Health Organization (WHO) as well as the International Osteoporosis Foundation (IOF) declared the matter of persistence a major challenge to effective long-term management [35]. It is unfortunate that no effects of telephone intervention were confirmed. Finding no effects is, however, in line with other non-FLS initiated studies, see Table 1 [14-26,34].

Nevertheless, a number of FLS-initiated actions need to be taken to ensure persistence [36]. Firstly, personal encouragement of taking medication should continue shortly after any traumatic and painful event [37]. Secondly, it is important to try and solve the matter of underestimating the impact of sustaining a fracture and the low attendance of FLS patients, as we have shown previously in an FLS questionnaire study [11]. This low attendance at FLSS is a world-wide phenomenon, resulting in a major care gap. This notion was one of the main starting points for the CtF campaign.

For observing persistence after initiating alendronate, BTMs can be used. However, 
any biomarker used to monitor persistence may be influenced by fracture repair and bone union. Moreover, the effects of fracture repair could last for more than 800 days, as was shown by data of our untreated reference group ((Fig. 2 (2.4 and 2.5)). Therefore, we compared the course of BTMs since fracture, since start of study and also at 180 days post-fracture, based on data of the minimal wash-out period of fracture effects $[38,39]$. Notably, the outcomes at the various timepoints were similar. Our findings support the results of the previous TRIO study that compared the persistence with several oral bisphosphonates by assessing P1NP and s-CTX and found that the use of BTMs is feasible [36]. In addition, we studied the individual persistence and our study revealed a promising exactness for S-CTX at 3 months. Compared to s-CTX precision, the reliability of P1NP for individual persistence at 12 months is somewhat lower, as is shown in Table 3.

Notably, data of the current study are based on LSP outcomes per identifiable patient, while previous data were reported at group level. In general, persistence indicated via P1NP and s-CTX agreed fairly well for P1NP, i.e. 36\% (current study) vs. 38\% (TRIO study), but the LSC cut-off point for s-CTX was clearly low in the current study (29\% vs. $56 \%$ (TRIO study)). Note the importance of the time point at which the BTM samples were taken and of the patient's physical condition at that moment. In our study, blood samples for BTM analysis were taken in recent fracture patients. Our next step was to study individual persistence after correction for outlying data due to biological variations caused by the very long wash-out period of fracture and fracture repair. Besides the Median of the reference group (MedREF) to calculate underrunning BTMs on alendronate treatment, we also compared persistence after correction for outliers as calculated with the MedMAD (see statistical paragraph) with most commonly used LSCS. Reference group-derived censors were compared to rule out effects for existing skewness and kurtosis of alendronate BTMs suppression and to avoid statistical bias of existing outliers and small sample size. However, use of reference-group-derived censors revealed no improvement in the prediction of alendronate persistence.

Several LSC thresholds have been reported using automated as well as manual assays. Roche Elecsys as used for this study is a commercially available assay and is widely used. Previously reported LSC declines were s-CTX lower than 27\% and P1NP lower than 20\% [30]. Clearly different LSCs have also been reported for several bisphosphonates, those for alendronate ranging from 38\% to $56 \%[30,36]$. These variations make it questionable whether the percentages reported for the same 
bisphosphonate can also be ascribed to related factors, for example retrospective or prospective cohort analysis, ethnicity or time of fracture repair. Moreover, in previous studies calculations were based on patients with older osteoporotic fractures $[28,30,33,36]$. Therefore, we decided to study real-life outcome data from this RCT describing a prospective Dutch FLS treated group shortly after fracture using previously reported Dutch LSC cut-off levels.

In our study, the presumed cut-off values reflecting persistence were rather similar to those reported by Rogers [30], which were 28\% for P1NP and 25\% for s-CTX versus $36 \%$ and 29\%, respectively, in our study. Regarding our calculated cut-off values, assessment of s-CTX at 3 months revealed to be best predictive on BTMs for one-year alendronate persistence. In more detail, in our study, an LSC of S-CTX lower than 29\% or a level of less than $415 \mathrm{ng} / \mathrm{L}$ (MedREF) at 3 months agreed with nearly all except 7 non-delivery cases. By contrast, these s-CTX cut-offs failed in 4 LSP-confirmed deliveries, see Table 3.

Comparing our results with the IOF-proposed LSCS showed less favorable results on pharmacy deliveries. The IOF cut-off levels, however, were not based on osteoporotic women with recent fractures [30,36].

In comparison to the high agreement regarding LSCS for both the time points 3 and 12 months, similarity in results was found in using the reference-group-based censor MedREF (s-CTX <415 ng/L and P1NP <53 ug/L); at 3 and 12 months, S-CTX was 96\% and 98\% respectively, and P1NP was 76\% and 97\%, respectively.

By contrast, less agreement was found at 3 months using the reference-group-based censor corrected for outliers MedMAD (s-CTX lower than 233 ng/L and P1 NP lower than $30 \mu \mathrm{g} / \mathrm{L}$ ); this was $75 \%$ for S-CTX and $42 \%$ for P1NP, respectively, although the difference decreased at 12 months and went up to 83\% for S-CTX and 81\% for P1 NP. This study has some important limitations. Firstly, the sample size is fairly small but our results on the absence of effects of telephone calls are in our opinion robust and clear. A second limitation is the use of the non-treated reference group, which is small as well, but accepted statistical techniques such as pooling data made the outcome of the reference group useful and valuable, especially for the calculated MedREF and MedMAD besides LSC. Thirdly, a limitation worth mentioning may be the introduction of a potential Hawthorne effect (5 blood drawings) towards persistence.

An important strength of this study was the use of identifiable LSP data, which served as proxy for persistence with any medication, for example treatment with alendronate. 
To conclude, this FLS-initiated study showed an alendronate persistence of 75\% after correction for individuals who had to stop taking bisphosphonates. Telephone intervention did not have an add-on effect to alendronate persistence in this study, but offered the advantage of early detection of any reason for stopping medication. LSC, particularly that of s-CTX (compared to baseline BTMs level) after early drop-out (1 to 3 months) is a practical measure to be used in an FLS real-life situation to analyze persistence with alendronate after one year providing use of adequate cut-off points. The weakness of this study is that outcome results have been reported in a small number of patients. Therefore, more FLS studies are needed to strengthen LSC data while comparing outcomes for different treatments and different populations.

Fig 3. Algorithm on Alendronate Persistence Follow-up

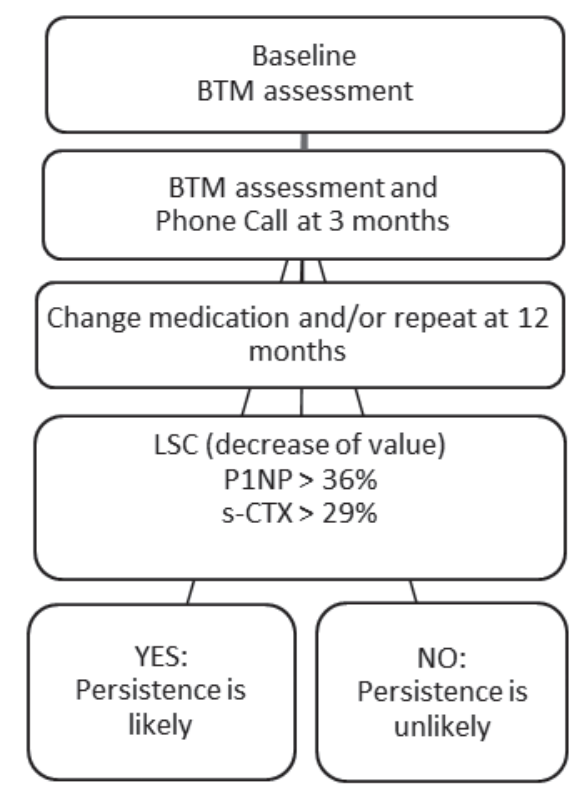

\section{Contributions.}

PVDB, DHS and PVH are responsible for the study design. EVDV analyzed the BTMs and provided Reference Intervals and z-scores. PVDB and DHS were the authors, strongly supported by PVH, who also performed all statistical analyses. PG and JVDB supported the process with important scientific contributions during the analyses. 


\section{References}

1. Eisman JA, Bogoch ER, Dell R, Harrington JT, McKinney RE Jr, McLellan A, Mitchell PJ, Silverman $\mathrm{S}$, Singleton R, Siris E. Making the first fracture the last fracture: ASBMR task force report on secondary fracture prevention. J Bone Miner Res. 2012 Oct;27(10):2039-46. doi: 10.1002/ jbmr.1698.

2. Lems WF, Dreinhöfer $K E$, Bischoff-Ferrari $H$, Blauth $M$, Czerwinski $E$, da Silva J, Herrera $A$, Hoffmeyer P, Kvien T, Maalouf G, Marsh D, Puget J, Puhl W, Poor G, Rasch L, Roux C, Schüler S, Seriolo B, Tarantino U, van Geel T, Woolf, Wyers C, Geusens P. EULAR/EFORT recommendations for management of patients older than 50 years with a fragility fracture and prevention of subsequent fractures. Ann Rheum Dis. 2016 Dec 22. pii: annrheumdis-2016-210289. doi: 10.1136/annrheumdis-2016-210289.

3. Huntjens KM, van Geel TA, van den Bergh JP, van Helden S, Willems P, Winkens B, Eisman JA, Geusens PP, Brink PR. Fracture liaison service: impact on subsequent nonvertebral fracture incidence and mortality. J Bone Joint Surg Am. 2014 19:96(4):e29. doi: 10.2106/JBJS.L.00223.

4. Marsh D, Akesson K, Beaton DE, Bogoch ER, Boonen S, Brandi ML, McLellan AR, Mitchell PJ, Sale JE, Wahl DA; IOF CSA Fracture Working Group. Osteoporos Int. 2011 22(7):2051-65. doi: 10.1007/ s00198-011-1642-X.

5. Svedbom A, Hernlund E, Ivergård, M Compston J, Cooper C, Stenmark J, McCloskey EV, Jönsson B, Kanis JA \& the EU review panel of the IOF Osteoporosis in the European Union: a compendium of country-specific reports. Arch Osteoporos. 2013 8:137 doi 10.1007/s11657-013-0137-0

6. Akesson K, Marsh D, Mitchell PJ, McLellan AR, Stenmark J, Pierroz DD, Kyer C, Cooper C (IOF Fracture Working Group). Capture the Fracture®: a Best Practice Framework and global campaign to break the fragility fracture cycle. Osteoporos Int. 2013 24(8):2135-52. doi: 10.1007/ s00198-013-2348-z.

7. Ganda K, Puech M, Chen JS, Speerin R, Bleasel J, Center JR, Eisman JA, March L, Seibel MJ (2013) Models of care for the secondary prevention of osteoporotic fractures: a systematic review and meta-analysis. Osteoporos Int. 24(2):393-406. doi: 10.1007/s00198-012-2090-y.

8. Mitchell PJ (2013) Best practices in secondary fracture prevention: fracture liaison services. Curr Osteoporos Rep. 11(1):52-60. doi: 10.1007/s11914-012-0130-3

9. Javaid MK, Kyer C, Mitchell PJ, Chana J, Moss C, Edwards MH, McLellan AR, Stenmark J, Pierroz DD, Schneider MC, Kanis JA, Akesson K, Cooper C; IOF Fracture Working Group; EXCO. Effective secondary fracture prevention: implementation of a global benchmarking of clinical quality using the IOF Capture the Fracture ${ }^{\circ}$ Best Practice Framework tool. Osteoporos Int. 2015 Nov;26(11):2573-8. doi: 10.1007/s00198-015-3192-0.

10. van den Berg P, Schweitzer DH, van Haard PM, van den Bergh JP, Geusens PP. Meeting international standards of secondary fracture prevention: a survey on Fracture Liaison Services in the Netherlands. Osteoporos Int. 2015 Sep;26(9):2257-63. doi: 10.1007/s00198-015-3117-y.

11. Dutch Institute for Healthcare Improvement CBO (2011) Richtlijn Osteoporose en Fractuurpreventie. www.diliguide.nl/document/1015/file/pdf/. (Dutch) Accessed 19 December 2015

12. Netelenbos JC, Geusens PP, Ypma G, Buijs SJ. Adherence and profile of non-persistence in patients treated for osteoporosis - a large-scale, long-term retrospective study in The Netherlands. Osteoporos Int. 2011 May;22(5):1537-46. doi: 10.1007/s00198-010-1372-5.

13. Klop C, Welsing PM, Elders PJ, Overbeek JA, Souverein PC, Burden AM, van Onzenoort HA, Leufkens HG, Bijlsma JW, de Vries F. Long-term persistence with anti-osteoporosis drugs after fracture. Osteoporos Int. 2015 Jun;26(6):1831-40. doi: 10.1007/s00198-015-3084-3. 
14. Clowes JA, Peel NF, Eastell R. The impact of monitoring on adherence and persistence with antiresorptive treatment for postmenopausal osteoporosis: a randomised controlled trial. J Clin Endocrinol Metab. 2004;89(3):1117-1123.

15. Schousboe JT, DeBold RC, Kuno LS, Weiss TW, Chen Y-T, Abbott TA III. Education and phone follow-up in postmenopausal women at risk for osteoporosis: effects on calcium intake, exercise frequency, and medication use. Dis Manag Health Outcomes. 2005;13(6):395-404

16. Cooper A, Drake J, Brankin E; PERSIST Investigators. Treatment persistence with once-monthly ibandronate and patient support vs. once-weekly alendronate: results from the PERSIST study. Int J Clin Pract. 2006;60(8):896-905.

17. Delmas PD, Vrijens B, Eastell R, et al; Improving Measurements of Persistence on Actonel Treatment (IMPACT) Investigators. Effect of monitoring bone turnover markers on persistence with risedronate treatment of postmenopausal osteoporosis. J Clin Endocrinol Metab. 2007;92(4):1296-1304.

18. Cook PF, Emiliozzi S, McCabe MM. Telephone counselling to improve osteoporosis treatment adherence: an effectiveness study in community practice settings. Am J Med Qual. 2007;22(6): 445-456.

19. Shu AD1, Stedman MR, Polinski JM, Jan SA, Patel M, Truppo C, Breiner L, Chen YY, Weiss TW, Solomon DH. Adherence to osteoporosis medications after patient and physician brief education: post hoc analysis of a randomized controlled trial. Am J Manag Care. 2009 Jul;15(7):417-24.

20. Waalen J, Bruning AL, Peters MJ, Blau EM. A telephone-based intervention for increasing the use of osteoporosis medication: a randomized controlled trial. Am J Manag Care. 2009;15(8):e60-e70.

21. Solomon DH, Iversen MD, Avorn J, et al. Osteoporosis telephonic intervention to improve medication regimen adherence: a large, pragmatic, randomized controlled trial. Arch Intern Med. 2012;172(6):477-483.

22. Tamone C, Fonte G, Panico A, Molinatti PA, D'Amelio P, Isaia GC. Impact of a phone follow-up program on persistence with teriparatide or PTH(1-84) treatment. Calcif Tissue Int. 2012;90(4): 272-278.

23. Stuurman-Bieze AG, Hiddink EG, van Boven JF, Vegter S. Proactive pharmaceutical care interventions decrease patients' nonadherence to osteoporosis medication. Osteoporos Int. 2014 Jun;25(6):1807-12. doi: 10.1007/s00198-014-2659-8.

24. Bianchi ML, Duca P, Vai S, Guglielmi G, Viti R, Battista C, Scillitani A, Muscarella S, Luisetto G, Camozzi V, Nuti R, Caffarelli C, Gonnelli S, Albanese C, De Tullio V, Isaia G, D'Amelio P, Broggi F, Croci M. Improving adherence to and persistence with oral therapy of osteoporosis. 2015 May;26(5):1629-38. doi: 10.1007/s00198-015-3038-9.

25. Hiligsmann M, Salas M, Hughes DA, Manias E, Gwadry-Sridhar FH, Linck P, Cowell W. Interventions to improve osteoporosis medication adherence and persistence: a systematic review and literature appraisal by the ISPOR Medication Adherence \& Persistence Special Interest Group. Osteoporos Int. 2013 Dec;24(12):2907-18. doi: 10.1007/s00198-013-2364-z.

26. Gleeson T, Iversen MD, Avorn J, et al. Interventions to improve adherence and persistence with osteoporosis medications: a systematic literature review. Osteoporos Int. 2009; 20(12):2127-2134.

27. Genant HK, Wu CY, van Kuijk C, Nevitt MC. Vertebral fracture assessment using a semiquantitative technique. J Bone Miner Res. 1993 Sep;8(9):1137-48.

28. Arends S, Spoorenberg A, Bruyn GA, Houtman PM, Leijsma MK, Kallenberg CG, Brouwer E, van der Veer $\mathrm{E}$. The relation between bone mineral density, bone turnover markers, and vitamin D status in ankylosing spondylitis patients with active disease: a cross-sectional analysis. Osteoporos Int. 2011 May;22(5):1431-9. doi: 10.1007/s00198-010-1338-7. 
29. https://www.vzVz.nl/uploaded/FILES/htmlcontent/Voorlichtingsmateriaal/Folder\%20met\%20 toestemmingsformulier\%20-\%20Engels.pdf. Assessed February 2017.

30. Diez-Perez A, Naylor KE, Abrahamsen B, Agnusdei D, Brandi ML, Cooper C, Dennison E, Eriksen EF, Gold DT, Guañabens N, Hadji P, Hiligsmann M, Horne R, Josse R, Kanis JA, Obermayer-Pietsch B, Prieto-Alhambra D, Reginster JY, Rizzoli R, Silverman S, Zillikens MC, Eastell R; Adherence Working Group of the International Osteoporosis Foundation and the European Calcified Tissue Society Working Group. Recommendations for the screening of adherence to oral bisphosphonates. Osteoporos Int. 2017 Mar;28(3):767-774. doi: 10.1007/s00198-017-3906-6. Epub 2017 Jan 16.

31. Vasikaran S, Eastell R, Bruyère O, Foldes AJ, Garnero P, Griesmacher A, McClung M, Morris HA, Silverman S, Trenti T, Wahl DA, Cooper C, Kanis JA; IOF-IFCC Bone Marker Standards Working Group. Markers of bone turnover for the prediction of fracture risk and monitoring of osteoporosis treatment: a need for international reference standards. Osteoporos Int. 2011 Feb;22(2):391420. doi: 10.1007/s00198-010-1501-1.

32. Leys, C., et al., Detecting outliers: Do not use standard deviation around the mean, use absolute deviation around the median, Journal of Experimental Social Psychology, Volume 49, Issue 4, July 2013, pp. 764-766.

33. Eekman DA, Bultink IE, Heijboer AC, Dijkmans BA, Lems WF. Bone turnover is adequately suppressed in osteoporotic patients treated with bisphosphonates in daily practice. BMC Musculoskelet Disord. 2011 Jul 21;12:167. doi: 10.1186/1471-2474-12-167.

34. Naylor KE, Jacques RM, Paggiosi M, Gossiel F, Peel NF, McCloskey EV, Walsh JS, Eastell R. Response of bone turnover markers to three oral bisphosphonate therapies in postmenopausal osteoporosis: the TRIO study. Osteoporos Int. 2016 Jan;27(1):21-31. doi: 10.1007/s00198-015-3145-

35. Sabaté E. Adherence to long-term therapies. Evidence for action. Geneva: World Health Organization, 2003 http://www.who.int/chp/knowledge/publications/adherence_report/en/. Published 2003. Accessed December 2015.

36. Ganda K, Schaffer A, Pearson S, Seibel MJ. Compliance and persistence to oral bisphosphonate therapy following initiation within a secondary fracture prevention program: a randomised controlled trial of specialist vs. non-specialist management. Osteoporos Int. 2014 Apr;25(4):134555. doi: 10.1007/s00198-013-2610-4.

37. Jacob L, Dreher M, Kostev K, Hadji P. Increased treatment persistence and its determinants in women with osteoporosis with prior fracture compared to those without fracture. Osteoporos Int. 2016 Mar;27(3):963-9. doi: 10.1007/s00198-015-3378-5.

38. Wölfl C, Schweppenhäuser D, Gühring T, Takur C, Höner B, Kneser U, Grützner PA, Kolios L. Characteristics of bone turnover in the long bone metaphysis fractured patients with normal or low Bone Mineral Density (BMD). PLoS One. 2014 May 1;9(5):e96058. doi: 10.1371/journal. pone.0096058. eCollection 2014.

39. Ivaska KK, Gerdhem P, Akesson K, Garnero P, Obrant KJ. Effect of fracture on bone turnover markers: a longitudinal study comparing marker levels before and after injury in 113 elderly women. J Bone Miner Res. 2007 Aug;22(8):1155-64. 


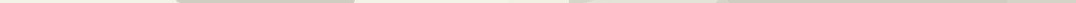


CHAPTER 8

SUMMARY 
In order to strive for standardized and optimal FLS-care, a systematic, preferably coordinator-based, approach for identification, enrollment, evaluation, treatment and monitoring of patients with a fracture after the age of 50 years has been proposed (van den Bergh JP, van Geel TA, Geusens PP. Osteoporosis, frailty and fracture: implications for case finding and therapy. Nat Rev Rheumatol. 2012). After identification of patients, a detailed evaluation of medical history, medication use, clinical risk factors, vitamin D status, dietary calcium intake, known contributors to secondary osteoporosis and fall risk should then be performed, together with assessment of BMD and VFA. Next, patients need to be further evaluated for undiagnosed contributors to secondary osteoporosis and metabolic bone disorders. Then a multifactorial intervention should follow, including lifestyle management recommendations, calcium and/or vitamin D supplementation if required, and treatment of underlying disorders. Specific anti-osteoporotic treatment should be considered in line with national guidelines with organized follow-up of patients after 3 months and annually, thereafter (Richtlijn Osteoporose en Fractuurpreventie - Dutch Institute for Healthcare Improvement - CBO 2011).

This dissertation consists of six studies on several aspects of secondary fracture prevention. We studied the Dutch FLS performance in Chapter 2. The hospital registration and patient-related factors that were associated with FLS attendance and non-attendance were studied in chapter 3 and in chapter 4 we further studied the reasons for non-attendance. In Chapter 5 we assessed if a Pulse Echo Ultrasound device enables identification of women with recent non-vertebral fractures at the FLS who would not need a DXANFA. In Chapter 6 we analyzed the daily calcium intake in FLS patients and in Chapter 7 the impact of telephone calls on one-year osteoporosis medication adherence was studied.

In Chapter 2 we evaluated the implementation of the "Capture the Fracture" standards proposed by the IOF in non-university hospitals in the Netherlands by questionnaire to gather information on the selection, evaluation and treatment of patients older than 50 years with a recent fracture. All 90 Dutch non-university hospitals received the invitation to participate in this survey which resulted in 24 (27\%) full responses, providing data of 24,468 consecutive patients, corresponding with 25\% of fracture patients in the Netherlands in the year 2012. The data showed that all FLSs in the participating hospitals scored above $90 \%$ for the following Best 
Practice Framework standards: identification of patients with a recent fracture in the hospitals, invitation for FLS, timing of assessment, identification of vertebral fractures, application of national guidelines, evaluation of secondary osteoporosis, drug initiation when indicated, communication with the general practitioner and application of follow-up strategy. Our data suggest that patients attending the Dutch FLSs were evaluated, treated and followed in high compliance with the IOF standards but with the major shortcoming that FLS's attendance rates are low and that future research should focus on identification of the causes of this low attendance rate and ways to improve it.

In Chapter 3 we studied hospital registration and patient-related factors that were associated with attendance or non-attendance to the Fracture Liaison Service (FLS). During the process of this study, we found that there was an important invitation gap, indicating that $14 \%$ (278 out of 2006 consecutive patients with a fracture) was not invited at the FLS due to administrative errors. All 1288 patients that were invited at the FLS received a questionnaire. A total of 745 patients (of whom 537 attended and 208 did not attend the FLS) returned an analyzable questionnaire. Non-attendance was associated with male gender, frailty, living alone, low education, being not interested in bone strength and being unaware of increased subsequent fracture risk (with Odds Ratios (ORs) between 1.62 and 2.08). Attendance was significantly associated with information perceived by the patient (OR: 3.32). Based on this study, failures in administrative fracture entry registration as well as frailty, male gender, having low general education, living alone, and low interest in bone health and subsequent fracture risk were independent determinants for FLS non-attendance. Adequate motivation of patients by the healthcare professional shortly after the fracture, or the lack of it, was the strongest determinant associated with both FLS attendance and non-attendance. Therefore, adequate registration processes and a more personal tailored approach with adequate patient information and shared decision making may improve FLS attendance rates.

In Chapter 4 we further analyzed the characteristics of patients who did not respond to an invitation for an FLS visit. Non-responders were traced and contacted by phone to consent with a home visit (HV) and to fill in a questionnaire or, if $\mathrm{HV}$ was refused, to receive a questionnaire by post $(\mathrm{Q})$, in order to gain insight in their believes on fracture 
cause and subsequent fracture risk. Of the 197 non-responders, 181 patients were traced and phoned until 50 consented with HV; 42 declined HV but consented with Q. Excluded were 8 Q-consenters to whom no choice was offered (either HV or Q) and 81 patients who declined any proposition (non-HV|Q); 62\% could recall the initial FLS invitation letter. Patient believes about the main causes of fracture significantly differed between HV and Q with regard to a fall (96\% vs 79\%), bad physical condition (36\% vs 2\%), dizziness or imbalance (24\% vs Q 7\%) and osteoporosis (16\% vs $2 \%$ ). Age $\geq 70$, woman gender and major fracture were significantly associated with consent for HV compared to Q (OR 2.7, 2.5 and 2.4, respectively) and HV compared to non-HV|Q (OR 16.8, 5.3 and 6.1). This study showed that FLS non-responders consider their fracture risk to be low. Note, 50 patients (about 25\%) consented with a home visit after one telephone call, mainly older women with a major fracture. This subgroup of non-responders with high subsequent fracture risk is therefore presumably still approachable for secondary fracture prevention.

In Chapter 5 we evaluated whether the application of Pulse-Echo Ultrasound (P-EU) enables the identification of women with recent non-vertebral fractures at the FLS who would not need a DXANFA referral because they had no osteoporosis and/or subclinical vertebral fractures. In this cross-sectional study, 209 consecutive women of 50-70 years with a recent non-vertebral fracture (NVF) were studied at the Fracture Liaison Service (FLS) of one hospital. All women received DXANFA and P-EU (Bindex®) assessments. Various P-EU thresholds (based on the Density Index (DI, g/ $\left.\mathrm{cm}^{2}\right)$ ) were analyzed to calculate the best balance between true negative (indeed no osteoporosis and/or subclinical VF) and false negative tests (osteoporosis and/or subclinical VF according to DXANFA). 83 women had osteoporosis (40\%) and 17 women at least one VF (8\%). Applying the manufacturer's recommended P-EU threshold (DI 0.844g/ $\mathrm{cm}^{2}$ ) being their proposed cut-off for not having hip osteoporosis resulted in 77 negative tests (37\%, 31\% true negative and 6\% false negative tests). A DI of $0.896 \mathrm{~g} / \mathrm{cm}^{2}$ resulted in 40 negative tests (19.3\%) (38 true negative (18.3\%) and 2 false negative tests (1.0\%)). The application of P-EU enabled the identification of a proportion of women with recent non-vertebral fractures at the FLS who would not need a DXA/ VFA referral because they had no osteoporosis and/or subclinical vertebral fractures. The most conservative P-EU threshold resulted in 18.3\% true negative tests verified by DXANFA against $1 \%$ false negative test results. 
In a dairy producing country such as the Netherlands (globally the second provider of dairy and agricultural products after the USA) milk consumption has been considered healthy and indispensable in a bone supporting menu mainly for the elderly. In Chapter 6 we investigated whether FLS patients complied with recommendations for daily calcium intake, and quantified the daily dairy calcium intake including milk, milk drinks, pudding, yoghurt, and cheese and compared outcomes with recent data of a healthy U.S. cohort (80\% Caucasians). We collected data of 1526 female and 372 male FLS patients older than 50 years of age. On average, participants reported three dairy servings per day, independently of age, gender or population density. Median calcium intake from dairy was 790 mg/day in women and men. Based on dairy products alone, $11.3 \%$ of women and $14.2 \%$ of men complied with Dutch recommendations for calcium intake (adults $\leq 70$ years: 1100 mg/day and >70 years: 1200 mg/day). After including $450 \mathrm{mg}$ calcium from basic nutrition, compliance with the recommendation raised to $60.5 \%$ and $59.1 \%$, respectively, compared to $53.2 \%$ in the U.S. cohort. While daily dairy calcium intake of Dutch fracture patients was well below the recommended dietary intake, it was comparable to intakes in a healthy U.S. cohort. These findings question recommendations for additional dairy products to preserve adult skeletal health, particularly when sufficient additional calcium is derived from adequate nondairy nutrition.

In Chapter 7 we focused on the treatment persistence in FLS patients who started with alendronate. Postmenopausal women with a recent fracture and osteoporosis who started alendronate were randomized to receive three phone calls (PC) (after 1, 4, and 12 months) or no phone calls (no PC). S-CTX and P1NP were measured at baseline and after 3, 6, 9, and 12 months. As a reference group, 30 postmenopausal osteopenic patients with a recent fracture were analyzed as well. Persistence was assessed using the Dutch National Switch Point Pharmacies-GPs database and crossreferenced with PC, no PC, and BTM changes. Cut-off values of BTMs were calculated based on least significant change (LSC) and also on underrunning median values of the untreated osteopenic postmenopausal reference group with a recent fracture. Out of 119 patients, 93 (78\%) completed 12 months follow-up (45 PC and 48 no PC). Mean age was 69 years. Persistence was similar in PC and no PC participants. Using an optimal cut-off value $>29 \%(<415 \mathrm{ng} / \mathrm{L})$ as LSC of s-CTX and $>36 \%(<53.1 \mu \mathrm{g} / \mathrm{L})$ as LSC of P1NP, alendronate persistence after 1 year was 93 and 88\% for PC and no $P C$, respectively. It was concluded that in this context, telephone calls did not 
Chapter 8

improve persistence. In around 90\% of patients, the 1-year alendronate persistence was confirmed by levels beyond the LSC of S-CTX and P1NP at 12 months compared to baseline values. 


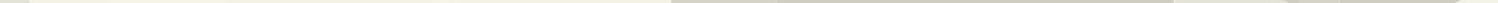




\section{CHAPTER 9}

Discussion and future perspectives 
The work presented in this dissertation is focused on the key steps of secondary fracture prevention at the Fracture Liaison Service (FLS) (Fig.1) [1]. First, in Chapter 2 a nationwide survey was performed on the implementation of quality standards in Dutch FLSs. Next, in Chapters 3 to 7 specific studies addressing FLS attendance and non-attendance, screening with peripheral ultrasound, evaluation of daily calcium intake and treatment persistence were performed based on data from the FLS of the 'Reinier de Graaf Gasthuis' Delft, in the Netherlands.

Fig 1. The 5- key steps for secondary fracture prevention and the items addressed in this dissertation.

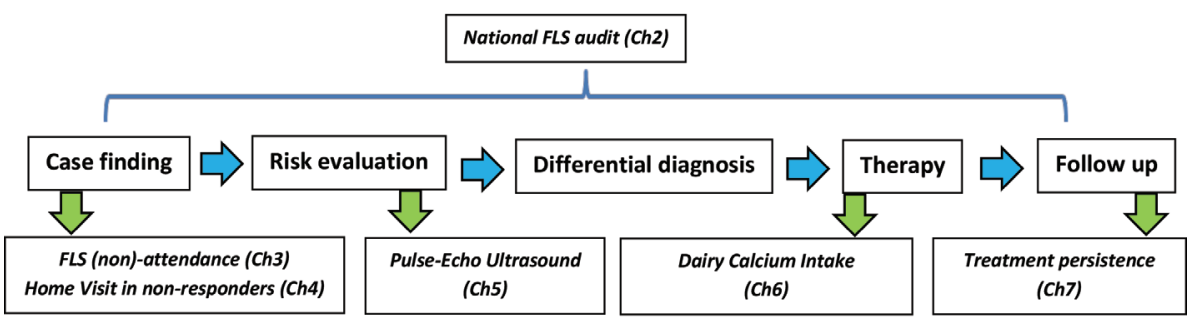

The FLS is supported by international and national scientific organizations as the most appropriate care model for secondary fracture prevention [2-6]. According to the Dutch guidelines, fracture risk assessment including clinical risk factors, DXA, VFA, laboratory testing and appropriate anti-osteoporosis treatment with adequate followup is considered as standard service to offer to patients older than 50 years with a recent fracture [7]. The primary FLS objective is obviously to prevent subsequent fractures. Published data that originate from FLS initiatives with high quality standards and excellent rankings have shown favorable outcomes with regard to subsequent fracture risk and mortality risk after introduction of FLS care [8-11].

According to information from the Dutch nationwide hospital quality indicator sets, in 2016 there were 90 non-university hospitals [12]. Although it is known that almost all Dutch hospitals deliver FLS care, detailed information about the implementation of quality standards was lacking. We, therefore performed a nationwide audit of Dutch FLSs, based on the 13 quality indicators defined by the Capture the Fracture ${ }^{\circledR}$ Best Practice Framework (CtF ${ }^{\circledR}$-BPF) by the International Osteoporosis Foundation (IOF), [13-15] as described in Chapter 2 of this dissertation. Our findings suggest that patients attending Dutch FLSs were evaluated, treated and followed-up with high compliancy using these IOF standards but with the major shortcoming that FLS attendance rates 
were low. Although the outcomes in Chapter 2 are promising since responding FLSS showed optimal level $\mathrm{CtF}^{\circledR}$-BPF related results, there may be bias to be accounted for since only 24 out of 90 FLSs responded to the questionnaire. Non-response bias to questionnaire studies is a well-known phenomenon and often under-estimated [16]. In particular respondents who perform well usually complete questionnaires $[17,18]$. Additionally non-response bias may also be caused by questionnaires that are too complex or extensive [17], which may be the case regarding the audit in Chapter 2 since it was based on the rather complex IOF CtF®-BPF questionnaire. Access to detailed hospital and registration data was a requisite for completing many questions in this audit and this could have attributed to non-response bias. [18,19]. Finally, predefined criteria on how to calculate FLS-attendance were not provided.

The number of patients that attended the FLS as numerator in the calculation is usually well registered. However, for the denominator various numbers can be used depending on identification and selection of patients (such as the total number of patients with a fracture or the total number of patients with a fracture minus number of deceased patients or number of otherwise intentionally not invited for FLS visit for various reasons or other combinations).

Since 2012, Dutch hospitals have to provide FLS-related data based on "osteoporosis Quality Indicators" requested by Dutch healthcare authorities wherein the number of patients with a fracture (based on DBC fracture type codes) and the proportion of those patients that had a DXA should be reported yearly [12]. In general, this proportion is reported to be near 33\% of all patients, with a range between 5-100\% $[12,20]$. This Quality Indicator does only provide limited information and is not consistent with internationally propagated standards of care quality measuring tools. In addition, as in our audit, response bias is also likely to be present regarding the yearly reports of this indicator.

Attempting to overcome non-response bias due to complex audit tools and to avoid low quality audits, a patient-level key performance indicator (KPI) set was developed on behalf of the IOF [21]. This set of KPIs adds simple numerical data to processrelated scores by mentioning practical and comprehensible issues. For example, rather than measuring DXA numbers alone, it adds quality issues to FLS'S DXA performance (i.e. quality of readings, arrival of readings in time, active performance of fracture and fall risk assessment, consequent initiation of treatment after diagnosis and follow-up). It is important to note that any KPI-type audit is only feasible in case of 
adequate registration of available data, software support and sufficient personnel to handle the extra workload [21]. This further emphasizes the importance of integrated registration and management of hospital data.

\section{Case finding}

Based on the findings from our national audit as described in Chapter 2 and the Dutch national osteoporosis Quality Indicator set [12], we studied FLS attendance and non-attendance in more depth at the FLS in Delft in Chapter 3 and 4 of the dissertation. In these Chapters, we studied hospital registration and patient-related factors that were associated with attendance or non-attendance and we found that $14 \%$ of consecutive patients with a fracture was not invited at the FLS due to administrative errors. We also found that frailty, male gender, having low general education, living alone, and low interest in bone health and subsequent fracture risk were independent determinants of FLS non-attendance. Additionally, adequate patient information provided by the healthcare professional shortly after the fracture, or the lack of it, was the strongest determinant associated with both FLS attendance and non-attendance. As mentioned before, there are no uniform criteria for selection of patients to be invited at the FLS and for calculation of FLS's attendance rates. Based on previously reported literature and on the Delft FLS experience described in Chapter 3 we developed the following flowchart from fracture registration to attendance to characterize case finding for FLS invitation. 
Fig 2. Flow chart for FLS invitation of patients 50 years or older with a recent fracture.

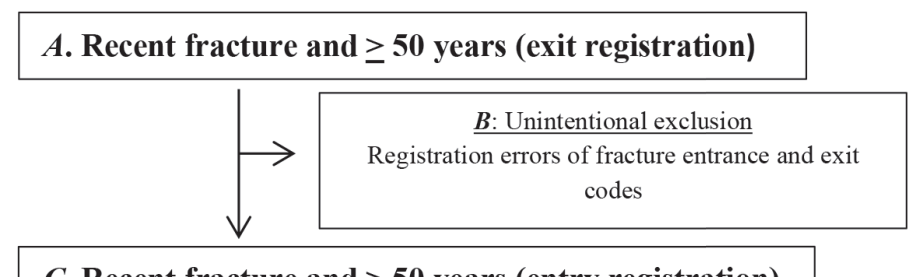

\section{Recent fracture and $\geq \mathbf{5 0}$ years (entry registration)}

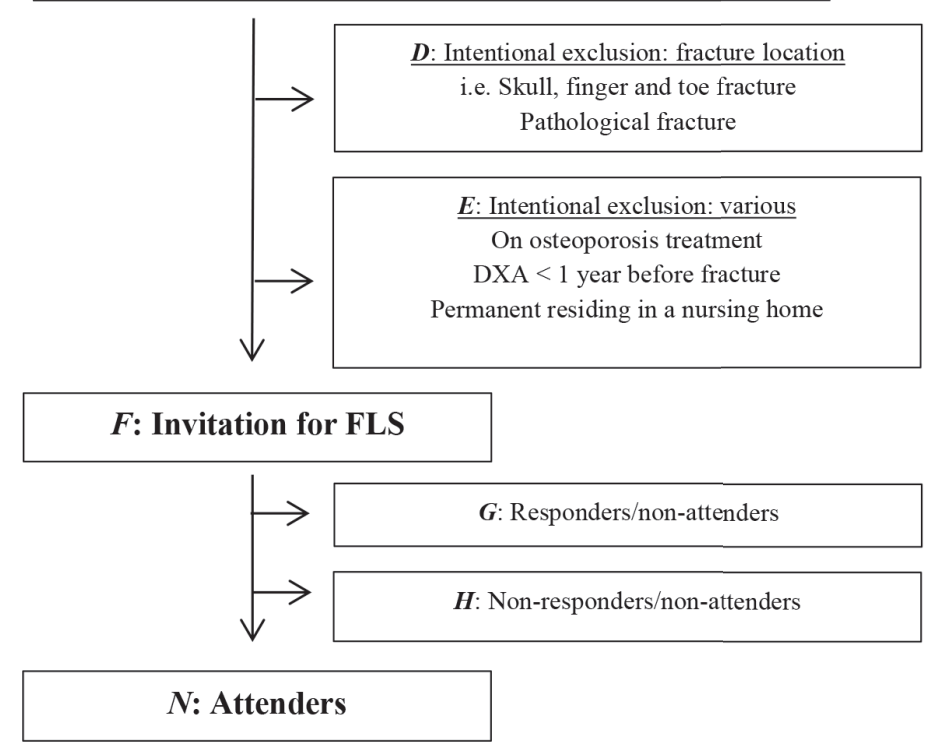

While the IOF/Capture the Fracture® Best Practice Framework (CtF®-BPF) calls to strive for a 90\% FLS attendance [13-15], it appears that in real life FLS attendance rates in the Netherlands are on average $30 \%$ and below $60 \%$ at its best $[12,20]$. We questioned whether the definition of 'FLS-attendance' attributes to misinterpretations. As presented in Fig 2, there can be various reasons that patients are not attending the FLS (Fig. 2). Subsequently, based on the way FLS attendance is calculated with $N$ as nominator and a variation of combinations from $A, C$ and $F$ as denominator there is a need for a clear definition of FLS attendance rate.

In the IOF CtF ${ }^{\circledR}$-BPF Questionnaire, the total number of attenders is divided by the total number of fracture registrations in patients $=>50$ years $(N / A)$, while in the Dutch Quality Indicator, it is the total number of performed DXA scans divided by the total number of fracture registrations in patients $=>50$ years $(A)$. In both calculations, a 
substantial proportion of registration errors are not included $(B)$, being $14 \%$ in our study (Ch 3). Additionally, a substantial proportion of patients are intentionally not invited, depending on local FLS protocols (D + E). In our study this was 22\% (Ch 3$)$.

Obviously, the number of unintentional exclusions (B) must be kept as low as possible. Based on our own experience we calculated FLS-attendance based on entry (emergency dept. medical codes) and exit registrations (hospital financial codes). Calculations based on financial codes showed 65\% FLS attendance (N/F) (see Fig 2.). However, if predetermined exclusions were not taken into account in the calculation, this number would drop to $41.9 \%$ (N/A).

In our opinion, uniformity in the definition of FLS attendance is needed, and this can be achieved by implementing a generally accepted formula. We propose to use the number of FLS attenders as nominator and the number of patients invited as denominator (N/F). When using this calculation, the number of patients intentionally not invited for FLS $(D+E)$ also have to be provided.

After reviewing our invitation strategy, our FLS attendance rate was 65\% using the formula N/F, which implied that one-third of patients we invited at the FLS did not receive FLS care. These patients can be divided in two groups, namely patients who responded and indicated that they did not feel the need for a FLS visit (G), which was only $1 \%$ of patients in our study (Ch 3). Therefore, almost all FLS non-attenders were non-responders to FLS invitation.

In Chapter 4 we intended to study the reasons for non-response by questionnaire and by home visits. We were able to reach 181 (92\%) of 197 non-responders of whom 50 patients (28\%) consented with a home visit, while 42 patients declined our request but completed a posted questionnaire. Remarkably, in terms of time effort it was far easier to collect patients who consented with a home visit than those who refused a home visit but consented to complete the posted questionnaire. This finding may be a novel opportunity to be used in future FLS initiated secondary fracture prevention. The patients that consented with a home visit were mainly elderly women and most of them had sustained a major fracture. These women considered a fall, their bad physical condition, dizziness or balance problems to be the main cause of fracture and underestimated their bone condition as well as subsequent fracture risk. None of the patients could remember that information was provided face-to-face by the health professional during fracture treatment, despite the fact this is a standard procedure according to our local FLS protocol. 
Most (88\%) of the FLS non-responders that agreed with a home visit had a hip, vertebral of major fracture (according to Warriner et al.) [22] reflecting index fractures with high subsequent fracture risk. In spite of this, many of these patients perceived their subsequent fracture risk being low or even neglectable. The findings in Chapter 4 imply that a substantial proportion of FLS non-responders is approachable for secondary fracture prevention. Since these are mainly elderly women with perceived bad physical condition, dizziness or balance problems it may be important to involve general practitioners in providing optimal care for these patients and to consider home visits as an extension of the traditionally hospital based FLS care.

\section{Risk Evaluation}

The risk of subsequent fractures is particularly high within the first years after a fracture in patients of 50 years and older [23,24]. This high and immediate risk of having subsequent fractures is referred to as 'imminent fracture risk'[25,26].

This high imminent fracture risk stresses the need for evaluation and treatment decisions shortly after a fracture. Disappointingly, as shown in Chapter 4 there still is a knowledge gap among patients regarding the imminent subsequent fracture risk. Ideally, fracture risk evaluation is initiated as soon as possible during initial fracture treatment, preferably at the emergency or plaster room department.

In Chapter 5 we studied whether the application of a non-ionizing peripheral Pulse Echo Ultrasound device (P-EU Bindex®) enables identification of women with recent non-vertebral fractures at the FLS who would not need a DXANFA.

There is a wide variability of reports comparing peripheral ultrasound and central DXA outcomes [27-30], but to the best of our knowledge there are no data comparing peripheral ultrasound with DXA outcomes (osteoporosis Yes/No) including VFA (prevalent vertebral fractures Yes/No). Additionally. and in contrast to previous studies using the same device (P-EU Bindex®), we focused on the identification of women who would not need a DXANFA referral because they had no osteoporosis and/or subclinical vertebral fractures and not to use the P-EU outcomes for fracture risk prediction. We performed this study in 50 to 70 years old women with a recent fracture because we expected a priori low probability for osteoporosis and/or subsequent vertebral fractures on VFA [31,32]. We found that the most conservative P-EU threshold resulted in $18.3 \%$ true negative DXANFA results against $1 \%$ false negative results. 
Since this was a study performed at the FLS, in a small group of women of 50-70 years and not among older women and/or men, the results cannot be extrapolated to the total group of patients with a fracture, especially elderly women or men. Also, the percentage of osteoporosis was higher and the number of subclinical VFs was smaller than expected. Therefore, further studies in a larger cohort of patients of 50 years and older including men are needed. In addition, this study was performed at the FLS, but should be ideally performed in the ER or plaster room setting. This would also allow to study a potential added value of screening patients in the early phase of fracture care, namely if a 'positive' P-EU test would attribute to a higher FLS attendance rate. Since "nudging", meaning influencing people's behavior is promising as it usually does not rely on the transfer of often complex health information [33], it is easier to reach patients with limited health literacy [34]. Therefore, the effect of "nudging" by a 'positive' P-EU test at the plaster room on FLS attendance rates is one of the future directives of our Delft FLS research planning.

\section{Differential diagnosis}

The $3^{\text {rd }}$ of the 5 key steps of secondary fracture prevention (Fig. 1) was not a part of the dissertation.

\section{Therapy: calcium intake}

In the context of the $4^{\text {th }}$ step, we aimed to analyze whether FLS patients complied with recommendations for daily calcium intake with specific focus on calcium intake from dairy products and complete nutrition in chapter 6. Today, there is still debate in the necessary amount of dietary calcium intake i.e. in dairy products and in non-dairy nutrition to preserve adult skeletal health and advices on intake are variable and country dependent [35]. Like in many other Western countries, Dutch recommendations on dairy consumption are based on authority-based opinions [36]. In chapter 6, we found that mean calcium intake from dairy products was 790 mg/day in both female and male FLS attenders older than 50 years. Based on calcium intake from dairy products alone, $11.3 \%$ of women and $14.2 \%$ of men complied with Dutch recommendations (adults $\leq 70$ years: $1100 \mathrm{mg} /$ day and $>70$ years: $1200 \mathrm{mg} /$ day) [7]. There were no differences between urbanized and countryside living patients. We calculated the total nutritional calcium intake based on the number of dairy servings 
per day plus 450 mg calcium from non-dairy nutrition based on the RIVM "Dutch National Food Consumption Survey 2007-2010: Diet of children and adults aged 7 to 69 years" (DNFCS)) [37]. When daily calcium intake was calculated based on the average $450 \mathrm{mg}$ from basic nutrition plus dairy intake, $60.5 \%$ of women and $59.1 \%$ of men complied with Dutch recommendations.

Based on the ease to estimate calcium intake from nutrition and our study outcome, we recommend that FLS nurse specialists (i.e. nurses, nurse practitioners and physician assistants) implement the assessment of dietary calcium intake of FLS patients in their daily routine. Additionally, tailor made dietary advices and, if needed prescribing calcium supplements should be provided in order to strive for a total daily calcium intake of 1100-1200 mg per day. If there appears to be any food intolerance, consultation of a dietician and oral calcium supplementation should be considered.

\section{Follow-up}

In the 5-step approach, treatment with anti-osteoporosis medication and adequate follow-up is the last and major pillar of fracture prevention. Initiation of medication at the FLS is encouraged by international and national experts, however if FLS attendance remains low, the treatment gap will not be closed. Another important issue regarding the treatment gap is treatment persistence. In the Netherlands, the one-year persistence of oral anti-osteoporosis medication was reported to be 45$50 \%$, and about a third of patients stopped taking anti-osteoporosis medication by 3 months [38]. A higher persistence of 75\% was found in FLS patients [39].

The concepts of adherence and persistence are regularly used interchangeably but basically medication adherence refers to 'the extent to which a patient acts in accordance with the prescribed interval and dose of a dosing regimen' while persistence refers to the duration of time from initiation to discontinuation of therapy'. Reasons for medication non-adherence and non-persistence are numerous and multidimensional and it is mandatory to understand the problem and the extent in order to identify solutions. Promising tailor-made actions include patient education with counselling, adherence monitoring with feedback and dose simplification including flexible dosing regimen [40]. A number of methods to improve medication persistence have been reported, such as telephone-based interventions [41,42] and tailored pharmaceutical care interventions including counseling sessions with nonadherent patients [43]. Since the response of bone turnover markers (BTMs) can be 
used to monitor the effect of anti-osteoporosis treatment [44], this response can also be used to counsel patients during treatment [45].

In a recent systematic review, it was reported that patient education, monitoring and supervision, changing drugs regimens and interdisciplinary collaboration had mixed results on persistence and adherence [46]. More positive effects were found for multicomponent interventions with active patient involvement, including individualized solutions based on patient and healthcare providers ' collaboration, counseling and shared decision making [46]. In the Netherlands the National Switch Point infrastructure (Landelijk Schakelpunt (LSP)) can be used to verify the last medication delivery to patients that consented with registration of their medication in this system [47].

In Chapter 7, we studied the influence of telephone calls and the predictive value of changes in bone turnover markers for evaluating persistence with alendronate. Persistence was objectified by LSP data. In this study, one-year alendronate persistence was $75 \%$ after correction for individuals who had to stop taking bisphosphonates (Gleffects and motivational issues to take oral bisphosphonates). These findings are in line with of another Dutch study in FLS patients [39]. We found that telephone calls did not have an add-on effect to alendronate persistence, but they offered the advantage of early detection of patients that stopped taking medication and the reason for it. An important contributive effect was that side effects could be detected at an early phase of treatment with the opportunity to switch to IV or SC administration of antiosteoporosis medication.

A decrease of the BTMS CTX and PINP at 3 months below the cut-off level that represented the least significant change, predicted nearly all LSP confirmed deliveries. This finding shows that monitoring of BTMs can be used in clinical practice in FLS patients using oral alendronate, despite the fact that BTMs are increased shortly after a fracture and gradually decrease over a period of months [44]. Apparently, the suppression of BTMs during treatment with alendronate is strong enough to induce a decrease greater than the least significant change.

According to the Dutch guidelines, a visit or telephone call at 3 months after treatment initiation is advocated [7]. This study (Chapter 7) showed that a contact at 3 months offered the advantage of early detection of side effects allowing a switch of medication before patients stop taking medication and early detection of patients that already stopped taking medication. We believe that it would be of additional 
value to evaluate treatment persistence by measuring BTMs at this timepoint in combination with verification of pharmacy deliveries in patients that gave permission for this registration (LSP).

\section{Future perspectives.}

FLS care is widely available and accessible in the Netherlands. FLSs increase the likelihood of BMD testing and treatment initiation. In this dissertation we studied a number of knowledge gaps in case finding strategies and in patient knowledge about the cause of their fracture and risk of subsequent fracture. Overall there is the need for efforts to reduce gaps regarding the implementation of case finding and to improve patients' knowledge gaps on subsequent fracture risk.

First, in order to further improve FLS care and to evaluate its performance in approaching patients for secondary fracture prevention in the Netherlands, we will need a standardized method for calculation of FLS attendance, taking into account exact and timely fracture registration as well as the in- and exclusion criteria for invitation. Our proposed FLS-attendance calculation aims at standardization and therefore adequate comparison of attendance rates between and within FLS facilities based on adequate reporting.

Second, there is need for evaluation of how information procedures can be improved towards patients with a recent fracture. There is a need for improving access to early diagnostic procedures during fracture treatment including immediate evaluation of clinical risk factors, scheduling immediate appointments for DXA, VFA and lab, and to intensify collaboration with Geriatric Trauma Units after hip or other major fractures that require hospitalization. Possibly screening strategies with peripheral devices such as ultrasound may contribute to further improvement of the diagnostic evaluation. Initiatives enabling early diagnostic procedures will contribute to the application of personalized medicine in the FLS. Questions such as in which patients one can omit diagnostics or start treatment immediately must be answered by scientific evidence. These questions are still to be studied in the clinic and at patients' private homes. Herein, further studies by and with FLS nurse specialists are needed to evaluate its effects on secondary fracture prevention.

The Multidisciplinary Trauma Unit (MTU) is a mandatory collaboration to be started in 2020 on behalf of the scientific associations of trauma (NVT) and orthopedic surgeons 
(NOV). Being in close cooperation with the MTU, it should be evaluated how FLS nurse specialists can establish and maintain contact with general practitioners and geriatricians or physicians in nursery homes. This new concept of MTU-care and its impact on FLS care should be evaluated.

This is the one of the first dissertations on nurse practitioner's-initiated research at the FLS. In this dissertation, we intended to contribute to FLS-related research from a nurse specialist's perspective. We believe that FLS nurse specialists (nurses, nurse practitioners and physician assistants) play an important role in secondary fracture prevention. In total 145 nurse specialists (of whom 66 nurse practitioners and/ or physician assistants) are (part-time) active in 74 FLSs divided amongst 72 nonacademic and 8 academic hospitals in the Netherlands. It is therefore important that nurse specialists are united in a solid organization focusing on further improvement of quality and knowledge of FLS care by combining patient care, management and research. In this context, future research should not only focus on adequate diagnosis, initiation and follow-up of treatment but also on other outcomes of FLS care such as improvement of quality of life and the reduction of fracture risk and mortality risk. 


\section{References}

1. van den Bergh JP, van Geel TA, Geusens PP. Osteoporosis, frailty and fracture: implications for case finding and therapy. Nat Rev Rheumatol. 2012 Jan 17;8(3):163-72. doi: 10.1038/ nrrheum.2011.217.

2. Eisman JA, Bogoch ER, Dell R, Harrington JT, McKinney RE Jr, McLellan A, Mitchell PJ, Silverman S, Singleton R, Siris E. Making the first fracture the last fracture: ASBMR task force report on secondary fracture prevention. J Bone Miner Res. 2012 Oct;27(10):2039-46. doi: 10.1002/jbmr.1698.

3. Lems WF, Dreinhöfer KE, Bischoff-Ferrari H, Blauth M, Czerwinski E, da Silva J, Herrera A, Hoffmeyer P, Kvien T, Maalouf G, Marsh D, Puget J, Puhl W, Poor G, Rasch L, Roux C, Schüler S, Seriolo B, Tarantino U, van Geel T, Woolf A, Wyers C, Geusens P. EULAR/EFORT recommendations for management of patients older than 50 years with a fragility fracture and prevention of subsequent fractures. Ann Rheum Dis. 2017 May; 76(5):802-810. doi: 10.1136/annrheumdis-2016-210289.

4. Dreinhöfer KE, Mitchell PJ, Bégué T, Cooper C, Costa ML, Falaschi P, Hertz K, Marsh D, Maggi S, Nana A, Palm H, Speerin R, Magaziner J; on behalf of: the Fragility Fracture Network (FFN); European Geriatric Medicine Society (EuGMS); European Federation of National Associations of Orthopaedics and Traumatology (EFORT); International Collaboration of Orthopaedic Nursing (ICON); International Geriatric Fracture Society (IGFS); International Osteoporosis Foundation (IOF). A global call to action to improve the care of people with fragility fractures. Injury. 2018 Aug;49(8):1393-1397. doi: 10.1016/j.injury.2018.06.032.

5. Conley RB, Adib G, Adler RA, Åkesson KE, Alexander IM, Amenta KC, Blank RD, Brox WT, Carmody EE, Chapman-Novakofski K, Clarke BL, Cody KM, Cooper C, Crandall CJ, Dirschl DR, Eagen TJ, Elderkin AL, Fujita M, Greenspan SL, Halbout P, Hochberg MC, Javaid M, Jeray KJ, Kearns AE, King $T$, Koinis TF, Koontz JS, Kužma M, Lindsey C, Lorentzon M, Lyritis GP, Michaud LB, Miciano A, Morin SN, Mujahid N, Napoli N, Olenginski TP, Puzas JE, Rizou S, Rosen CJ, Saag K, Thompson E, Tosi LL, Tracer H, Khosla S, Kiel DP. Secondary Fracture Prevention: Consensus Clinical Recommendations from a Multistakeholder Coalition. J Bone Miner Res. 2020 Jan;35(1):36-52. doi: 10.1002/jbmr.3877.

6. McLellan AR, Gallacher SJ, Fraser M, McQuillian C (2003). The fracture liaison service: success of program for the evaluation and management of patients with osteoporotic fracture. Osteoporos Int 14:1028-1034.

7. Dutch Institute for Healthcare Improvement CBO (2011) Richtlijn Osteoporose en Fractuurpreventie. www.diliguide.nl/document/1015/file/pdf/. (Dutch) Assessed 14-02-2019.

8. Huntjens KM, van Geel TA, van den Bergh JP, van Helden S, Willems P, Winkens B, Eisman JA, Geusens PP, Brink PR. Fracture liaison service: impact on subsequent non-vertebral fracture incidence and mortality. J Bone Joint Surg Am. 2014 Feb 19;96(4):e29. doi: 10.2106/JBJS.L.00223.

9. Huntjens KM, van Geel TC, Geusens PP, Winkens B, Willems P, van den Bergh J, Brink PR, van Helden S. Impact of guideline implementation by a fracture nurse on subsequent fractures and mortality in patients presenting with non-vertebral fractures. Injury. 2011 Sep;42 Suppl 4:S39-43. doi: 10.1016/S0020-1383(11)70011-0.

10. van Geel, TC, Bliuc D, Geusens, PPM, Center, JR, Dinant, G-J, Thach Tran, T, van den Bergh, JPW, McLellan AR, Eisman JA. Reduced mortality and subsequent fracture risk associated with oral bisphosphonate recommendation in a fracture liaison service setting: A prospective cohort study. PLOS ONE, 13(6), [0198006]. https://doi.org/10.1371/journal.pone.0198006.

11. Geusens P, Bours SPG, Wyers CE, van den Bergh JP. Fracture liaison programs. Best Pract Res Clin Rheumatol. 2019;33(2):278-289.

12. https://www.zorginzicht.nl/kwaliteitsinstrumenten/osteoporose-indicatoren 
13. Akesson K, Marsh D, Mitchell PJ, McLellan AR, Stenmark J, Pierroz DD, Kyer C, Cooper C (IOF Fracture Working Group) (2013). Capture the Fracture®: a Best Practice Framework and global campaign to break the fragility fracture cycle. Osteoporos Int. 24(8):2135-52. doi: 10.1007/ s00198-013-2348-z.

14. https://www.capturethefracture.org/ (assessed 25-3-2020)

15. https://www.iofbonehealth.org/ (assessed 25-3-2020)

16. Catalogue of Bias Collaboration. Turk A, Heneghan C, Nunan D. Non-response bias. In: Catalogue of Bias 2019. https://catalogofbias.org/biases/non-response-bias/

17. Lewis EF, Hardy M, Snaith B. Estimating the effect of nonresponse bias in a survey of hospital organizations. Eval Health Prof. 2013 Sep;36(3):330-51. doi: 10.1177/0163278713496565.

18. Cheung KL, Ten Klooster PM, Smit C, de Vries H, Pieterse ME. The impact of non-response bias due to sampling in public health studies: A comparison of voluntary versus mandatory recruitment in a Dutch national survey on adolescent health. BMC Public Health. 2017 Mar 23;17(1):276. doi: 10.1186/s12889-017-4189-8.

19. F Pouwer, HM van der Ploeg, I Bramsen. Straying in the Methodology II. Bias Introduced by Questionnaires. Ned Tijdschr Geneeskd. 1998 Jul 4;142(27):1556-8. [Article in Dutch]

20. https://opendata.cbs.nl/statline/\#/CBS/nl/navigatieScherm/zoeken?searchKeywords= osteoporose. Assessed 25-3-2020.

21. Javaid MK, Sami A, Lems W, Mitchell P, Thomas T, Singer A, Speerin R, Fujita M, Pierroz DD, Akesson K, Halbout P, Ferrari S, Cooper C. A patient-level key performance indicator set to measure the effectiveness of fracture liaison services and guide quality improvement: a position paper of the IOF Capture the Fracture Working Group, National Osteoporosis Foundation and Fragility Fracture Network. Osteoporos Int. 2020 Apr 8. doi: 10.1007/s00198-020-05377-1. [Epub ahead of print].

22. Warriner AH, Patkar NM, Yun H, Delzell E. Minor, Major, Low-Trauma, and high-trauma fractures: What are the subsequent fracture risks and how do they vary? Curr Osteoporos Rep. 2011 Sep;9(3):122-8.

23. van Geel TA, van Helden S, Geusens PP, Winkens B, Dinant GJ. Clinical subsequent fractures cluster in time after first fractures. Ann Rheum Dis. 2009 Jan;68(1):99-102. doi: 10.1136/ ard.2008.092775.

24. Balasubramanian A, Zhang J, Chen L, Wenkert D, Daigle SG, Grauer A, Curtis JR. Risk of subsequent fracture after prior fracture among older women. Osteoporos Int. 2019 Jan;30(1):79-92. doi: 10.1007/s00198-018-4732-1.

25. Toth E, Banefelt J, Åkesson K, Spångeus A, Ortsäter G, Libanati C. History of Previous Fracture and Imminent Fracture Risk in Swedish Women Aged 55 to 90 Years Presenting With a Fragility Fracture. J Bone Miner Res. 2020 Jan 8. doi: 10.1002/jbmr.3953. [Epub ahead of print].

26. Johansson H, Siggeirsdóttir K, Harvey NC, Odén A, Gudnason V, McCloskey E, Sigurdsson G, Kanis JA. Imminent risk of fracture after fracture. Osteoporos Int. 2017 Mar;28(3):775-780. doi: 10.1007/s00198-016-3868-0.

27. Hans D, Baim S. Quantitative Ultrasound (QUS) in the Management of Osteoporosis and Assessment of Fracture Risk.J Clin Densitom. 2017 Jul - Sep;20(3):322-333. doi: 10.1016/j. jocd.2017.06.018.

28. Thomsen K, Jepsen DB, Matzen L, Hermann AP, Masud T, Ryg J. Is calcaneal quantitative ultrasound useful as a prescreen stratification tool for osteoporosis? Osteoporos Int. 2015 May;26(5):145975. doi: 10.1007/s00198-014-3012-y.

29. Schousboe JT, Riekkinen O, Karjalainen J. Prediction of hip osteoporosis by DXA using a novel pulse-echo ultrasound device. Osteoporos Int 2017 28:85-93 . doi: 10.1007/s00198-016-3722-4. 
30. Schneider J, Ramiandrisoa D, Armbrecht G, Ritter Z, Felsenberg D, Raum K, Minonzio JG. In Vivo Measurements of Cortical Thickness and Porosity at the Proximal Third of the Tibia Using Guided Waves: Comparison with Site-Matched Peripheral Quantitative Computed Tomography and Distal High-Resolution Peripheral Quantitative Computed Tomography. Ultrasound Med Biol. 2019 May;45(5):1234-1242. doi: 10.1016/j.ultrasmedbio.2019.01.008.

31. van der Velde RY, Wyers CE, Geusens PPMM, van den Bergh JPW, de Vries F, Cooper C, van de Staa TP, Harvey NC. Incidence of subsequent fractures in the UK between 1990 and 2012 among individuals 50 years or older. Osteoporos Int. 2018 Nov;29(11):2469-2475. doi: 10.1007/s00198018-4636-0.

32. Lötters FJ, van den Bergh JP, de Vries F, Rutten-van Mölken MP. Current and Future Incidence and Costs of Osteoporosis-Related Fractures in The Netherlands: Combining Claims Data with BMD Measurements. Calcif Tissue Int. 2016 Mar;98(3):235-43. doi: 10.1007/s00223-015-0089-z.

33. Leonard TC, Thaler RH, Cass R. Sunstein CR, Nudge: Improving decisions about health, wealth, and happiness. Const Polit Econ 19, 356-360 (2008). https://doi.org/10.1007/s10602-008-9056-2.

34. https://www.loketgezondleven.nl/vraagstukken/nudging (Dutch, Dutch Health Government) (assessed 15-5-2020)

35. https://www.who.int/dietphysicalactivity/publications/trs916/en/gsfao_osteo.pdf?ua=1 (assessed 28-5-2020)

36. https://www.gezondheidsraad.nl/binaries/gezondheidsraad/documenten/adviezen/2018/09/18/ gezondheidsraad-herziet-voedingsnormen-voor-volwassenen/kernadvies+Voedingsnormen+ voor+vitamines+en+mineralen+voor+volwassenen.pdf (Dutch) (assessed 25-5-2020)

37. National Institute for Public Health and the Environment RIVM. Dutch National Food Consumption Survey 2007-2010: Diet of children and adults aged 7 to 69 years.

38. Netelenbos JC, Geusens PP, Ypma G, Buijs SJ. Adherence and profile of non-persistence in patients treated for osteoporosis--a large-scale, long-term retrospective study in The Netherlands. Osteoporos Int. 2011 May;22(5):1537-46. doi: 10.1007/s00198-010-1372-5.

39. Klop C, Welsing PM, Elders PJ, Overbeek JA, Souverein PC, Burden AM, van Onzenoort HA, Leufkens HG, Bijlsma JW, de Vries F. Long-term persistence with anti-osteoporosis drugs after fracture. Osteoporos Int. 2015 Jun;26(6):1831-40. doi: 10.1007/s00198-015-3084-3.

40. M Hiligsmann, D Cornelissen, B Vrijens, B Abrahamsen, N Al-Daghri, E Biver, M L Brandi, O Bruyère, N Burlet, C Cooper, B Cortet, E Dennison, A Diez-Perez, A Gasparik, A Grosso, P Hadji, P Halbout, J A Kanis, J M Kaufman, A Laslop, S Maggi, R Rizzoli, T Thomas, S Tuzun, M Vlaskovska, J Y Reginster. Determinants, Consequences and Potential Solutions to Poor Adherence to Anti-Osteoporosis Treatment: Results of an Expert Group Meeting Organized by the European Society for Clinical and Economic Aspects of Osteoporosis, Osteoarthritis and Musculoskeletal Diseases (ESCEO) and the International Osteoporosis Foundation (IOF) Osteoporos Int. 2019 Nov;30(11):21552165. doi: 10.1007/s00198-019-05104-5.

41. Waalen J, Bruning AL, Peters MJ, Blau EM. A telephone-based intervention for increasing the use of osteoporosis medication: a randomized controlled trial. Am J Manag Care. 2009;15(8):e60-e70.

42. Solomon $\mathrm{DH}$, Iversen MD, Avorn J, et al. Osteoporosis telephonic intervention to improve medication regimen adherence: a large, pragmatic, randomized controlled trial. Arch Intern Med. 2012;172(6):477-483.

43. Stuurman-Bieze AG, Hiddink EG, van Boven JF, Vegter S. Proactive pharmaceutical care interventions decrease patients' nonadherence to osteoporosis medication. Osteoporos Int. 2014 Jun;25(6):1807-12. doi: 10.1007/s00198-014-2659-8. 
44. Vasikaran S, Eastell R, Bruyère O, Foldes AJ, Garnero P, Griesmacher A, McClung M, Morris HA, Silverman S, Trenti T, Wahl DA, Cooper C, Kanis JA; IOF-IFCC Bone Marker Standards Working Group. Markers of bone turnover for the prediction of fracture risk and monitoring of osteoporosis treatment: a need for international reference standards. Osteoporos Int. 2011 Feb;22(2):391420. doi: 10.1007/s00198-010-1501-1.

45. Delmas PD, Vrijens B, Eastell R, et al; Improving Measurements of Persistence on Actonel Treatment (IMPACT) Investigators. Effect of monitoring bone turnover markers on persistence with risedronate treatment of postmenopausal osteoporosis. J Clin Endocrinol Metab. 2007;92(4):1296-1304.

46. Cornelissen D, de Kunder S, Si L, Reginster JY, Evers S, Boonen A, Hiligsmann M; European Society for Clinical and Economic Aspect of Osteoporosis, Osteoarthritis and Musculoskeletal Diseases (ESCEO). Interventions to improve adherence to anti-osteoporosis medications: an updated systematic review. Osteoporos Int. 2020 May 1. doi: 10.1007/s00198-020-05378-0.

47. https://www.volgjezorg.nl/en/lsp (Assessed 25-5-2020) 

Nederlandse samenvatting

Valorization

Dankwoord

Curriculum vitae 


\section{SAMENVATTING}

Met als doel een gestandaardiseerde en optimale zorg op een Fractuur \& Osteoporose polikliniek (Fracture Liaison Service, FLS) na te streven, wordt een systematische, en bij voorkeur coördinator gestuurde aanpak voor identificatie, FLS aanmelding, evaluatie, behandeling en monitoring van patiënten met een recente fractuur van 50 jaar en ouder geadviseerd*. Na identificatie van de patiënten met een recente fractuur, wordt aanbevolen een gedetailleerde evaluatie van de medische voorgeschiedenis, medicatiegebruik, klinische risicofactoren, vitamine D-status, calciuminname met de voeding, bekende veroorzakers van secundaire osteoporose en valrisico uit te voeren, gelijktijdig met een beoordeling van botmineraaldichtheid (BMD) en Vertebral Fracture Assessment (VFA, beeldvorming van de wervelkolom). Vervolgens wordt aanbevolen dat patiënten verder worden geëvalueerd op niet eerder gediagnosticeerde oorzaken van secundaire osteoporose en metabole botaandoeningen. Aansluitend volgt een multifactoriële interventie, inclusief aanbevelingen voor leefstijl, calcium- en / of vitamine D-suppletie indien vereist en indien nodig een behandeling van onderliggende aandoeningen. Specifieke antiosteoporose behandeling moet worden aangeboden in overeenstemming met nationale richtlijnen en met een georganiseerde patiënten follow-up na 3 maanden en daarna jaarlijks (Richtlijn Osteoporose en Fractuurpreventie; Nederlands Instituut voor Verbetering van de Gezondheidszorg; CBO 2011).

Dit proefschrift bestaat uit zes onderzoeken naar verschillende aspecten van secundaire fractuurpreventie. We hebben de implementatie van FLS in Nederlandse Fractuur \& Osteoporose poliklinieken bestudeerd in Hoofdstuk 2. De ziekenhuisregistratie en patiënt-gerelateerde factoren die geassocieerd waren met het al dan niet bezoeken van de FLS werden bestudeerd in Hoofdstuk 3 en in Hoofdstuk 4 hebben we de redenen voor het niet bezoeken van de FLS verder onderzocht. In Hoofdstuk 5 hebben we onderzocht of een Pulse-Echo Ultrasound apparaat de identificatie mogelijk maakt van vrouwen met een recente niet-wervel fractuur op de FLS die geen DXANFA nodig zouden hebben. In Hoofdstuk 6 hebben we de dagelijkse calciuminname bij FLS patiënten geanalyseerd en in Hoofdstuk 7 werd de impact van telefoongesprekken op de therapietrouw van osteoporose medicatie gedurende één jaar bestudeerd.

* van den Bergh JP, van Geel TA, Geusens PP. Osteoporosis, frailty and fracture: implications for case finding and therapy. Nat Rev Rheumatol. 2012 
In Hoofdstuk 2 hebben we de implementatie van de fractuur en osteoporosezorg in Nederlandse niet-universitaire ziekenhuizen geëvalueerd met gebruik van een vragenlijst aan de hand van de vastgestelde FLS zorgstandaarden geformuleerd door de International Osteoporosis Foundation (IOF) in het Capture the Fracture Best Practice Framework (CtF-BPF) om informatie te verzamelen over de behandelsituatie in Nederland ten aanzien van casefinding, de risico evaluatie en de ingestelde behandelingen bij patiënten van 50 jaar en ouder na een recente fractuur. Alle (toen nog) 90 Nederlandse niet-universitaire ziekenhuizen kregen de uitnodiging om deel te nemen aan dit onderzoek. Dit resulteerde in 24 (27\%) volledig evalueerbare vragenlijsten, met gegevens van 24.468 opeenvolgende patiënten, wat overeenkomt met 25\% van alle patiënten ouder dan 50 jaar met een fractuur in Nederland, in het jaar 2012. De gegevens toonden aan dat alle deelnemende ziekenhuizen boven de 90\% scoorden voor de volgende CtF-BPF normen: identificatie van patiënten met een recente fractuur in de ziekenhuizen, uitnodiging voor FLS, timing van beoordeling, identificatie van wervelfracturen, toepassing van nationale richtlijnen, evaluatie van secundaire osteoporose, start met medicatie indien geïndiceerd, communicatie met de huisarts en de toepassing van een vervolgstrategie. Deze bevindingen suggereren dat het merendeel van de Nederlandse FLS-en die de vragenlijst invulden voldoen aan de criteria van het 'beste FLS-model ' (gebaseerd op de CtFBPF zorgstandaarden), waaronder de aanwezigheid van een gespecialiseerde FLS verpleegkundige, een hoogwaardige FLS service en wanneer geïndiceerd de start van anti-osteoporosemedicatie. Een ander belangrijk onderzoeksresultaat was dat van alle geïdentificeerde fractuurpatiënten slechts 50\% op de uitnodiging inging en de FLS bezocht. We concludeerden dat patiënten die deze FLS-en bezochten, in hoge mate werden geëvalueerd, behandeld en opgevolgd volgens de CtF-BPF zorgstandaarden. Een belangrijke tekortkoming blijkt te zijn dat te weinig uitgenodigde patiënten daadwerkelijk de FLS bezochten. Toekomstig onderzoek zou zich zou moeten concentreren op het identificeren van de oorzaken van deze lage komst naar de FLS en het zoeken naar manieren om het te verbeteren.

In Hoofdstuk 3 hebben we ziekenhuisregistratie en patiënt-gerelateerde factoren bestudeerd die verband hielden met het al dan niet bezoeken van de FLS door fractuurpatiënten die waren uitgenodigd in 2016. Tijdens deze studiewerd aangetoond dat 14\% van de fractuurpatiënten, 278 van 2006 opeenvolgende patiënten, vanwege administratieve fouten niet was uitgenodigd de FLS te bezoeken. Alle 1288 patiënten 
die wèl werden uitgenodigd voor FLS bezoek kregen een vragenlijst toegestuurd. In totaal stuurden 745 patiënten (van wie 537 wèl de FLS bezochten en 208 de FLS niet bezochten) een analyseerbare vragenlijst terug. Het niet bezoeken van de FLS kon worden geassocieerd met mannelijk geslacht, een kwetsbare gezondheid, het alleen wonen, een laag opleidingsniveau, het niet geïnteresseerd zijn in de kwaliteit van het bot en het niet op de hoogte zijn van een toegenomen opvolgend fractuurrisico (met Odds Ratio's; OR's) tussen 1.62 en 2.08). Het wèl bezoeken van de FLS was significant geassocieerd met aan de patiënt verstrekte informatie (OR: 3.32). Uitkomst van deze studie toonde aan dat uitnodigen op basis van een onvolledige registratie leidde tot het onterecht niet oproepen van 14\% van alle patiënten. Daarnaast toonde dit onderzoek dat mannelijk geslacht, kwetsbare gezondheid, een lage algemene opleiding, het alleen-wonen en een lage interesse in botgezondheid en het opvolgende fractuurrisico onafhankelijke determinanten zijn voor het niet ingaan op de FLS uitnodiging. Het al dan niet motiveren van patiënten door de behandelende zorgverlener kort na het doormaken van de fractuur was de sterkste determinant geassocieerd met het wel of niet bezoeken van de FLS. Het is van belang de DBC registratie te gebruiken die het ziekenhuis ook gebruikt voor de facturatie voor het uitnodigingsproces op de FLS en te werken aan een FLS uitnodigingstraject op maat waarin de zorgverlener met hulp van adequate patiëntinformatie en gedeelde besluitvorming het FLS bezoek kan verbeteren.

In Hoofdstuk 4 hebben we onderzocht of screening met een draagbaar ultrasound apparaat interessant zou kunnen zijn om verwijzingen voor Dual X-Ray Absorptiometry (DXA) en Vertebral Fracture Assessment (VFA) te beperken. We hebben het aantal negatieve DXA/VFA uitkomsten voor osteoporose en/of subklinische wervelfracturen (VF's) berekend en vergeleken met uitkomsten van Pulse-Echo Ultrasonometry (P-UE) op basis van verschillende drempelwaarden. In deze cross-sectionele studie werden 209 opeenvolgende vrouwen van 50-70 jaar met een recente niet-wervelfractuur (NVF) onderzocht op de Fracture Liaison Service (FLS) van het Reinier de Graaf gasthuis in Delft. Deze vrouwen kregen naast DXA / VFA ook een P-EU (Bindex®) -beoordeling. Verschillende P-EU-drempelwaarden (gebaseerd op de P-EU dichtheidsindex (DI, g/cm2)) werden geanalyseerd om de beste balans te berekenen tussen echtnegatief (inderdaad geen osteoporose en/of subklinische VF) en fout-negatieve tests (osteoporose en/of subklinische VF volgens DXA / VFA). 83 vrouwen hadden osteoporose (40\%) en 17 vrouwen tenminste één VF (8\%). Het toepassen van de 
door de fabrikant aanbevolen P-EU drempelwaarde (DI $0.844 \mathrm{~g} / \mathrm{cm} 2$ ) als voorgestelde grenswaarde voor het niet hebben van osteoporose in de heup(hals) resulteerde bij 77 vrouwen in negatieve testen (37\%, 31\% echt-negatieve en 6\% fout-negatieve tests). Een DI van $0.896 \mathrm{~g} / \mathrm{cm} 2$ resulteerde bij 40 deelnemende vrouwen in een negatieve test (19.3\%) (38 echt-negatieve (18.3\%) en 2 fout-negatieve testen (1.0\%). Uit de onderzoeksresultaten blijkt dat door de toepassing van P-EU een deel van de deelnemende vrouwelijke fractuurpatiënten tussen 50-70 jaar geen DXA/VFA nodig zou hebben omdat er geen osteoporose en/of subklinische wervelfracturen werden aangetoond. De toepassing van de meest conservatieve P-EU drempelwaarde 0.896 $\mathrm{g} / \mathrm{cm} 2$ ) resulteerde in $18.3 \%$ echt-negatieve testresultaten tegen $1 \%$ fout-negatieve testresultaten geverifieerd door DXANFA in de onderzochte groep vrouwen 50-70 na een recente fractuur.

In Hoofdstuk 5 hebben we de kenmerken van patiënten die niet ingingen op de FLS uitnodiging verder geanalyseerd door hen tijdens een huisbezoek (HV) door een FLS medewerkster een vragenlijst in te laten vullen of, als HV werd geweigerd, een vragenlijst per post toe te sturen (Q) om inzicht te krijgen in hun mening over de oorzaak van de fractuur en hun mening te vragen over het opvolgende fractuurrisico. Van deze 197 fractuurpatiënten die niet reageerden op de FLS uitnodiging (nonresponders) werden 181 patiënten opgespoord en gebeld totdat 50 van hen met $\mathrm{HV}$ instemden. 42 patiënten weigerden $\mathrm{HV}$, maar stemden in met Q, 81 patiënten wezen elk voorstel af (non-HV | Q). Van de HV en Q-patiënten kon 62\% zich de eerste FLS uitnodigingsbrief herinneren. De mening van de patiënt over de belangrijkste oorzaak van fracturen verschilde tussen HV en Q en was: de val (HV 96\% versus Q $79 \%, p=.02$ ), slechte fysieke conditie (HV 36\% versus Q 2\%, $p=.0001$ ), duizeligheid of disbalans (HV 24\% versus Q 7\%, $\mathrm{p}=.03$ ), osteoporose (HV16\% versus Q 2\%, $\mathrm{p}=$ .02) en verhoogd fractuurrisico (HV 26\% versus Q 17\%, NS). Leeftijd $\geq 70$, vrouwelijk geslacht en een ernstige fractuur waren significant geassocieerd met toestemming voor HV in vergelijking met Q (respectievelijk OR 2.7, 2.5 en 2.4) alsook HV vergeleken met non-HVIQ (OR 16.8, 5.3 en 6.1). FLS non-responders achten hun opvolgende fractuurrisico laag. Toch stemde $25 \%$ in met een huisbezoek na één telefoontje, voornamelijk oudere vrouwen na een ernstige fractuur. Deze subgroep van FLS non-responders met een hoog daaropvolgend fractuurrisico lijkt dan ook goed benaderbaar voor secundaire fractuurpreventie. 
In Hoofdstuk 6 hebben we onderzocht of patiënten met een recente fractuur voldeden aan de aanbevelingen voor dagelijkse calciuminname en de gekwantificeerde dagelijkse calciuminname uit zuivel (melk, melkdranken, pudding, yoghurt en kaas) in een Nederlands cohort van fractuurpatiënten en de resultaten vergeleken met recente gegevens van een gezond Amerikaans cohort (80\% kaukasisch). Dit observationele onderzoek analyseerde de calciuminname van 1526 vrouwelijke en 372 mannelijke Nederlandse fractuurpatiënten van 50 jaar en ouder die de FLS van het Reinier de Graaf Gasthuis bezochten. De deelnemers namen gemiddeld drie porties melk per dag, onafhankelijk van leeftijd, geslacht of bevolkingsdichtheid. De mediane calciuminname uit zuivel was 790 mg/dag bij vrouwen en mannen. Op basis van zuivelproducten alleen voldeed 11,3\% van de vrouwen en 14,2\% van de mannen aan de Nederlandse aanbevelingen voor calciuminname (volwassenen $\leq 70$ jaar: 1100 mg / dag en > 70 jaar: 1200 mg / dag). Met een aanvullende berekening waarbij uitgegaan werd van $450 \mathrm{mg}$ calcium uit de basisvoeding voldeed respectievelijk $60.5 \%$ en $59.1 \%$ aan de Nederlandse aanbevelingen vergeleken met $53.2 \%$ in Amerikaanse cohort. Hoewel de dagelijkse zuivelcalciuminname van Nederlandse fractuurpatiënten ver onder de aanbevolen inname lag, was deze vergelijkbaar met de inname in een Amerikaans cohort (met/zonder fracturen) uit een studie van Fulgoni. Tijdens de anamnese naar de consumptie van calcium dient men niet alleen het aantal zuivelproducten maar ook de overige voeding mee te tellen.

In Hoofdstuk 7 hebben we ons gericht op de medicatie persistentie van patiënten die na FLS bezoek met orale anti-osteoporose behandeling (alendronaat) waren begonnen. Postmenopauzale vrouwen na een recente fractuur en osteoporose die met alendronaat begonnen, werden gerandomiseerd om drie ondersteunende telefoongesprekken te krijgen (PC) (na 1, 4 en 12 maanden) of geen ondersteunende telefoongesprekken (no PC) te krijgen. De botombouw merkstoffen (BM) s-CTX en P1NP werden gemeten bij aanvang van het onderzoek (vóór medicatiestart) en na 3, 6, 9 en 12 maanden. Als referentiegroep werden ook 30 postmenopauzale osteopenie patiënten met een recente fractuur geanalyseerd. De medicatie persistentie werd beoordeeld met behulp van het Landelijk Schakelpunt (LSP) waarin de afleverdata van apotheken door geauthoriseerde zorgverleners kunnen worden ingezien) en vergeleken met PC, no PC en de veranderingen in de BM. De afkapwaarden van de BM werden berekend op basis van de "kleinste significante verandering" (Least Significant Change, LSC) evenals op het onderschrijden van de mediane waarden 
van de onbehandelde postmenopauzale osteopenie referentiegroep na een recente fractuur. De onderzoeksresultaten toonden dat van de 119 patiënten, 93 patiënten (78\%), gemiddelde leeftijd 69 jaar, na 12 maanden medicatie persistent waren (45 PC en 48 no PC). Deze persistentie was vergelijkbaar tussen de PC en de no PC deelnemers. De BM afkapwaarde voor s-CTX werd bepaald op $>29 \%$ (<415 ng/L) als LSC en voor P1NP op >36\% (<53,1 $\mu \mathrm{g} / \mathrm{L})$ als LSC. De afkapwaarden toonden alendronaat persistentie bij respectievelijk 93 en 88 \% van de patiënten. Wij concludeerden dat telefoongesprekken in dit verband de medicatie persistentie niet verbeterden. Bij ongeveer 90\% van de patiënten werd de 1-jaars persistentie ten aanzien van alendronaat bevestigd door het bereiken van LSC van S-CTX en van P1NP, waarbij de uitgangswaarden werden vergeleken met waarden na 3,6,9 en 12 maanden. 


\section{VALORIZATION}

\section{Introduction}

This chapter describes valorization of a number of our findings in this dissertation, focusing on secondary fracture prevention and the Fracture Liaison Service (FLS), from a nurse practitioner `s perspective. The importance of Secondary fracture prevention in general is recognized and supported by the International Osteoporosis Foundation (IOF) and by other international and national scientific organizations and authorities. In view of effectiveness, FLS care has become highly recommended. However, the low FLS attendance rate of patients with a recent fracture has been recognized as a huge problem needing further exploration. In this dissertation, we examined the following topics related to secondary fracture prevention: hospital registration, patient information and patient knowledge about their subsequent fracture risk, value of a portable ultrasound device in screening, nutritional calcium intake and medication adherence.

\section{Valorization}

In the Reinier de Graaf Hospital, we discovered that 14\% of patients older than 50 years with a fracture were not invited at the FLS, due to hospital registration inaccuracies. The cause is that FLS invitation strategies are traditionally based on hospital registrations at entry, not on exit registration and between these time points a diagnosis of fracture could have been added. Use of financial department registrations (using exit DBC registrations) is recommended to increase the accuracy of FLS invitation.

The second topic studied is patient information, which is part of our invitation strategy to attend the FLS. Surprisingly, our personal information given to the patient was not recalled by any of our non-attending fracture patients. In contrast, more than half of FLS attenders could recall the information letter received as a reason to attend the FLS. We also observed a major knowledge gap regarding the increased imminent subsequent fracture risk, which was often grossly underestimated. The main reasons were low interest in bone health and (according to the literature) low health illiteracy. These findings emphasize the need for a systematic FLS nurse-led approach to ensure adequate and timely information to patients, preferentially as soon as possible after the initial fracture, e.g. during the fracture healing phase. This 
practice has been routinely implemented in the Reinier de Graaf Hospital FLS setting. Patient information is given by our plaster nurses and/or orthopedic and trauma surgeons, but still needs improvement so that patients recall this information.

Another topic addressed in this dissertation is the reinforcement of screening procedures. By using a portable ultrasound device, we yielded a 19 percent benefit by avoiding the performance of DXA and VFA in low risk women of 50-70 years. In addition, this might be attractive as a moment of persuasion to strengthen the message to our patients, since a 'positive' outcome could motivate patients to agree with further assessment by DXA and VFA, while a negative outcome could reassure patients without the need of further assessments. However, it should be further evaluated whether the same holds for elderly patients.

We also performed an audit in the Netherlands on Dutch FLS quality using the Capture the Fracture ${ }^{\circledR}(\mathrm{CtF} \circledast)$ Best Practice Framework Standards of Care. FLS attendance reported by 24 Dutch FLS's was on average 49\%, which obviously is too low. In FLS attenders the FLS's complied for more than 90\% on the 13 CtF® Standards of care and for more than $70 \%$ with fall prevention strategies. Currently there is no nationwide database on patients evaluated in Dutch FLSs. Based on the findings of this first audit in the Netherlands, we were able to bring the results to the attention of the Dutch governmental Health Council (Zorginstituut) focusing on the unacceptably low FLS attendance rates.

Reasons for 'non-attendance' were further assessed in two FLS studies, carried out in the Reinier de Graaf hospital. Frailty, male gender, having low general education, living alone, and low interest in bone health and subsequent fracture risk were independent determinants for FLS non-attendance. Adequate motivation of patients by the healthcare professional shortly after the fracture, or the lack of it, was the strongest determinant associated with both FLS attendance and non-attendance. Remarkably, still 25\% of non-responders to FLS invitation consented with a home visit after one telephone call, and these were mainly older women with a major fracture, i.e. those who would most benefit from secondary fracture prevention. These patients could not recall any face-to-face patient information given to them in the hospital. Still FLS invitation by letter was recalled in more than 60\%. FLS nurses and nurse practitioners could therefore ease the transition from hospital to GP care in the high-risk group of FLS non-responders/non-attenders to contact the GP for further evaluation and treatment. For the nurse in charge with FLS logistics it may be 
advisable to contact the non-responding patients and organize further FLS care in collaboration with GPs. Care for the patient, wherever offered, is part of our mission and is directly in line with the vision propagated by Value Based Health Care (VBHC). Our study on dairy calcium consumption among fracture patients turned out to be very feasible. We found a shortage of daily dairy calcium intake in many fracture patients, independently of age, gender or residential area (urban or rural). A good nutritional history and advice is therefore part of the basic package of care that can specifically be offered by FLS nurses.

Based on well reported follow-up strategies by 24 FLS's in the Netherlands (as reported in our Dutch audit), we decided to study our own performance with regard to oral bisphosphonates-initiation and adherence. One telephone call at three months after treatment initiation was useful to discuss adherence, eventual side effects or medication discontinuation. Additional telephone calls during follow-up appeared not to be efficacious. Corrected bone turnover marker levels (P1NP and S-CTX) showed high agreements with pharmacies deliveries according to the Dutch Landelijk Schakelpunt database (LSP) by 12 months. Since LSP is accessible to all health care professionals, we propose that FLS nurses can use LSP to assure adherence to oral bisphosphonates at 12 months post-treatment initiation. Thus, one telephone call is advised for evaluating adherence, side effects and if applicable, reasons for medication discontinuation. The value of measuring and following bone markers is more complex, as it needs strict monitoring of timing of blood samples and additional studies on cost.

The work presented in this dissertation is based on nurse practitioner initiated studies. This should be a stimulus for nurse colleagues for initiating new FLs studies on their role in secondary fracture prevention. We foresee a challenging role for NPS to participate in future initiatives. Therefore, Dutch FLS nurses and nurse practitioners should further strengthen their vision and experience with implementation in the national professional association (VF\&O) guaranteeing professional information and training for newcomers. Moreover, next to nurses, nurse practitioners act in a coordinative role in many FLS's throughout the country. Their legal authorizations are not only confined to traditional aspects of nursery care, lifestyle aspects and nutrition, but also include initiation of medical therapies and consequent medication adherence.

Finally, dedicated nurses and/or nurse practitioners support the vision of a FLS 
nurse-led model in line with the concepts of Value Based Health Care (VBHC). Our professional association was privileged to participate in the national working group for the preparation of a national guideline and working group on standards of osteoporosis care. In this position, the nurses' association can propagate their visions on transition of hospital care in the Zinnige Zorg Trajectory on Osteoporosis (Dutch governmental Health Council, Gezondheidsraad) and the National Guideline on Osteoporosis and Fracture prevention.

In summary, this dissertation may serve as a blueprint of our motivation and scientific interest. I would like to commission my work to all colleague nurses and nurse practitioners who act according to care, cure and scientific reasoning. 


\section{DANKWOORD}

Dit proefschrift zou niet tot stand zijn gekomen als ik daarin niet door collega 's, vrienden en familie met veel belangstelling zou zijn gesteund: ik ben iedereen daarvoor zeer dankbaar!

Eigenlijk is dit proefschrift de ontknoping van jarenlange groei door alle werkzame jaren in de gezondheidszorg, toegespitst op de zorg voor fractuur patiënten. De basis daarvoor werd gelegd tijdens mijn opleiding tot verpleegkundige in het toenmalige St. Hippolytus ziekenhuis in Delft en vervolgens tot gipsverbandmeester in het Academisch Ziekenhuis Leiden, nu LUMC, in veel opzichten een leerzame periode. Maar pas de afgelopen 15 jaar ben ik gegroeid in het inzicht dat een fractuur op oudere leeftijd veel meer impliceert dan het gevolg van een trauma en daarmee ook vraagt om een veel bredere benadering dan vaak gebruikelijk.

Met grote dankbaarheid kijkik terug op de voorbije jaren in het Delftse Reinier de Graaf Gasthuis waarin de kwaliteit van zorg altijd uitgangspunt was (en is!): dit topklinische ziekenhuis met al die prachtige collega `s die mij in staat stelden en motiveerden tot groei en ontwikkeling. Ik was bevoorrecht authentieke collega ‘s (verpleegkundigen, artsen en minstens zo belangrijk: al die andere ziekenhuis collega `s!) te mogen ontmoeten, van hen te mogen leren en met hen samen te mogen werken. De pionierende fase na de entree van de verpleegkundig specialisten was boeiend en heeft tot de huidige implementatie mogen leiden (dank Marieke, Colette, Nel, Sandra, Yvonne en Miep). Bijzondere dank aan orthopedisch chirurg Bernard Jansen die me uitdaagde zelfstandig na te denken, keuzes te maken en daar ook naar te handelen ("als jij je werk niet goed doet zal ik die patiënt toch moeten opereren'). Met wat heimwee maar ook voldoening zie ik terug op de 'domein ' discussies. Verpleegkundigen (en daarmee dus gipsverbandmeesters!) en verpleegkundig specialisten zullen zelf het domein moeten afbakenen en de transitie vervolgens blijvend en verantwoord moeten inrichten.

Een aantal mensen komt een bijzonder woord van dank toe.

Prof. dr. J.J.P. van den Berg, beste Joop, je bent gedreven en hebt een enorme parate kennis. Je overziet als geen ander de consequenties die de details soms kunnen hebben voor het grotere geheel. Secundaire fractuur preventie in Nederland heeft je volle aandacht en je ziet kans alle initiatieven met elkaar te verbinden. Je lijkt over 
een vrijwel onuitputtelijke energie te beschikken om voortdurend present te zijn je kennis uit te dragen en daarmee secundaire fractuurpreventie de plaats te geven die het verdient. Altijd als ik dacht dat een artikel `af `was, had jij wel scherpe suggesties die opnieuw tot nadenken stemden. Ik ben je dankbaar voor de kansen die ik van je kreeg om in jouw groep te promoveren.

Prof. dr. P.P. Geusens, beste Piet, we hebben als promotiecommissie wat moeten wennen aan het moderne promoveren, de afstand en het werken met skype, maar dat verliep allengs steeds beter. Ik leerde je aanvankelijk kennen als getalenteerd redenaar op diverse bijeenkomsten. Onze eerste ontmoetingen tijdens en na het FFN congres in Berlijn illustreerden bij uitstek je creatieve denken over de Fractuurpreventie \& Osteoporosepoliklinieken als "best model of care" voor de kwaliteitsverbetering van de secundaire fractuurpreventie. Tijdens onze waardevolle skype gesprekken leerde ik van je om hoofd- en bijzaken te onderscheiden en nam het onderzoek door jouw creatieve suggesties geregeld onverwachte wendingen.

Dr. D.H. Schweitzer, allerbeste Dave, co-promotor maar vooral vriend: we made it! We hebben het voor elkaar gekregen, maar zonder jouw motivatie en échte ondersteuning zou dit proefschrift er nooit zijn gekomen! Jouw creatieve geest is een bruisende bron van inspiratie en je vrijwel ongelimiteerde inzet bij het nadenken over de aanpak en interpretatie van een onderzoek is een enorme stimulans voor de promovendus. Enorm veel dank voor je vele geïnvesteerde uren in het lezen en corrigeren van teksten waarin naast correcte verslaglegging de hoge kwaliteit van het taalgebruik erg belangrijk voor je was. Als team vullen we elkaar naadloos aan en zouden we met jouw creativiteit nog jaren als onderzoekers vooruit kunnen. Veel dank voor alle kennis waarin je me hebt meegenomen en die je onvermoeibaar met me deelt, maar vooral voor de plaats die ik als vriend in het leven van jou en Myra mocht gaan innemen.

Dr. P.M.M. van Haard, beste Paul, statistische held, onze eerste ontmoetingen speelden zich af in jouw kantoor in Delft te midden van stapels papieren. Mijn eerste kennismaking met de échte statistiek maakte op mij grote indruk. Al snel vormden we met Dave een hecht team en steeds opnieuw bleek je inzet veel groter dan alleen de statistische analyse. Tijdens de diners met jou en Hennie bleek ook je grote algemene kennis en je beeldende culinaire bespiegelingen! Je meedenken bij de interpretatie en de verwerking van de data in een ongeëvenaard hoog tempo en je grote bijdrage in de correctie van papers: geweldig. Elke vraag om uitleg leverde mij naast antwoorden ook weer nieuwe statistische vragen en stapels verduidelijkende artikelen op. Ik heb 
enorm veel van je geleerd en voel me erg bevoorrecht door je vriendschap.

Veel dank ben ik verschuldigd aan de beoordelingscommissie en hun deskundige en weloverwogen oordeel: prof. dr. LW. van Rhijn, prof. dr. M.C. Zillikens, prof. dr. M.H. Emmelot, prof. dr. L.P.S. Stassen en dr. S.P.G. Bours.

Dank aan Marsha van Oostwaard voor alle gesprekken over het gestructureerde verpleegkundig aandeel in fractuurpreventie en osteoporose zorg. Met de oprichting van VF\&O hebben we dat op gang gebracht en blijvend op de zorgkaart gezet. En nu ook jouw promotie: houd vol! Je ziet dat het kan, het lukt jou ook! Dank voor de inspirerende samenwerking met het huidige VF\&O bestuur (Jennie, Hetty, Anja en Ingrid) waar ik opnieuw deel van uit ben gaan maken, nu in de rol van voorzitter. Mooi dat we met ons aller inzet (en dankzij de meer dan bereidwillige inzet van docenten) zo `n gave opleiding konden opzetten en dank voor de inzet van al die bevlogen VF\&O verpleegkundigen en verpleegkundig specialisten die fractuurpreventie als dagelijkse zorg invulling geven.

Hartelijk dank aan de directe collega's op de Fractuurpreventie \& Osteoporose polikliniek Wil, Sabine, Yvonne en Astrid. Wil, dank aan jou als pionierende bevlogen kracht achter deze polikliniek in de beginjaren en door de start met onderzoek tegen wil en dank ook organisator van talloze administratieve zaken. We hebben heel wat samen moeten uitvinden en wanneer jij dan zorgde voor de uitwerking kwam het altijd goed. Sabine, dank voor de verdere stroomlijning en uitrol van polikliniektaken bij groeiende patiëntenstromen die nieuwe uitdagingen vormden, dank voor de uitwerking van onderzoeksdata en het organiseren van databases. Dank aan de huidige collega `s Yvonne en Astrid voor de verdere voortzetting van het werk op het stevig gelegde fundament door Wil en Sabine.

Een speciaal woord van dank richt ik aan Luc Huijskes. Luc is van meet af aan betrokken geweest bij de Delftse Fractuurpreventie \& Osteoporose polikliniek en bouwde de basis database zodanig dat deze als managementtool geschikt was voor het doen van onderzoek maar - minstens zo belangrijk - ook geschikt als ingenieus instrument voor het monitoren van medicatietrouw.

Dank aan alle gipsverbandmeesters op de mooiste afdeling van het Reinier de Graaf Gasthuis (en tevens van elk ziekenhuis in het algemeen): de gipskamer, inmiddels ook al jaren de vaste aanlandplek voor een internist-endocrinoloog. Nicole, Evelien, Stephanie, Danny, Lisette, Anouk, Han, Christiane, Dirk, Lonneke (met een aantal van jullie gaat een hechte band al heel lang terug!) en de administratieve talenten 
Kim en Amber: heel veel dank voor alle collegialiteit, luisterende oren en jullie support en de mooie afdeling die we in de afgelopen jaren met $z$ ' $n$ allen mochten opbouwen.

Dank past zeker ook aan de collegiale en betrokken ondersteuning door de vakgroep nucleair geneeskundigen waar de DXA onderzoeken werden gedaan. Grote dank ben ik verschuldigd aan de (voormalig) DXA laborante Jeanette van de afdeling Nucleaire Geneeskunde. Toen alles nog in ontwikkeling was en we de processen nog op elkaar moesten laten aansluiten was jij de drijvende kracht vanuit de afdeling Nucleaire Geneeskunde om de flow in dat proces te brengen en het contact tussen de beide afdelingen te laten opbloeien, Loes heeft het goed van je overgenomen. Helaas zijn ons in die periode ook voor de afdeling belangrijke mensen ontvallen. Van groot belang is de inzet van jou en Marc geweest voor de studie naar ultrageluid en DXA: razend snel was je in staat alle noodzakelijke activiteiten te organiseren. Veel dank, patiënten waren altijd blij met je levenswijze Twentse aanpak.

Ik ben het bestuur van de Stichting Evidence Based Fracture Care (inmiddels Stichting Fragility Fracture Care Delft) erkentelijk waarin ik - na oprichting door (de te vroeg overleden) Ron te Slaa, Maarten van der Elst en ikzelf - nog steeds mag samenwerken met de bestuursleden Dieu Donné, Maarten en Dave (orthopedisch chirurg, traumachirurg, internist-endocrinoloog en een verpleegkundig specialist: FLS team in optima forma!) met inmiddels focus op "fragility fracture care": geïntegreerde fractuurbehandeling en secundaire fractuurpreventie door de specialismen heen. Onze stichting is nauw verbonden met het internationale Fragility Fracture Network (FFN) waarvan Dieu Donné bestuurslid is. We beogen de komende jaren een verdere uitbouw van deze internationale samenwerking.

Dank voor de betrokken belangstelling van de zijde van de orthopedisch chirurgen en traumachirurgen van het Reinier de Graaf Gasthuis. Het zoeken naar verbinding is uitgangspunt voor alle beleid in het Reinier de Graaf Gasthuis en ik ben er trots op dat ik zo lang 'verbindend' in dit ziekenhuis heb mogen werken. Mede door de verbindende gedeeldevisie op secundaire fractuurpreventie en de consensus daarover binnen fractuur-behandelende specialismen konden we de Fractuurpreventie \& Osteoporose polikliniek maken tot wat deze vandaag is. In de geest van de Delftse Evidence Based Fracture Care congressen van indertijd moet dat perspectief bieden voor de Multidisciplinaire Trauma Unit (MTU) in ons ziekenhuis zoals deze per januari 2021 van start zal gaan. 
Dank aan alle vrienden (Bram, Ada, Lex, Arna, Peter, Thuly, Ferry en Carla) die ik geregeld te kort heb gedaan omdat er weer eens te weinig tijd was of omdat m ' $n$ hoofd er weer niet goed bij was. Ondanks dat bleven jullie me uitnodigen! Dank ook aan al m `n fietsmaten (Ronald, Astrid, Marcel, Marlies, Frans, Ton, Ward, Lars en natuurlijk Pault) voor jullie betrokkenheid en het accepteren van mijn achterblijvende prestaties en het overslaan van de beurt bij `t kopwerk. We pakken de draad weer op!

De paranimfen Jurriën, mijn zoon, en Peter, één van mijn 'ouwe trouwe' vrienden, beiden ook vaste volgers van het hele promotieproces vanaf het prille begin: dank dat jullie deze rol op jullie wilden nemen!

Dank aan Sophie, mijn zus en haar echtgenoot Chris, en ook alle schoonzussen en zwagers en alle andere familieleden voor de niet aflatende belangstelling gedurende dit hele proces!

Lieve ma, als inmiddels 90 jarige vrouw ben je dapper doorgegaan na het overlijden van pa, nu 10 jaar geleden. Pa en ma: ik ben er zo trots op jullie zoon te mogen zijn. Ma, je geest is helder en ik weet dat je je snel bezorgd maakt, de laatste diagnose maakte dat ook niet beter. Deze ziekte wint het langzaam van je en dat doet me veel verdriet. Je was tot op het laatst erg betrokken bij je kinderen, maar minstens zo begaan met en geïnteresseerd in de ontwikkeling van je klein- en achterkleinkinderen. Ook met de eenzaamheid leerde je omgaan, steeds meer van je leeftijdsgenoten vielen de laatste jaren weg en nu was zelfs je wekelijkse kerkgang (én het koffiedrinken daarna!) niet meer mogelijk. Ik houd van je, we houden allemaal van je en bewonderen je sterke levenshouding.

Lieve Maria, mijn meisje, als laatste maar beslist de allerbelangrijkste ben ik jou dankbaar dat je me de ruimte hebt gegeven zoveel tijd in de promotie te hebben mogen investeren. Je accepteerde meestal zonder bezwaren vele uren afwezigheid ("ga je weer naar boven") en mijn beperkte beschikbaarheid voor activiteiten samen en bezoek aan onze vrienden. We zijn al lang samen en gaan dat ook nog een hele tijd zijn, ik beloof je meer tijd en oprechte aandacht. Dank aan onze prachtige kinderen, dochter Maaike, haar echtgenoot Fred, zoon Jurriën en vriendin Monique, en zeker ook aan onze geweldige en sportieve kleinkinderen Noa en Tom als ik weer eens tijd tekort dacht te hebben om naar jullie sportwedstrijden te komen kijken. 


\section{CURRICULUM VITAE}

Peter van den Berg was born in Delft, the Netherlands, on May 28th 1955. After graduating from secondary school (Dr. Kuyper MULO) he served in the Dutch military and in 1981 he graduated as nurse at the St. Hippolytus Hospital, Delft, The Netherlands. He also followed two traineeships at the Intensive Care and Coronary Care unit. This early episode in Delft was followed by a full traineeship at the University Hospital Leiden for his cast-technician traineeship that ended by 1986. His fully graduated professional career was continued at the Reinier de Graaf Gasthuis, meanwhile a merged hospital of three former Delft hospitals, and soon he was elected to become a board member (secretary) of the Dutch national cast-technicians association (VGN).

He obtained a bachelor degree in Healthcare Management (Leiden Hogeschool 2005) and the degree of Master of Advanced Nursing Practice (Leiden Hogeschool 2007). In January 2015, a PhD trajectory started at NUTRIM (Maastricht University Medical Center), which resulted in the present dissertation (promotores: prof. dr. J.P. van den Bergh and prof. dr. P.P. Geusens; co-promotor dr. D.H. Schweitzer). The scientific work described in this dissertation has been published in peer reviewed medical journals and presented at national and international conferences. He also was cofounder of VF\&O, the Dutch association of FLS nurses and nurse practitioners (2008) and was elected as president of VF\&O. Today, he is head coordinator of the Fracture Liaison Service (FLS), Reinier de Graaf Gasthuis and supports osteoporosis care in a number of Dutch organizations. Peter is married to Maria van Woerden, they have two children Maaike and Jurriën and two grandchildren Noa and Tom. 